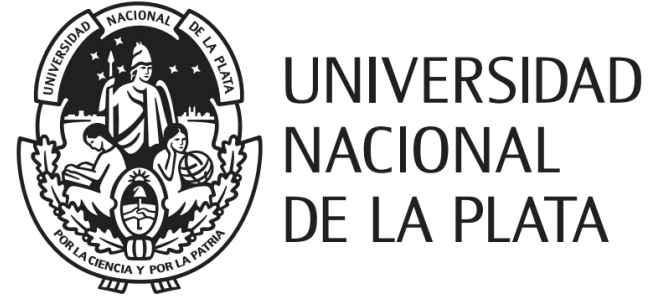

UNIVERSIDAD NACIONAL DE LA PLATA

FACULTAD DE ARQUITECTURA Y URBANISMO

DOCTORADO EN ARQUITECTURA Y URBANISMO

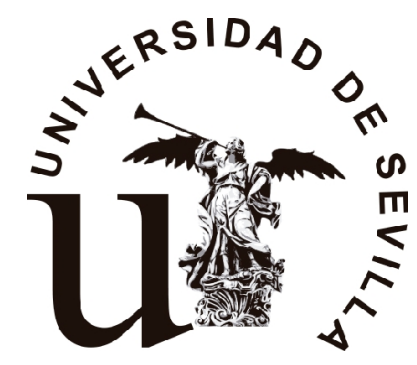

UNIVERSIDAD DE SEVILLA

ESCUELA TÉCNICA SUPERIOR DE ARQUITECTURA

DEPARTAMENTO DE

CONSTRUCCIONES ARQUITECTÓNICAS I

\title{
EL USO DE ALGORITMOS GENÉTICOS APLICADOS AL DISEÑO BIOAMBIENTAL PARAMÉTRICO
}

\author{
Tesis doctoral presentada por
}

PATRICIA EDITH CAMPOREALE

\author{
ante la Facultad de Arquitectura y Urbanismo de la \\ Universidad Nacional de La Plata y la Universidad de Sevilla
}

para acceder al grado académico de

DOCTOR EN ARQUITECTURA Y URBANISMO

Dirección de tesis en cotutela:

Director: Dr. Ing. Arq. Jorge Daniel Czajkowski UNLP

Directora: Dra. Arq. María del Pilar Mercader Moyano US

La Plata, Argentina, 15 de mayo de 2017 


\section{Agradecimientos}

Quiero agradecer a todos los que contribuyeron, de una manera u otra, a culminar este sueño gestado mucho tiempo atrás y postergado por circunstancias de la vida. Sin su ayuda no hubiera sido posible alcanzar este objetivo.

A mi director, el Dr. Jorge Czajkowski, por confiar en la idea con la que me presenté un día en su laboratorio, ofrecerme su espacio de trabajo y guiarme hasta la meta.

A mi directora, la Dra. Pilar Mercader Moyano, por alentarme a confiar en mis propias capacidades y darme toda su experiencia y apoyo.

Al Dr. Antonio Ramírez de Arellano por su aliento y entusiasmo.

Al Dr. Gautam Dutt por iniciarme en la investigación, ofreciéndome todo su conocimiento e infundirme confianza en lo que podia lograr.

A Paz Diulio, por su inestimable ayuda y compañía y a mis compañeros del laboratorio por las horas compartidas.

A mis amigos, en especial Patricia, por acompañarme y alentarme a seguir en los momentos difíciles.

Y por último, a mi familia. A Claudio por alentarme en esta empresa, asumiendo la responsabilidad del hogar durante mi estancia doctoral en España. A mis hijos, Luciana por su paciencia de tenerme a la distancia, y a Ayelén y Eric por su permanente aliento y sus valiosas revisiones.

Fueron muchas las personas que contribuyeron para la culminación de este trabajo, donde no faltaron los obstáculos pero que, al haberlos superado, no hicieron más que fortalecerme. A todos y cada uno, gracias por haber hecho posible esta tesis. 
Indice 
El uso de algoritmos genéticos aplicados al diseño bioambiental paramétrico 


\section{Introducción}

Consideraciones previas 3

Motivación $\quad 5$

$\begin{array}{ll}\text { Estado del arte } & 7\end{array}$

Objetivos de la investigación $\quad 9$

$\begin{array}{ll}\text { Metodología } & 10\end{array}$

$\begin{array}{ll}\text { Estructura del documento } & 11\end{array}$

Resumen- Abstract 13

\section{Estado de la cuestión}

\section{Marco teórico disciplinar}

1.1. Delimitación del problema de investigación y marco teórico 19

1.2. Energía y ambiente 19

1.2.1 La energía en Argentina 20

1.2.2. La energía en España 23

1.3. Arquitectura bioclimática 25

1.4. Conclusiones 29

2. Cibernética y diseño digital

2.1. Arquitectura algorítmica

2.2. Arquitectura emergente: Sistemas materiales, morfogénesis digital y desempeño energético

2.3. Los algoritmos genéticos $\quad 37$

2.4. Programas de diseño evolutivo: GENR8 38

2.5. Otros programas de diseño paramétrico 40

2.6. Diseño paramétrico y evaluación energética 41

2.7. Conclusiones 45

3. El modelo bioambiental paramétrico y los otros modelos

3.1. El modelo académico $\quad 49$

3.2. El modelo bioclimático, bioambiental y ambientalmente consciente 50

3.2.1. El programa ENERGOCAD 52

3.3. El modelo bioambiental paramétrico 52

3.4. Comparación entre los diferentes modelos 55

3.5. Conclusiones 57

4. Normativa local e internacional: eficiencia energética en edificios

4.1. Introducción 
El uso de algoritmos genéticos aplicados al diseño bioambiental paramétrico

4.2. Normativa y legislación en Argentina

4.2.1. Normas IRAM

4.2.1.1. Norma IRAM 11507-1. Carpintería de obra.

Ventanas exteriores. Requisitos básicos y clasificación

4.2.1.2. Norma IRAM 11507 4. Carpintería de obra y fachadas integrales livianas. Ventanas exteriores. Parte 4:

Requisitos complementarios

4.2.1.3. Norma IRAM 11601. Aislamiento térmico de edificios.

Métodos de cálculo. Propiedades térmicas de los componentes y elementos de construcción en régimen

estacionarios. Aislación térmica

4.2.1.4. Norma 11603. Acondicionamiento térmico de edificios.

Clasificación bioambiental de la República Argentina

4.2.1.5. IRAM 11604. Coeficiente volumétrico de calefacción: $\mathrm{G}_{\mathrm{CAL}}$

4.2.1.6. Norma IRAM 11605. Acondicionamiento térmico de edificios.

Condiciones de habitabilidad en edificios. Valores máximos de transmitancia térmica e cerramientos opacos

4.2.1.7. Norma IRAM 11659-2. Acondicionamiento térmico de edificios.

Verificación de sus condiciones higrotérmicas. Ahorro de energía en refrigeración. Parte 2: Edificios para viviendas

4.2.2. Ley 13059 decreto 1030/2010 de la Provincia de Buenos Aires.

Condiciones de Acondicionamiento Térmico exigibles en la construcción de edificios.

4.2.3. Ordenanza $8757 / 13$ de la Ciudad de Rosario. "Aspectos Higrotérmicos

y Demanda Energética de las Construcciones"

4.2.4. Ley 4458 "Normas de Acondicionamiento Térmico en la Construcción de

Edificios" de la Ciudad Autónoma de Buenos Aires

4.3. Normativa y legislación en España

4.3.1. Código Técnico Español: Documento Básico HE/ DccHE

4.3.1.1. Sección HE 0: Limitación del consumo energético de calefacción

4.3.1.2. Sección HE 1: Limitación de la demanda energética

4.3.1.3. Documentos de apoyo

4.3.1.4. Apéndice B: Zonas climáticas

4.4. Normativa europea

4.4.1. Norma UNE-EN ISO 13790: Eficiencia energética en edificios.

Cálculo del consumo de energía para calefacción y refrigeración de espacios 87

4.4.2. CIBSE TM41: 2006. Teoría de los grados días y aplicación 
4.5. Normativa en EEUU

4.5.1. ASHRAE Handbook Fundamentals SI. Cálculo de las cargas térmicas por calefacción y refrigeración

4.5.2. Norma ANSI-ASHRAE/IES 90.1-2010: Normativa para edificios excepto edificios residenciales bajos (Edición I-P)

4.5.3. Norma ANSI-ASHRAE/IES 90.2-2010: Normativa para edificios residenciales bajos (Edición I-P)

II Objetivos, metodología y desarrollo de la investigación

5. Objetivos

6. Metodología

7. Etapa 1: Diseño del modelo bioambiental paramétrico

7.1. Génesis del modelo bioambiental paramétrico

7.2. Estructura del modelo

7.2.1. Estructura del modelo

7.2.2. Procesamiento de ls datos

7.2.3. Resultados

8. Etapa 2. Edificio de nueva planta en el área metropolitana de Buenos Aires. Subetapa 2.1: Datos de entrada

8.1. El edificio

8.1.1. Implantación

8.1.2. Programa funcional

8.1.3. Transmitancia térmica de la envolvente

8.1.4. Ocupación

8.1.5. Equipamiento

8.2. Datos climáticos

8.2.1. Temperatura

8.2.2 Viento

9. Etapa 2. Edificio de nueva planta en el área metropolitana de Buenos Aires. Subetapa 2.2: Estructuración de los datos

9.1. Determinación de la implantación y la geometría edilicia

9.2. Temperaturas de diseño y horarias 
El uso de algoritmos genéticos aplicados al diseño bioambiental paramétrico

9.3. Infiltración y renovaciones de aire

9.4. Cálculo del coeficiente global de pérdidas de calor $\left(\mathrm{G}_{\mathrm{CAL}}\right)$

9.5. Cálculo del coeficiente volumétrico de refrigeración $\left(G_{R E F}\right)$

9.6. Cálculo del índice bioclimático de calefacción para un día típico de invierno ( $\left.\mathrm{B}_{\mathrm{CAL}}\right) 157$

9.7. Cálculo del índice bioclimático de de refrigeración para un día típico de verano $\left(B_{\text {REF }}\right)$

9.8. Cálculo de las ganancias térmicas para la hora pico solar: $\mathrm{Q}_{\mathrm{h} 14}$ de un día típico de invierno

\section{Etapa 2. Edificio de nueva planta en el área metropolitana de Buenos} Aires.

Sub-etapa 2.3: Optimización de la morfología y la envolvente edilicias

10.1. Integración de las variables a optimizar. El uso del AG

10.2. Iteración del AG: Optimización de la morfología

10.3. Iteración del AG: Optimización de los elementos vidriados

10.4. El cálculo de la demanda de calefacción a la hora pico solar: QcaLh14

10.5. Relación entre el índice bioclimático de refrigeración $B_{R E F}$ y la demanda de calefacción a la hora pico solar: QcALh14

10.6. Validación de los resultados

\section{Etapa 3. Rehabilitación energética: viviendas en Sevilla}

11.1. El modelo de diseño paramétrico bioambiental aplicado a un caso de rehabilitación energética: su adaptación metodológica

11.2. Descripción del caso de estudio

11.2.1. Clima

11.2.2. El edificio

11.3. Optimización multi-objetivo

11.3.1. Proceso de optimización. Etapa 1: Performance energética

11.3.2. Demanda energética: DIVA/ EnergyPlus

11.3.3. Validación de BCAL-BREF con EnergyPlus

11.3.4. Proceso de optimización. Etapa 2: Factibilidad financiera

\section{Conclusiones}

\section{Conclusiones}

12.1. Conclusiones acerca del estado del arte 209

12.2. Conclusiones acerca del modelo propuesto y sus aplicaciones 210 


\section{Anexo 1: Datos climáticos de Buenos Aires}

Tabla A1-1: Temperaturas máximas y mínimas julio estación Gonnet 237

Tabla A1.2: Temperaturas máximas y mínimas enero estación Gonnet 238

Tabla A1.3: Radiación solar por orientación y horizontal (invierno). 239

Tabla A1.4: Radiación solar por orientación y horizontal (verano) 240

Tabla A1.5: Temperaturas horarias julio (invierno 241

Tabla A 1.6: Temperaturas horarias enero (verano) 242

Tabla A1.7: Temperaturas sol-aire $14 \mathrm{~h}$ enero (verano) 243

Tabla A1.8: Temperaturas sol-aire en muros N julio (invierno) 244

Tabla A1.9: Temperaturas sol-aire en muros S julio (invierno) 245

Tabla A1.10: Temperaturas sol-aire en muros E julio (invierno) 246

Tabla A1.11: Temperaturas sol-aire en muros O julio (invierno) 247

Tabla A1.12: Temperaturas sol-aire en cubiertas julio (invierno) 248

Tabla A1.13: Temperaturas sol-aire en muros N enero (iverano) 249

Tabla A1.14: Temperaturas sol-aire en muros S enero (iverano) 250

Tabla A1.15: Temperaturas sol-aire en muros E enero (iverano) 251

Tabla A1.16: Temperaturas sol-aire en muros $O$ enero (iverano) 252

Tabla A1.17: Temperaturas sol-aire en cubiertas para un día típico de verano 253

Tabla A1.18: Variación de la velocidad del viento y del largo de junta de carpintería con la altura

\section{Anexo 2: Resultados obtenidos en la optimización del edifício en torre}

Tabla A2.1: Resultados de la optimización geométrica y del área vidriada del edificio en torre

Tabla A 2.2.: Porcentajes de muro y área vidriada según cada orientación

\section{Anexo 3: Datos climáticos de Sevilla}

Tabla A3-1: Datos estación meteorológica Sevilla Aeropuerto 261

Tabla A3-2: Radiación solar media horaria enero (invierno) 261

Tabla A3.3: Radiación solar media horaria julio (verano) 262

Tabla A3.4: Temperaturas horarias julio (verano) 263

Tabla A3.5: Temperaturas horarias enero (invierno) 264

Tabla A3.6: Temperaturas sol-aire en muros N enero (invierno) 265 
Tabla A3.7: Temperaturas sol-aire en muros S enero (invierno) 266

Tabla A3.8: Temperaturas sol-aire en muros E enero (invierno). 267

Tabla A3.9 Temperaturas sol-aire en muros O enero (invierno) 268

Tabla A3.10 Temperaturas sol-aire en muros NO enero (invierno) 269

Tabla A3.11 Temperaturas sol-aire en muros NE enero (invierno) 270

Tabla A3.12 Temperaturas sol-aire en muros SE enero (invierno) 271

Tabla A3.13 Temperaturas sol-aire en muros SO enero (invierno) 272

Tabla A3.14. Temperaturas sol-aire en cubiertas enero (invierno) 273

Tabla A3.15 Temperaturas sol-aire en muros Norte julio (verano) 274

Tabla A3.16. Temperaturas sol-aire en muros Sur julio (verano) 275

Tabla A3.17. Temperaturas sol-aire en muros Este julio (verano) 276

Tabla A3.18.Temperaturas sol-aire en muros Oeste julio (verano) 277

Tabla A3.19.Temperaturas sol-aire en muros NO julio (verano) 278

Tabla A3.20.Temperaturas sol-aire en muros NE julio (verano) 279

Tabla A3.21.Temperaturas sol-aire en muros SE julio (verano) 280

Tabla A3.22.Temperaturas sol-aire en muros SO julio (verano) 281

Tabla A3.23. Temperaturas sol-aire en cubiertas para un día típico de verano. (julio) 282 
Introducción 
El uso de algoritmos genéticos aplicados al diseño bioambiental paramétrico 


\section{Consideraciones previas}

Nuestra sociedad enfrenta una crisis de recursos energéticos debida a nuestro modelo de desarrollo, esto ha provocado el agotamiento de los recursos fósiles y- en gran medidael Cambio Climático, que afectan de manera directa la construcción del ambiente y determinan la necesidad de un desarrollo sustentable. Como ya fue definido en el informe Bruntland (ONU, 1987), el desarrollo sustentable es aquél “... que satisface las necesidades del presente sin comprometer la capacidad de las generaciones futuras para satisfacer las propias". La emisión de gases de efecto invernadero (GEI) desde la Revolución Industrial, se ha acelerado exponencialmente con el empleo de los combustibles fósiles que- por una parte - permitieron el desarrollo de la economía actual y — por la otra- provocaron en gran medida, dicho Cambio Climático.

Por otra parte, las migraciones de la población rural hacia las ciudades harán que éstas alberguen al $66 \%$ de la población mundial para el año $2050^{1}$, por lo que el consumo energético de dichos asentamientos, será tan significativo que se hace imprescindible un cambio de paradigma en la arquitectura y el urbanismo. A partir de ello, las intervenciones arquitectónicas y urbanas deberían asegurar su viabilidad a través del manejo sustentable de los recursos energéticos disponibles, haciendo un uso eficiente de aquéllos no renovables e implementando el de aquéllos renovables. Este objetivo puede alcanzarse por medio de estrategias de eficiencia energética edilicia, como por ejemplo, acondicionamiento pasivo/ activo, y generación de energía a partir de fuentes renovables, aun cuando la disponibilidad de estas últimas fuentes estará siempre limitada por la inversión y las características locales del recurso. Si bien la eficiencia energética es condición necesaria para la aplicación de energías renovables, aquélla debe estar incorporada como variable desde el comienzo del proceso de diseño. En ese momento es cuando se adoptan las decisiones que influirán a lo largo de todo el proyecto, la construcción y la vida útil del edificio.

Como puede observarse, la complejidad de las cuestiones que debe afrontar el arquitecto actualmente, excede la formación específica y hace necesaria la incorporación de técnicas y herramientas de otras ciencias, como la física de la edificación y las ciencias de la computación, que permitan su resolución, con lo cual, este trabajo pretende contribuir. Por una parte, incorpora el desempeño energético como una variable de modelado formal en las fases iniciales del proceso de diseño arquitectónico y constituye un aporte a la investigación en eficiencia energética. Por otra parte, facilita al arquitecto una herramienta digital que

\footnotetext{
${ }^{1}$ Informe ONU 10/7/2014- http://www.un.org/es/development/desa/news/population/worldurbanization-prospects-2014.html consultado el 3/4/16
} 
provee alternativas morfológicas sustentables, retomando así la cuestión de la relación entre forma edilicia y demanda energética en un entorno gráfico CAD.

Así como describe Manuel De Landa (De Landa, 2011) la simbiosis y cooperación en la sopa prebiótica entre bacterias y células primitivas, y la consecuente aparición de las mitocondrias, la respiración celular y la evolución de la vida hacia organismos más complejos, Laureano (Laureano, 2013) hace lo propio con el funcionamiento del oasiscomo paradigma de desarrollo sostenible-, donde esa simbiosis y cooperación se revelan en un ambiente extremo como el desierto. Se puede inferir, a la luz de las nuevas teorías de la complejidad (Maturana \& Varela García, 1994) y la emergencia (Page \& Miller, 2007), cómo el ambiente —no ya como dicotomía naturaleza/ cultura (Ábalos I. \& Herreros J., 2002) - puede derivar hacia un desequilibrio irreversible o, aprendiendo de las culturas primitivas, cuyas prácticas se enraizan profundamente en los ecosistemas que habitan, hacia un oasis en medio del cosmos.

Ahora que la arquitectura se ha convertido en un paisaje artificial, incorporando la variable energético- ambiental en el diseño, uso y fin de la vida útil de un edificio, la función del arquitecto es más que nunca la de gerenciar el proyecto, dando una respuesta que sintetice una solución al problema. El rango de acción de éste parece estrecharse hacia uno de estos dos roles: o deviene un experto que ofrece diseños y se especializa en la forma...o intenta, mediante una intensa cooperación e inteligente negociación con los varios actores involucrados ${ }^{2}$, transformarse en una especie de manager, el último "generalista" en una sociedad de expertos (Lootsma, 1999).

\footnotetext{
2 Koolhas, Rem (1998) Delirious New York- Thames / Hudson- Londres- Reino Unido-

“... la interminable negociación entre fuerzas competidoras, regulaciones, criterios de planificación también conocidos como procedimientos de planificación por medio de los cuales se administra todo el espacio hoy; en el sentido que ha escrito Tafuri, una compleja tarea de gerenciamiento que caracteriza largamente la profesión de la arquitectura y define su principal modo de trabajo" trad. de la autora
} 


\section{Motivación}

Desde la carrera de grado, surgió el interés por los aspectos ambientales de la arquitectura, teniendo como referentes aquellos arquitectos, como F. L. Wright, Aalto o Eduardo Sacriste, que respondían con sus diseños al lugar donde se insertaba la obra, adaptándose al clima, materiales y tecnologías locales. Luego, en mi desempeño profesional intenté materializar estos conceptos en mis obras y también transmitirlos en mi labor docente desde la cátedra de Diseño Arquitectónico IV del arq. Jorge Mele en la Facultad de Arquitectura de la Universidad Católica de La Plata (UCALP). Pero la necesidad de formación científica que sustentara la actividad proyectual, motivó mi acercamiento al Centro de Hábitat y Energía (CIHE) de la Facultad de Arquitectura, Diseño y Urbanismo (FADU) de la Universidad de Buenos Aires (UBA) a fin de cursar el Programa de Arquitectura Bioclimática y Solar, dictado por el Dr. Arq. John Martin Evans (Evans, 1988). A partir de allí, comencé mi tarea de investigadora dentro del $\mathrm{CIHE}$ y las presentaciones de trabajos científicos en congresos nacionales e internacionales. La necesidad de seguir ampliando esos conocimientos, hizo que cursara Uso Eficiente de la Energía Eléctrica y Energías Renovables en la Facultad de Ingeniería de la (FIUBA) con el Dr.Ing. Gautam Dutt. Junto con él, editamos el Manual de la Iluminación Eficiente entre la Universidad Tecnológica Nacional y el programa ELI (Efficient Lighting Initiative) con recursos del Fondo Mundial para el Medio Ambiente Mundial (FMAM) más conocido como Global Environmental Facilities (GEF). Complementé dicho manual con nuevos capítulos de mi autoría sobre dispositivos pasivos de iluminación natural: ductos de luz y colectores anidólicos cenitales y estrategias de diseño eficiente aplicado a diferentes usos: oficinas y comercial. También implementamos un Seminario de lluminación Eficiente que acompaña al Manual con una guía para el docente y otra para el alumno con ejercitación pertinente (Dutt, G. \& Camporeale, P. (Ed.), 2006). Simultáneamente, seguí desarrollando mi labor como profesional independiente, diseñando viviendas y otros edificios de variados destinos, así como también, prestando asesoramiento en eficiencia energética edilicia.

La falta de integración entre la etapa de croquis y las de verificación de desempeño energético del edificio, me llevaron a querer profundizar el estudio de las técnicas proyectuales, para lo cual cursé la Maestría en Diseño Arquitectónico Avanzado, dirigida por el arq. J. Solsona, en la FADU-UBA. A partir del proyecto de tesis de Maestría, los estudios sobre arquitectura algorítmica emergente junto con la formación bioclimática, convergieron en la elaboración de este documento, que requirió el estudio pormenorizado de la normativa y la legislación nacionales e internacionales en eficiencia energética, el análisis de los trabajos científicos relacionados con el tema y la formación específica de cursos de posgrado en eficiencia energética, diseño paramétrico, modelos matemáticos y otros propios del Doctorado. Simultáneamente, se presentaron trabajos de investigación sobre temas de 
la tesis en congresos realizados en el país y en el exterior. También implementé un curso de posgrado en diseño estructural paramétrico, que fue dictado en la FAU-UNLP, en el marco de un convenio de cooperación técnica entre la empresa Entheus y el LAYHS (FAU-UNLP).

Los problemas arquitectónicos propuestos responden a las inquietudes que la práctica profesional y la investigación me he planteado a lo largo de todos estos años. En el ámbito privado, a través del proyecto y construcción de viviendas, oficinas, templos, edificios administrativos, culturales y comerciales. En el ámbito académico, en proyectos de arquitectura en el CIHE, FADU, UBA bajo la dirección del Dr. Arq. John M. Evans como el desarrollado para el Centro de Interpretación de la Reserva Ecológica de la ciudad de Buenos Aires y en mi carrera como investigadora independiente en el monitoreo energético de edificios que proyecté y construí, desarrollados bajo premisas de la arquitectura bioclimática.

Surge así el problema que lleva a esta tesis y la necesidad de poder contar con una herramienta de "prediseño" edilicio que brinde las alternativas formales y tecnológicas basadas en variables bioclimáticas, energéticas, normativas y legales. 


\section{Estado del arte}

Se realizó un relevamiento ${ }^{3}$ bibliográfico exhaustivo a nivel local e internacional relacionado con la delimitación del marco teórico disciplinar y extradisciplinar de la investigación, lo cual originó, a su vez, que se incursionara en:

- la relación entre el consumo energético y el parque edilicio- siendo este sector uno de los principales consumidores- y por lo tanto, uno de los factores responsables del Cambio Climático

- el paradigma biológico como precursor de la inteligencia artificial, las redes neurales, el aprendizaje de máquina y los algoritmos genéticos, entre otros desarrollos computacionales (Russell, 2016) y el software basado en estos conceptos

- el diseño paramétrico incorporado a los programas de dibujo 3D

- los métodos de diseño sostenible aplicados a las primeras fases de este proceso

- estudio de la normativa local (Argentina y España) e internacional (Europa y EEUU) referente al ahorro energético en edificios.

El espectro de la investigación a cubrir aún no ha sido desarrollado ni en Argentina, España ni fuera de ellos, tal como lo manifiestan algunos autores (Lin, E. \& Gerber, D., 2013) y otorga al trabajo su originalidad, debido a que se trata de una herramienta abierta ${ }^{4}$, que permite adecuarla a cada caso. No utiliza programas comerciales, como sucede en el caso de algunos trabajos consultados (Chronis, Liapi, \& Sibetheros, 2012). No se han encontrado trabajos similares, en Argentina; entre los realizados en Conservación + Pasivos $(C+P)$, en centros de investigación en Salta (INENCO-UNSA), Mendoza (LAB.- CRiCYT), Rosario (CEB-UNR), Buenos Aires (CNIE, INTI, CIHE-FADU-UBA, Tucumán (CEEMA-FAU-UNT), La Plata (IAS, IDEHAB, LAyHS) y otros grupos en Neuquén, Córdoba y Chaco. Tampoco se han encontrado ejemplos con una visión sinérgica del problema que profundice las herramientas del proceso de diseño ambientalmente consciente ${ }^{5}$.

En la Escuela Técnica Superior de Arquitectura de la Universidad de Sevilla, donde se realizó una estancia doctoral en cotutela con la universidad de origen, se relevaron los grupos de investigación del Instituto Universitario Arquitectura y Ciencias de la Construcción en sus dos líneas de investigación: TEP 206 "Tecnología de los materiales y sistemas

\footnotetext{
${ }^{3}$ Relevamiento: 1. m. Arg., Bol., Chile y Ur. Estudio de un terreno para analizar sus características

${ }^{4}$ En el sentido que puede ser adaptada para resolver otro problema. Consultado el 14/11/16 en https://opensource.org/

5PID Conicet (1989-91)- Unidad de Investigación Energía y Ambiente" FAU- UNLP
} 
constructivos: caracterización, mantenimiento, restauración y sostenibilidad" y el TEP 130 "Arquitectura, Patrimonio y Sostenibilidad", pero no se encontraron desarrollos en el campo de referencia. Esta búsqueda se extendió a otros grupos de investigación españoles, arrojando los mismos resultados.

Con esta tesis, se pretende continuar la investigación propuesta por el programa EnergoCAD (Czajkowski, J. \& Rosenfeld, E., 1992), incorporando la parametrización de los datos de entrada y la optimización formal mediante algoritmos genéticos (AGs). De esta forma, se genera una retroalimentación entre la entrada de datos y los croquis iniciales, con resultados morfológicos evaluados energéticamente, que permiten el control del diseñador en esta fase inicial del proceso de diseño, aportando un número de alternativas morfológicas. Sin un programa apropiado, este proceso sería costoso en tiempo y recursos. 


\section{Objetivos de la investigación}

El objetivo principal es desarrollar un modelo energético ambiental digital que optimice morfologías edilicias paramétricas, mediante algoritmos genéticos (AGs), a través de la parametrización de variables bioambientales, aplicable a las fases iniciales del proyecto arquitectónico.

Los objetivos secundarios que permiten alcanzar el objetivo principal, se ordenan de acuerdo a las siguientes etapas (Mercader Moyano, M., 2010) (fig. 0.1):

- El Objetivo 1 consiste en la creación de un modelo digital para resolver morfologías y/o envolventes sostenibles, en climas templados: Buenos Aires y Sevilla.

- El Objetivo 2 propone el desarrollo de un caso de estudio, aplicando el modelo a un edificio de nueva planta en torre, situado en Buenos Aires, mediante la parametrización de las variables geométricas, materiales (composición de la envolvente), climáticas, operativas (ocupación) y normativas, que permita la optimización de la morfología edilicia.

- El Objetivo 3 plantea la aplicación del modelo a un caso de rehabilitación energética de un edificio en tira: Barriada RENFE, Sevilla, optimizando no sólo el desempeño energético de la envolvente sino también su factibilidad financiera. 


\section{Metodología}

La metodología propuesta responde a los objetivos planteados, con una estructura similar que se articula en cada etapa, definidas a continuación:

- Etapa 1: Diseño de un modelo bioambiental paramétrico para climas templados que integre las variables en un programa adaptativo, que se conforma de dos instancias: y estructura.

- Etapa 2: Aplicación del modelo a un edificio de nueva planta, una torre polifuncional en el Área Metropolitana de Buenos Aires (AMBA). Asimismo, se diseñaron nuevos índices bioclimáticos de demanda energética para una evaluación bioclimática de las morfologías edilicias. El método empleado para la generación de las morfologías es bottom-up ${ }^{6}$ (Schweers, R., 2002).

- Etapa 3: Aplicación del modelo a un edificio existente: viviendas en bloque RENFE en Sevilla. Al igual que en el apartado anterior, comprende los datos de entrada del modelo y su procesamiento a los efectos de obtener las mejores soluciones desde el punto de vista energético, agregando la factibilidad financiera. Se obtienen envolventes edilicias optimizadas mediante un algoritmo genético (López, J., 2013). y el consumo energético mediante el programa de simulación térmica EnergyPlus. Por último, se optimiza la factibilidad financiera de las opciones.

\footnotetext{
${ }^{6}$ partiendo de los elementos geométricos, materiales, energéticos e informativos que componen la envolvente y sus usos y, siguiendo leyes simples de generación, agrupamiento y crecimiento, se obtienen morfologías a escala urbana o edilicia, según el caso.
} 


\section{Estructura del documento}

El documento se divide en tres partes:

- I: Estado de la cuestión.

- II: Objetivos, metodología y desarrollo de la investigación

- III: Conclusiones

En la primera parte de esta tesis, se desarrollan los aspectos teóricos que dan sustento a la investigación. Si bien está situada en el campo disciplinar de la arquitectura bioclimática según la definición del Diccionario de Arquitectura en la Argentina (Aliata, F., Liernur, F., Crispiani, A., \& Silvestri, G., 2004) (Aliata, F. et al., 2004), incorpora conceptos e instrumentos de las ciencias de la computación y la física de la construcción: programas de computación 3D y desempeño energético alimentan el prediseño paramétrico de morfologías edilicias. Se reseña el desarrollo del bioclimatismo: sus exponentes en el mundo y en nuestro país.

Luego, se describe la aparición de la arquitectura paramétrica o algorítmica (Schumacher, 2011). - a partir de los avances de las ciencias de la computación—, sus implicancias en el diseño arquitectónico y sus aplicaciones en el ámbito de la construcción. Más adelante, se incorpora la emergencia (Johnson, 2004) como ciencia sinérgica donde confluyen los procesos de autoorganización biológicos correspondientes la teoría de la complejidad (Maturana \& Varela García, 1994) y sus derivaciones en el diseño arquitectónico, dando lugar al diseño emergente.

El marco normativo para el desarrollo de las morfologías edilicias está dado por las normas argentinas de confort higrotérmico, y sus leyes y ordenanzas de eficiencia energética, que incorporan dichas normas y el Código de Edificación y el Ambiental de Ciudad de Buenos Aires, junto con las normas del Código Técnico Español sobre ahorro de energía, para climas templados. Se analizan asimismo las normas europeas y norteamericanas sobre el tema.

La segunda parte corresponde al desarrollo de la investigación, y se estructura en coincidencia con las etapas mencionadas en los objetivos y la metodología:

- Etapa 1: Creación e instrumentación de un modelo digital

- Etapa 2: Aplicación del modelo bioambiental paramétrico a un edificio de nueva planta en el Área Metropolitana de Buenos Aires. 
- Etapa 3: Aplicación del modelo bioambiental paramétrico a la rehabilitación energética de un edificio en tira en Sevilla

La tercera parte de la tesis se refiere al análisis y discusión de los resultados, conclusiones y líneas de investigación a desarrollar en el futuro. El campo de aplicación de este tipo de herramientas ofrece múltiples posibilidades aún no exploradas suficientemente, tanto para el diseño de nuevos edificios como para la rehabilitación de edificios existentes.

El Anexo 1 comprende los datos climáticos utilizados en el cálculo de nuestro caso de estudio en Buenos Aires.

El Anexo 2 provee los resultados obtenidos en la optimización del edificio en torre.

El Anexo 3 comprende los datos climáticos utilizados en nuestro caso de estudio en Sevilla.

El Anexo 4 proporciona los resultados obtenidos en la optimización del edificio en bloque. 


\section{Resumen}

El avance de las herramientas digitales y el incremento de los problemas medioambientales han tenido un importante impacto sobre el diseño arquitectónico. La optimización basada en la performance energética ha demostrado su potencial para integrar diseño y energía cuando se ha aplicado a las primeras etapas del proceso de diseño, o a la rehabilitación de un edificio existente. La forma edilicia y la composición de la envolvente son determinantes en la demanda energética pero esta cuestión es generalmente soslayada en la etapa inicial debido a que la información necesaria para su cálculo aún no está lo suficientemente definida. El objetivo de este trabajo es presentar y testear una metodología de diseño que permita a los diseñadores unir instrumentos de performance y optimización en un flujo ininterrumpido de trabajo: un modelo de optimización multi-objetivo (MOMO). La metodología del trabajo se divide en tres etapas, donde en primer lugar se estructura el modelo de diseño bioambiental paramétrico, en segundo lugar, se aplica dicho modelo a un caso de estudio y en tercer lugar, a otro caso de estudio. En el primero, la demanda energética optimiza la morfología y materialidad de la envolvente de una torre de nueva planta en el Área Metropolitana de Buenos Aires. En el segundo caso de estudio, la demanda energética y la factibilidad financiera optimizan la materialidad de la envolvente de un edificio rehabilitado; el modelo muestra su robustez y validez de la herramienta para mejorar su desempeño energético agregando su viabilidad financiera. Los modelos de optimización multi-objetivo presentan una aplicación efectiva para asistir a las decisiones de diseño en casos experimentales, así como también reales.

\section{Abstract}

The advancement of digital tools and the increase of environmental concerns have had an important impact on architectural design. Performance-driven optimization has shown its potential to integrate design and energy performance when applied in the conceptual design, as well as in building retrofit. Building shape and envelope composition are determinant to the energy demand, but this issue is commonly overlooked in the early stages because the necessary detailed data is not yet available. The scope of this work is to present and test a design methodology to enable designers to couple material morphology with performance and optimisation tools in a seamless workflow: multi-objective optimization method (MOOM). The methodology has three steps: the first one sets up the model framework, the second and the third one consist in applying the model to different kinds of buildings. The first case study is referred to a new tower in the Buenos Aires Metropolitan Area, where the energy demand optimizes the shape and envelope composition. The second case is referred to a housing block retrofit in Seville, where the energy demand optimizes the envelope composition, showing the robustness and validity of the framework to improve its energy performance and 
El uso de algoritmos genéticos aplicados al diseño bioambiental paramétrico

financial feasibility. Multi-objective design optimization presents effective application to assist design decisions in both experimental and real cases. 
El uso de algoritmos genéticos en el diseño bioambiental paramético 
El uso de algoritmos genéticos aplicados al diseño bioambiental paramétrico 


\subsection{Delimitación del problema de investigación}

El marco teórico de la herramienta ${ }^{1}$ proyectual/evaluativa desarrollada en esta tesis pertenece al ámbito de la arquitectura bioambiental o ambientalmente consciente y se nutre de otros campos disciplinares como las ciencias de la computación y la física de la edificación, como vemos en la figura 1.1, articulando sinérgicamente el proceso de diseño arquitectónico.

La complejidad de la construcción de un hábitat sustentable requiere el auxilio de otras ciencias que provean herramientas de análisis y técnicas adecuadas. La arquitectura como mímesis de la naturaleza en su origen, puede recuperar su función de cobijo de las actividades humanas desde una perspectiva holística ${ }^{2}$, en armonía con el medioambiente.

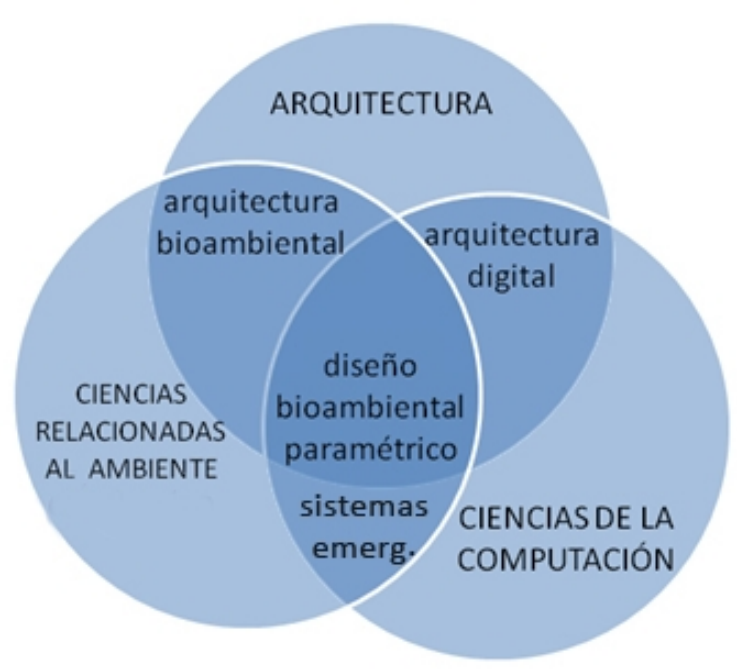

Fig.1.1: Esquema teórico disciplinar del diseño bioambiental paramétrico. Fuente: la autora

\subsection{Energía y ambiente}

Como ya mencionáramos, el Cambio Climático ha adquirido una magnitud que torna imprescindible un cambio de paradigma en la construcción del hábitat. La quema de combustibles fósiles - motores de la economía actual- ha provocado que los gases de efecto invernadero (GEI), producto de esa combustión, sean una de las causas del Cambio Climático (Fig. 1.2). El agotamiento de estos combustibles hace necesario un cambio radical de la matriz energética, favoreciendo el uso de las energías renovables a costos viables, favoreciendo la generación local, y a la eficiencia energética, si se pretende apuntar a un modelo de desarrollo sustentable (ONU, 1987).

\footnotetext{
1. 1. Instrumento, por lo común de hierro o acero, con que trabajan los artesanos. http://dle.rae.es/?id=KErLk81 Real Academia Española (RAE)- consultado el 3/4/16 2 1. adj. Fil. Perteneciente o relativo al holismo. Holismo: 1. m. Fil. Doctrina que propugna la concepción de cada realidad como un todo distinto de la suma de las partes que lo componen. http://dle.rae.es/?id=KZXeaPx- consultado el 3/4/16
} 


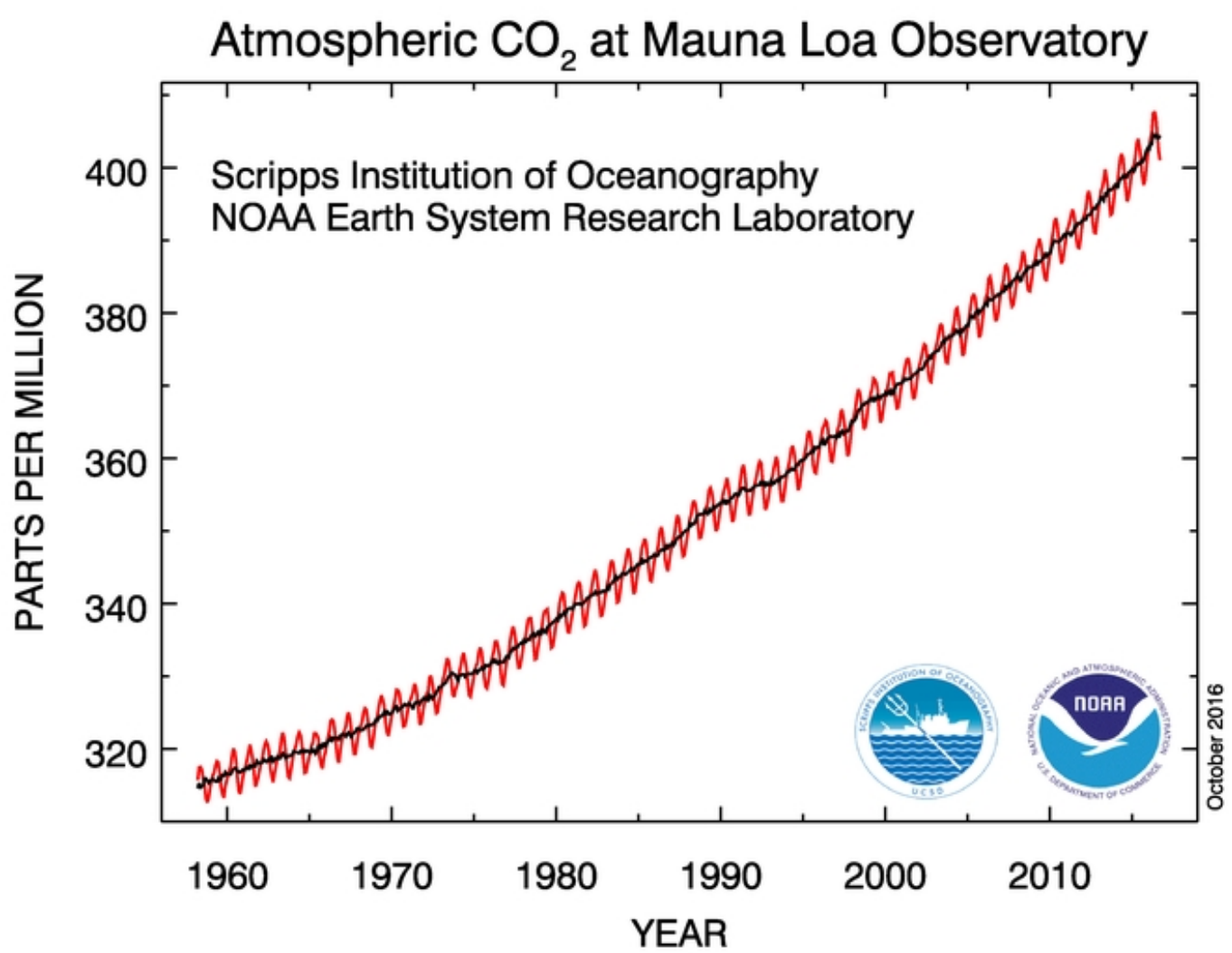

Fig. 1.1: Evolución de CO2 atmosférico en Maunaloa, Hawaii Fuente: Earth System Research

$$
\text { Laboratory }{ }^{3}
$$

La crisis energética de los años '70 hizo que Japón, EEUU, Francia, Escandinavia y en menor medida el resto de Europa, consiguieran aumentar su consumo energético disminuyendo su demanda. En cambio, en nuestro país, sólo se han aplicado cambios tarifarios sin avanzar en una política de Uso Racional de la Energía. Mientras la tecnología constructiva mejora geométricamente, el parque edilicio argentino se degrada en su calidad térmica desde hace 40 años (Czajkowski, Jorge D., 2009). Hoy se percibe, una crisis ambiental derivada, entre otras, del mal uso y derroche energético, principalmente en sectores urbanos. En estos sectores, se emiten buena parte de los contaminantes atmosféricos y que —en el caso de la región metropolitana de Buenos Aires- alcanza a 91

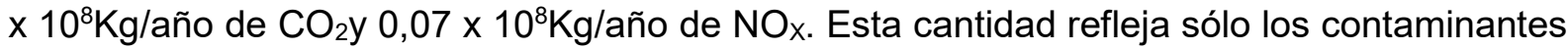
emitidos en acondicionamiento ambiental edilicio (Rosenfeld, E., Czajkowski, J., Discoli, C., \& Ferreyro, C., 1996).

\subsubsection{La energía en Argentina}

\footnotetext{
${ }^{3}$ Consultado el 21/10/16 U.S. Department of Commerce | National Oceanic and Atmospheric Administration- Earth System Research Laboratory |- Global Monitoring Division http://www.esrl.noaa.gov/gmd/obop/mlo/index.html
} 
En Argentina, el consumo de energía del parque edilicio representa el $36 \%$ del total de la energía secundaria producida en el país, según el Balance energético Nacional del año 2013 (Ministerio de Economía de la República Argentina, 2014) ${ }^{4}$ (Fig.1.2), considerando el sector residencial (28\%) junto con el comercial y público (8\%).

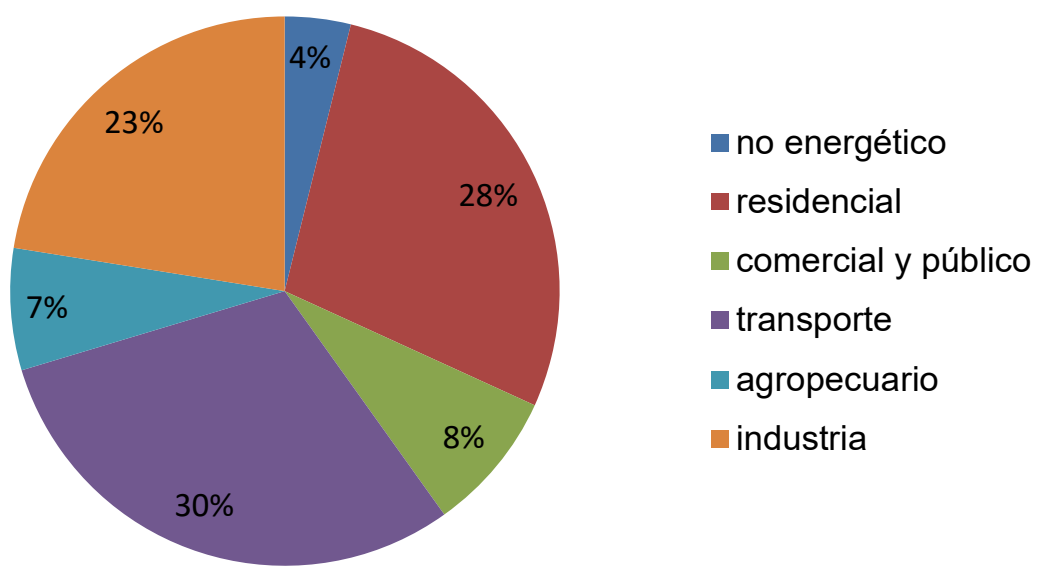

Fig.1.2: Consumo de energía secundaria por sectores. Fuente BEN 2013 gráfico de la autora

Si discriminamos los usos finales por fuentes (Fig. 1.3), observamos que dicho sector consume $58.15 \%$ de la electricidad, $56.31 \%$ del gas natural y $84 \%$ del gas licuado de petróleo (GLP). De ese $84 \%$ de GLP consumido, el 52\% corresponde a calefacción y el 32\% restante a cocción y agua caliente sanitaria (Tanides, C., Nicchi, F., Lavoria, M., \& Mazzitelli, A., 2013).

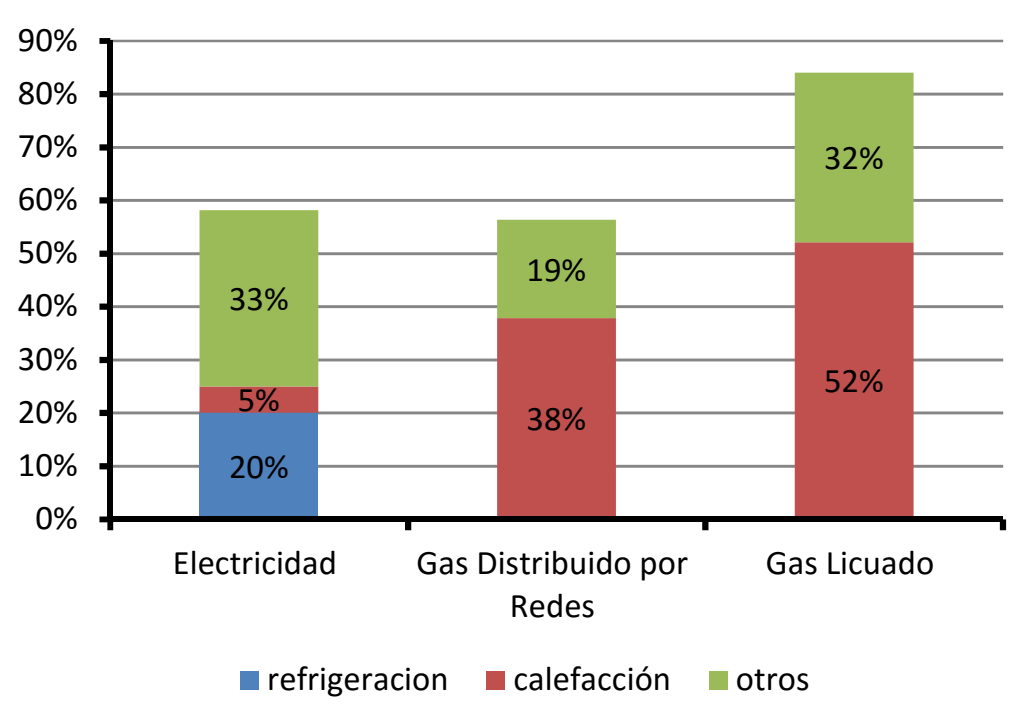

Fig. 1.3: Consumo energético del sector residencial-comercial-público por usos finales respecto de la producción total. Fuente: BEN, 2013, gráfico de la autora

\footnotetext{
${ }^{4}$ BEN Balance Energético Nacional, Ministerio de Econnomía de la República Argentina http://www.energia.gov.ar/contenidos/verpagina.php?idpagina=3366
} 
El sector residencial consume el $49 \%$ de la demanda total anual de gas natural. Existe una importante variación estacional que está relacionada principalmente a la demanda de calefacción (62\% del total), y una menor variación en los rubros de cocción y calentamiento de agua doméstica, las que también tienden a aumentar en los meses más fríos (38\%). Se expresan los promedios ponderados de cada sector.

El sector edilicio (residencial y comercial/ público) totaliza el $25 \%$ de la demanda total de electricidad, el $38 \%$ de la demanda total del gas de red y el $52 \%$ de la demanda total de GLP (Fig. 1.4). En la fig. 1.5, observamos dichos consumos discriminados por usos finales de cada sector, siendo de nuestro interés, aquéllos correspondientes a la climatización del edificio: refrigeración y calefacción.

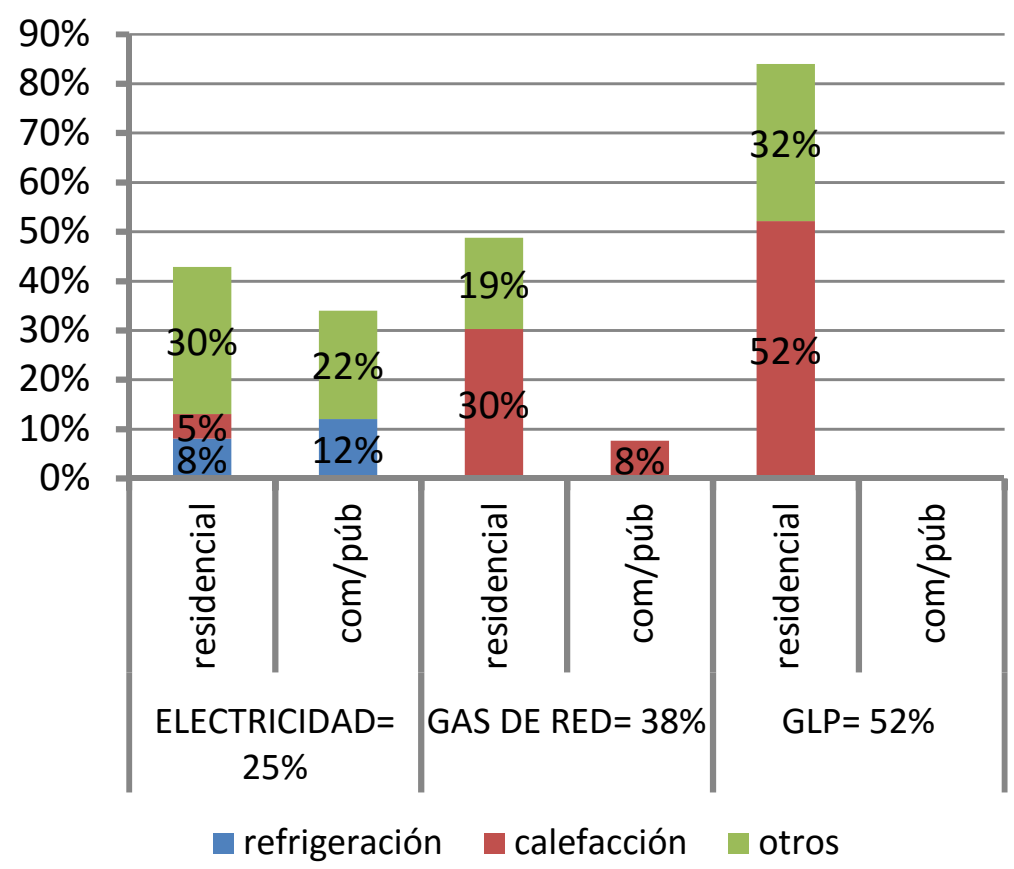

Fig. 1.4: Consumo discriminado por usos finales en los sectores residencial y comercial y público, respecto de la producción total- Fuente: BEN 2013, gráfico de la autora

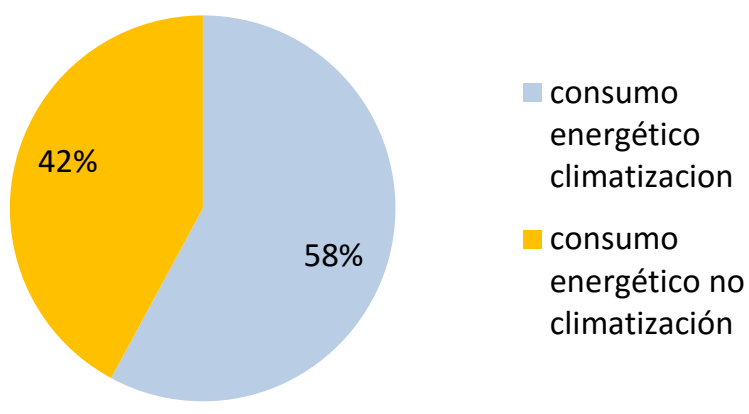

Fig. 1.5: Consumo de energía secundaria en climatización para el sector edilicio. Fuente: BEN 2013, gráfico de la autora 


\title{
1.2.2. La energía en España
}

El consumo de energía por sectores en España en 2014 se muestra en la Fig. 1.7, donde se puede observar que el sector edilicio, residencial y de servicios, consumen el $29,87 \%$, lo que equivale a 23.560,93 ktep (Secretaría de Estado de Energía, 2016) (IDAE, 2015) .

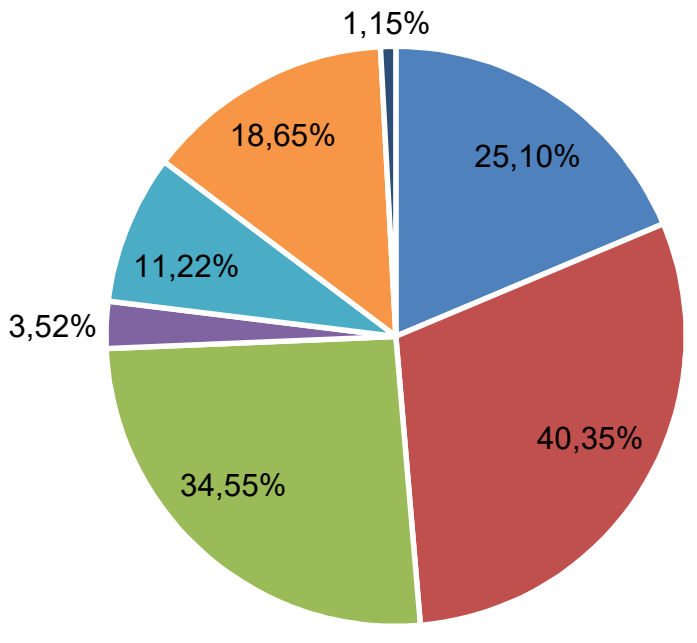

\author{
- Industria \\ - Transporte \\ - Usos diversos \\ - Agricultura y pesca \\ - Comercio, Servicios y \\ Admin. Públicas \\ - Residencial \\ - Otros usos diversos no \\ especificados
}

Fig. 1.7. Consumo de energía secundaria por sectores. Fuente: IDAE $E^{5}$ gráfico de la autora

En cuanto a la energía consumida por el sector de edificios residenciales y de servicios, se observa que la fuente más usada es la electricidad, con un $62,15 \%$ del total producido en el país, le siguen las energías renovables, que totalizan el 53,21\% del total, luego el gas natural, con un $311,79 \%$. Es baja la participación del consumo de gas licuado de petróleo y otros combustibles líquidos, $10,10 \%$ en estos sectores edilicios. Por último, se ubica el carbón con un 6,96\% (Fig. 1.8).

Si se discrimina el consumo por usos finales en el sector residencial (Fig. 1.9), observamos que del total de carbón empleado en el sector, el $5,67 \%$ de toda la producción del país se destina a calefacción y el 1,29\% a otros usos. El 4,85\% de la producción de gas licuado de petróleo (GLP) se emplea en calefacción y el 2,07\% en otros usos, mientras que el 10,03\% del gas natural se destina a calefacción y el 11,62\% a otros usos (ACS, cocción, etc.). Las energías renovables tienen una amplia participación, 48,58\% en calefacción y un $5,35 \%$ en otros usos, quedando para la refrigeración, un $0,04 \%$ de toda la producción. Por último, se utiliza un 2,30\% del total de la energía eléctrica en calefacción, un 0,73\% en refrigeración y un $28,87 \%$, en otros usos (iluminación, equipamiento, etc.).

\footnotetext{
${ }^{5}$ Instituto para la Diversificación y el Ahorro de la Energía. Ministerio de Energía, Turismo y Agenda Digital, Gobierno de España
} 


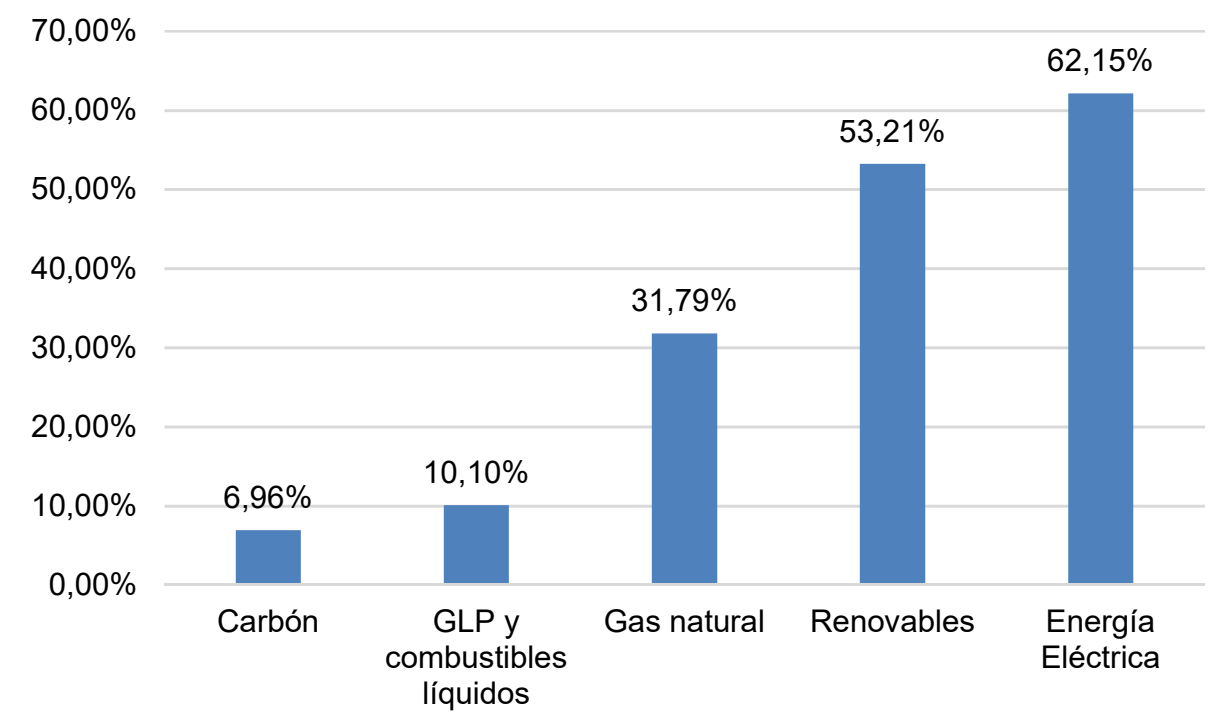

Fig. 1.8. Consumo porcentual del total de la producción de energía de los sectores residencial y de servicios. Fuente: IDAE, gráfico: la autora

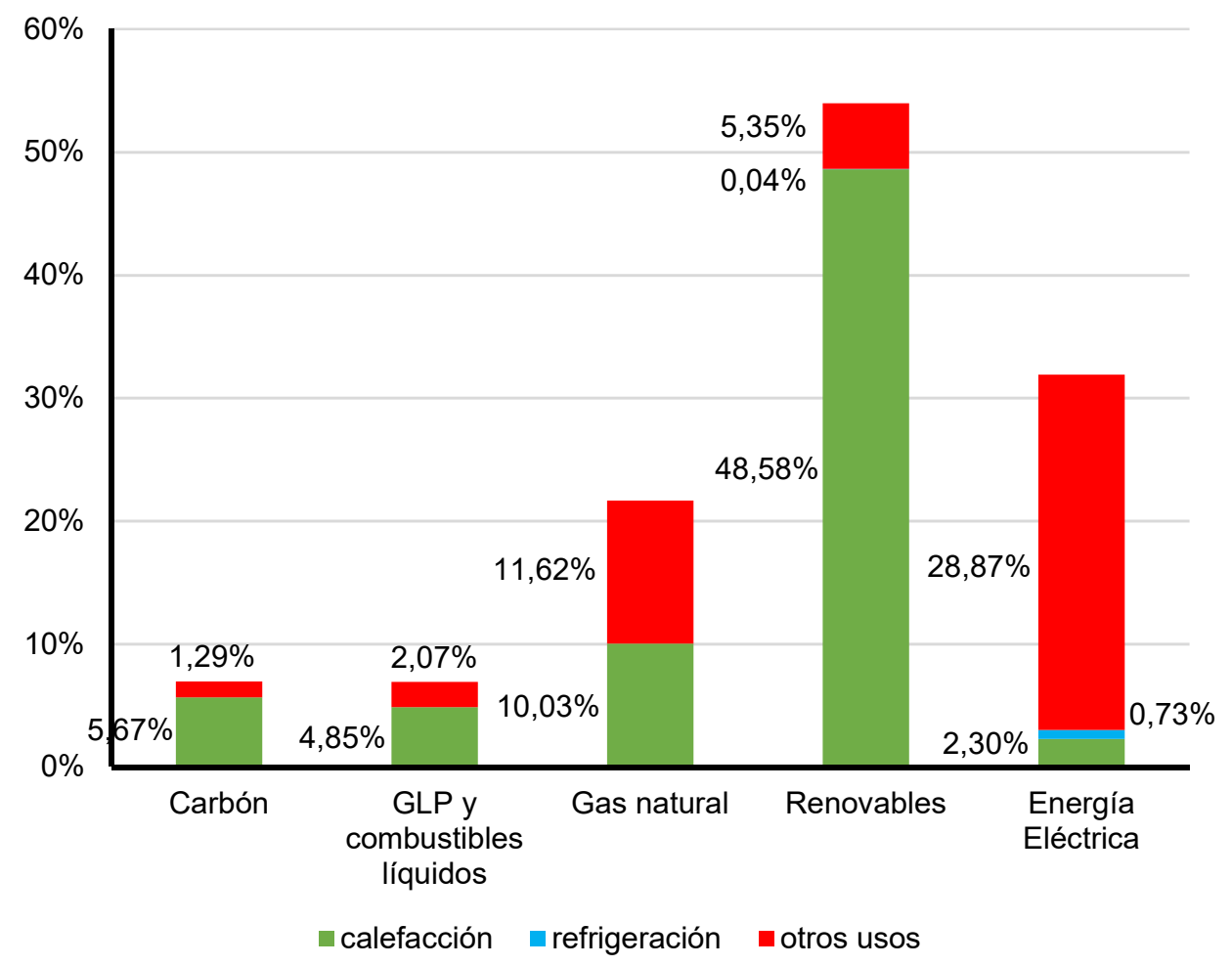

Fig. 1.9. Consumo residencial por fuentes y usos finales. Fuente: IDAE, gráfico: la autora

Cuando analizamos el consumo de energía sin discriminar las fuentes, observamos la fuerte incidencia del consumo en calefacción para el sector residencial (Fig. 1.10). Del total de 6455 ktep de energía consumida para climatización, el $97,77 \%$ se destina a calefacción y solamente el $2,23 \%$ restante a refrigeración. 
No se han podido realizar estos análisis para el sector de servicios porque no se cuenta con datos discriminados por usos finales.

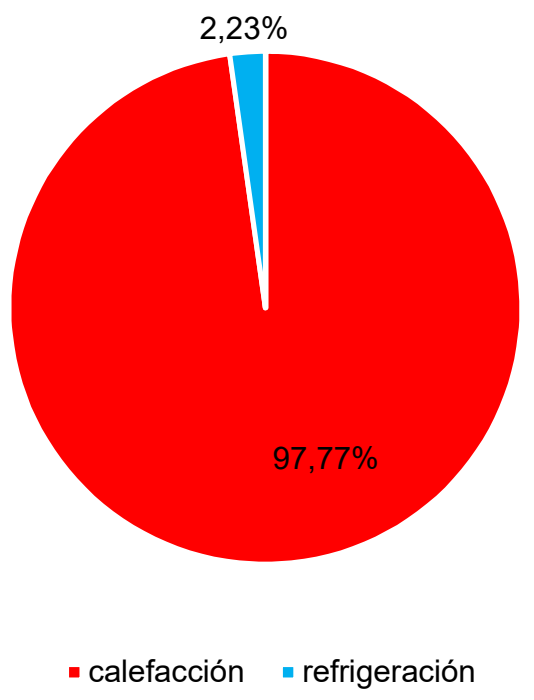

Fig.1.10. Consumo de energía en climatización del sector residencial. Fuente: IDAE, gráfico: la autora

\subsection{Arquitectura bioclimática}

Mucho antes de la crisis del petróleo, Victor Olgyay (Olgyay \& Olgyay, 1963) planteó la teoría de un diseño arquitectónico acorde al clima del lugar, tomando como base modelos biológicos (colonias de termitas, nidos de aves) y ejemplos de arquitectura vernácula. Ya en ese momento, advertía la futura necesidad de ampliar la base de conocimiento científico que proveyera información multidisciplinaria para la construcción del hábitat: climatología, tecnología y biología desde un enfoque holístico (Fig.1. 11).

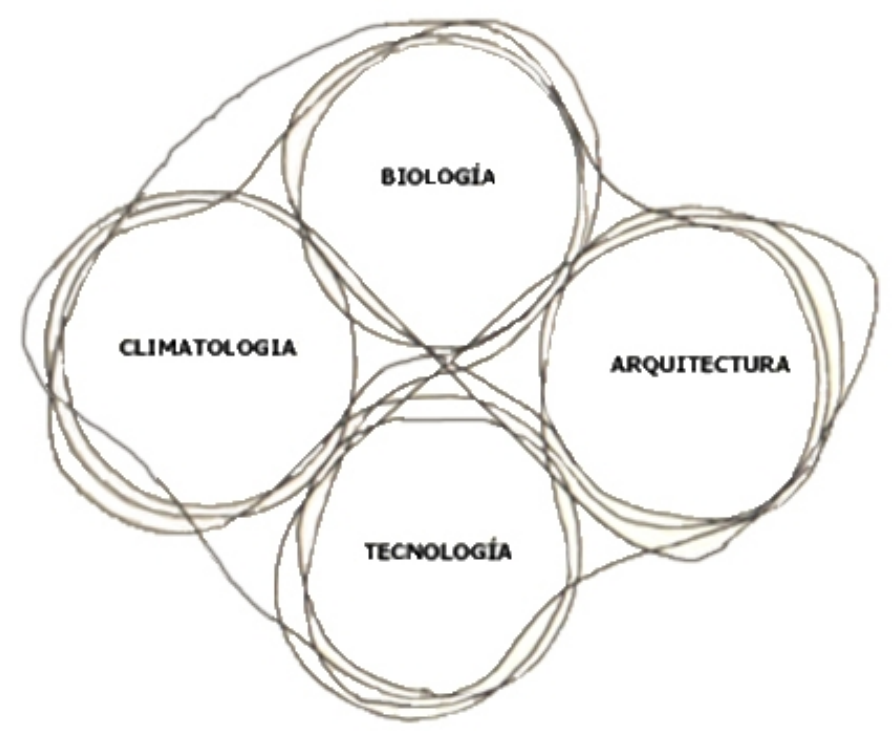

Fig. 1.11: Entrelazado de diferentes disciplinas del equilibrio climático. Fuente: modificado de Olgyay op.cit. pág. 12 
Su método de diseño consta de cuatro etapas: datos climáticos, la evaluación biológica de confort humano- utilizando la carta bioclimática (Fig. 1.12) - el uso de tecnologías que favorezcan el aprovechamiento pasivo del clima del lugar y la aplicación al diseño arquitectónico de las recomendaciones obtenidas en las tres primeras etapas. La Tabla Bioclimática considera temperatura y humedad ambientes, temperatura radiante promedio, velocidad del viento, radiación solar y enfriamiento evaporativo. El eje de las abcisas muestra la humedad relativa y el de las ordenadas, la temperatura de bulbo seco. El análisis de los datos climáticos incluye la radiación solar, el viento y el confort en las escalas del territorio, de la ocupación humana y del microclima del lugar.

A partir de allí, Olgyay evaluó estos parámetros y ponderó en su importancia, aplicando métodos de cálculo de sombras, radiación, vientos, lluvias, humedad y materiales de construcción aptos. A continuación, enumeró sus hallazgos, tomó en cuenta ejemplos afirmando que existen varias soluciones apropiadas para un mismo problema- y concluyó con una síntesis de recomendaciones para las tres escalas mencionadas.

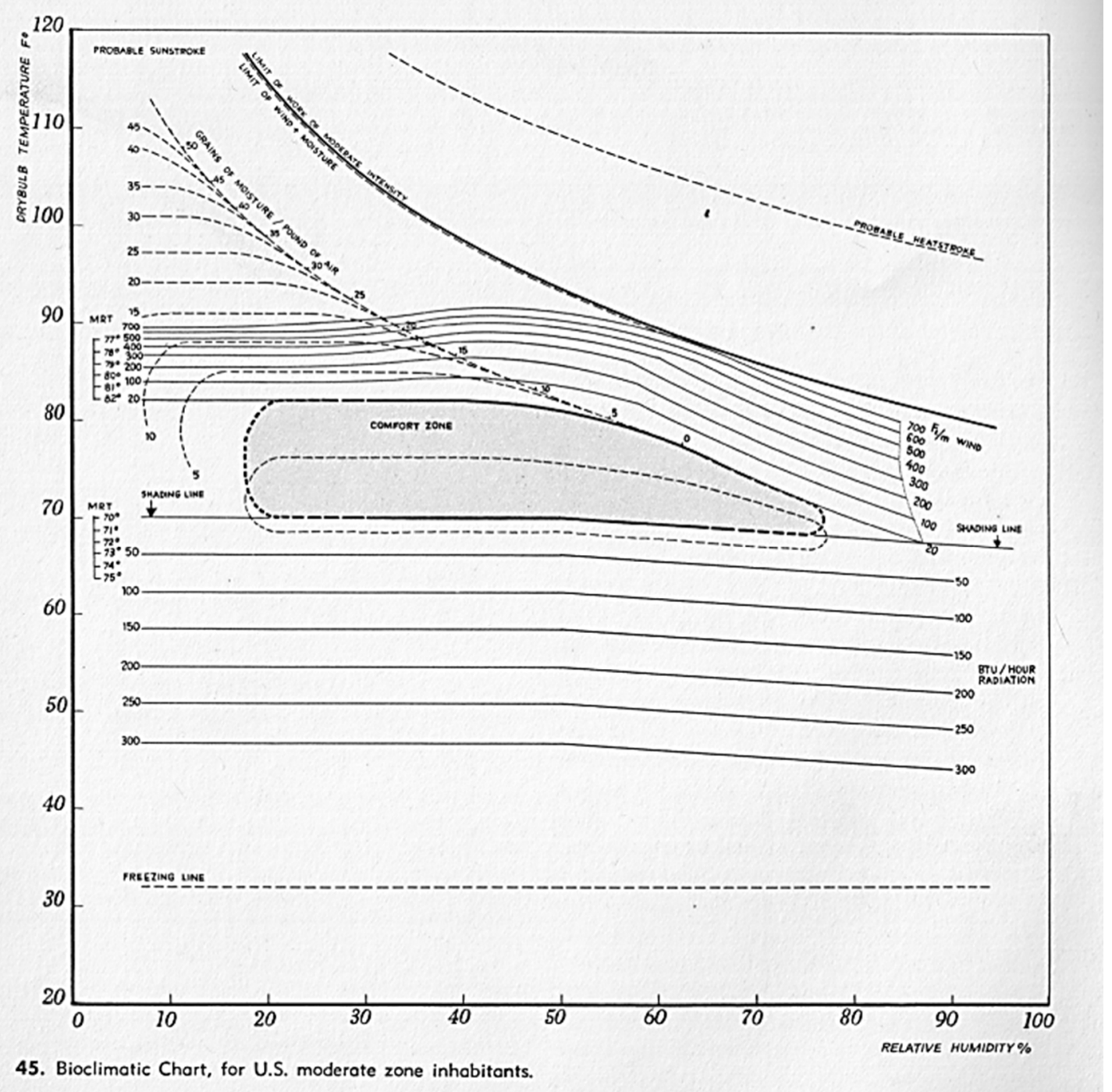

Fig. 1.12: Tabla bioclimática para clima templado en EEUU, mostrando la zona de confort higrotérmico Fuente: Olgyay op.cit. pág. 22 
En 1969, Victor Olgyay trabajó en el Instituto de Tecnología Industrial (INTI) como asesor de Asistencia Técnica de las Naciones Unidas. De este trabajo, surgieron conclusiones con recomendaciones sobre orientación y tipologías para nuestro país, plasmadas en un libro que se transformó en manual de referencia sobre el tema (Álvarez Forn, R \& Lotersztain, I, 1970)

A partir de su obra, otros arquitectos continuaron esta línea de investigación, entre ellos, Givoni (Givoni, B, 1969), autor del climograma (Fig. 1.13), donde- a partir del clima- se recomiendan técnicas de acondicionamiento pasivo. A diferencia de Olgyay- que considera las condiciones del clima exterior para alcanzar el confort- Givoni desarrolló estudios sobre el diseño y los materiales de la envolvente arquitectónica para conseguir niveles de confort, a partir de las condiciones higrotérmicas interiores.

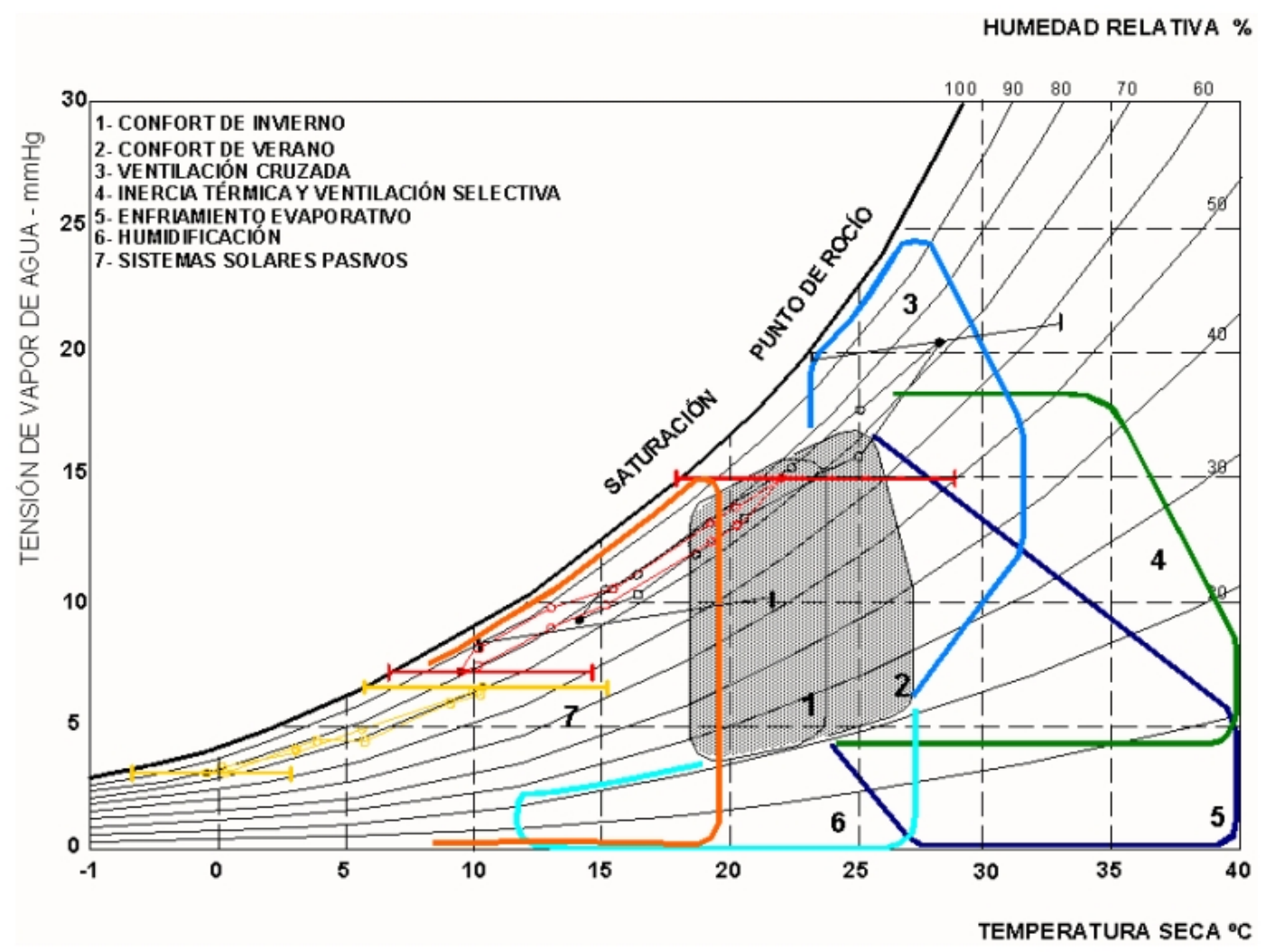

Fig.1.13: Climograma de Givoni: Argentina. Fuente: Jorge Daniel Czajkowski ${ }^{6}$

Otro pionero de la arquitectura solar y bioclimática es Edward Mazria (Mazria, 1985), que escribió La Casa Solar Pasiva, en 1979. Allí compila las estrategias de diseño pasivo, (captación solar directa, invernaderos, lechos de piedra, muros Trombe, etc.) y provee las

${ }^{6} \mathrm{http}: / /$ commons.wikimedia.org/wiki/File:Climograma_de_givoni_argentina.png\#/media/File:Climogram a_de_givoni_argentina.png 
fórmulas para el cálculo de la ganancia solar pasiva. Actualmente dirige Architecture $2030^{7}$ que es un grupo de investigación que publicó la iniciativa 2030 Challenge en 2006, para abogar por una arquitectura libre de emisiones, para el año 2030. Architecture 2030 desarrolló la plataforma 2030 Palette $^{8}$, que es una plataforma que provee principios y acciones para un medio ambiente construido resiliente ${ }^{9}$ y de bajas emisiones para los profesionales del diseño (Mazria et al., 2007).

En nuestro país, uno de los pioneros en la difusión de la consideración del asoleamiento y la orientación, fue el arquitecto Wladimiro Acosta. Este arquitecto de origen ruso, fue discípulo de Walter Gropius y arribó al país en 1928. En 1936, escribió Vivienda y Ciudad (Acosta, W., 1936) donde explicaba su sistema Helios para protección solar junto con la correcta orientación (Fig. 1.14). Asimismo realizó valiosos estudios sobre el clima urbano, anticipando problemas contemporáneos como la eliminación de residuos volátiles y el efecto de isla de calor (Acosta, W., 1976).

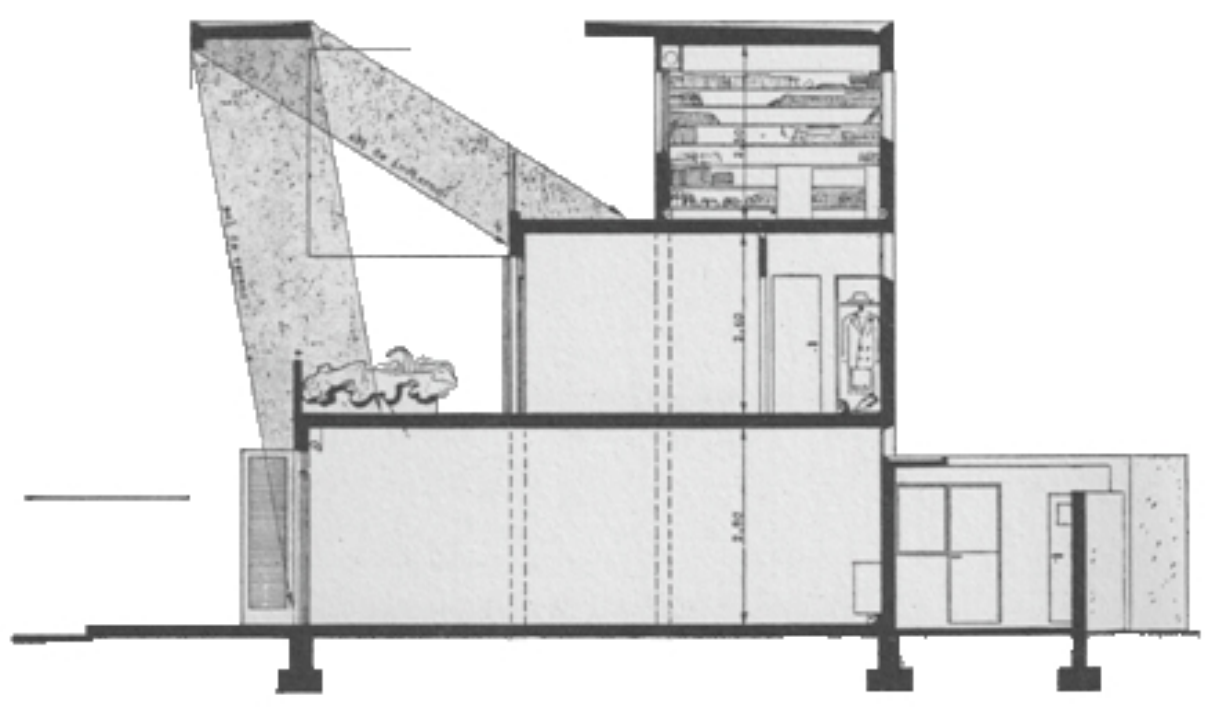

Fig. 1.14: Sistema Helios aplicado a una vivienda en Buenos Aires- Fuente: modificado de Acosta op.cit.

Otro arquitecto destacado por considerar al ambiente como condicionante de diseño, fue Eduardo Sacriste, que entendía que el clima ejercía una influencia directa sobre el diseño arquitectónico. Enunció recomendaciones para la zona Noroeste de nuestro país, más precisamente Tucumán, donde residió y desarrolló su labor docente y profesional, tales

\footnotetext{
${ }^{7}$ http://architecture2030.org/about/leadership/

8 http://2030palette.org/about

${ }^{9}$ Resiliencia: 1. f. Capacidad de adaptación de un ser vivo frente a un agente perturbador o un estado o situación adversos.

2. f. Capacidad de un material, mecanismo o sistema para recuperar su estado inicial cuando ha cesado la perturbación a la que había estado sometido RAE
} 
como aleros, patios y ventilación cruzada. Su enfoque fue más empírico que técnico. En las décadas posteriores, se generalizaron la consideración de la orientación, la ventilación cruzada, el asoleamiento y la protección solar (Sacriste, 1968).

Diversos arquitectos prosiguieron la investigación sobre el tema: Di Bernardo creó el Centro de Estudios Bioambientales de la Facultad de Arquitectura y Urbanismo de la Universidad de Rosario (FAU- UNR), Rosenfeld, el Instituto de Arquitectura Solar (IDEHAB-FAU-UNLP) en 1976, y en 1984, Evans, el Centro de Hábitat y Energía (Evans, J. M. \& de Schiller, S., 1988) (CIHE-FADU-UBA), siendo el más desarrollado del país, el Instituto Nacional de Energía No Convencional (INENCO), de la Universidad Nacional de Salta, creado por los físicos Saravia y Lesino. Asimismo el arquitecto Eduardo Yarke creó el Instituto Solar Buenos Aires, donde trabajó en el desarrollo de tablas para medir el aporte solar de sistemas pasivos de climatización para nuestro país, junto al físico Aldo Fabris (Yarke et al, 2006). Existen también grupos de investigación en Mendoza (LAHV CRICYT), en Tucumán (IAA-FAU-UNT), en Neuquén (CEVEQu- UNN) y San Juan (IRPHa-FAUDI-UNS).

En el IDEHAB-FAU-UNLP, Czajkowski y Rosenfled desarrollaron un programa con interfaz gráfica y planilla de cálculo para el balance térmico de calefacción y refrigeración mediante el uso de una biblioteca de tipos de muros, techos, puertas y ventanas, una base de datos climáticos y otra de tipos edilicios, ENERGOCAD (Czajkowski, J. \& Rosenfeld, E., 1992). El programa calcula el consumo de energía en estado estacionario considerando las cargas solares y la ocupación, a lo largo del año. Esta tesis retoma el problema planteado por ENERGOCAD y lo desarrolla en un entorno 3D paramétrico.

\subsection{Conclusiones}

Como se ha descripto en este apartado, el sector edilicio es responsable del consumo a nivel mundial de más de un tercio de la energía secundaria generada (IEA, 2013) y de las emisiones de GEI que esto provoca. La arquitectura sostenible puede dar una respuesta a la reducción de estas emisiones, para mitigar el Cambio Climático y disminuir el consumo de energía mediante la eficiencia energética, las estrategias pasivas y las activas como la incorporación de las energías renovables. Por su naturaleza, esta arquitectura, se adapta al entorno físico, clima, recursos y tecnología locales, Pero necesita otras heurísticas ${ }^{10}$ (J. López, 2013) que permitan resolver las nuevas problemáticas que condicionan el producto arquitectónico, incluyendo el proceso de la construcción de un hábitat sustentable en todo su ciclo de vida (Guinée, 2002) (ISO, 2006)

\footnotetext{
10 "Puede definirse como heurística a aquellos aspectos vinculados con la utilización de conocimiento para realizar una tarea. Es decir, a una técnica, método o procedimiento inteligente que no es producto de un análisis formal, sino más bien de conocimiento experto sobre el tema. Las heurísticas son procedimientos específicos, que se aplican en la resolución de problemas determinados, caracterizándose por tener buen rendimiento, aportando soluciones de calidad y poca utilización de recursos." (López, 2013) pág. 25
} 
El uso de algoritmos genéticos aplicados al diseño bioambiental paramétrico 
2. Cibernética y diseño digital 
El uso de algoritmos genéticos aplicados al diseño bioambiental paramétrico 


\subsection{Arquitectura algorítmica}

La arquitectura se ha caracterizado desde el Renacimiento (Benevolo, 1988) por priorizar el diseño de la forma antes que su materialización, utilizando las herramientas de representación para la descripción de lo que luego habría de construirse, trasladando el dibujo a la obra. Salvo algunas excepciones, que utilizaron modelos biológicos, como Antoni Gaudí (Bassegoda Nonell, 1971) o Frei Otto (Otto, Rasch and Schanz, 2006), los arquitectos han separado la definición de la forma de su construcción, a diferencia de lo que ocurre con las arquitecturas vernáculas donde forma, función y materialidad son inseparables. La diferencia estriba en la metodología empleada: Otto, Gaudí y la arquitectura vernácula emplean un método bottom-up, mientras que la formación académica tradicional emplea un método top-down. En el primer método, se considera cada uno de los elementos que integran un todo, que configuran un sistema con propiedades diferentes a las de los elementos por separado y donde el "todo es más que la suma de las partes" (Aristóteles and Sola, 1956). También la teoría de la Gestalt (Read, 1968) y la arquitectura de sistemas, adoptan este principio, considerándolo un producto sinérgico ${ }^{1}$ dentro de una visión holística ${ }^{2}$. En el método top-down, se parte de un todo que luego se va refinando en los detalles de cada uno de sus componentes, desde arriba hacia cada una de sus partes; en el bottom-up, el principio organizativo se aplica desde los elementos más simples hacia arriba.

Según Stafford Beer $^{3}$, la cibernética ${ }^{4}$ estudia los flujos de información de un sistema (Beer, 2001). Es una ciencia multidisciplinaria que comprende aspectos de la física, la biología y la teoría de la información. Los primeros experimentos y reflexiones acerca de la cibernética aparecen en las décadas del 50 y 60 . Norbert Wiener fue quien acuñó el término, derivado del griego kybernetes - que significa timonel- comparando la habilidad del timonel en el manejo de una nave, con la complejidad de los sistemas a decodificar. Publicó su manifiesto Cybernetics en 1949, (Wiener, 1999) sobre funciones de control y comunicación en organismos vivos y computadoras, basándose en el proceso de retroalimentación de la información. Estas investigaciones conducen al enfoque sistémico y la mímesis con los modelos biológicos aplicados al diseño. Von Neumann (Von Neumann, 2012), que desarrolló entre otros muchos inventos, el autómata celular artificial, comparando su máquina con los automátas naturales y los procesos de autoorganización. Este tema será recogido por la teoría de la complejidad que se desarrolla alrededor de los años '60 y da

\footnotetext{
${ }^{1}$ Sinergia: 1. f. Acción de dos o más causas cuyo efecto es superior a la suma de los efectos individuales. Diccionario de la Real Academia Española-consultado el 6/4/16

${ }^{2}$ Holismo: 1. m. Fil. Doctrina que propugna la concepción de cada realidad como un todo distinto de la suma de las partes que lo componen. Diccionario de la Real Academia Española-consultado el 6/4/16 ${ }^{3} \mathrm{http}: / /$ wosc.co/outstanding-contributors/stafford-beer/

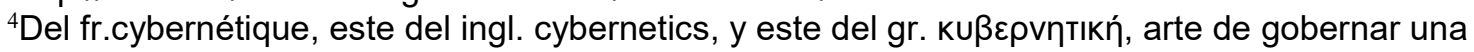
nave).1. f. Estudio de las analogías entre los sistemas de control y comunicación de los seres vivos y los de las máquinas; y en particular, el de las aplicaciones de los mecanismos de regulación biológica a la tecnología- Diccionario de la RAE- ed. $22^{\circ}$-2012- consultado el 3/4/16
} 
El uso de algoritmos genéticos aplicados al diseño bioambiental paramétrico

origen a una nueva epistemología (Morin, E., 2004). Los procesos biológicos, físicos, sociales son recursivos en cuanto autopoiéticos ${ }^{5}$ (Maturana and Varela, 1972) , y obligan, a partir de ellos, a considerar el todo y las partes a un mismo tiempo (Rodríguez, D. and Torres, J., 2003). Así también, se los considera desde el punto de vista de la emergencia, donde se verifica el surgimiento de estructuras, patrones y propiedades nuevas y coherentes durante el proceso de autoorganización en sistemas complejos, que las partes que los constituyen, no poseían individualmente (Vivanco, 2014) (ver apartado 2.1)

En la década del '70, el arquitecto y matemático Christopher Alexander (Alexander, 1976), propuso un enfoque sistémico del proceso proyectual buscando reducir al mínimo el momento de "caja negra" para racionalizar al máximo la toma de decisiones proyectuales. El enfoque sistémico de Alexander se vinculaba con el cibernético al comparar el edificio y las ciudades con organismos vivos que deben adaptarse a su contexto - donde cualquier modificación de una parte del sistema afecta al todo - mientras que la retroalimentación posibilita una mejor adaptación al entorno, fruto del intercambio de información, materia y energía entre ambos. En su artículo "La ciudad no es un árbol" (Alexander, C., 1983) ejemplificó, de manera elocuente, la complejidad de las relaciones que afectan el entorno urbano. Si bien la lógica era una herramienta muy eficaz a la hora de explorar el orden y el desarrollo de un problema de diseño, la complejidad y el número de variables a considerar hicieron que ese proceso fuera manualmente inviable.

Todavía el software para esas experimentaciones no se había desarrollado. Los primeros programas de dibujo digital, se orientaron hacia las herramientas de representación CAD pero las decisiones proyectuales siguieron circunscriptas a la decisión humana. Aún, un uso frecuente que solemos observar de los programas de dibujo en $3 \mathrm{~d}$, es la manipulación de los puntos de control de superficies basadas en $\mathrm{NURBS}^{6}$ por medio del mouse, que son simplemente transformaciones morfológicas como traslación, rotación, etc (Kourkoutas, V., 2007) ${ }^{7}$. Con la aparición del scripting ${ }^{8}$, el diseñador accede a la parametrización de las variables matemáticas que constituyen el edificio sean éstas, lógicas, geométricas, físicas o de otro orden. Cada variable se define como un rango, no como una constante y se fijan las relaciones entre dichas variables. A partir de allí, se asume el control sobre la forma, no ya como una NURB con puntos de control sino sobre su génesis misma, como producto del cálculo numérico. En vez de una aleatoriedad ciega, los algoritmos son capaces de controlar

\footnotetext{
${ }^{5}$ Autopoiesis: capacidad de los organismos vivientes de producir y reproducir por sí mismos los elementos que los constituyen. Consultado en http://www.scielo.br/pdf/soc/n9/n9a05 ${ }^{6}$ NURBS (acrónimo inglés de la expresión Non UniformRational B-splines) es un modelo matemático muy utilizado en la computación gráfica para generar y representar curvas y superficieshttp://es.wikipedia.org/wiki/NURBS

${ }^{7}$ Para una descripción más detallada de estos procedimientos ver: Kourkoutas V. (2007) Parametric

Form Finding in Contemporary Architecture- Technischen Universität Wien- Austria

${ }^{8}$ Scripting: programación en algún lenguaje de nivel superior
} 
selectivamente el modelado de la información. Mientras que la cantidad y composición de los datos externos podrían parecer infinitas, aleatorias o incoherentes, un filtrado lógico conducirá progresivamente a una formación ordenada. Si estos eventos son posibles sin intervención humana, es inevitable asumir que alguna inteligencia humana interviene en la selección del proceso que mejor se ajusta al problema: la inteligencia aparece como un acto de preferencia del diseñador. Pero, ¿qué papel juega el diseñador en este proceso? Si dejamos el proceso creativo en manos de los algoritmos y la inteligencia artificial (IA), observaremos sus impactos negativos: el diseñador se transforma en un instrumento de trabajo menos creativo y el resultado es formalismo no procesado, sin contenido cultural o significado ya que la cultura, - en términos de interpretación humana - no tiene sentido para las máquinas. Lo humano es proyectado en el material a través del proceso de codificación que le da a la forma generada, el contenido para ser reutilizada (Sevaldson, B., 2000).

Un uso verdaderamente creativo de la computadora, a través de la exploración de técnicas de scripting, como archivo de órdenes, nos permite el manejo de una cantidad de información impensada para un diseñador. Podemos incorporarla a nuestro proceso mental y dejar que una parte de ese proceso sea desarrollado por la máquina, codificando el rango de las variables entre las cuales pretendemos que itere, produciendo una cantidad de alternativas que serían prácticamente imposibles de plantear en forma manual. Así, el rol del diseñador no se limita, sino que se expande al incorporar procedimientos algorítmicos que requieren una nueva forma de entender la proyectación arquitectónica. El poder de la computadora, que involucra grandes cantidades de cálculos, análisis combinatorio, aleatoriedad o recursividad, por nombrar algunos procedimientos, señala nuevos procesos de "pensamiento" que podrían no haber ocurrido nunca en la mente humana. Estos "generadores de ideas", basados en esquemas computacionales, tienen la profunda habilidad no sólo de expandir los límites de la imaginación humana, sino también señalar sus potenciales limitaciones.

Como Terzidis (Terzidis, K., 2006), podemos considerar que el diseño no es propiamente una invención - la creación de algo absolutamente nuevo - sino un proceso de develación o redescubrimiento, Podemos concebir a la computadora, no como una extensión de la mente del diseñador sino como un "otro", un socio no humano, en el proceso proyectual, con aptitudes y formas de razonar diferentes a la humana. El proceso de hacer arquitectura siempre fue considerado como un compromiso entre lo reglado y lo trasgresor, donde las restricciones estimulan la imaginación y la espontaneidad responde a algunos principios ocultos, pero ambos procesos conviven dentro de la mente del diseñador. Podría pensarse que una parte de ese proceso en un punto se exteriorizara y se encarnara en la computadora como un reflejo de nosotros mismos en tanto diseñadores: "Actualmente, se 
El uso de algoritmos genéticos aplicados al diseño bioambiental paramétrico

está formulando una elección alternativa que podría escapar a estas estrategias dialécticamente opuestas: la arquitectura algorítmica ${ }^{9}$. Esto implica utilizar programas para generar espacio y forma desde una lógica basada en reglas, inherente a las variables a considerar... El diseño algorítmico no erradica las diferencias sino que incorpora el uso creativo de las computadoras a la complejidad computacional. Para los arquitectos, el diseño algorítmico posibilita que el rol del diseñador se desplace desde la "programación arquitectónica" a la "arquitectura programable"... Por primera vez quizá, el diseño arquitectónico tenga la posibilidad de no alinearse ni con el formalismo ni el racionalismo sino con la creatividad inteligente y trazable"1011.

\subsection{Arquitectura emergente: Sistemas materiales, morfogénesis digital y performance energética}

John Frazer fue un pionero en la búsqueda de una arquitectura generativa (Frazer, 1995) asimilándola a un proceso de vida artificial, susceptible a la influencia del ambiente en su evolución. Consideraba el producto arquitectónico como una biomorfología sensible al ambiente y un sistema termodinámico abierto y a la arquitectura, como una forma de vida artificial, sujeta - al igual que el mundo natural- a principios de morfogénesis, codificación genética, replicación y selección. El objetivo de la arquitectura evolutiva era conseguir en el medio construido el comportamiento simbiótico y el balance metabólico que caracterizan el entorno natural. Continuando con esta línea de investigación, la arquitectura emergente (Hensel, Menges and Weinstock, 2010) propone emplear un método bottom-up donde la morfogénesis y la materialidad estén presentes desde la concepción del edificio, de una manera similar al desarrollo de un ser vivo: desde la etapa embrionaria, ya contiene todo lo necesario para el desarrollo de un individuo adulto. Se requiere un entendimiento de la forma, el material y la estructura como una compleja interrelación que se explora mediante un proceso computacional. Debe diferenciarse de las simulaciones materiales digitales $\mathrm{BIM}^{12}$ que necesitan una definición de todos sus datos de entrada como constantes, para su modelización. Mediante este procedimiento, se explora el diseño del espacio a partir de las variables paramétricas de un sistema material, que incluye lo estructural, energético y ambiental y conduce a resultados no determinados a priori, por ello se los considera sistemas emergentes.

\footnotetext{
${ }^{9}$ Algoritmo:1. m. Conjunto ordenado y finito de operaciones que permite hallar la solución de un problema. Diccionario de la Lengua Española- RAE- http://dle.rae.es/?id=1nmLTsh- consultado el 7/4/16

${ }^{10}$ Terzidis, Kostas (2009) op. cit. Trad. de la autora- pág. xii

${ }^{11}$ Trazabilidad: 3.f. Propiedad de un resultado de medida que permite relacionarlo con una referencia superior mediante una cadena documentada de calibraciones (RAE).

${ }^{12}$ BIM: Building Information Modelling
} 
La autoorganización caracteriza a este tipo de sistemas, ya que las unidades más pequeñas se organizan siguiendo algunos principios básicos, como ocurre en una colmena o un hormiguero, donde la colonia adquiere propiedades que no poseen sus individuos (Johnson, 2004). Esta última característica no es privativa de los organismos vivientes, también la encontramos en la química inorgánica cuando dos gases a presión ambiente, oxígeno e hidrógeno, al combinarse, forman agua: esta es líquida y tiene propiedades diferentes a los elementos que la originan.

Si se considera la construcción artificial del ambiente como un sistema material y energético, veremos que - a diferencia de los sistemas biológicos - este producto de la cultura humana ha tenido un profundo impacto en el ambiente. Como se explica más arriba, se define como sistema material no sólo los elementos constructivos que constituyen un edificio sino también, en un marco teórico sistémico, la compleja reciprocidad entre materialidad, forma, estructura y espacio, los procesos de producción y ensamblado y la infinidad de efectos de comportamiento que emanan de la interacción con el medioambiente. Mientras que la evolución biológica ha provocado que las especies se adapten a su medio, la evolución de la cultura humana ha adaptado los ambientes naturales a la especie humana. Así como la información biológica es transmitida verticalmente a través de las generaciones, la información cultural es transmitida además horizontalmente entre congéneres y oblicuamente entre diferentes generaciones en localizaciones vecinas. Comparada con la evolución biológica, la evolución cultural puede ser extremadamente rápida y sus consecuencias mucho más profundas para el medio ambiente (Weinstock, 2010).

\subsection{Los algoritmos genéticos}

En 1975, un discípulo de Norbert Wiener en el MIT, John Holland (Holland, 2001) diseñó los algoritmos genéticos, que simulan procesos de evolución de manera simplificada y son aplicables a la optimización de procesos digitales. Al aparecer la posibilidad de simular digitalmente un proceso biológico - mediante la parametrización de las variables de diseño- surgió la idea de optimizar la forma arquitectónica, aplicando algoritmos genéticos. Mientras los procesos biológicos no podían ser emulados en una computadora, los programas de dibujo se utilizaban solamente para reemplazar el dibujo manual. Pero, al poder expresar digitalmente un desarrollo biológico como, por ejemplo, la proliferación, solo faltaba un paso para aplicarlo al diseño de las formas artificiales. Un algoritmo genético es un proceso de simulación simplificada de la evolución- comportamiento y adaptación de una población- a través del tiempo, donde las generaciones son creadas, probadas y seleccionadas mediante la reproducción y mutación. Se dice simplificada porque en la evolución natural, no se prescinde de los cambios en el contexto a través del tiempo, como 
El uso de algoritmos genéticos aplicados al diseño bioambiental paramétrico

sucede en nuestro caso de estudio. El algoritmo busca de forma estocástica, la posibilidad de una solución mejor: el proceso computacional no requiere esfuerzo, es rápido y preciso.

Contrariamente a la creencia general, los algoritmos no siempre se basan en una solución estratégica concebida enteramente por la mente de un programador humano. Muchos algoritmos son simulaciones del funcionamiento de procesos naturales, por ejemplo, la selección natural (Dawkins, 2006) y- como tales- no deben ser considerados invenciones humanas sino, descubrimientos. A diferencia de las invenciones, los descubrimientos no son concebidos por la mente humana, ni pertenecen o son controlados por ella, aun cuandoen tanto procesos abstractos- puedan ser capturados, codificados y ejecutados por un sistema computacional. En este caso, el programador traduce un proceso externo a la mente humana para que sea compilado en lenguaje de máquina, el cual es también otro proceso externo a su mente. Ningún elemento del algoritmo es invención humana; este proceso llamado "selección natural" ocurre en la naturaleza independientemente de la presencia humana y el desarrollo de los cálculos computacionales; es lógico o aritmético, prescindiendo también de la intervención humana (Terzidis, K., 2006).

\subsection{Programas de diseño evolutivo: GENR8}

En la búsqueda del software apropiado para llevar a cabo nuestra investigación, se han explorado diferentes programas disponibles en el mercado. El primero de ellos fue $G E N R 8^{13}$, un plug-in de libre descarga para MAYA ${ }^{14}{ }^{14}$, desarrollado por Martín Hemberg en el MIT (Hemberg et al., 2008). Este genera superficies combinando computación evolutiva y vida artificial, utilizando el sistema de Lyndenmayer (L-system) (O’Reilly, U., Hemberg, M. and Menges, A., 2004) para explicar el desarrollo de las especies vegetales. No permite un control dimensional sobre los parámetros. Genr8, corre dentro de MAYA $®$ de Autodesk, un programa de modelado y animación computada de libre descarga muy utilizado en películas y juegos.

Los ejemplos mostrados a continuación ilustran las formas paramétricas generadas con GENR8. Se experimentó el crecimiento de superficies en cajas contenedoras y bajo la influencia de repulsores y atractores. Estos últimos elementos geométricos influyen sobre la generación de la superficie de estudio (figs. 2.1, 2, 3 y 4).

Se obtenían líneas que luego se debían procesar con Rhinoceros (P. Cook, 2013) para su transformación en superficies, pero no era posible la parametrización arquitectónica de los elementos geométricos ni la introducción de un AG dentro del programa para optimizar el resultado. El editor de GENR8 en Maya Embedded Language (MEL) contenía errores por

\footnotetext{
${ }^{13}$ http://projects.csail.mit.edu/emergentDesign/genr8/ consultado el 3/4/2011

${ }^{14}$ MAYA Autodesk programa de animación en 3D en lenguaje MEL. 
tratarse de una versión beta ${ }^{15}$, lo cual dificultaba el manejo de los resultados. Como uno de los objetivos era que todo el proceso paramétrico y de evaluación se diera dentro del mismo entorno y esto no era posible con este software, se descartó esta opción. No obstante, se rescata la valiosa experiencia con GEN8 como explorador creativo de formas aplicables a cubiertas generativas.

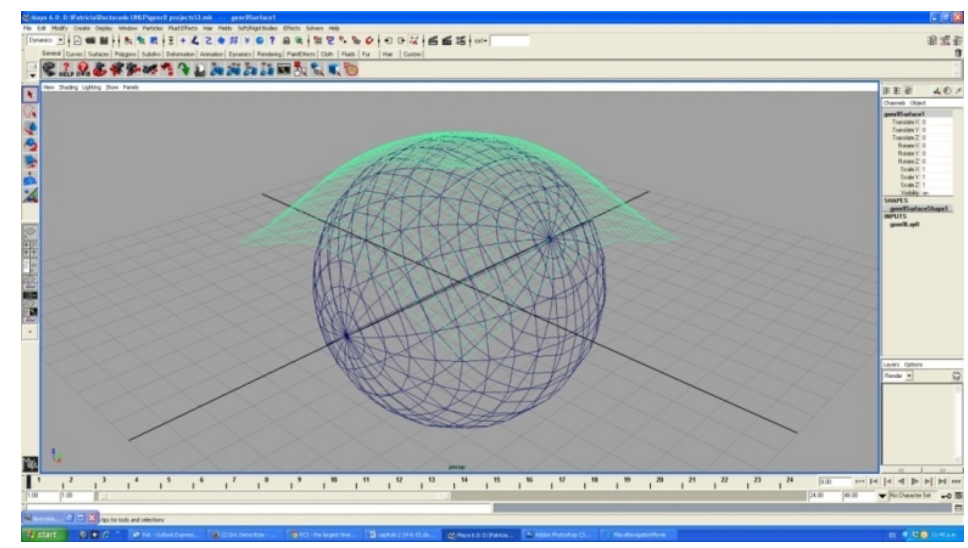

Fig. 2.1: Superficie atraída por una esfera atractora simulando el peso gravitatorio. Fuente: la autora

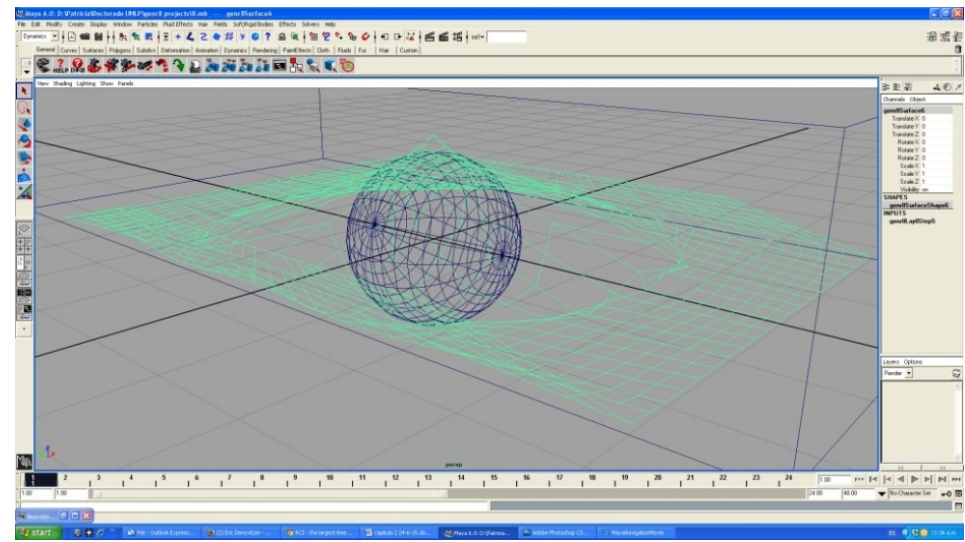

Fig. 2.2: Superficie limitada por una caja contenedora y una esfera repulsora. Fuente: la autora

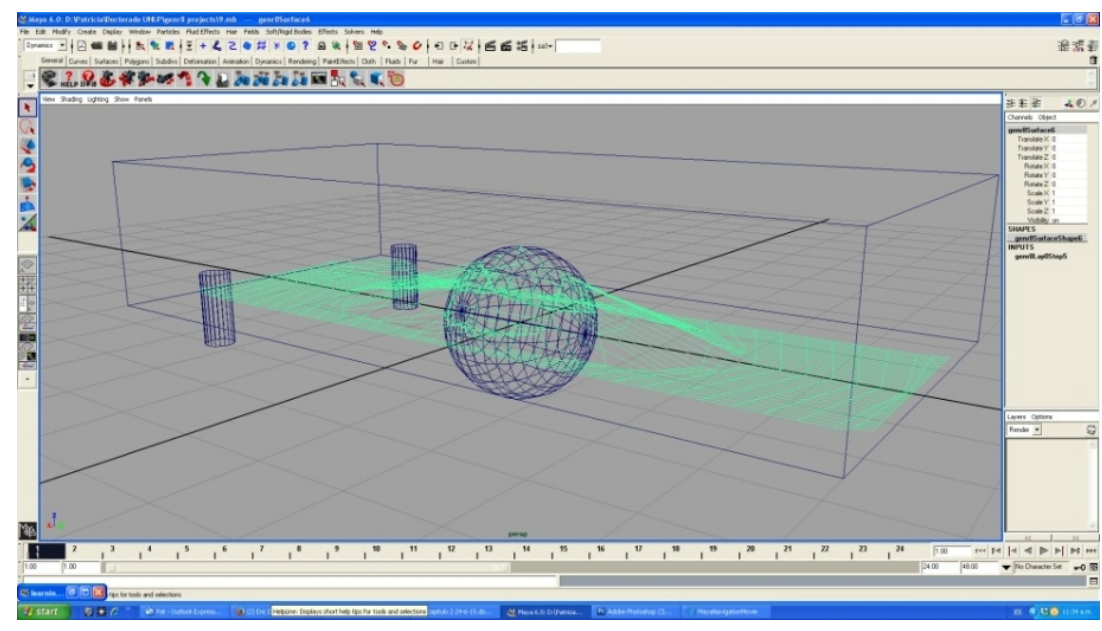

Fig. 2.3: Superficie limitada por una caja contenedora, dos cilindros y una esfera repulsores. Fuente: la autora

\footnotetext{
${ }^{15}$ Hemberg M., 2011, comunicación personal
} 


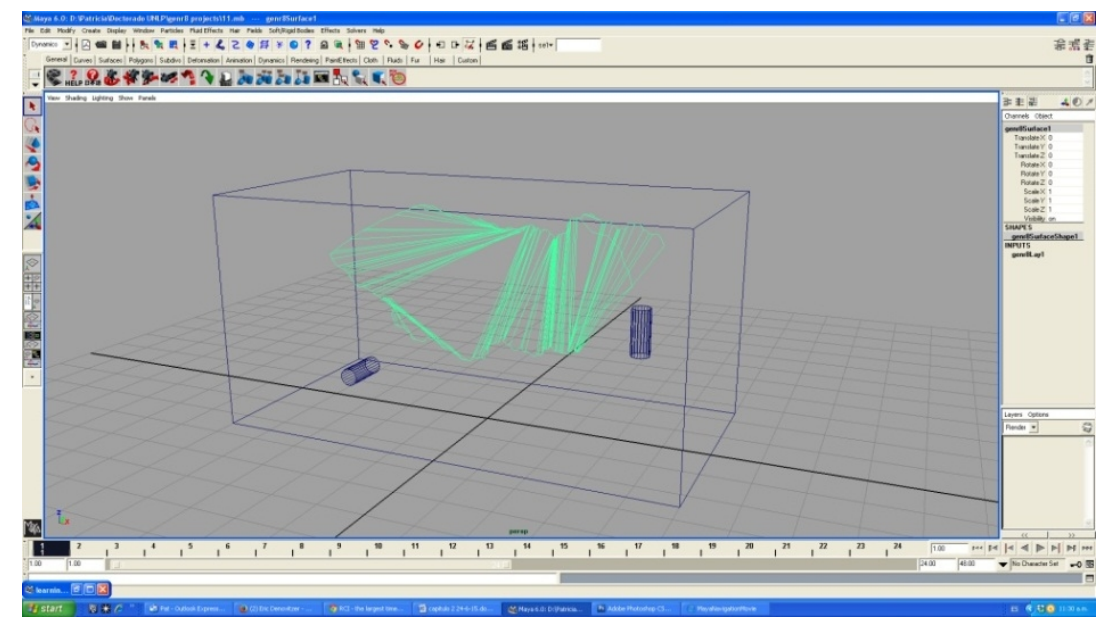

Fig. 2.4: Superficie reglada a partir de una curva generatriz con dos cilindros repulsores, limitada por una caja contenedora

\subsection{Otros programas de diseño paramétrico}

Se analizó, GenerativeComponents ${ }^{\circledR}(G C)$, de Bentley® , ampliamente utilizado por la oficina de cálculo estructural Buro Happold ${ }^{16}$ junto al estudio de arquitectura de ZahaHadid ${ }^{17}$ en sus diseños, así como también en los seminarios de la Architectural Association de Londres, dictados por Hensel, Weinstock y Menges ${ }^{18}$..Es de libre descarga para su versión beta y propone un diseño paramétrico. Para la evaluación energética se conecta con un programa de simulación térmica: AECOsim Building Designer, también de Bentley. Habiendo consultado con profesionales de Buro Happold, se lo consideró una opción inviable para la investigación ${ }^{19}$, ya que, era necesario un conocimiento de scripting que no poseía y una interfaz poco amigable para usuarios que no manejaran conocimientos de programación (Jonas, K., 2011). Asimismo, el programa está fuertemente orientado a los aspectos estructurales del proyecto Obtener el entrenamiento para este programa estaba fuera de mis posibilidades materiales ya que no poseía los recursos para un curso en el exterior.

También se analizó el lenguaje Processing ${ }^{20}$ (Terzidis, 2009) que actualmente está siendo desarrollado en Boston por Fathom Information Design, en Los Angeles por la UCLA Arts Software Studio, y en New York por NYU's ITP. Es un lenguaje de programación para diseño visual basado en Basic muy utilizado en arte digital pero que requiere el dominio de ese lenguaje. Dentro de Processing, se desarrolló el programa $A N A R+{ }^{21}$ que es una biblioteca de geometrías paramétricas en JAVA, utilizada para parametrizar edificios y evaluar su desempeño energético (Nembrini, Samberger and Labelle, 2014). Ambos programas son de libre descarga pero requieren conocimientos de programación.

\footnotetext{
${ }^{16} \mathrm{http}: / / \mathrm{www}$. burohappold.com/

${ }^{17} \mathrm{http}: / /$ www.zaha-hadid.com/

${ }^{18} \mathrm{http} / / / \mathrm{www}$.aaschool.ac.uk/STUDY/GRADUATE/?name=emtech

${ }^{19}$ Comunicación personal con KatrinJonas, ingeniera de Buro Happold.2/10 2013

${ }^{20} \mathrm{https}$ ://processing.org/consultado el 9/5/16

${ }^{21}$ https://processing.org/discourse/beta/num 1241433067.htmlconsultado el 9/5/16 
Investigando los contenidos de la maestría dictada en el Instituto para Arquitectura Avanzada de la Universidad de Barcelona (IAAC) ${ }^{22}$ sobre diseño generativo y fabricación digital, se observó que utilizaban Rhinoceros $®$, un programa de diseño 3D por NURBS y su plug-in de diseño paramétrico, Grasshopper@ (A. Payne and R. Issa, 2009). Este programa y su plug-in permiten el scripting en Visual Basic mediante una interfaz gráfica. Es el más versátil de todos los programas explorados y se pueden observar los cambios en tiempo real y de manera transparente. Asimismo, puede relacionarse con programas de simulación térmica como Energy Plus y Ecotect mediante diferentes plug-ins. Para ello, existe un plugin de Grasshopper - Honeybee - que lo conecta EnergyPlus, Radiance, Daysim y OpenStudio. Otro plug-in, Ladybug, provee herramientas para análisis de radiación solar y diagrama psicrométrico utilizando archivos climáticos *.epw ${ }^{23}$. Otros plug-ins son DIVA para EnergyPlus - se puede bajar una versión gratuita para estudiantes desde la página de Solemma LLC ${ }^{24}-\mathrm{y}$ Geco@, para Ecotect. Los demás programas son abiertos y de libre descarga desde la página de Rhinoceros ${ }^{\circledR}$ : Food4Rhino ${ }^{25}$.

\subsection{Diseño paramétrico y evaluación energética}

Se realizó una búsqueda bibliográfica exhaustiva donde se analizó una extensa cantidad de trabajos científicos. Uno de los objetivos de esta búsqueda era identificar los programas que mejor se adaptaban a la formación académica del arquitecto. Según Bambardekar (S. Bambardekar and U. Poerschke, 2009), los métodos de diseño computacionales aplicados a las primeras etapas del diseño, se encuentran entre las últimas opciones del diseñador frente al uso de la intuición, la experiencia empírica, las guías de diseño y las reglas del arte. A partir de encuestas con usuarios, este autor llegó a la conclusión que el programa mejor posicionado resultó ser Ecotect, seguido de lejos por IES VE ${ }^{26}$ y Green Building Studio ${ }^{\circledR}$ de Autodesk. Este resultado se vio respaldado por el estudio de Attia y otros, donde se compararon diez programas de simulación: ECOTECT, HEED, Energy 10, DesignBuilder, eQUEST, DOE-2, Green Building Studio, IES VE, Energy Plus and Energy Plus-SketchUp, Plugin (OpenStudio), con el objetivo de relevar aquéllos que fueran amigables para el arquitecto (Attia et al., 2012). La metodología tradicional de diseño aplicada por los arquitectos está fundamentalmente basada en criterios estéticos y funcionales, no así en el comportamiento energético, aun cuando, en las primeras etapas del diseño arquitectónico, morfología y materialidad de la envolvente determinan dicha performance. Así como está ampliamente aceptado que la eficiencia energética y el costo final están mayormente

\footnotetext{
${ }^{22} \mathrm{http} / / /$ iaac.net/educational-programs/master-in-advanced-architecture/

${ }^{23} \mathrm{https} / / / \mathrm{www}$.energyplus.net/weather

${ }^{24}$ http://www.solemma.net/DIVA-for-Rhino/DIVA-for-Rhino.html- consultado el 9/5/16

${ }^{25}$ http://www.food4rhino.com/?ufh consultado el 9/5/16

${ }^{26}$ https://www.iesve.com/software/ve-for-architects consultado el 10/5/16
} 
El uso de algoritmos genéticos aplicados al diseño bioambiental paramétrico

determinadas en las primeras etapas, lo mismo puede aplicarse al caso de rehabilitaciones edilicias (Murray et al., 2014).

Al existir un creciente interés científico para facilitar métodos basados en el desempeño energético, como ha señalado Nguyen (Nguyen, Reiter y Rigo, 2014), muchos investigadores han presentado la asociación de diseño paramétrico y simulación energética (BPS) con métodos de optimización (Turrin, von Buelow y Stouffs, 2011). Estos métodos metaheurísticos (J. López, 2013), entre los cuales encontramos los algoritmos genéticos, han mostrado ser un camino apropiado para resolver cuestiones de mútiples objetivos como el comportamiento medioambiental y energético (Harding and Shepherd, no date). Los algoritmos de optimización han sido extensamente desarrollados y aplicados a diferentes campos: enjambre de partículas, hill-climbing, recocido simulado y algoritmos genéticos (AGs), entre otros (Russell, 2016). John Holland desarrolló en la Universidad de Michigan, los algoritmos genéticos (AGs) que, basados en la biología evolutiva, simulan los procesos de selección natural: herencia, mutación selección y cruzamiento (Holland, 1992). Los AGs han sido testeados para resolver una amplia variedad de problemas de optimización y han mostrado sus pro y sus contras (Mitchell, 2006). Los trabajos de Goldberg- discípulo de Holland- establecieron un paralelo entre los algoritmos genéticos y el proceso de diseño (Goldberg, 2003), siendo uno de los primeros trabajos de aplicación al diseño, el desarrollado por Caldas y Norford en el MIT (Caldas y Norford, 2002). Mediante un AG y el programa DOE2. $\mathrm{IE}^{27}$ - el programa de cálculo de análisis de costo y uso de energía en edificios del Departamento de Energía de los Estados Unidos de Norteamérica —se optimizaba el tamaño de las ventanas de un edificio, de acuerdo a la orientación para diferentes climas. Caldas continuó trabajando en el tema y desarrolló un programa llamado GEN_ARCH, para optimización de variables contrapuestas como son la iluminación natural y la eficiencia energética de la envolvente arquitectónica, no siendo este programa de acceso público (Caldas, 2008).

Muchos de los trabajos consultados para esta tesis, están focalizados en el desempeño energético y pocos abordan la variabilidad de la morfología edilicia en su materialidad: la mayoría: considera formas definidas a priori para su evaluación, pero no las redefine con una retroalimentación del sistema, a partir de la optimización de un objetivo. Las variaciones suelen enfocarse en la composición constructiva de la envolvente (Banihashemi $\mathrm{S}$ et al., 2015), (Ferrara et al., 2014), (lqbal and Al-Homoud, 2007), (Verso et al., 2014), en el diseño y las dimensiones de los vanos de las fachadas (Nembrini et al, 2014), en rotaciones de las plantas de una morfología edilicia en altura (Lin and Gerber, 2014) o bien, o la relación topológica entre volúmenes urbanos como la rotación de un complejo edilicio buscando

\footnotetext{
${ }^{27}$ http://www.doe2.com/consultado el 9/5/16
} 
optimizar la radiación solar y ventilación natural (Chronis, Liapi and Sibetheros, 2012) (Kanters and Horvat, 2012).

Muy pocos se retroalimentaban para optimizar la morfología; uno de estos trabajos, proponía la interacción con programas de dinámica computacional de fluídos (CFD) y ANSYS-CFX mediante el agregado de un componente en C\# que activaba un script en Python para comunicar ambos programas y optimizar la velocidad del viento en espacios urbanos, variando la morfología urbana, utilizando Rhinoceros ${ }^{\circledR}, \mathrm{GH}$ y Galápagos para un caso de estudio en Dubai. Los parámetros considerados eran la razón entre altura y profundidad de los bloques urbanos, la orientación respecto de los vientos predominantes y las características de sus aristas más o menos redondeadas. En una segunda etapa, se optimizaba la radiación solar para reducir la carga térmica de refrigeración (Taleb and Musleh, 2015). También se analizaron trabajos que, utilizando diferentes tipos bloques edilicios implantados en una manzana urbana, determinaban la disponibilidad de energía solar para paneles fotovoltaicos en fachadas y cubiertas, mediante Ecotect ${ }^{\circledR}$ y DIVA como el citado de Kanters y Horvat.

Los trabajos de Stouffs, Turrin y von Buelow muestran un interesante proceso de búsqueda de soluciones sustentables, considerando la importancia de la retroalimentación de la geometría edilicia y la elección de los algoritmos genéticos como buenos optimizadores, siguiendo las recomendaciones de otros investigadores como la citada Luisa Caldas, al buscar mejorar variables bioambientales: confort higrotérmico, exposición solar e iluminación natural para el diseño de espacios públicos semicubiertos . Para ello, desarrollaron un programa -ParaGen - que contiene un algoritmo genético para diseñar morfologías proveyendo los valores de las variables independientes a través de un proceso de selección, recombinación y mutación. La morfología es generada con GenerativeComponents, pero podría admitir Rhinoceros ${ }^{\circledR}$ y Grasshopper@ ${ }^{\circ}$. Luego son evaluados la iluminación natural y el desempeño energético con Ecotect, para un caso de estudio. Las soluciones se alojan en una base de datos SQL y pueden ser filtradas según criterios diferentes. Los recursos necesarios para implementar esta solución fueron una red de computadoras corriendo en paralelo con Windows 7 y un servidor web Linux, en un trabajo conjunto de las Universidades de Michigan, el Taubman College y la Tecnológica de Delft (Turrin et al., 2012).

Se ha observado entre los resultados de las investigaciones sobre optimización por AGs aplicados a problemas arquitectónicos, que éstos algoritmos son apropiados cuando deben resolver problemas dentro de un amplio espacio de búsqueda, evitando óptimos locales (Wright, Loosemore and Farmani, 2002). Otros grupos de investigación han utilizado algoritmos genéticos de soluciones no dominadas II (NSGA-II) y EnergyPlus (US Department of Energy, 2015) para resolver problemas multi-objetivo, o sea, cuando se trata 
El uso de algoritmos genéticos aplicados al diseño bioambiental paramétrico

de compatibilizar objetivos competitivos entre sí, agregando un frente de Pareto (Méndez Echenagucia et al., 2015). Gerber ha integrado Revit ${ }^{\mathrm{TM}}$, Green Building Studio ${ }^{\mathrm{TM}}$ y Microsoft Excel $^{\mathrm{TM}}$, aplicando un método de optimización multi-objetivo (Lin and Gerber, 2014). En el caso de Revit, la optimización formal se realiza mediante el uso de familias conectándolo con un plug-in paramétrico Dynamo y un algoritmo genético de soluciones no dominadas NSGA el H.S. Beagle ${ }^{T M}$. Asimismo, Gerber y otros han experimentado una metodología que integra múltiples entornos como el programa de modelado 3D Rhinoceros ${ }^{\mathrm{TM}}$ y el plug-in de modelado algorítmico Grasshopper@, junto con Ladybug/Honeybee $\odot$, para vincularse con Daysim/Radiance y EnergyPlus/Open Studio respectivamente (Gerber, Pantazis and Wang, 2017). Asadi y otros han propuesto otro esquema: TRNSYS, GenOpt y una técnica de optimización, Tchebycheff, desarrollada en MATLAB (Asadi et al., 2012). Ferrara y otros. han utilizado el mismo esquema de optimización (Ferrara et al., 2014). Asl y otros. han explorado el plug-in Dynamo para extender la parametrización en Revit ${ }^{\mathrm{TM}}$, y optimizar mediante Optimo, un paquete gratuito que emplea un NSGA-II (Rahmani Asl et al., 2015).

Algunos investigadores han explorado las posibilidades de un esquema que integra Rhinoceros $^{\mathrm{TM}}$, Grasshopper@ (GH), el algoritmo evolutivo de GH: Galápagos (Rutten, 2013) y DIVA (Design, Iterate, Validate, Adapt) (K. Lagios, J. Niemasz and C. Reinhardt, 2010). DIVA es un plug-in para conectar Rhino/GH con EnergyPlus para realizar simulación térmica y Daysim/Radiance, para realizar simulación de iluminación natural (González and Fiorito, 2015). Como señalan Ercan et al. (Ercan and Elias-Ozkan, 2015), Galápagos tiene la limitación de optimizar una función objetivo por vez, por lo tanto, en el caso de funciones multi-objetivo como generalmente ocurre con los problemas de diseño, los resultados deben ser procesados a posteriori. Este algoritmo evolutivo puede minimizar o maximizar una o más variables relacionadas en una función de adecuación: fitness function. El mecanismo de selección está condicionado a la posibilidad de aumentar la aptitud de aparejamiento, que aumenta a medida junto con la aptitud; el mecanismo de transmisión hereditaria es una fusión combinada que promedia los genes de los padres agregando preferencias, que dependen a la vez, de su aptitud. Para evitar quedar atrapados en un punto óptimo local, se pueden introducir manualmente mecanismos de mutación (Calcerano and Martinelli, 2016). En trabajos anteriores, hemos explorado la unión de Rhinoceros/Grasshopper/Galápagos con Ecotect ${ }^{\mathrm{TM}}$ a través de Geco@ $(G e c o, 2016)$ (Camporeale, Patricia E., 2013a) (Camporeale, Patricia E., 2013b).

Otros autores han investigado métodologías más directos como la optimización mediante AGs combinado con métodos térmicos estacionarios: grados días (GD) o grados hora (GH) (Jin and Jeong, 2014), pero agregando ganancias solares e internas al balance térmico y no sólo las pérdidas-ganancias por la envolvente (Granadeiro et al., 2013). El método GD ha resultado ser útil en climas fríos y cielos cubiertos pero no en los templados soleados, como 
el caso de Sevilla. El coeficiente de forma (CF), empleado por este método, es la razón entre la superficie de la envolvente del edificio y su volumen de aire, dando como resultado un índice de la compacidad del edificio y permitiendo estimar la demanda energética. Pero como han señalado Depecker et al (Depecker et al., 2001) en los climas templados, la compacidad no es directamente proporcional a la demanda de calefacción: por lo tanto, en invierno, la radiación solar que ingresa a través de las ventanas puede compensar las pérdidas térmicas de la envolvente. Asimismo, la radiación solar puede provocar sobrecalentamiento en el interior del recinto, dependiendo de la masa térmica disponible, según el área de captación en las fachadas al Sur, en el caso del hemisferio Norte y en las fachadas al Norte, en el caso del Hemisferio Sur.

\subsection{Conclusiones}

Como hemos visto a lo largo de este capítulo, el trabajo abreva en diversas fuentes científicas, pretendiendo lograr una sinergia entre sustentabilidad ambiental, emergencia, diseño digital y producción arquitectónica. Si observamos diacrónicamente los eventos descriptos, veremos que un hilo conductor los hilvana. Desde la concepción de la arquitectura de Olgyay (fig.5) - que recomendaba un enfoque multidisciplinario de biología, arquitectura, clima y tecnología para resolver los problemas de la construcción del ambiente - hasta la teoría de sistemas, la cibernética, la teoría de la complejidad y, últimamente, la arquitectura emergente, vemos una convergencia en la concepción del funcionamiento de los sistemas complejos.

La aparición de la inteligencia artificial, el aprendizaje de máquina y otros recursos computacionales (Russell, 2016), hicieron suponer que la lógica digital podría, en algún momento, reemplazar la función del diseñador, pero faltaba aún una integración entre el accionar del diseñador y el ordenador. El uso de los medios digitales de diseño no se limita a exploradores de forma, sino que el diseño de espacio y materialidad, junto con clima y energía puede sintetizarse en un proceso integral y no desde acciones y disciplinas separadas. Pero, se hacen necesarios un cambio metodológico estructural y un cuestionamiento de conceptos enraizados en la práctica arquitectónica actual. Cada sistema material necesita del desarrollo técnicas propias que correspondan a las características del mismo: no existe una solución única para todos los casos. Se trata de un cambio de actitud metodológica frente a la forma de aproximarse al diseño, permitiendo el despliegue de capacidades y cualidades espaciales inherentes a cada sistema material. 
El uso de algoritmos genéticos aplicados al diseño bioambiental paramétrico 


\section{El modelo bioambiental paramétrico y los otros}

modelos 
El uso de algoritmos genéticos aplicados al diseño bioambiental paramétrico 


\subsection{El modelo académico}

En nuestras escuelas de arquitectura, la enseñanza del diseño sigue un método de aprendizaje a través del estudio de las obras paradigmáticas contemporáneas y pasadas. La experimentación está vinculada a aspectos morfológicos ya sean de representación analógica y/o digital. En general, no se considera la materialidad, entendida en su dimensión física, ni se la toma como punto de partida de una idea proyectual. Tampoco son un punto de partida del diseño, los materiales y técnicas locales disponibles, ni el consumo energético o la variable económico- financiera.

El proceso proyectual se sigue dividiendo en una primera etapa de recolección de datos del contexto físico, legal, socioeconómico, programático, ambiental y demás aspectos según el caso. Luego, esos datos ingresan a una "caja negra"1 junto con el bagaje cultural del diseñador y se obtiene un output ${ }^{2}$, que es el croquis del proyecto (Jones et al., 1969; Jones, 1982) (Fig. 3.1).

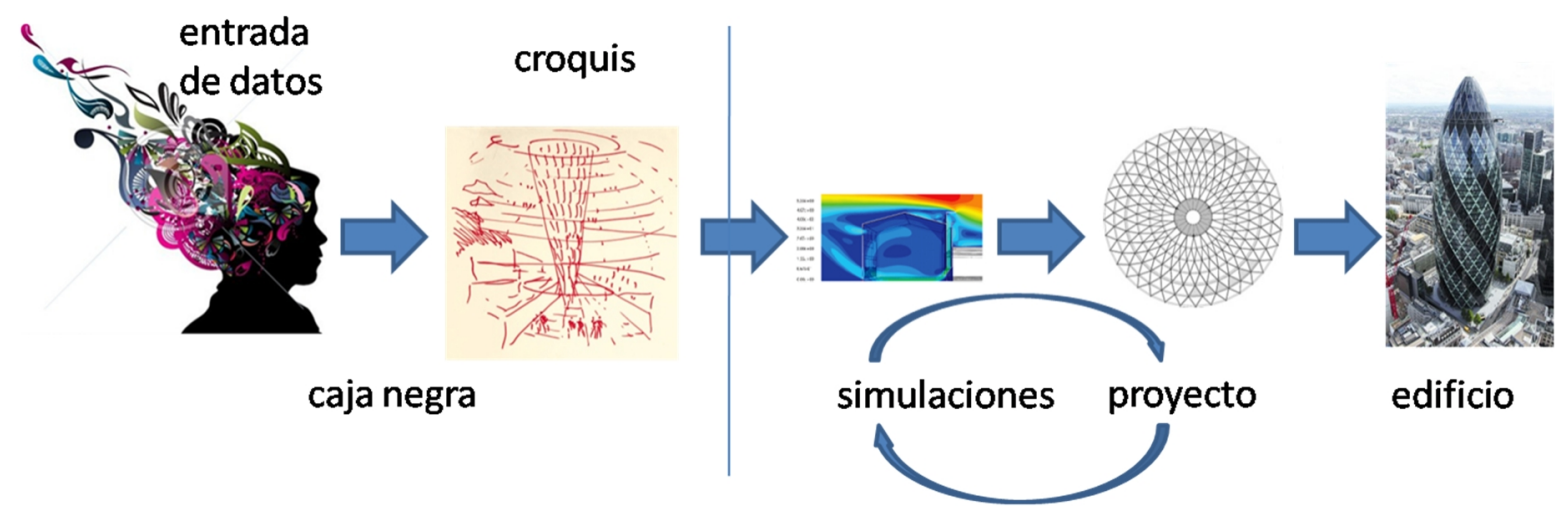

Fig. 3.1: Esquema de proceso de diseño tipo "caja negra". Fuente: la autora

Este croquis debiera sintetizar todos los inputs ${ }^{3}$ ingresados, cuantificándolos y jerarquizándolos en su justa medida, habiendo evaluado críticamente las alternativas y combinaciones posibles. Pero, en esta instancia y con esta metodología, es imposible la evaluación simultánea de variables sustentables (ahorro de energía, disminución del impacto ambiental, etc.). Sin embargo, es precisamente en este estado embrionario del producto arquitectónico donde se toman las decisiones que afectarán todo el desarrollo del proyecto, la materialización del

\footnotetext{
${ }^{1} \mathrm{f}$ s. Fís. Método de análisis de un sistema en el que únicamente se considera la relación entre las entradas o excitaciones y las salidas o respuestas, prescindiendo de su estructura interna- Diccionario de la Lengua Española- RAE- http://dle.rae.es/srv/fetch?id=6dxYOPn. Consultado el 7/4//16 ${ }^{2} \mathrm{~m}$. Inform. Información que sale procesada por un sistema informático o por una computadora. U. t. en sent. fig. Diccionario de la Lengua Española- RAE- http://dle.rae.es/?id=LidSP6a. Consultado el 7/4/16 ${ }^{3} \mathrm{~m}$. Inform. Conjunto de datos que se introducen en un sistema informático. Diccionario de la Lengua Española- RAE- http://dle.rae.es/?id=RLWOVVw. Consultado el 7/4/16
} 
edificio, su vida útil y su eventual deconstrucción (Guinée, 2002). Como se mencionó en el capítulo precedente, Alexander intentó una sistematización de la información para tener mayor control sobre los primeros croquis (Alexander, Ishikawa and Silverstein, 1977).

Este modelo se aplica, asimismo, a la práctica profesional (Evans, J. M., 2007). Puede suceder que se consulte al asesor bioclimático para adaptar el proyecto a un diseño sostenible. Entonces, se modificará la envolvente para hacerla eficiente mediante el cumplimiento de las normativas y certificaciones argentinas, españolas y/o internacionales (LEED, BREEM, etc), estimando su desempeño energético. Se podrá monitorear el proyecto con programas de simulación energética (Energy Plus, Calener, Trnsys, etc.) pero sólo se estará evaluando un proyecto por vez cuya materialidad está definida. Cualquier cambio que se pretenda introducir, implicará iniciar todo el proceso desde el comienzo. Las etapas están separadas entre sí por lo que no permiten la retroalimentación de la información que modifique la obra desde el croquis. Al no haber diseñado un edificio bioambiental paramétrico y, optimizado las variables de interés desde el comienzo, no se obtendrán las mejores alternativas proyectuales, porque no se habrán evaluado desde las primeras etapas: es un ejemplo de abordaje "top-down" del problema. Como ya se dijo, este método no considera el edificio como un organismo que intercambia información, materia y energía con su ambiente, adaptándose al mismo. Se lo concibe como una morfología inicial estática que responde a condicionantes estéticos, funcionales o de otra índole, a la que adicionamos materialidad y desempeño energético, en instancias posteriores.

El margen de operación es más estrecho cuanto más avanzada esté la definición del proyecto: a veces, sólo se puede hacer eficiente la envolvente.

\subsection{El modelo bioclimático, bioambiental y ambientalmente consciente}

Podríamos decir que el diseño bioclimático aparece oficialmente con los estudios de Olgyay y se continúa con los de Givoni y sus sucesores. En sus comienzos, se la llamó arquitectura bioclimática, término acuñado por Olgyay(Olgyay and Olgyay, 1963). Luego, apareció la arquitectura bioambiental, de acuerdo al término que utiliza la norma IRAM 11603 (IRAM, 2012) sobre la zonificación bioambiental de la Argentina, en 1981. En La Plata, se acuñó el término diseño ambientalmente consciente (DAl) para referirse a esta arquitectura. Los alcances del concepto se fueron ampliando a medida que los problemas ambientales fueron cobrando mayor importancia debido al Cambio Climático y éste comenzó a incidir visiblemente en el clima mundial. En España, se refiere a la arquitectura sostenible como aquélla que utiliza la mínima cantidad de recursos para no comprometer su disponibilidad futura. Pero el término 
3. El modelo bioambiental paramétrico y los otros modelos

sostenibilidad también incluye aspectos sociales y económicos por lo que sería más pertinente hablar de sostenibilidad ambiental.

Como mencionáramos en el capítulo anterior, en Argentina, la arquitectura bioclimática asociada a la arquitectura solar, comenzó a difundirse a fines de los años '70. En la Facultad de Arquitectura de Universidad Nacional de La Plata, el arq. Elías Rosenfeld fundó el Instituto de Arquitectura Solar (IDEHAB-FAU-UNLP) en 1976, y en 1984 el arq. John Martin Evans, el Centro de Hábitat y Energía (CIHE-FADU-UBA). Luego, centros de investigación similares fueron proliferando en otras universidades del país.

Si bien existen algunas diferencias entre los diversos centros de investigación, su enseñanza consiste en el estudio de las características climáticas de cada lugar y la aplicación de las correspondientes estrategias de diseño. Se busca el aprovechamiento de la iluminación natural, la radiación solar, la ventilación natural para conseguir confort higrotérmico, minimizando el uso de dispositivos que consuman energía. Asimismo, se busca la protección de los agentes que provocan disconfort: vientos no deseados, radiación solar excesiva y otros factores. Se estudian las normas de confort higrotérmico nacionales (IRAM) e internacionales (LEED, BREEM, ASHRAE, etc.) para asegurar el diseño de envolventes eficientes según cada localización, considerando su microclima y las tecnologías locales disponibles.

Otros temas que se abordan en este modelo de enseñanza del diseño son:

- comportamiento térmico de los materiales de construcción

- geometría solar

— viento y mediciones

— iluminación y ventilación natural

- estudio de soluciones de la arquitectura vernácula para los diferentes climas, adaptándolas, si fuera necesario, a las tecnologías locales

- cálculo de las emisiones GEI de los edificios y su posible mitigación

- incorporación del concepto de ciclo de vida para evaluar el consumo energético del edificio desde la fabricación de sus componentes hasta el fin de su vida útil

- aplicación de las energías renovables a la arquitectura: solar térmica para calentamiento de agua sanitaria, solar fotovoltaica y eólica para generación de energía eléctrica, dispositivos híbridos que integren más de un tipo, y diseño y cálculo de las instalaciones

- auditorías energéticas

— diseño y cálculo térmico de envolventes eficientes, adecuación a normas vigentes 
Antes de contar con el software actual, se utilizaban maquetas a escala donde se verificaban el asoleamiento en el heliodón, la iluminación natural para cielos cubiertos, en el cielo artificial y la incidencia de los vientos, en el túnel de viento. Los programas de simulación actuales permiten utilizar modelos digitales y mensurar los resultados obtenidos. Entre los más difundidos nombraremos EnergyPlus, Transys, y Ecotect, entre otros. En nuestro país, se diseñaron programas adaptados a nuestro clima y técnicas constructivas. En Salta de desarrolló el programa Symedif para simular consumo energético (Flores Larsen, S. and Lesino, G., 2001).

\subsubsection{El programa ENERGOCAD}

En La Plata, Czajkowski desarrolló el ENERGOCad (Czajkowski, J. and Rosenfeld, E., 1992), que es una herramienta digital que evalúa desempeño energético. Constituye un modelo de integración tipológico-energético que consta de una base de datos con tipologías, clima, tecnologías, normativa, energía, etc. Los módulos interrelacionados entre sí son:

- un gestor de datos climáticos y bioclimáticos

- un gestor de datos tipológicos

- un gestor de datos gráficos de diagnóstico y simulación térmica.

El proceso de carga del edificio a evaluar se compone de bloques con atributos en el entorno de AutoCad 10. Se dispone de un catálogo de diez tipos diferentes de muros exteriores y otro tanto, de muros interiores, cinco tipos de puertas y ventanas y diez tipos de cubiertas, como si se tratara del ensamblado de un sistema prefabricado. Desde el entorno CAD se accede a un módulo de evaluación energética: BaICAD y otro de simulación: SimCAD. Existe otro par calcular la condensación intersticial y superficial llamado ConCAD.

El programa cuenta con las siguientes bases de datos que proveen la información de entrada:

- edilicia

- climática y bioclimática

- tecnológica

- gráfica

En este momento se sigue utilizando en el Laboratorio de Arquitectura y Hábitat Sustentable (LAyHS-FAU-UNLP).

\subsection{El modelo bioambiental paramétrico}

El modelo es una herramienta, con una concepción cibernética del diseño, donde el edificio se relaciona y adapta - como un ser vivo- al entorno, intercambiando materia, información y 
3. El modelo bioambiental paramétrico y los otros modelos

energía. Se ha analizado como este enfoque del diseño arquitectónico evolucionó a medida que se instrumentaron los medios para materializarlo. Desde los conocimientos empíricos de la arquitectura vernácula, transformados en conocimiento científico por los pioneros de la arquitectura bioclimática, junto con la mímesis ${ }^{4}$ de los modelos de Gaudí (Bassegoda Nonell, 1971) y Otto (Otto et al., 1971) hasta los avances en Ciencias de la Computación -IA, machine learning, AGs - que permitieron la aparición de modelos algorítmicos aplicados al diseño.

Este modelo surge como respuesta a la necesidad de incorporar la variable sustentable al proceso de diseño. Por ello, se propone crear una herramienta concebida como un sistema emergente (De Landa, 2011), o sea, capaz de autoorganizarse frente a las demandas del entorno, adaptando su configuración material (geometría, envolvente, implantación, etc.) en un proceso de optimización. El edificio modifica su materialidad inicial dentro de los parámetros previstos, mejorando su desempeño ambiental, en las sucesivas alternativas optimizadas.

Este modelo cumple con las premisas iniciales: un flujo de trabajo continuo donde, en un único entorno, se optimicen la geometría paramétrica, a través la evaluación energética, sin necesidad de conocimientos de un lenguaje de programación y con los recursos computacionales disponibles. Otra condición era que esta herramienta fuera accesible a los arquitectos y que alcanzara con poseer conocimientos lógico-matemáticos para transformar la información en órdenes computacionales.

Rhinoceros es un programa de modelado en 3D por NURBS, como ya se explicara en el apartado 1.3. En la pantalla de Rhinoceros, Grasshopper $(\mathrm{GH})$ - un plug-in de Rhino para el scripting y la parametrización de la forma- dibuja el edificio directamente en tres dimensiones. No se detallan plantas, cortes y vistas, para no avanzar en la definición del proyecto ni consumir recursos computacionales y poder operar así en la fase inicial sobre la morfología. A diferencia de otros programas, donde se debe definir cada elemento constructivo para poder hacer una simulación, se opera con los rangos de las variables: materialidad de los cerramientos opacos, transparentes, cubiertas, carpinterías y la morfología edilicia, las ecuaciones para el cálculo de índices y coeficientes normativos, si los hubiere, o cualquier otro parámetro de sostenibilidad que se desee cuantificar.

La optimización del proceso se realiza a través de Galápagos, que es un AG de GH. El gráfico ilustra las relaciones entre los elementos mencionados (fig. 3.2). Existe otro algoritmo de optimización dentro de Galápagos, que simula el recocido — “simulated annealing”- pero

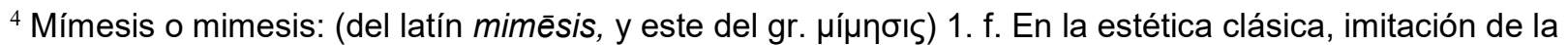
naturaleza que como finalidad esencial tiene el arte. Diccionario RAE. http://dle.rae.es/?id=PHHa8xx.

Consultado el $7 / 4 / 16$
} 

según la recomendación de trabajos científicos analizados, el algoritmo genético es más apropiado para el tipo de problemas planteados (Caldas, 2008).

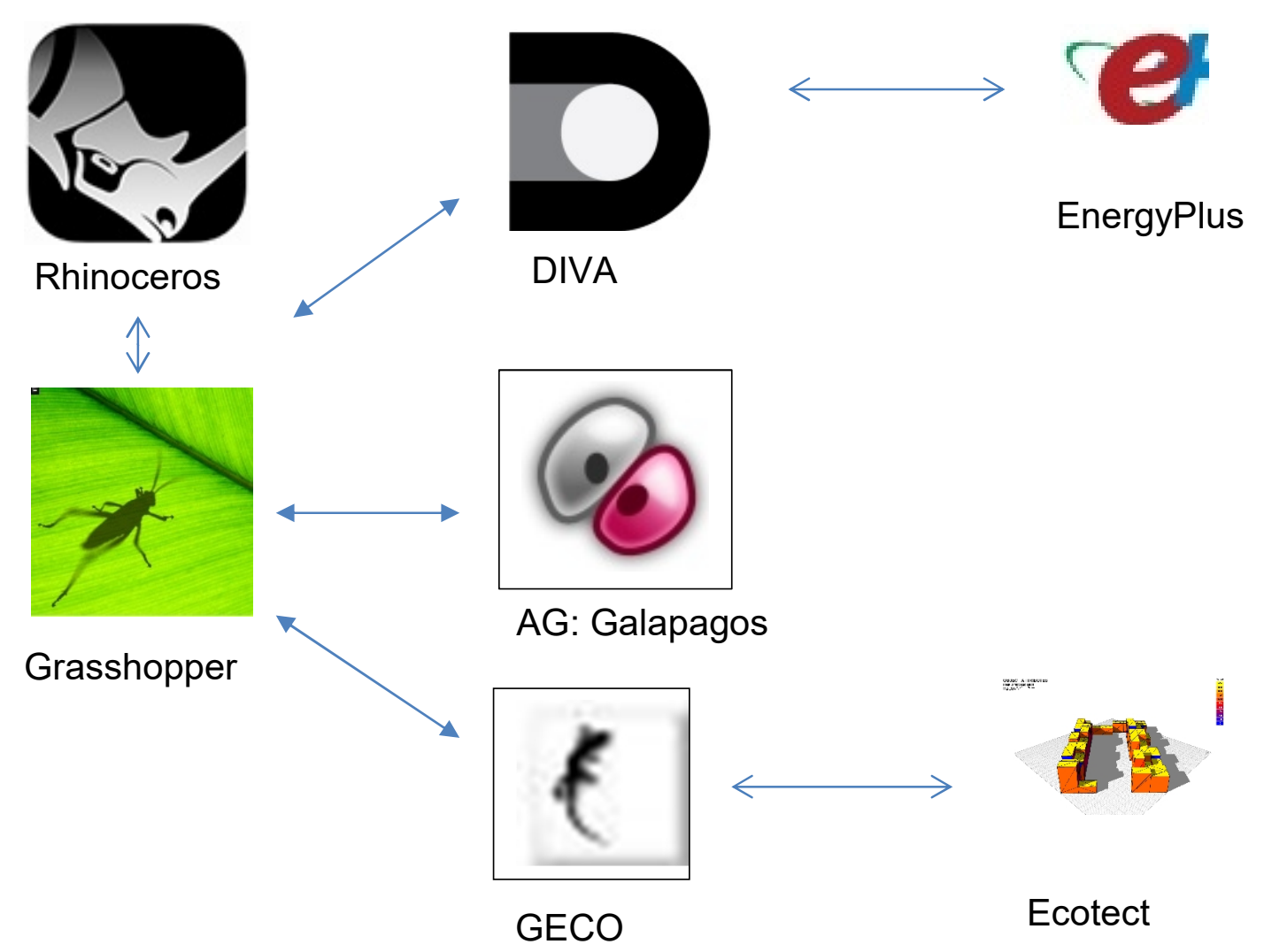

Fig. 3.2: Relaciones entre el programa de modelización y los programas de simulación energética, vinculados por el AG. Fuente: la autora

Los datos de entrada dependerán del objetivo a cumplir, se experimentaron modelos optimizados de:

- edificio en torre de baja demanda energética de calefacción y refrigeración

- edificio en bloque a rehabilitar energéticamente

- máxima envolvente solar (Knowles, R., 2003) de manzanas urbanas para asoleamiento de espacios exteriores (Camporeale, P., 2013a)

- maximización de superficies de captación solar, para manzanas urbanas.(Camporeale, P., 2013b)

Este proceso iterativo entre los datos de entrada del edificio y las magnitudes bioambientales permite al diseñador seleccionar las mejores morfologías obtenidas. En el caso de la rehabilitación, si bien, no se modifica la forma externa del edificio, se opera sobre la composición de la envolvente y las carpinterías. 
3. El modelo bioambiental paramétrico y los otros modelos

DIVA (Design Iterate Validate Adapt) es un plug-in de análisis sustentable que vincula la iluminación natural a través de DAYSIM y Radiance (K. Lagios, J. Niemasz and C. Reinhardt, 2010) y el análisis térmico, mediante EnergyPlus (Jakubiec, A. and Reinhardt, C., 2011). Puede operarse con Rhinoceros y/o Grasshopper. Establece un flujo de trabajo sin interrupciones entre las aplicaciones manteniéndose siempre en el mismo entorno de Rhino/GH. Las herramientas exploradas de DIVA son: solar envelope, solar fan, del menú de las herramientas solares y las herramientas del análisis térmico. La validación del modelo bioambiental paramétrico se realiza con Energy+ a través de DIVA.

Geco $^{\text {TM }}$ (Grabner, T. and Frick, U., 2013), es un plug-in que habilita la interconexión entre GH y Ecotect ${ }^{\circledR}$. Se realizaron experimentos con el modelo bioambiental paramétrico para optimizar la captación de la radiación solar en muros y cubiertas, para la colocación de dispositivos solares (fotovoltaicos o solar térmicos), correspondientes a una manzana urbana..

A diferencia del método tradicional de génesis de la forma arquitectónica, enseñado en las Escuelas de Arquitectura - donde se lo concibe de lo general a lo particular, top-down - se propone entender el proyecto como un sistema que integra múltiples vectores que le dan forma, donde el medioambiente y la morfología edilicia como sistema material, energético e informativo (Hensel, Menges and Weinstock, 2010), negocian para alcanzar un equilibrio dinámico entre ambos.

Dentro de este enfoque sistémico (Alexander, Ishikawa and Silverstein, 1977), se desarrolla como ejemplo, un edificio en torre. Primeramente, se parametrizan los datos de entrada: lote de terreno, geometría edilicia, materialidad de la envolvente, requisitos funcionales, ocupación, datos climáticos (temperatura, viento), restricciones de los códigos y normas de edificación vigentes. Luego, se calculan las demandas energéticas mediante los métodos de coeficiente volumétrico de refrigeración ( $\mathrm{G}_{\mathrm{REF}}$ ) y calefacción ( $\mathrm{G}_{\mathrm{CAL}}$ ), junto con nuevos índices propuestos en este trabajo y se optimizan estos resultados mediante un algoritmo genético, que retroalimenta el proceso de generación de la forma edilicia. También se calcula la demanda de la hora pico solar (14h) para invierno, a los efectos de observar el equilibrio entre ganancias solares, internas y aislación térmica.

La contrastación se realiza mediante el desarrollo de un experimento de un edificio en torre en el área metropolitana de Buenos Aires (Argentina) y otro en bloque en la ciudad de Sevilla (España). La obtención de resultados avala la hipótesis; se adjuntan otros experimentos de escala edilicia y urbana que corroboran la misma.

\subsection{Comparación entre los diferentes modelos}


A partir del siguiente cuadro comparativo, podemos observar cómo se administran los datos de entrada, el flujo de la información y los resultados morfológicos y energéticos en las primeras etapas del diseño arquitectónico en los diferentes modelos (Fig. 3.3).

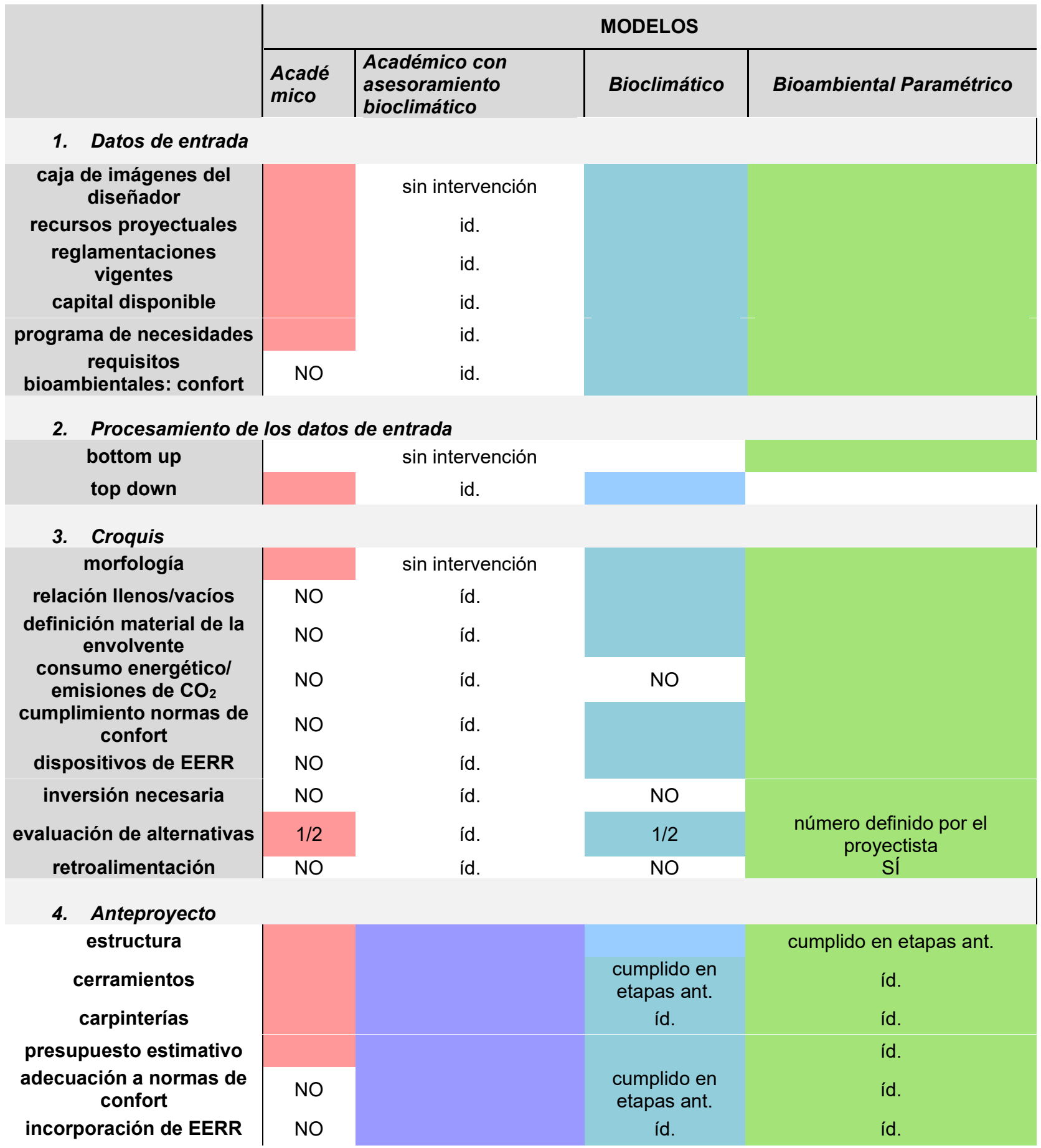

Fig. 3.3: Cuadro comparativo entre los diferentes modelos de proceso de diseño. Fuente: la autora 
3. El modelo bioambiental paramétrico y los otros modelos

El cuadro muestra las cuatro etapas del proceso de diseño desde el encargo hasta el anteproyecto: los datos de entrada, el procesamiento de los mismos, los croquis y el anteproyecto. En la columna de modelo académico, se especifican con color rosa aquéllos aspectos que son cubiertos por este modelo. El asesoramiento bioclimático actúa en las últimas etapas del modelo académico, dichas etapas se representan en color lila. El modelo bioclimático considera los aspectos ambientales pero su generación es top-down, los cuales se indican en color celeste. El modelo bioambiental paramétrico se diferencia del resto por ser de generación bottom-up, tener retroalimentación y permitir generar un número amplio de alternativas de diseño. Los aspectos que considera se destacan en color verde.

El modelo académico, al seguir un proceso top-down, va definiendo el proyecto de lo general a lo particular, pero aun existiendo un asesoramiento bioclimático en la etapa de anteproyecto, los principales lineamientos ya están decididos. Sus datos de entrada provienen de la formación profesional del diseñador (recursos proyectuales, conocimientos empíricos), reglamentaciones vigentes, capital, programa funcional y otros. El confort higrotérmico no es una variable considerada en esta etapa.

En el modelo académico con asesoramiento bioclimático, las variables de confort higrotérmico y la inclusión de energías renovables (EERR) son incorporadas, recién en el anteproyecto. La aplicación de estrategias pasivas de diseño en cambio es más difícil cuanto mayor es el avance del proyecto arquitectónico (Evans, J. M. and de Schiller, S., 1988).

El modelo bioclimático incorpora, desde las primeras etapas, las variables relativas al confort y las estrategias pasivas y activas para disminuir el consumo energético. Es muy importante el conocimiento que posea el diseñador de dichas estrategias. Al ser un método manual de diseño, la cantidad de alternativas morfológicas es acotada.

El modelo bioambiental paramétrico permite la evaluación de mayor cantidad de variables en la etapa de croquis y la optimización de los resultados, obteniendo un número considerable de alternativas eficientes. Las alternativas proyectuales que aparecen en dicha etapa, permiten, mediante la retroalimentación, el mejoramiento de las mismas y la consideración de mayor número de variables, que otros modelos recién integran en etapas posteriores.

\subsection{Conclusiones}

Se puede decir que se ha dado un salto cualitativo en cuanto al proceso de diseño arquitectónico, con la incorporación de la computadora como partícipe imprescindible de dicho proceso, utilizando herramientas como la recursividad, la retroalimentación y la optimización. 
Desde siempre, se ha buscado estimular la creatividad mediante técnicas. En un principio, la computadora sólo era un instrumento de ayuda de dibujo y de cálculo. Con la aparición de la inteligencia artificial, el "aprendizaje de máquina" y otros desarrollos, el ordenador se transformó en un "socio" ampliando el poder de la mente humana a la vez que marcando sus limitaciones. El modelo aquí propuesto no consume demasiado tiempo ni se necesitan grandes recursos computacionales, así como tampoco requiere de especialistas en simulación energética con el consecuente costo que eso implica. Esto lo transforma en una herramienta ideal para las primeras etapas del proceso de diseño arquitectónico/ urbano. 
4. Normativa y legislación:

Eficiencia energética en edificios 
El uso de algoritmos genéticos aplicados al diseño bioambiental paramétrico 


\subsection{Introducción}

La normativa y legislación vigentes en Argentina contemplan diferentes estrategias para disminuir el consumo energético en calefacción y refrigeración en edificios. Por una parte, existen las normas del Instituto Argentino de Certificación y Normalización (IRAM) de confort higrotérmico, que proveen los conceptos y procedimientos a seguir con el objeto de disminuir la demanda energética, siendo de cumplimiento optativo. Por otra parte, la legislación sobre eficiencia energética en edificios que incorpora dichas normas haciéndolas así de cumplimiento obligatorio. Esta legislación comprende: la ley 13059 (Gobierno de la Provincia de Buenos Aires, 2010) de la provincia de Buenos Aires "Condiciones de Acondicionamiento Térmico exigibles en la construcción de edificios", la ordenanza 8757 de la Ciudad de Rosario "Aspectos Higrotérmicos y Demanda Energética de las Construcciones" (Comisión de Planeamiento y Urbanismo, 2011) y la ley 4458 de la Ciudad de Buenos Aires "Normas de Acondicionamiento Térmico en la Construcción de Edificios" (Gobierno de la Ciudad Autónoma de Buenos Aires, 2013).

La falta de voluntad política hacia la creación y cumplimiento de leyes de eficiencia energética en el país es de larga data. Las normas IRAM de eficiencia energética no eran de cumplimiento obligatorio hasta la aparición del Etiquetado Energético de Edificios (IRAM, 2010c) el 19/5/2010. La ley bonaerense 13059/03 decreto 1030/2010 sobre Eficiencia energética edilicia no se cumple más que en algunos municipios (Vicente López, Moreno). La ley 4458 no está en vigencia por un veto parcial del Poder Ejecutivo de la Ciudad de Buenos Aires. No se cuenta en el país con un Código Técnico de Edificación basado en la sostenibilidad y la mitigación al Cambio Climático, similar al implementado en España. Por lo expresado más arriba, se infiere que la falta de control del cumplimiento efectiva de las normas y leyes, sea una de las barreras a la eficiencia energética.

A continuación, analizamos las leyes de eficiencia energética en ese país y detallamos las normas IRAM 11507-1 (IRAM, 2010a) y 11507-4 (IRAM, 2010b), 11603 (IRAM, 2012) ,11604 (IRAM, 2001) , 11605 (IRAM, 1996), 116591 (IRAM, 2004), 11659-2 (IRAM, 2007) y 11900 (IRAM, 2010c) para el cálculo de la demanda de energía en calefacción y refrigeración, que luego se utilizan en el desarrollo de esta tesis.

Analizamos asimismo la normativa española, europea y estadounidense relacionada con las normas a fin de comparar los diferentes parámetros considerados en unas y otras.

\subsection{Normativa y legislación en la Argentina}

\subsubsection{Normas IRAM}

El Instituto Argentino de Normalización y Certificación es una asociación civil sin fines de lucro cuyas finalidades específicas, en su carácter de Organismo Argentino de 
Normalización son establecer normas técnicas, sin limitaciones en los ámbitos que abarquen, además de propender al conocimiento y la aplicación de la normalización como base de la calidad, promoviendo las actividades de certificación de productos y de sistemas de calidad en las empresas para brindar seguridad al consumidor. IRAM es el representante de la Argentina en la International Organization for Standardization (ISO), en la Comisión Panamericana de Normas Técnicas (COPANT) y en la Asociación MERCOSUR de Normalización (AMN). Las Normas son el fruto del consenso técnico entre los diversos sectores involucrados los que, a través de sus representantes han intervenido en los Organismos de Estudio de Normas correspondientes.

\subsubsection{Norma IRAM 11507-1. Carpintería de obra. Ventanas exteriores. Requisitos básicos y clasificación}

Esta Norma considera los requisitos básicos de las ventanas y ventanas balcón exteriores con sus componentes: vidrios, accesorios y herrajes, clasificándolas según su resistencia al viento, estanqueidad al agua e infiltración de aire. No contempla el caso de las fachadas integrales livianas o estructurales de vidrio.

Para la infiltración considera 3 tipos según el caudal de aire por $\mathrm{m}^{3} / \mathrm{hm}$ (Tabla 1.4.1):

\begin{tabular}{|c|c|c|}
\hline $\begin{array}{c}\text { Clasificación según la } \\
\text { infiltración }\end{array}$ & Caudal de aire por metro de junta $\left(\mathrm{m}^{3} / \mathrm{hm}\right)$ & Designación \\
\hline IRAM A1 & Mayor que 4,01 hasta 6 & Normal \\
\hline IRAM A2 & Mayor que 2,01 hasta 4 & Mejorada \\
\hline IRAM A3 & Hasta 2 & Reforzada \\
\hline
\end{tabular}

Tabla 1.4.1: Caudal de aire para una presión de $100 \mathrm{~Pa}\left(10 \mathrm{~mm} \mathrm{H}_{2} \mathrm{O}\right)$ Fuente IRAM 11507-1

La estanqueidad de las aberturas se clasifica de acuerdo a la Tabla 1.4.2:

\begin{tabular}{|c|c|c|c|}
\hline $\begin{array}{c}\text { Clasificación según la } \\
\text { estanqueidad }\end{array}$ & $\begin{array}{l}\text { Presión estática } \\
\text { (Pa) }\end{array}$ & Velocidad del viento $(\mathrm{km} / \mathrm{h})$ & Designación \\
\hline IRAM E1 & 100 & 46 & Normal \\
\hline IRAM E2 & 200 & 65 & Mejorada \\
\hline IRAM E3 & 300 & 80 & Reforzada \\
\hline IRAM E4 & 500 & 105 & Muy reforzada \\
\hline IRAM E5 & 700 & 124 & Excepcional \\
\hline
\end{tabular}

Tabla 1.4.2: Estanqueidad al agua para un caudal de agua de 2,00 (dm $\left.3 / \mathrm{min}^{2} \mathrm{~m}^{2}\right)$. Fuente: IRAM

La clasificación según su resistencia a la acción del viento es la siguiente (Tabla 1.4.3): 
Clasificación según su resistencia a la acción del viento

IRAMV2

IRAM V3

IRAM V4
Ensayo

Deformación (P1)

$(\mathrm{Pa})$

500

1000

1700

1500

2400

2000

3000

Tabla 1.4.3: Resistencia a la acción del viento. Fuente: IRAM

\subsubsection{Norma IRAM 11507 4. Carpintería de obra y fachadas integrales livianas. Ventanas exteriores.Parte 4: Requisitos complementarios. Aislación térmica}

Esta Norma rige para las ventanas que cumplen con la Norma IRAM 11507-1. Las condiciones complementarias se refieren a la aislación térmica de las carpinterías.

Se clasifican las ventanas de acuerdo a su transmitancia térmica en 5 categorías desde $\mathrm{K}<1$ $\mathrm{W} /{ }^{\circ} \mathrm{C} \mathrm{m}{ }^{2}$ hasta $3<\mathrm{K}<4 \mathrm{~W} /{ }^{\circ} \mathrm{C} \mathrm{m}{ }^{2}$. Para valores superiores, se consideran no clasificables. La Tabla A1 de la norma proporciona la transmitancia térmica de ventanas con perfilería de aluminio y diferentes tipos de vidrio. La Tabla A2 proporciona la transmitancia térmica de los vidrios según la Cámara del Vidrio Plano. La Tabla A3 proporciona la transmitancia térmica de los perfiles de aluminio con y sin ruptura de puente térmico.

El cálculo de la resistencia térmica total es la siguiente [1.4.1]:

$$
R_{t}=\frac{1}{K_{i}}
$$

$\mathrm{Rt}=$ resistencia térmica total en $\mathrm{m}^{2} \mathrm{~K} / \mathrm{W}$

$\mathrm{Ki}=$ transmitancia térmica en $\mathrm{W} / \mathrm{m}^{2} \mathrm{~K}$

La transmitancia térmica media ponderada se calcula así [2]:

$$
K^{\prime}{ }_{m}=\frac{\sum_{1}^{n}\left(K_{i} S_{i}\right)}{\sum_{1}^{n} S_{i}}
$$

siendo:

$\mathrm{K}_{\mathrm{m}}^{\prime}=$ transmitancia térmica ponderada en $\mathrm{W} / \mathrm{m}^{2} \mathrm{~K}$

$\mathrm{S}_{\mathrm{i}}=$ superficie de cada componente de la ventana en $\mathrm{m}^{2}$ 
El uso de algoritmos genéticos aplicados al diseño bioambiental paramétrico $\mathrm{K}_{\mathrm{i}}=$ transmitancia térmica de cada componente en $\mathrm{W} / \mathrm{m}^{2} \mathrm{~K}$

La diferencia térmica superficial exterior e interior se aplica para el caso de doble vidriado hermético $(\mathrm{DVH})[1.4 .3]$ :

$$
\Delta R_{S}=R_{S}-R_{S}
$$

$\Delta R_{\mathrm{si}}=$ diferencia térmica superficial en $\mathrm{m}^{2} \mathrm{~K} / \mathrm{W}$

$R_{\mathrm{si}}=$ resistencia térmica superficial interior en $\mathrm{m}^{2} \mathrm{~K} / \mathrm{W}$

$\mathrm{R}_{\mathrm{se}}=$ resistencia térmica superficial exterior en $\mathrm{m}^{2} \mathrm{~K} / \mathrm{W}$

En el Anexo B se agregaron tablas con los coeficientes de transmitancia térmica de ventanas con perfilería de PVC (Tabla B1) y de la perfilería de PVC (Tabla B3).

\subsubsection{Norma IRAM 11601. Aislamiento térmico de edificios. Métodos de cálculo. Propiedades térmicas de los componentes y elementos de construcción en régimen estacionario}

Provee los métodos de cálculo para la resistencia térmica [1.4.4]:

$$
R=\frac{e}{\lambda}
$$

$R=$ resistencia térmica en $m^{2} K / W$

e= espesor de la capa en $\mathrm{m}$

$\lambda=$ conductividad térmica del material en $\mathrm{W} / \mathrm{mK}$

La transmitancia térmica se calcula así [1.4.5]:

$$
K=\frac{1}{R_{t}}
$$

La resistencia térmica de un componente plano formado por capas homogéneas perpendiculares al flujo de calor entre ambas caras se calcula así [1.4.6]:

$$
R_{t}=R_{1}+\ldots R_{n}
$$

$R_{1} \ldots R_{n}=$ resistencia térmica de cada capa homogénea en $m^{2} \mathrm{~K} / \mathrm{W}$

En el caso de calcular la resistencia de aire a aire [1.4.7]:

$$
R_{T}=R_{s}+R_{t}+R_{S}
$$

La Norma provee el cálculo de la resistencia de las cámaras de aire y también las tablas con las propiedades térmicas de los materiales de construcción. 


\subsubsection{Norma 11603. Acondicionamiento térmico de edificios. Clasificación bioambiental de la República Argentina}

Esta norma (IRAM, 11603, 2011) establece la zonificación de la República Argentina según un criterio bioambiental, indicando las características climáticas de cada zona.

Asimismo, da pautas generales para el diseño, la evaluación de las orientaciones favorables y el cumplimiento del asoleamiento mínimo de los edificios. Se establece la caracterización meteorológicadelosmicroclimasy su evaluación desde el punto de vista del acondicionamiento térmico edilicio. En el Anexo A, se incluye un listado con los datos climáticos de ciento sesenta y cinco estaciones meteorológicas del país.

Las zonas bioambientales se definen de acuerdo con el mapa de la fig. 1.4.1. Esta clasificación se ha desarrollado teniendo en cuenta los índices de confort de la temperatura efectiva corregida (TEC) corelacionado con el voto medio predecible (VMP) y el índice de Beldin y Hatch $(\mathrm{IBH})$ desarrollados para las zonas cálidas. La evaluación de las zonas frías no se realizó con los índices de confort sino con los grados días para las necesidades de calefacción.

Zona I: Muy cálida. Comprende la región donde los valores de TEC media, enel día típcamente cálido, son superiores a $26,3^{\circ} \mathrm{C}$.Se extiende en la región centro Este del extremo Norte del país con ua entrada al Sud-Oeste en las zonas bajas de Catamarca y La Rioja. Durante la época caliente todas las zonas presentan temperaturas máximas superiores a $34^{\circ} \mathrm{C}$ y medias superiores a $26^{\circ} \mathrm{C}$, con amplitudes térmicas siempre inferiores a los $15^{\circ} \mathrm{C}$. El período invernal es poco significativo con temperaturas medias superiores a $12^{\circ} \mathrm{C}$, durante el mes más frío. Esta zona se divide en dos subzonas a y b en función de las amplitudes térmicas:

- la: amplitudes térmicas mayores a $14^{\circ} \mathrm{C}$

- Ila: amplitudes térmicas menores a $14^{\circ} \mathrm{C}$

Zona II: Cálida. Limitada por las isolíneas de TEC $26,3^{\circ} \mathrm{C}$ y $24^{\circ} \mathrm{C}$, comprende el conjunto de dos angostas fajas de territorio, una de extensión Este-Oeste centrada alrededor del paralelo $30^{\circ}$ y otra de extensión Norte-Sur recortada sobre la falda oriental de la Cordillera de los Andes. En esta zona, es el verano la estación crítica, con temperaturas medias superiores a los $24^{\circ} \mathrm{C}$ y máximas superiores a $30^{\circ} \mathrm{C}$. Las mayores amplitudes térmicas suceden en esta época del año, con valores que no superan $\operatorname{los} 16^{\circ} \mathrm{C}$. El invierno es más seco con bajas amplitudes térmicas y temperaturas medias que oscilan entre $8^{\circ} \mathrm{C}$ y $12^{\circ} \mathrm{C}$. Esta zona se subdivide en dos subzonas a y b en función de la amplitud térmica: 
- Subzonalla: amplitudes térmicas mayores a $14^{\circ} \mathrm{C}$

- Subzonallb: amplitudes térmicas menores a $14^{\circ} \mathrm{C}$

Zona III: Templada Cálida. Limitada por las isolíneas de TEC $24,6^{\circ} \mathrm{C}$ y $22,9^{\circ} \mathrm{C}$, esta zona tiene igual distribución que la zona II, con la faja de extensión Este-Oeste centrada alrededor del paralelo $35^{\circ}$ y la de extensión Norte-Sur, ubicada en la primeras estribaciones montañosas al Noroeste del país, sobre la Cordillera de los Andes. Los veranos son relativamente calurosos y presentan temperaturas medias que oscilan entre $20^{\circ} \mathrm{Cy} 26^{\circ} \mathrm{C}$, con máximas medias que superan los $30^{\circ} \mathrm{C}$, sólo en la faja de extensión Este-Oeste. El invierno no es muy frío y presenta valores medios de temperatura entre $8^{\circ} \mathrm{C}$ y $12^{\circ} \mathrm{C}$, y valores mínimos que rara vez son menores que $0^{\circ} \mathrm{C}$. En general en esta zona se tienen inviernos relativamente benignos, con veranos no muy calurosos. Esta zona se subdivide en dos subzonas: a y b, en función de las amplitudes térmicas.

- Subzona III a: amplitudes térmicas mayores que $14^{\circ} \mathrm{C}$

- Subzona III b: amplitudes térmicas menores que $14^{\circ} \mathrm{C}$

\section{Zona IV: Templada Fría}

Esta zona tiene como límite superior la isolínea de 1170 grados días (coincidente con la isolínea de $22,9^{\circ} \mathrm{C}$ de TEC), y como límite inferior la isolínea de 1950 grados días. Presenta una faja meridional paralela a la correspondiente a la zona III, ubicada a mayor altura de la Cordillera de los Andes y la región llana del centro y Sur del territorio, que alcanza la costa atlántica de la Provincia de Buenos Aires y Río Negro. Los veranos no son rigurosos y presentan máximas promedio que rara vez superan los $30^{\circ} \mathrm{C}$. Los inviernos son fríos, con valores medios entre $4^{\circ} \mathrm{C}$ y $8^{\circ} \mathrm{C}$, y las mínimas medias alcanzan muchas veces valores menores a $0^{\circ} \mathrm{C}$. Esta zona se subdivide en 4 subzonas:

- SubzonalVa: de montaña

- SubzonalVb: de máxima irradiancia

- Subzona IVc: de transición

- Subzona IVd: marítima

\section{Zona V: Fría}

Limitada entre las isolíneas de 1950 grados días y 2730 grados días, comprende una extensa faja Norte-Sur a lo largo de la Cordillera yla región central de la Patagonia. Los inviernos son rigurosos, con temperaturas medias de $4^{\circ} \mathrm{C}$ y mínimas menores de $0^{\circ} \mathrm{C}$. Los veranos son frescos con temperaturas medias inferiores a los $16^{\circ} \mathrm{C}$. 


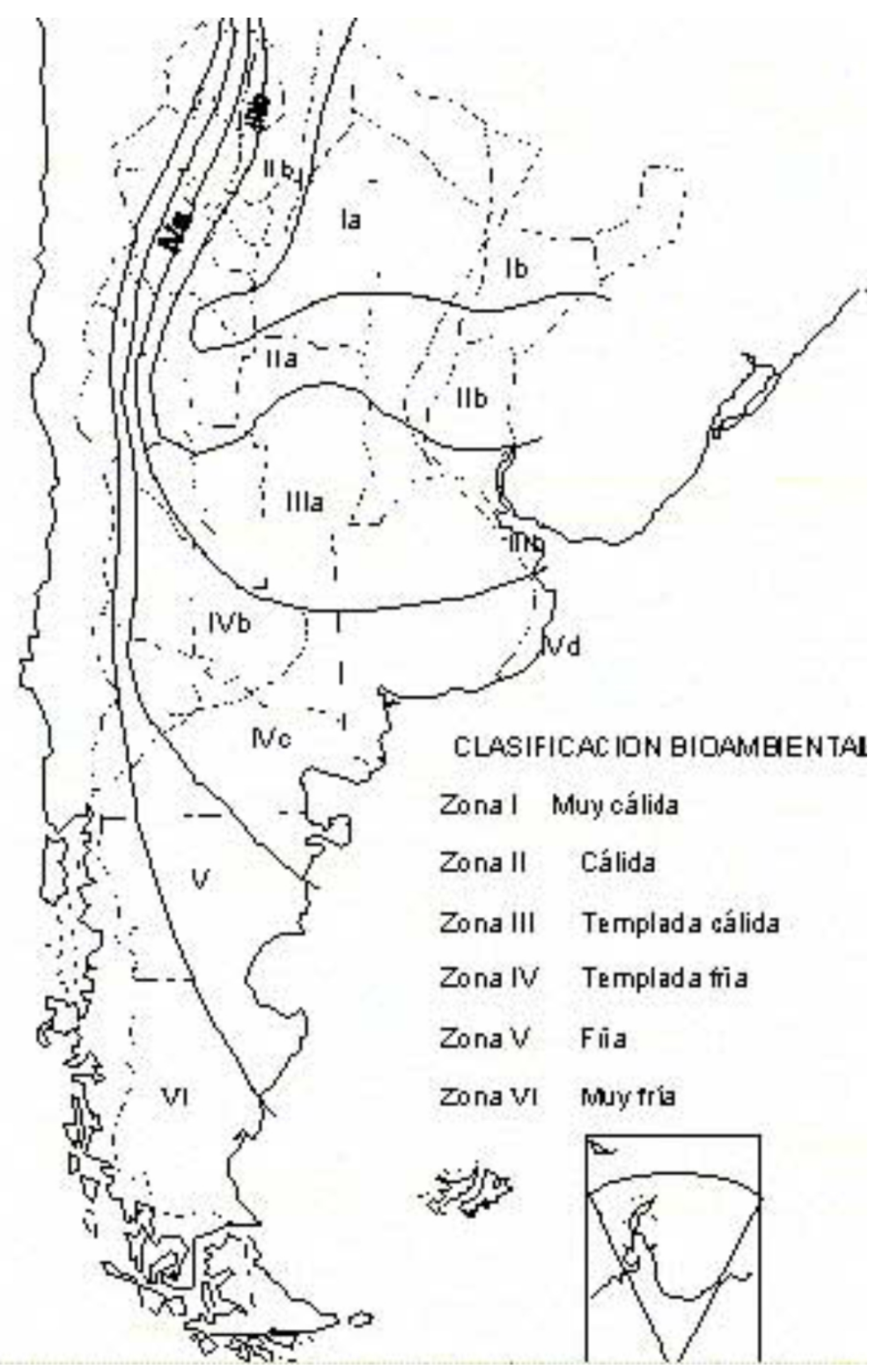

Fig. 4.1: Clasificación biombiental de la República Argentina. Fuente: IRAM

Zona VI: Muy Fría. Ubicada en la región donde los valores en grados días son mayores a 2730 , en consecuencia comprende toda la región de las altas cumbres de la Cordillera de los Andes y el extremo Sur de la Patagonia, Tierra del Fuego, Islas Malvinas y Antártida En verano las temperaturas medias son menores a $12^{\circ} \mathrm{C}$. La faja que se extiende al Norte del paralelo $37^{\circ}$ presenta la rigurosidad propia de la altura y como característica importante, una alta intensidad de radiación solar.

La norma también establece recomendaciones generales de diseño:

Zona de litoral maritimo y lluvial deben tomarse precauciones para evitar la condensación debida al alto tenor de humedad. 
El uso de algoritmos genéticos aplicados al diseño bioambiental paramétrico

Respetar orientaciones recomendades por zona

Proveer protección contra el viento en las zonas IV, $\mathrm{V}$ y $\mathrm{VI}$

Las recomendaciones para cada zona son las siguientes:

Zona l: colores claros en paredes exteriores y techos, gran aislación térmica en techos y paredes al Este y el Oeste, el eje mayor del edificio será preferentemente EsteOeste, protección solar en todas las superficies, si es posible no orientar ventanas al Este u Oeste, minimizar su superficie. Proveer ventilación cruzada aprovechando los vientos dominantes, tener espacios semicubiertos protegidos de los insectos, minimizar superficies al Este y Oeste.

Zona II: tienen validez las recomendaciones para la zona I

Zona III. Subzonallla: debido a la gran amplitud térmica se recomienda el agrupamiento de los edificios y mejoras de la inercia térmica de los mismos, tiene menores exigencias de orientación y ventilación pero el Oeste debe ser evitado, las aberturas tendrán protección solar y los coloresde las paredes y techos serán claros.

Subzonalllb: no hay gran amplitud térmica por lo que se recomiendan las orientaciones, protecciones y colores de la subzonallla.

Zona IV. Subzona IV a y b: por la gran amplitud térmica en verano es necesario el agrupamiento de los edificios y la mejora de la inercia térmica.

SubzonalVc: Zona de transición entre la de mayor y la de menor amplitud térmica.

SubzonalVd: pequeñas amplitudes térmicas, alto tenor d ehumedad, se recomienda protección solar en verano.

Zona $V$ : proveer suficiente aislación térmica en toda la envolvente, reducir el área de las ventanas salvo la orientación Norte, considerar riesgos de condensación superficial e intersticial, evitar puentes térmicos.

Zona IV: se acentúan las recomendaciones dadas para la zona $\mathrm{V}$, para las viviendas al Sur del paralelo $38^{\circ}$, se requiere correcto asoleamiento y protección contra el viento en espacios exteriores comunes, además de agrupamiento de los edificios. Para las viviendas al Norte del paralelo $38^{\circ}$ se recomienda mayor inercia térmica de la envolvente debido a la gran amplitud térmica.

Las orientaciones recomendadas por zona son las siguientes: 
Zona II: N y S

Zona III: NO-N-NE-E

Zona IV: para latitudes superiores a $30^{\circ}$ : NO-N-NE-E, para latitudes inferiores a $30^{\circ}$ : NO-N-NE-E-SE

Zona V: necesita asoleamiento todo el año

Zona IV: tienen validez las mismas recomendaciones de la zona $\mathrm{V}$

El asoleamiento en invierno está recomendado por sus beneficios psicohigiénicos, por disminuir la demanda de energía para calefacción y mejorar la calidad de la iluminación natural. En viviendas ubicadas al norte de la latitud $47^{\circ} \mathrm{S}$, se requiere un mínimo de dos horas de asoleamiento mínimamente en la mitad de las habitaciones, a verificar el 23 de junio. Para viviendas ubicadas al sur de la latitud $47^{\circ} \mathrm{S}$, la verificación se realizará el 14 de agosto. Cuando existan sistemas solares pasivos, se deberán asegurar un mínimo de seis horas de asoleamiento.

La Norma también prevé el caso de los microclimas y la necesidad de su estudio particularizado. Las causas que provocan microclimas son variadas: en las ciudades se producen fenómenos de "isla de calor", en las costas marinas se pueden producir circulaciones de aire entre la masa de agua y la tierra, en la montaña pueden aparecer climas de sotavento y barlovento, con brisas de valle y de montaña y en las zonas boscosas.

Se recomiendan pautas de diseño para los microclimas en zonas frías, templadas y cálidas.

\subsubsection{IRAM 11604. Coeficiente volumétrico de calefacción: GCAL}

El control del clima en el interior de un edificio depende de la adecuada selección de los materiales empleados en su construcción, y el óptimo diseño de los espacios y orientaciones. Dos edificios con idéntica envolvente pueden tener diferentes pérdidas de calor globales debidas a la forma: a mayor compacidad, menores pérdidas.

Esta norma (IRAM 11604, 2001) se utiliza para el cálculo del coeficiente volumétrico de calefacción $\mathrm{G}_{\mathrm{CAL}}[1.4 .8]$ para viviendas, oficinas, comercio, industria y salud, que cumplen con las Normas 11605,11625 y 11630. Considera las pérdidas de los elementos opacos, no opacos y en contacto con el terreno, las pérdidas por renovación de aire del edificio calefaccionadoSe aplica en las zonas bioambientales III, IV, V y VI (IRAM 11603, 2011), y en todas las localidades que superan los 900 grados días, con una temperatura base de $18^{\circ} \mathrm{C}$, excluyendo aquéllas que superen los 5000 grados días de calefacción [Ec. 4.1].

$$
G_{C}=\frac{\sum K_{m} \cdot S_{m}+K_{v} \cdot S_{v}+\sum \gamma K_{r} \cdot S_{r}+P \quad \cdot P_{p}}{V}+0,35 \cdot n
$$


siendo:

$\mathrm{G}_{\mathrm{CAL}}=$ coeficiente volumétrico de calefacción en $\mathrm{W} / \mathrm{m}^{3} \mathrm{~K}$

$\mathrm{K}_{\mathrm{m}}=$ transmitancia térmica del componente opaco exterior (muro, techo) en $\mathrm{W} / \mathrm{m}^{2} \mathrm{~K}$

$\mathrm{S}_{\mathrm{m}}=$ área de dichos componentes en $\mathrm{m}^{2}$

$\mathrm{K}_{\mathrm{v}}=$ transmitancia térmica de los componentes no opacos exteriores (muros y techos) en

$\mathrm{W} / \mathrm{m}^{2} \mathrm{~K}$

$\mathrm{S}_{\mathrm{v}}=$ área de dichos elementos en $\mathrm{m}^{2}$

$\mathrm{YK}_{\mathrm{r}}=$ transmitancia térmica corregida de los elementos que lindan con locales no calefaccionados en $\mathrm{W} / \mathrm{m}^{2} \mathrm{~K}$. Se puede calcular analíticamente o adoptar los valores provistos por la norma: $y=1$, en el caso de edificio contiguo no calefaccionado y $\mathrm{y}=0,5$ en el caso de edificio contiguo calefaccionado.

$\mathrm{S}_{\mathrm{r}}=$ área de dichos elementos en $\mathrm{m}^{2}$

Per= el perímetro del piso en contacto con el aire exterior en $\mathrm{m}$

$P_{p}=$ las pérdidas del piso en contacto con el terreno en $\mathrm{W} / \mathrm{m}$

$0,35=$ es la capacidad específica del aire en $\mathrm{Wh} / \mathrm{m}^{3} \mathrm{~K}$

$\mathrm{n}=$ el número de renovaciones por aire que la norma fija en $2 / \mathrm{h}$ o que puede ser calculado por la ecuación [Ec. 4.2].

$$
n=\frac{\sum 0,0 \quad \text { li } q\left[0,5 \quad(\text { civ } v)^{2}\right]^{0,6}}{V}
$$

siendo:

$\mathrm{l}_{\mathrm{i}}=$ el largo de las juntas de contacto de cada tipo de carpintería en m

$\mathrm{q}_{\mathrm{i}}=$ el caudal de infiltración de aire por unidad de longitud de la junta (ver Norma IRAM 11523, presión de ensayo $100 \mathrm{~Pa}$ ) de cada carpintería de la envolvente del edificio en $\mathrm{m}^{2} / \mathrm{h}$ $\mathrm{c}_{\mathrm{i}}=$ coeficiente de corrección dela velocidad media del viento con la altura del edificioy la rugosidad del terreno (Tabla B.1. Anexo B. IRAM 11604)

$V=$ volumen del edificio en $\mathrm{m}^{3}$. 
La Norma provee las tablas de $\mathrm{G}_{\mathrm{CAL} \text { adm }}$ para las tipologías de torre y bloque de viviendas con un $20 \%$ de área vidriada.Para edificios que superan ese porcentaje de área vidriada, se

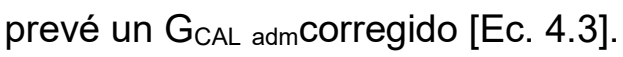

$$
G_{C} \quad \text { aı } \quad c c \quad=G_{a \iota}+\left(1,75 \cdot \frac{S_{V}}{S_{E}}-0,347\right)
$$

siendo:

$\mathrm{S}_{\mathrm{V}}=$ superficie vidriada de la envolvente en $\mathrm{m}^{2}$

$S_{E}=$ superficie total de la envolvente en contacto con el exterior en $\mathrm{m}^{2}$

$\frac{S_{V}}{S_{E}}=$ relación entre la superficie vidriada y total de la envolvente que debe cumplir con la condición siguiente: $0,2<\frac{\mathrm{S}_{\mathrm{V}}}{\mathrm{S}_{\mathrm{E}}} \leq 1$

Una vez obtenido el $\mathrm{G}_{\text {cal }}$, se puede calcular la carga térmica de calefacción anual Q [Ec.4.4]:

$$
Q_{C}=\frac{2^{\underline{0}} D G_{C} \quad V}{1}
$$

siendo:

$\mathrm{Q}_{\mathrm{CAL}}=$ carga térmica de calefacción en $\mathrm{kWh}$

24= tiempo de calefacción pordía en $\mathrm{h}$

${ }^{\circ} \mathrm{D}=$ grados días de calefacción anual, obtenidos de la norma IRAM 11603, en grados

Celsius

$\mathrm{G}_{\mathrm{CAL}}=$ coeficiente volumétrico de pérdida de calor del edificio calefaccionado en $\mathrm{W} / \mathrm{m}^{3} \mathrm{~K}$

$V=$ volumen interior de aire del edificio calefaccionado en $\mathrm{m}^{3}$

Otros factores a tener en cuenta y que no contempla esta Norma, son la humedad relativa, la condensación superficial eintersticial, la inercia térmica de paredes y techos, las ganancias térmicas por asoleamiento e iluminación artificial, las ganancias internas por personas y equipamiento, el efecto de "isla de calor" en las ciudades, la parquización, las pérdidas por formas de ventilación no contempladas.

El aporte de la energía solar a través de sistemas solares activos o pasivos no está considerado en esta Norma. El proyectista deberá calcularlo en régimen transitorio especificando los procedimientos seguidos y las hipótesis adoptadas. Se seguirán las recomendaciones de la Norma IRAM11603 y se adoptará en un nivel A para los edificios que cuenten con estos sistemas, según la Norma11605. Se implementarán recursos de 
El uso de algoritmos genéticos aplicados al diseño bioambiental paramétrico diseño para almacenar calor, evitar sobrecalentamiento y controlar la amplitud térmica tales como materiales de gran capacidad térmica, ventilación natural o forzada para evacuar aire caliente, sistemas fijos o móviles de protección solar según la latitud y clima.

\subsubsection{Norma IRAM 11605. Acondicionamiento térmico de edificios. Condiciones de habitabilidad en edificios. Valores máximos de transmitancia térmica e cerramientos opacos.}

Esta Norma (IRAM 11605, 1996) establece los valores máximos de transmitancia térmica aplicables a muros y techos de edificios de vivienda, a fin de asegurar condiciones mínimas de habitabilidad. Establece también la evaluación de los puentes térmicos.

Los niveles de confort higrotérmico son los siguientes:

Nivel A: recomendado

Nivel B: Medio

Nivel C: Mínimo

La verificación se realizará para las condiciones de invierno y verano para todas las zonas bioambientales excepto las zonas V y VI (IRAM 11603) donde sólo será exigible para el invierno.

Los valores máximos de transmitancia térmica para la condición de invierno dependerán de la temperatura de diseño de la localidad donde se encuentre emplazado el edificio. En el anexo B de la Norma se detallan los valores mínimos de transmitancia para evitar la condensación superficial en lugares críticos.

Los valores máximos de transmitancia térmica para la condición de verano corresponden a cerramientos con un coeficiente de absorción de la radiación solar de $0,7 \pm 0,1$. Fuera de este rango, se indican las correcciones a efectuar.

En todos los casos, la transmitancia de los puentes térmicos no superará el $50 \%$ de la del muro opaco. La aislación se colocará del lado interior. En el caso de columnas la aislación será del doble de su ancho.

El criterio adoptado para evitar la condensación superficial en invierno se determinó, considerando las temperaturas de diseño siguientes:

Nivel $\mathrm{A}=22^{\circ} \mathrm{C}$

Nivel $\mathrm{B}=20^{\circ} \mathrm{C}$ 
Nivel $\mathrm{C}=18^{\circ} \mathrm{C}$

La diferencia de temperatura entre la interior de diseño y la superficial del cerramiento será:

Nivel $\mathrm{A}: 1^{\circ} \mathrm{C}$

Nivel $B=2,5^{\circ} \mathrm{C}$

Nivel $\mathrm{C}=4^{\circ} \mathrm{C}$

La condición de verano se define en forma análoga a la de invierno

\subsubsection{Norma IRAM 11659-2. Acondicionamiento térmico de edificios. Verificación de sus condiciones higrotérmicas. Ahorro de energía en refrigeración. Parte 2: Edificios para viviendas.}

El control de los efectos del clima en un edificio depende de los materiales de la envolvente, del diseño de sus espacios, vanos y orientaciones. El cumplimiento del nivel de transmitancia térmica puede no ser suficiente para controlar las ganancias de calor, por eso la necesidad de definir un parámetro global que pondere todos los elementos. Dos edificios de idéntica envolvente pueden diferir en su demanda energética si difiere su forma. A mayor compacidad y volumen interior a refrigerar, menor consumo energético. Durante el verano, el edificio recibe calor proveniente de diversas fuentes, que el equipo de refrigeración debe extraer para reducir la temperatura interior y mantener el confort higrotérmico.

Como se indica en la norma IRAM 11659-1, el calor se calcula según la forma en que se manifiesta: el calor sensible y el latente. El calor sensible es el que genera un incremento de la temperatura del local, y el calor latente es el que aporta el vapor de agua pero no eleva la temperatura. Las fuentes de calor sensible son las ganancias por conducción a través de la envolvente, las ganancias solares, las del aire exterior, las personas y el equipamiento. Las fuentes de calor latente son las personas (respiración+ transpiración), el aire exterior, los equipos para cocción o calentamiento de agua.

Esta norma provee la metodología de cálculo delacarga térmica total en refrigeración $\left(Q_{r}\right.$ en $W)$, el coeficiente volumétrico de refrigeración $\left(G_{R E F}\right)$, que es la demanda energética por unidad de volumen $\left(G_{R E F}\right.$ en $\left.W / m^{3}\right)$, la carga térmica por unidad de superficie $\left(S_{r}\right.$ en $\left.W / m^{2}\right)$.

También provee las tablas de los valores admisibles de $Q_{R E F}, G_{R E F}$ y $S_{R E F}$ para viviendas unifamiliares y edificios multifamiliares tipo bloque y torre.

Sirven como fuente para esta norma, las normas IRAM 31-4, 11549, 11601, 11603, 11605 y 11659-2. 
Esta norma es aplicable a edificios de viviendas refrigeradas con subsuelos no refrigerados, si hubiere. Se aplica para las zonas bioambientales I, II, III y IV (IRAM 11603), como así también para todas aquellas localidades y microclimas donde se superen los $30^{\circ}$ de temperatura máxima de diseño $\left(T_{\mathrm{DMX}}\right)$ o donde se prevea un equipo de aire acondicionado

La carga térmica de un edificio local refrigerado se compone así [ec. 4.5] (Fig. 4.2):

$$
Q_{R}=Q_{c}+Q_{a}+Q_{s}+Q_{o}
$$

siendo:

$Q_{\mathrm{REF}}=$ carga térmica total de refrigeración en $\mathrm{W}$

$Q_{c}=$ carga térmica por conducción a través de la envolvente en $\mathrm{W}$

$\mathrm{Q}_{\mathrm{a}}=$ carga térmica por ventilación en $\mathrm{W}$

$\mathrm{Q}_{\mathrm{s}}=$ carga térmica solar en $\mathrm{W}$

$Q_{0}=$ carga térmica por fuentes internas (personas, iluminación, equipamiento) en W

La carga térmica por conducción se compone así [Ec. 4.6]:

$$
Q_{c}=K_{i} \cdot A_{i} \cdot\left(t_{e}-t_{i}\right)
$$

$Q_{c}=$ carga térmica por conducción en $W$

$\mathrm{K}_{\mathrm{i}}=$ la transmitancia térmica del cerramiento (muro, techo piso y ventanas) en $\mathrm{W} / \mathrm{m}^{2} \mathrm{~K}$

$A_{i}=$ la superficie del cerramiento en $\mathrm{m}^{2}$.

$t_{e}=$ temperatura exterior de diseño (Tabla 3 Norma IRAM 11603) en grados Celsius

$t_{i}=$ temperatura de confort interior (tabla 2 y 3 de la norma IRAM 11659-1) en grados Celsius

La carga térmica por ventilación se expresa en la ecuación [Ec. 4.7]. El edificio se considera hermético y el equipo de refrigeración incorpora una cantidad de aire exterior para mantener la calidad del aire interior.

$$
Q_{a}=C_{A} \cdot(0,25 \cdot \Delta+0,61 \cdot \Delta)
$$

siendo:

$\mathrm{Q}_{\mathrm{a}}=$ carga térmica por ventilación en $\mathrm{W}$

$\mathrm{C}_{\mathrm{AR}}=$ caudal de aire a renovar en $\mathrm{m}^{3} / \mathrm{h}$ 
$0,25=e s$ la constante del cociente entre el calor específico del aire húmedo a $21^{\circ} \mathrm{C}$ de temperatura y $50 \%$ de humedad relativa, y el volumen específico de la misma mezcla de aire en $\mathrm{W} / \mathrm{m}^{3} \mathrm{~K}$

$\Delta t=$ diferencia entre la temperatura exterior y la interior en grados Celsius

0,61 = es la constante entre el valor medio de la cantidad de calor cedida por la condensación de un gramo de vapor de agua y el volumen específico de la misma mezcla de aire en $\mathrm{W} / \mathrm{m}^{3} \mathrm{~g}$

$\Delta w=l a$ diferencia entre la humedad específica del aire exterior y la humedad específica del aire interior en $\mathrm{g} / \mathrm{kg}$

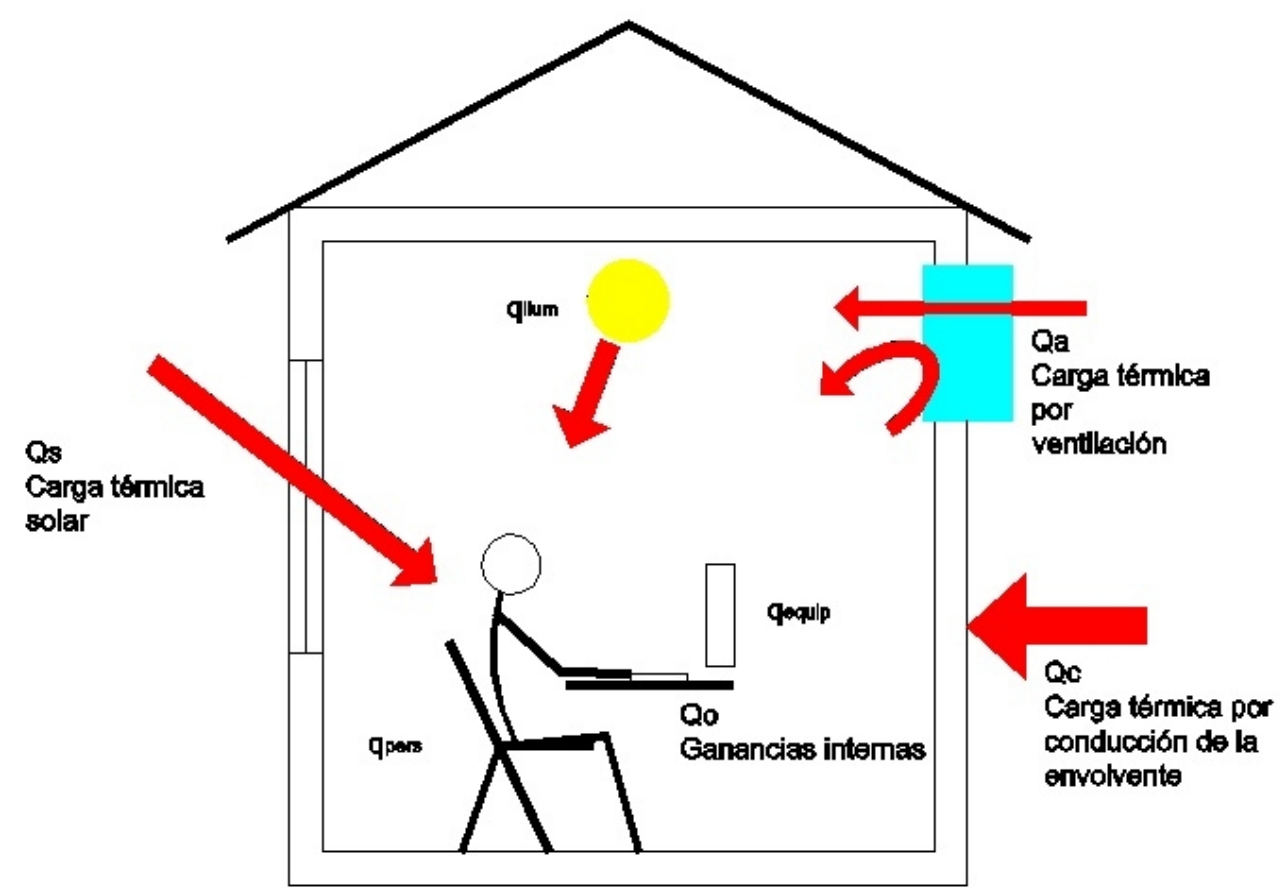

Fig. 4.2: Carga térmica de un local en verano. Fuente: la autora

El caudal de aire a renovar lo obtenemos de la siguiente ecuación [Ec. 4.8]:

$$
C_{A}=N_{p} \quad \cdot C_{A}
$$

$\mathrm{N}_{\text {pers }}=$ cantidad de personas que ocupan el edificio o local

$\mathrm{C}_{\mathrm{ARP}}=$ caudal de aire a renovar por persona en $\mathrm{m}^{3} / \mathrm{h}$.pers

La carga térmica solar se calcula con la siguiente expresión [Ec. 4.9]:

$$
Q_{S}=\sum_{i=1}^{n} A_{i} \cdot I_{S} \cdot F_{e_{i}}
$$

siendo: 
$\mathrm{Q}_{\mathrm{s}}=$ carga térmicasolar en $\mathrm{W}$

$A=$ superficie vidriada en $\mathrm{m}^{2}$

$I_{S}=$ intensidad de la radiación solar en $\mathrm{W} / \mathrm{m} 2$

$F_{\text {es }}=$ factor de exposición solar del vidrio o de la carpintería

La carga térmica por fuentes internas se expresa [Ec. 4.10]:

$$
Q_{o}=Q_{p}+Q_{i l}+Q_{e}
$$

siendo:

$Q_{0}=$ carga térmica por fuentes internas en $\mathrm{W}$

$Q_{\text {pers }}=$ carga térmica debida a las personas, determinada por la cantidad de personas que ocupan el edificio o local por el coeficiente de calor metabólico (M) emitido por las personas en W [Ec. 4.11]:

$$
Q_{p} \quad=N_{p} \quad . M
$$

La carga térmica debida a la iluminación se obtiene así [Ec. 4.12]:

$$
Q_{i l}=\sum_{i=1}^{n} q_{i l} \quad . A_{i} \cdot C_{T_{i}}
$$

siendo:

qilum= número de fuentes de iluminación

$A_{i}=$ área a iluminar en $\mathrm{m} 2$

$\mathrm{C}_{\mathrm{T}}=$ coeficiente térmico según el tipo de iluminación (Tabla 5 de la norma IRAM 11659-1)

La carga térmica debida al equipamiento se determina de acuerdo a la sig. ecuación [Ec. 4.13]:

$$
Q_{e} \quad=\sum_{i=1}^{n} q_{a}{ }_{i} \cdot N_{a r_{i}}
$$

siendo:

$q_{\text {arti }}=$ calor emitido por los artefactos (Tabla 7 norma IRAM 11659-1)

$\mathrm{N}_{\text {arti }}=$ cantidad de artefactos de cada tipo

Luego se calcula el coeficiente volumétrico $G_{R}$ [Ec. 4.14]:

$$
G_{R}=\frac{Q_{R}}{V}
$$


$\mathrm{G}_{\mathrm{REF}}=$ coeficiente volumétrico de refrigeración en $\mathrm{W} / \mathrm{m}^{3}$

$Q_{\mathrm{REF}}=$ carga térmica por refrigeración en $\mathrm{W}$

$V=$ volumen de aire del edificio o local refrigerado en $\mathrm{m}^{3}$

El coeficiente de refrigeración por unidad de superficie se calcula así [Ec. 4.15]:

$$
S_{R} \quad=\frac{Q_{R}}{A}
$$

siendo:

$S_{R E F}=$ coeficiente de refrigeración por unidad de superficie en $\mathrm{W} / \mathrm{m}^{2}$

$Q_{R}=$ carga térmica total de refrigeración en $W$

$A=$ superficie del local o edificio refrigerado en $\mathrm{m}^{2}$.

\subsubsection{Ley 13059 decreto $1030 / 2010$ de la Provincia de Buenos Aires. Condiciones de Acondicionamiento Térmico exigibles en la construcción de edificios}

Esta ley ${ }^{1}$ habilita como unidad de ejecución a los municipios e incorpora las siguientes Normas IRAM:

- $\mathrm{N}^{0} 11549$. Aislamiento térmico de edificios. Vocabulario.

- No 11601. Aislamiento térmico de edificios. Propiedades térmicas de los materiales para la construcción. Método de cálculo de la resistencia térmica total.

- No 11603. Aislamiento térmico de edificios. Clasificación bioambiental de la República Argentina.

- No 11604. Aislamiento térmico de edifícios. Ahorro de energía en calefacción. Coeficiente volumétrico $\mathrm{G}$ de perdidas de calor.

- $N^{0} 11605$. Aislamiento térmico de edificios. Condiciones de habitabilidad en viviendas. Valores máximos admisibles de Transmitancia Térmica "K" (como máximo los valores correspondientes a Nivel B).

- No 11625. Aislamiento térmico de edificios. Verificación del riesgo de condensación del vapor de agua superficial e intersticial en paños centrales.

- No 11630. Aislamiento térmico de edificios. Verificación riesgo de condensación intersticial y superficial en puntos singulares.

\footnotetext{
${ }^{1}$ http://www.incose.org.ar/portal/novedades-del-incose/75-ley-13059-sobre-acondicionamiento-termico-enla-pcia-de-bs-as.html
} 
- N¹1507-1. Carpintería de obra. Ventanas exteriores. Requisitos básicos y clasificación.

- N¹1507-4. Carpintería de obra. Ventanas exteriores. Requisitos complementarios. Aislación térmica.

Se exige que la envolvente del edificio cumpla con el nivel $B$ del coeficiente de transmitancia máximo admisible (K $\mathrm{K}_{\text {MÁXADM }}$ ) de la norma IRAM 11605 para la condición de invierno y de verano. También se exige que el coeficiente volumétrico de calefacción $\mathrm{G}_{\mathrm{CAL}}$ sea inferior al GCALADM de la norma 11604.

Las aberturas deben cumplir con la clasificación A1 hasta 10m de altura y A2 por sobre este nivel, respecto de la infiltración de aire (IRAM 11507-1) y los niveles K5 hasta 10m de altura y K4 por sobre este nivel, respecto de la aislación térmica (IRAM 11507-4).

También deben cumplir la verificación de condensación intersticial y superficial en paños centrales (IRAM 11625) y puntos singulares (IRAM 11630).

No se exige en cambio que cumpla la norma IRAM 11659 1-2 de carga térmica de refrigeración.

En cuanto a la implementación de esta ley sólo es exigible en algunos municipios de la provincia y, en el caso de Vicente López, deja como responsables exclusivos de su cumplimiento al propietario y al profesional (Decreto 3071, 2011)2.

\subsubsection{Ordenanza 8757/13 de la Ciudad de Rosario. "Aspectos Higrotérmicos y Demanda Energética de las Construcciones"}

En el caso de la ley que rige en la ciudad de Rosario, se incorporan las exigencias de la ley dentro del Reglamento de Edificación, mediante la ordenanza 8757/11 (Ordenanza $8757,2011)$ y se habilita al Municipio como autoridad de aplicación ${ }^{3}$. Se incorporan las normas IRAM 11507/1, 11601, 11603, 11604,11605, 11625, 11630 y 11659 1-2. Aislamiento térmico de edificios. Verificación de sus condiciones higrotérmicas. Ahorro de energía en refrigeración. Parte 1: vocabulario, definiciones, tablas y datos para determinar la carga térmica de verano. Parte 2: Verificación de sus condiciones higrotérmicas. Ahorro de energía en refrigeración. Parte 2: Edificios para viviendas. Esta última corresponde al cálculo de la demanda de refrigeración.

En cuanto al nivel exigible de $\mathrm{K}_{\mathrm{ADMMAX}}$, para edificios de más de $500 \mathrm{~m}^{2}$ de superficie y/o $10 \mathrm{~m}$ de altura, se establece el A (IRAM 11605). Para aquéllos edificios de menos de $500 \mathrm{~m}^{2} \mathrm{y} / \mathrm{o}$

\footnotetext{
${ }^{2}$ http://iniciativa-vl.blogspot.com.ar/2012/08/ahorro-de-energia-en-edificios-en.html ${ }^{3}$ Texto completo disponible en http://www.rosario.gov.ar/sitio/arquitectura/obras_particulares/higrotermicos.jsp 
10m de altura, se establece el nivel B (IRAM11605). Considera un factor de protección solar (Fs) de 0,7 para fijar los valores de transmitancia máxima en cerramientos opacos y transparentes. Para la infiltración de las aberturas, exige para edificios de nivel A, el tipoA2 y para edificios de nivel B, el A1 (IRAM 11507-1).

\subsubsection{Ley 4458 "Normas de Acondicionamiento Térmico en la Construcción de Edificios" de la Ciudad Autónoma de Buenos Aires}

Esta ley fue incorporada al Código de Edificación de la Ciudad de Buenos Aires y publicada en el boletín oficial $4142(13 / 12 / 2012)^{4}$ (Ley 4458, 2013). En ella se incorporan las normas IRAM 11507/1-4, 11549, 11601, 11603, 11604, 11605, 11625, 11630, 11659/1-2 y 11900 “, siendo ésta última la de" Etiquetado de Eficiencia Energética de Calefacción para Edificios".

El ámbito de aplicación es exigible solamente para construcciones nuevas de más de $1.500 \mathrm{~m}^{2}$, correspondientes a edificios públicos o privados.

Se excluyen del campo de aplicación:

a) aquellas edificaciones que por sus características de utilización deban permanecer abiertas.

b) construcciones provisionales.

c) edificios industriales, salvo sus sectores administrativos.

d) depósitos que no requieran climatización.

Pero la presente Ley $\mathrm{N}^{\circ} 4458$ fue vetada parcialmente en su artículo $4^{\circ}$, por el Decreto $\mathrm{N}^{\circ}$ 25/13, y publicado en el Boletín Oficial $N^{\circ} 4080$, del día 23 de enero de 2013, por lo que no está siendo exigible.

\subsection{Normativa y legislación en España}

Con la directiva 2002/91/CE (Parlamento Europeo, 2002) se instrumenta la eficiencia energética en edificios a nivel de la Unión Europea, a lo cual se suma la suscripción del protocolo de Kyoto para limitar las emisiones de $\mathrm{CO}_{2}$ y mitigar las consecuencias del Cambio Climático (Mercader Moyano, M., Claro, J., \& Ramos, M., 2016).

En España ya existía una norma básica de cumplimiento obligatorio referida a la eficiencia de la envolvente edilicia para reducir el consumo energético. Pero a partir de 2006, con la aparición del Código Técnico de Edificación (Ministerio de Fomento, 2016) esta normativa se

\footnotetext{
4 Texto completo disponible en http://boletinoficial.buenosaires.gob.ar/documentos/boletines/2013/04/20130430.pdf Pág. 12 y ss.
} 
endurece. También se implementa el Reglamento de Instalaciones Térmicas en los Edificios, mediante el Real Decreto 1027/2007. Viendo que las consecuencias del Cambio Climático iban a provocar una suba de más de $2^{\circ} \mathrm{C}$ de la temperatura del planeta, se fijan metas para el 2020 con la Directiva 2010/31/UE (refundición) (Parlamento Europeo, 2010), la cual se conoce como Horizonte 2020 donde se propone una reducción de las emisiones de GEl en un mínimo del $20 \%$.

\subsubsection{Código Técnico Español: Documento Básico HE/ DccHE}

El Código Técnico de la Edificación (Ministerio de Fomento, 2013) es el marco normativo que establece las exigencias que deben cumplir los edificios en relación con los requisitos básicos de seguridad y habitabilidad establecidos en la Ley 38/1999 de 5 de noviembre, de Ordenación de la Edificación (LOE) (Ministerio de Fomento, 1999, p. 38)

En virtud de las disposiciones de la Unión Europea (UE) a través de la Directiva 2010/31/UE del Parlamento Europeo y del Consejo de 19 de mayo de 2010 relativa a la eficiencia energética de los edificios, se establece un nuevo modelo mucho más ambicioso que el anterior (Parlamento Europeo, 2002) que supone el endurecimiento de los requisitos mínimos hasta conseguir, de cara a 2020, edificios de consumo de energía prácticamente nulo (Mercader Moyano, M. et al., 2016). La instrumentación de esta directiva se hace a través del CTE mediante el DB HE que es el documento específico, que regula el cumplimiento de la necesidad básica de ahorro energético limitando la demanda y el consumo edilicios. El DccHE contiene actualizaciones a marzo de 2016 (Ministerio de Fomento, 2016).

En el artículo 15 de la Parte I del CTE es donde se reglamenta el ahorro de energía:

- Exigencia básica HE0: Limitación el consumo energético

- Exigencia básica HE 1: Limitación de la demanda energética

- Exigencia básica HE 2: Rendimiento de las instalaciones térmicas

- Exigencia básica HE 3: Eficiencia energética de las instalaciones de iluminación

- Exigencia básica HE 4: Contribución solar mínima de agua caliente sanitaria

- Exigencia básica HE 5: Contribución fotovoltaica mínima de energía eléctrica

Las normas europeas que sirven de referencia para la redacción del Documento Básico HE Ahorro de energía, son:

— UNE EN ISO 10211-1:1995 "Puentes térmicos en edificación. Flujos de calor y temperaturas superficiales. Parte 1. Métodos generales de cálculo"

- UNE EN ISO 10211-2: 2002 "Puentes térmicos en edificación. Flujos de calor y temperaturas superficiales. Parte 2: Puentes térmicos lineales" 
— UNE EN ISO 6946: 1997 "Elementos y componentes de edificación. Resistencia y transmitancia térmica. Métodos de cálculo"

- UNE EN ISO 13370: 1999 "Prestaciones térmicas de edificios. Transmisión de calor por el terreno. Métodos de cálculo"

- EN ISO 13788: 2001 "Características higrotérmicas de los elementos y componentes de la edificación. Temperatura superficial interior para evitar la humedad superficial crítica y la condensación intersticial. Métodos de cálculo"

- UNE EN 673: 1998 "Vidrio en la construcción" Determinación del coeficiente de transmisión térmica U. Métodos de cálculo".

- UNE EN 673/A1: 2001

- UNE EN 673/A2: 2003

— UNE EN ISO 10077 "Características térmicas de ventanas, puertas y contraventanas. Cálculo del coeficiente de transmisión térmica. Parte 1: Método simplificado".

— UNE EN 410: 1998 "Vidrio para la edificación. Determinación de las características luminosas y solares de los acristalamientos".

- UNE EN 410:1998 "Vidrio para la edificación. Determinación de las características solares y luminosas de los acristalamientos"

- UNE EN 1026: 2000 "Ventanas y puertas. Permeabilidad al aire. Método de ensayo".

— UNE EN 12207: 2000 "Puertas y ventanas. Permeabilidad al aire. Clasificación".

\subsubsection{Sección HE 0: Limitación del consumo energético de calefacción}

Se define primeramente el ámbito de aplicación: edificios nuevos y solamente ampliaciones de los edificios existentes, no la totalidad de ellos, y aquéllos edificios que estén abiertos de manera permanente y tengan acondicionamiento térmico.

El consumo se limita de acuerdo a la zona climática donde se implanta el edificio y su uso. Los edificios que estén abiertos de forma permanente deben ser satisfacer su consumo energético exclusivamente por fuentes renovables (Tabla 4.5).

El consumo de energía primaria (EP) no renovable de un edificio o una ampliación no puede superar el valor límite $C_{\text {ep.lim }}$ [Ec.4.16]

$$
C_{e . l i}=C_{e . b} \quad+\frac{F_{e} \cdot s}{S}
$$

donde:

$\mathrm{C}_{\mathrm{ep.lim}}=$ valor límite de $\mathrm{EP}$ no renovable en $\mathrm{kWh} / \mathrm{m}^{2}$.año

$\mathrm{C}_{\text {ep.base }}=$ valor base de EP no renovable dependiente de la zona climática donde se sitúe el edificio que considera los valores de la Tabla 4.5 . 
$F_{\text {ep.sup }}=$ factor de corrección del consumo de EP no renovable, respecto de la superficie, que se obtiene de la Tabla 1 y se expresa en kWh/año

$\mathrm{S}=$ superficie útil de los espacios habitables del edificio o ampliación en $\mathrm{m}^{2}$

\begin{tabular}{r|cccccc} 
& \multicolumn{7}{|c|}{ Zona climática de invierno } \\
\hline & a & A $^{*}$ & B $^{*}$ & C $^{*}$ & D & E \\
\hline Cep.base $\boldsymbol{k W h} / \boldsymbol{m}^{2}$ año & 40 & 40 & 45 & 50 & 60 & 70 \\
\hline $\boldsymbol{F}_{\text {ep.sup }}$ & 1000 & 1000 & 1000 & 1500 & 1300 & 4000
\end{tabular}

* Los valores de $C_{e p . b a s e}$ para las zonas climáticas de invierno A, B y C de Canarias, Baleares, Ceuta y Melilla deberán multiplicarse por 1,2

Tabla 4.5: Valor base y factor corrector por superficie del consumo energético. Fuente: CTE

Los valores límite para distintas superficies útiles se expresan en la Tabla 4.6.

La calificación de los edificios exige una eficiencia igual o superior a la clase $\mathrm{B}$, incluyendo el consumo en calefacción, refrigeración, agua caliente sanitaria y para uso no residencial privado, la iluminación.

El consumo energético de calefacción y refrigeración se obtendrá a partir del cálculo de la demanda que se desarrolla en la sección HE1. El consumo energético del agua caliente sanitaria (ACS) se obtendrá de acuerdo a lo especificado en la sección HE4 y el de iluminación, de la sección HE de este documento básico.

\begin{tabular}{|c|c|c|c|c|c|c|}
\hline \multirow{2}{*}{$\begin{array}{r}\text { Superficie } \\
{\text { útil } m^{2}}^{2}\end{array}$} & \multicolumn{6}{|c|}{ EP límite según la zona climática de invierno $\mathrm{kWh} / \mathrm{m}^{2} a \tilde{a} o$} \\
\hline & $\alpha$ & A & B & C & $\mathrm{D}$ & E \\
\hline 100 & 50 & 50 & 55 & 65 & 90 & 110 \\
\hline 500 & 42 & 42 & 47 & 53 & 66 & 78 \\
\hline 1000 & 41 & 41 & 46 & 52 & 63 & 74 \\
\hline 5000 & 40 & 40 & 45 & 50 & 60 & 71 \\
\hline
\end{tabular}

Tabla 4.6: Valores límite de consumo de EP en $\mathrm{kWh} / \mathrm{m}^{2}$ año.Fuente: CTE

El cálculo del consumo puede realizarse en forma detallada o simplificada, que considere los siguientes aspectos:

— demanda energética de calefacción y refrigeración de acuerdo al procedimiento explicado en HE1

- demanda energética de ACS

- demanda energética de iluminación en uso no residencial privado

- dimensionado y rendimiento de los equipos de frío, calor, ACS e iluminación

- empleo de distintas fuentes de energía

- factores de conversión de energía final a primaria de fuentes no renovables 
- contribución de energías renovables in situ o próximas a la parcela

\subsubsection{Sección HE 1: Limitación de la demanda energética}

El documento HE1, especifica que los edificios dispondrán de una envolvente de características tales que limite adecuadamente la demanda energética necesaria para alcanzar el bienestar térmico en función del clima de la localidad, del uso del edificio en régimen de verano y de invierno, así como por sus características de aislamiento e inercia, permeabilidad al aire y exposición a la radiación solar, reduciendo el riesgo de aparición de humedades de condensación superficiales e intersticiales que puedan perjudicar sus características y tratando adecuadamente los puentes térmicos para limitar las pérdidas o ganancias de calor y evitar problemas higrotérmicos en los mismos.

El ámbito de aplicación incluye además de lo mencionado más arriba, las reformas que no sean producto del mantenimiento edilicio o por un cambio de uso.

El documento provee información acerca de las zonas climáticas de España, divididas de acuerdo a sus características en dos partes: invierno y verano, en su apéndice D "Zonas Climáticas" (ver apartado 4.3.1.4). La letra indica la clasificación de invierno y el número, la de verano (Ministerio de Fomento, 2017).

La demanda está limitada en función de la zona climática donde se implanta el edificio y su uso. La envolvente de los espacios habitables debe estar evitar la pérdida de calidad térmica entre unidades de uso y con las zonas comunes. Se evitarán las condensaciones superficiales e intersticiales y se fijan transmitancias máximas para los puentes térmicos

El valor límite de la demanda de calefacción se expresa así [Ec. 4.17]:

$$
D_{C . l i i}=D_{C} . b \quad+\frac{F_{C} . s}{S}
$$

donde:

$D_{\text {cal.lim }}=$ valor límite de la demanda en $\mathrm{kWh} / \mathrm{m}^{2} a n ̃ o$

$D_{\text {cal.base }}=$ valor base de la demanda de calefacción según la zona climática de invierno cuyos valores se toman de la Tabla 3, expresada en $\mathrm{kWh} / \mathrm{m}^{2} a n ̃ o$

$F_{\text {cal.sup }}=$ factor corrector de demanda de calefacción respecto de la superficie útil del edificio que se muestra en la Tabla 4.7 y se expresa en kWh/año. 


\begin{tabular}{l|cccccc} 
& A & A & B & C & D & E \\
\hline$D_{\text {cal.base }} \boldsymbol{k W h} / \boldsymbol{m}^{2}$ año & 15 & 15 & 15 & 20 & 27 & 40 \\
\cline { 2 - 6 } & 0 & 0 & 0 & 1000 & 2000 & 3000
\end{tabular}

Tabla 4.7: Valor base y factor corrector de superficie para el cálculo de la demanda de calefacción.

Fuente: CTE

Los valores límite para las distintas superficies se expresan en la sig. tabla (Tabla 4.8):

\begin{tabular}{|c|c|c|c|c|c|c|}
\hline \multirow{2}{*}{$\begin{array}{c}\text { Superficie } \\
\text { útil } m^{2}\end{array}$} & \multicolumn{6}{|c|}{ Demanda límite según la zona climática de invierno $\mathrm{kWh} / \mathrm{m}^{2}$ año } \\
\hline & $\alpha$ & $A^{*}$ & $B^{*}$ & $\mathrm{C}^{*}$ & $\mathrm{D}$ & $\mathrm{E}$ \\
\hline 100 & 15 & 15 & 15 & 30 & 50 & 70 \\
\hline 500 & 15 & 15 & 15 & 22 & 34 & 46 \\
\hline 1000 & 15 & 15 & 15 & 21 & 32 & 43 \\
\hline 5000 & 15 & 15 & 15 & 20 & 30 & 41 \\
\hline
\end{tabular}

Tabla 1.4.8: Valores límite de demanda de calefacción según la superficie útil de los espacios habitables. Fuente: CTE

La demanda de refrigeración del edificio o su ampliación no debe superar el valor límite $D_{\text {ref.lim }}=15 \mathrm{kWh} / \mathrm{m}^{2}$ año para las zonas climáticas de verano 1,2 y 3 y el $D_{\text {ref.lim }}=20 \mathrm{kWh} / \mathrm{m}^{2}$ año para la zona climática 4.

Las cargas internas debidas a ocupación, equipamiento e iluminación se encuentran limitadas, de acuerdo a lo indicado en la Tabla 4.9:

Para edificios de uso no residencial privado, el porcentaje de ahorro de la demanda de calefacción y refrigeración conjunta respecto del edificio de referencia, debe ser igual o superior a los valores especificados en la Tabla 2.2 del documento DBHE (pág. 14) (Ministerio de Fomento, 2016)

\begin{tabular}{c|c} 
Carga interna & Densidad de las fuentes internas CFI \\
\cline { 2 - 2 } Baja & W/m2 \\
Media & 66 \\
Alta & $6-9$ \\
Muy alta & $9-12$ \\
\end{tabular}

Tabla 4.9: Carga interna en función de la densidad de las fuentes internas. Fuente: CTE

Se considera una ventilación constante de $0,8 \mathrm{ren} / \mathrm{h}$. Los edificios de otros usos pero asimilables a los de uso residencial privado, podrán aplicar los criterios correspondientes a estos últimos. 
La transmitancia térmica de los elementos de la envolvente $(U)$ y la permeabilidad al aire de los huecos no debe superar los valores expresados en la Tabla 4.10

\begin{tabular}{|c|c|c|c|c|c|c|}
\hline \multirow{2}{*}{ Parámetro } & \multicolumn{6}{|c|}{ Zona climática de invierno } \\
\hline & $\alpha$ & $A$ & B & C & $\mathrm{D}$ & $\mathrm{E}$ \\
\hline $\begin{array}{r}U_{\text {máx }} \text { muros y elementos en contacto con } \\
\text { el terreno } 0^{1} \mathrm{~W} / \mathrm{m}^{2} \mathrm{~K}\end{array}$ & 1,35 & 1,25 & 1,00 & 0,75 & 0,60 & 0,55 \\
\hline$U_{\text {máx }}$ cubiertas y suelos $W / m^{2} K$ & 1,20 & 0,80 & 0,65 & 0,50 & 0,40 & 0,35 \\
\hline$U_{\text {máx }}$ huecos ${ }^{2} W / m^{2} K$ & 5,70 & 5,70 & 4,20 & 3,10 & 2,70 & 2,50 \\
\hline $\begin{array}{r}\text { Permeabilidad al aire de los huecos }{ }^{3} \\
\qquad \mathrm{~m}^{3} / \mathrm{hm}^{2}\end{array}$ & $\leq 50$ & $\leq 50$ & $\leq 50$ & $\leq 27$ & $\leq 27$ & $\leq 27$ \\
\hline
\end{tabular}

1. los elementos en contacto con el terreno serán el primer metro de muro enterrado o el primer metro del perímetro de suelo apoyado sobre el terreno hasta una profundidad de 0,50m

2. se considera vidrio y marco, incluye claraboyas y lucernarios

3. a una presión de $100 \mathrm{~Pa}$

Tabla 4.10: Transmitancia térmica máxima de la envolvente y permeabilidad al aire de los huecos. Fuente: CTE

Se establecen asimismo los valores máximos de transmitancia de particiones interiores entre otras unidades de distinto uso, zonas comunes y medianeras, al igual que para el mismo uso (Tabla 4.11).

\begin{tabular}{|c|c|c|c|c|c|c|c|}
\hline \multirow{2}{*}{ Uso } & \multirow{2}{*}{$\begin{array}{c}\text { Tipo de } \\
\text { particiones }\end{array}$} & \multicolumn{6}{|c|}{ Zona climática de invierno } \\
\hline & & $\alpha$ & A & B & C & D & E \\
\hline $\begin{array}{r}\text { Distinto uso, medianeras } \\
\text { y zonas comunes }\end{array}$ & $\begin{array}{l}\text { horizontales y } \\
\text { verticales }\end{array}$ & 1,35 & 1,25 & 1,10 & 0,95 & 0,85 & 0,70 \\
\hline \multirow{2}{*}{ Unidades del mismo uso } & horizontales & 1,90 & 1,80 & 1,55 & 1,35 & 1,20 & 1,00 \\
\hline & verticales & 1,40 & 1,40 & 1,20 & 1,20 & 1,20 & 1,00 \\
\hline
\end{tabular}

Tabla 4.11: Transmitancia térmica máxima entre particiones en $\mathrm{kWh} / \mathrm{m}^{2} \mathrm{~K}$

En obras que conlleven una renovación mayor al $25 \%$ de su envolvente y en las destinadas a un nuevo uso, la demanda debe ser inferior a la del edificio de referencia.

Los datos para el cálculo de la demanda energética pueden ser divididos en:

- Solicitaciones exteriores: dependerán de las características de cada zona climática

- Solicitaciones interiores y condiciones operacionales: son las cargas térmicas internas debidas a ocupación, equipos e iluminación, con las temperaturas de consigna de calefacción y refrigeración

El grado de ventilación de cálculo no está prefijado y debe ser coherente con el cumplimiento de otras exigencias y del proyecto. 
El uso de algoritmos genéticos aplicados al diseño bioambiental paramétrico

El cálculo de la demanda de calefacción y refrigeración se calcula para un año, mediante una simulación térmica o un método simplificado. La página del CTE provee una herramienta gratuita, LIDER- CALENER para llevar a cabo las verificaciones de algunas exigencias establecidas en este documento.

El método simplificado sólo considera las cargas térmicas por la envolvente y un factor de carga por ganancias internas sea ésta alta, media o baja y la verificación de las condensaciones superficiales, intersticiales y puentes términos

\subsubsection{Documento de apoyo}

El documento DB-HE se complementa con los siguientes documentos:

- DB-HE/1: Cálculo de parámetros característicos de la envolvente

- DB-HE/2: Comprobación de limitación de condensaciones superficiales e intersticiales en los cerramientos

- DB-HE/3: Puentes térmicos

- DB-HE Climas de referencia: documento descriptivo de climas de referencia

- DB-HE .MET Climas: Archivos de datos de todas las zonas climáticas

- Historial de cambios: Historial de cambios de los Documentos de Apoyo

Los apéndices que acompañan al documento DB-HE son los siguientes:

- Apéndice A: Terminología

- Apéndice B: Zonas climáticas Notaciones y unidades

- Apéndice C: Perfiles de uso

- Apéndice D: Definición del edificio de referencia

- Apéndice E: Cálculo de los parámetros característicos de la demanda

- Apéndice F: Resistencia térmica total de un elemento de edificación constituído por capas homogéneas y heterogéneas

- Apéndice G: Condensaciones

- Apéndice H: Fichas justificativas de la opción simplificada

El Apéndice A provee un glosario de términos. En el Apéndice $B$, se clasifican las zonas climáticas de España. Los datos completos pueden obtenerse como archivo .MET de la página del CTE. El Apéndice $C$, provee los perfiles de uso normalizados de los edificios en función de su uso, densidad de las fuentes internas (baja, media o alta) y período de utilización (8, 12, 16 y 24h). El Apéndice D, proporciona las características generales de dicho edificio y los parámetros característicos límite de la envolvente, para cada zona climática. El Apéndice E, provee los valores orientativos de los parámetros característicos de la envolvente térmica. 


\subsubsection{Apéndice B: Zonas climáticas}

Las zonas climáticas de España se encuentran divididas en doce áreas de acuerdo a sus temperaturas de invierno y verano. La clasificación de verano es $A, B, C, D$ y $E$, la clasificación de invierno, 1, 2, 3, 4, y 5. De las veinte combinaciones posibles, se consideran solamente doce, en las cuales se encuentran las localidades españolas (Fig. 4.3). En esta figura, se ubican las zonas según la severidad climática de invierno sobre el eje de las abcisas y la severidad climática de verano sobre el eje de las ordenadas. La severidad climática combina los grados día y la radiación de una localidad, tanto para invierno como para el verano.

Las zonas A1 y A2 se considerarán a todos los efectos equivalentes a la zona $A 3$, las zonas B1 y B2 serán equivalentes a la zona B3 y las zonas E2, E3 y E4, a la zona E1.

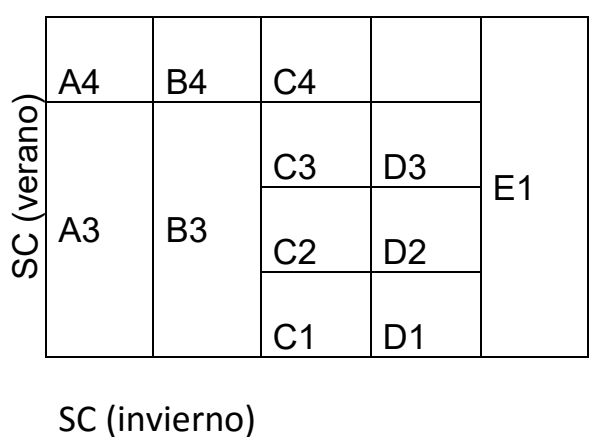

Fig. 4.3 Zonas climáticas de España. Fuente: CTE

Su distribución geográfica se muestra en la Fig. 1.4.4. La clasificación climática corresponde a las doce zonas mencionadas, indicándose con la letra a, a los archipiélagos balear y canario.

Para determinar la zona a la que pertenece cada capital, se provee la Tabla B1 del apéndice B del CTE (Tabla A2.1) (ver Anexo 2).

\subsection{Normativa europea}

\subsubsection{Norma UNE-EN ISO 13790: Eficiencia energética en edificios. Cálculo del consumo de energía para calefacción y refrigeración de espacios}

Esta norma proporciona los medios para evaluar la contribución de los edificios en la conservación de la energía y la eficiencia energética. Forma parte de una serie de normas dirigidas a la armonización a nivel europeo de la metodología de cálculo de la eficiencia energética de los edificios (AENOR, 2011)

Los principales datos de entrada para esta norma son los siguientes:

— propiedades de transmisión y ventilación 
El uso de algoritmos genéticos aplicados al diseño bioambiental paramétrico

- ganancias de calor a partir de fuentes internas y solar

- datos climáticos

- descripción del edificio y sus componentes, sistemas y uso

- requisitos de confort (temperaturas de consigna y tasas de ventilación)

- datos relacionados con la calefacción, refrigeración, agua caliente, ventilación y sistemas de iluminación

— tasa de caudal de aire

El esquema de los procedimientos de cálculo comprende el balance energético a nivel de edificio y sistemas (sólo se considera el calor sensible):

- condiciones de confort interior y climáticas

- transferencia de calor por transmisión entre el espacio acondicionado y el espacio exterior, determinada por la diferencia de temperatura entre ambos espacios.

- transferencia de calor por ventilación natural y/o mecánica, determinada por la diferencia de temperatura entre la zona acondicionada y la del aire suministrado.

- transmisión y transferencia de calor de ventilación entre espacios acondicionados y adyacentes

- ganancias internas de personas, equipamiento, iluminación, etc.

- ganancias solares a través de la envolvente

- parámetros dinámicos

Esta norma europea provee dos tipos básicos de cálculo de la demanda energética: cuasi estacionario y transitorio (Fig. 4.5)

- un método cuasi estacionario mensual

- un método cuasi estacionario estacional

- un método horario simple en estado dinámico

- un método detallado para simulaciones en estado dinámico

- En los métodos cuasi-estacionarios, los efectos dinámicos son considerados mediante la introducción de factores de corrección. Para el cálculo monozona, la temperatura de consigna de calefacción o refrigeración no debe diferir más de $4 \mathrm{~K}$ y los sistemas de calefacción y refrigeración deben ser los mismos para toda la zona. El sistema de ventilación, si lo hubiere, debe cubrir al menos el $80 \%$ de la superficie de la zona. En caso contrario, se debe optar por un cálculo multizona. 


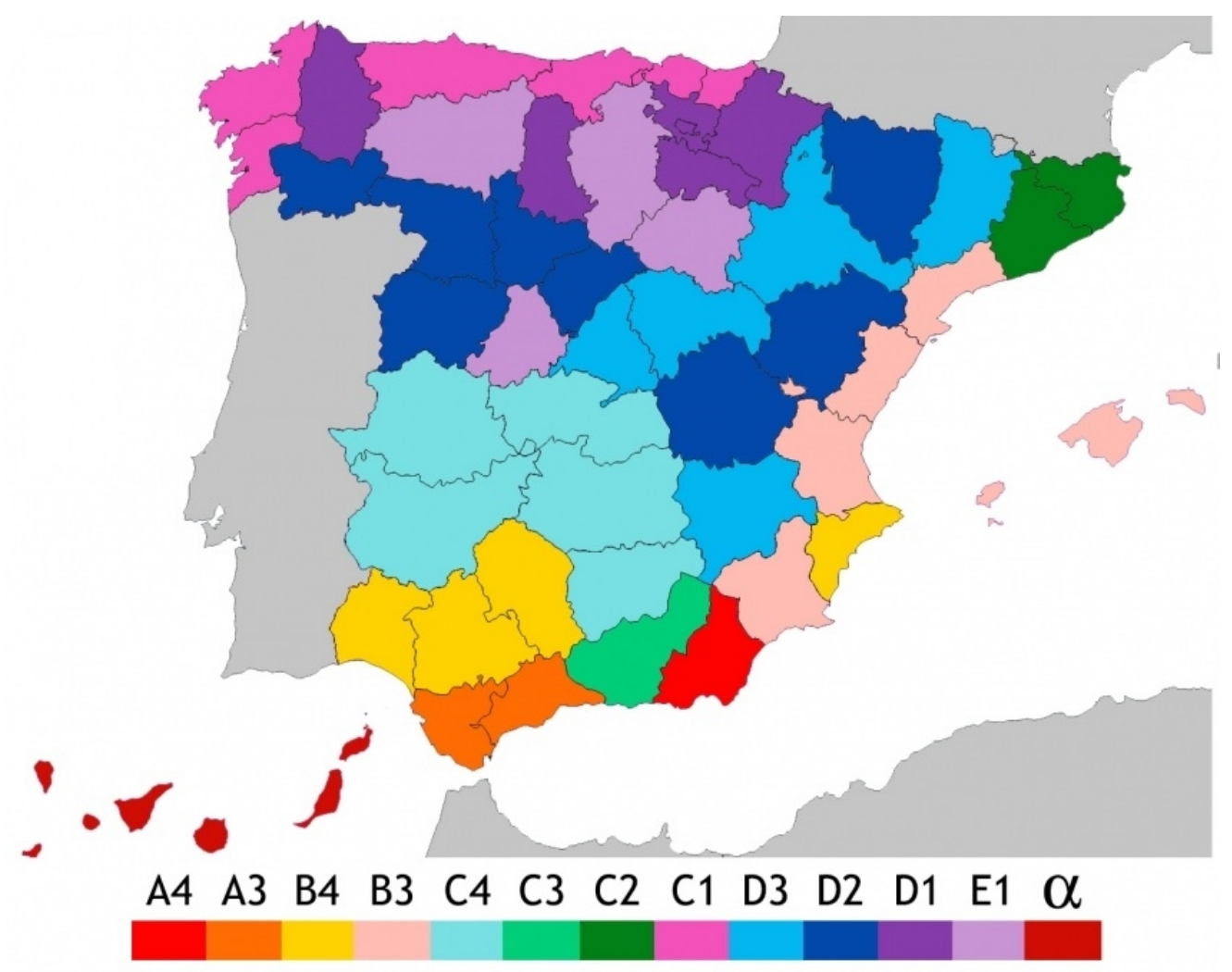

Fig. 4.4. Zonas climáticas de España. Fuente: CTE

Detallaremos a continuación el método cuasi estacionario mensual o estacional para un edificio a calefaccionar, donde la carga térmica mensual se determina así [Ec. 4.18]:

$$
Q_{H, n, c}=Q_{H, h t}-\eta_{H, g} Q_{H, g}
$$

siendo:

$Q_{H, n d, c o n t}=$ demanda de energía en calefacción para un mes en MJ

$Q_{\mathrm{H}, \mathrm{ht}}=$ son las pérdidas por conducción de la envolvente y por ingreso de aire exterior en MJ

$\eta_{\mathrm{H}, \mathrm{gn}}=$ factor de utilización de las ganancias de calor

$Q_{H, g n}=$ ganancias internas y por ventilación en MJ

La demanda de energía en calefacción anual es la suma de todos los meses con demanda positiva de calefacción [Ec. 4.19]:

$$
Q_{h, a}=\sum_{m=1}^{1} Q_{h, m}
$$

En la norma, la razón entre la ganancia y la pérdida de calor se define de la siguiente manera [Ec. 4.20]:

$$
\gamma=\frac{Q_{g}}{Q_{L}}
$$


La constante de tiempo del edificio se calcula de la siguiente forma [Ec. 4.21]:

$$
\tau=\frac{C}{H}
$$

siendo:

$\mathrm{C}=$ capacidad interna de calor del edificio en $\mathrm{J} / \mathrm{K}$

$\mathrm{H}=$ coeficiente de pérdidas totales de calor en W/K

El factor de utilización para ganancias de calor $\eta$ es definido en la norma con las siguientes ecuaciones [Ec. 4.21] y [Ec. 4.22] (Fig. 4.6):

$$
\begin{aligned}
& \text { Si } \gamma \neq 1: \eta=\frac{1-\gamma^{a}}{1-\gamma^{a+1}} \\
& \text { Si } \gamma=1: \eta=\frac{a}{a+1}
\end{aligned}
$$

siendo:

a= parámetro numérico que depende de la constante de tiempo del edificio definida así [Ec. 4.23]:

$$
a=a_{0}+\frac{\tau}{\tau_{0}}
$$

$a_{0}=$ parámetro numérico igual a 1 para el cálculo de la demanda mensual y 0,8 para el estacional de calefacción en edificios de uso continuo

$\mathrm{T}_{0}=15 \mathrm{~h}$ para el cálculo de la demanda mensual y 30 para el estacional de calefacción en edificios de uso continuo

Para uso intermitente, se adopta una temperatura media interna. Esta norma utiliza la temperatura media exterior para el cálculo pero no los grados días. La temperatura media no refleja las fluctuaciones de la temperatura exterior. 


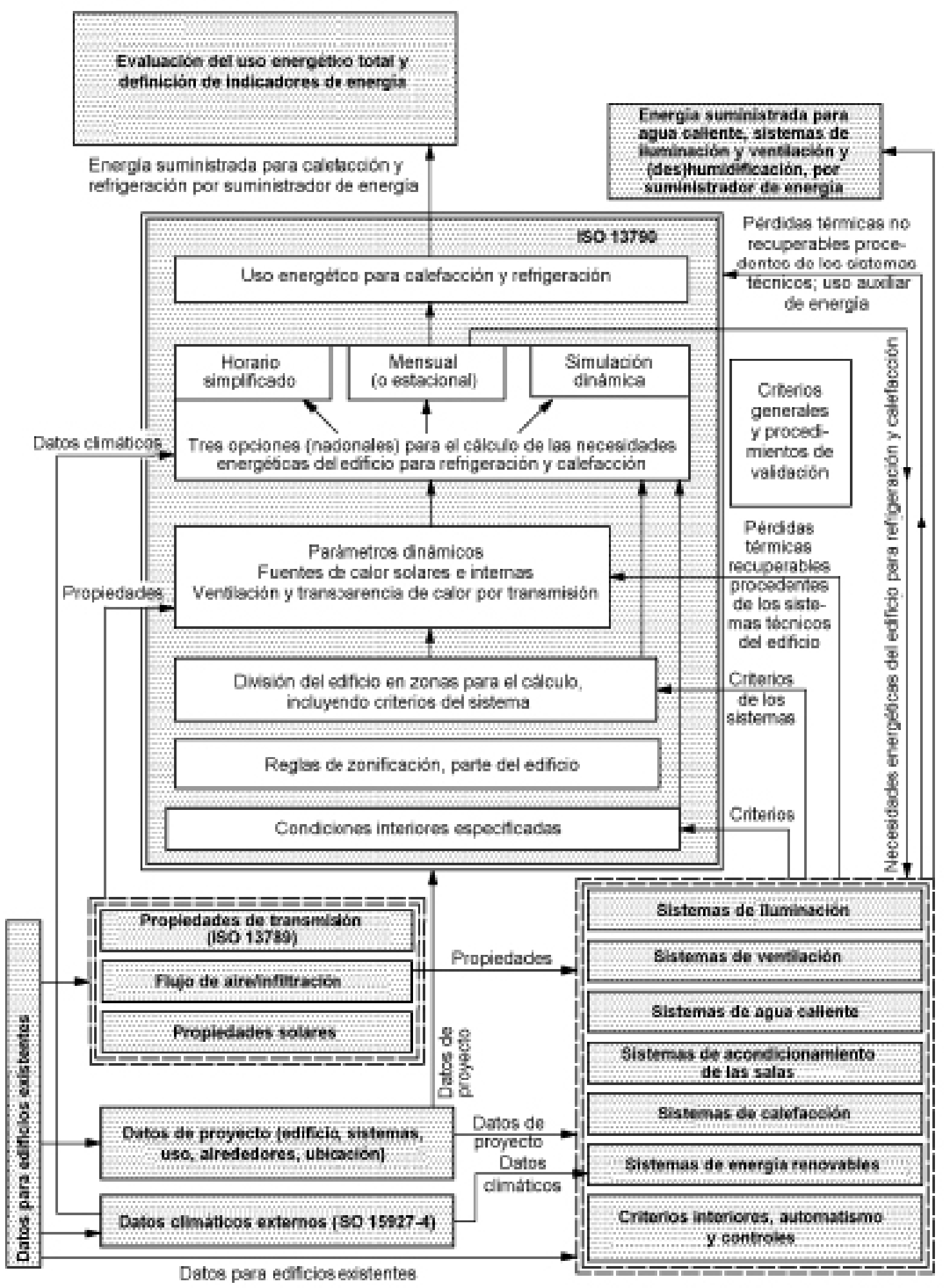

Fig. 4.5: Metodología de la Norma EN ISO 13790. Fuente: Norma ISO-13790

En el método de los grados día, las necesidades energéticas para calefacción se calculan sin tener en cuenta explícitamente el efecto de las ganancias solares e internas. Este defecto se compensa tomando sólo un subconjunto del número de días (método grados-día) u horas (método grados-hora) cuando se calcula la transferencia de calor por transmisión y ventilación. En este método sólo se suman los días donde la temperatura exterior es inferior 
a la temperatura base (Parlamento Europeo, 2009) pero la reducción no se basa en un conocimiento del balance específico entre las ganancias y las transferencia de calor, lo que lo convierte en un método más aproximado que el del factor de utilización.

Resumiendo, se podría decir que:

- en el método de factor de utilización, todas las horas del mes se incluyen en el cálculo de la diferencia de temperatura acumulada.

- no se distingue entre días u horas con temperatura exterior superior o inferior a una temperatura de base

- la temperatura interior es la de consigna y no la de base

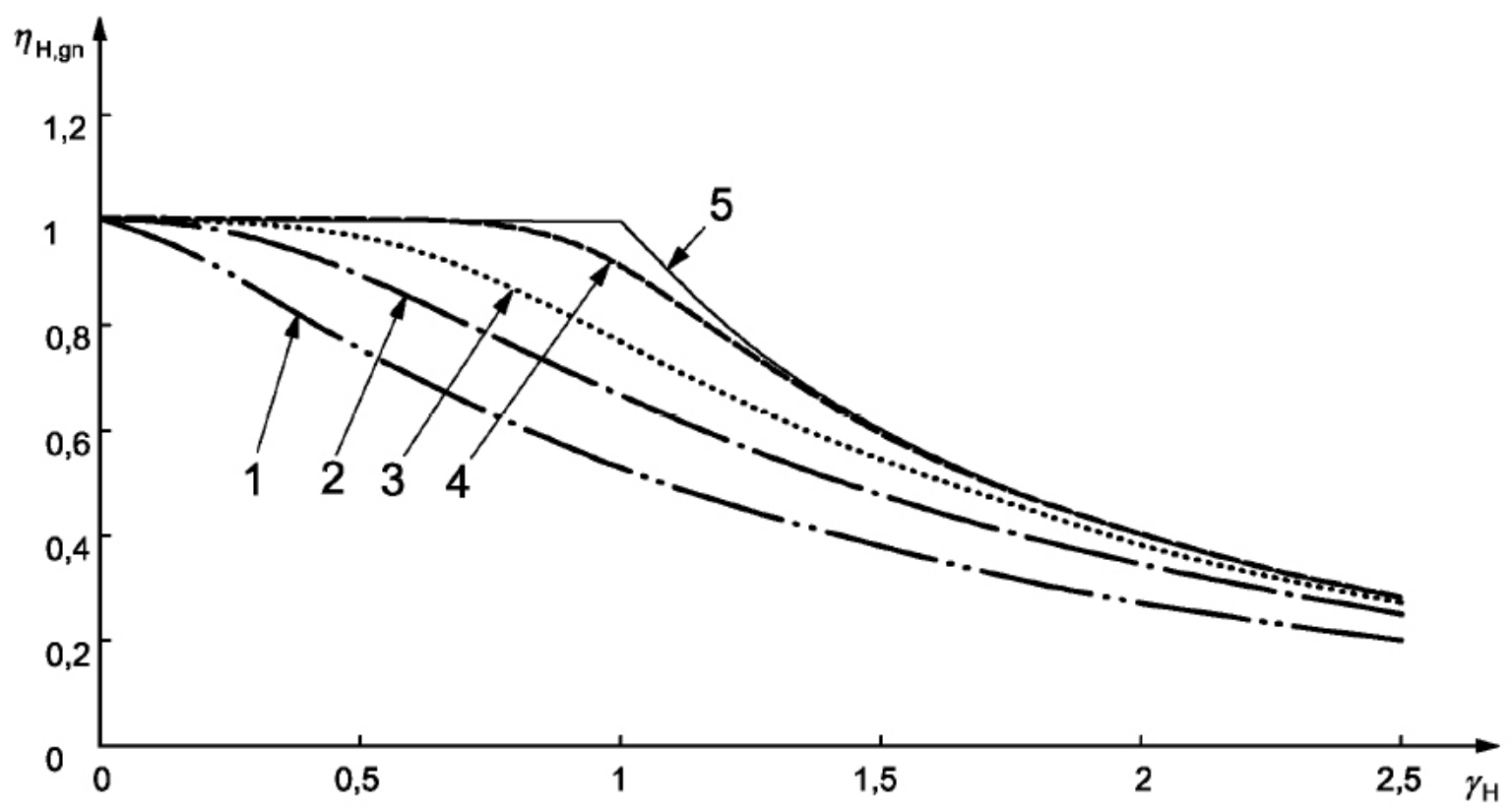

Curvas para diferentes constantes de tiempo:

$1=8 h$ (inercia baja); $2=1 d ; 3=2 d ; 4=7 d ; 5=$ infinita (inercia elevada)

Fig. 4.6. Factor de utilización de ganancias para calefacción para constantes de tiempo para el método de cálculo mensual. Fuente: Modificado de Norma UNE-EN ISO 13790

Para el cálculo de la demanda de refrigeración, se procede de manera similar a la de calefacción [Ec. 4.24]:

$$
Q_{C, n, c}=Q_{C, g}-\eta_{C, l:} Q_{C, h t}
$$

$Q_{\mathrm{C}, \text { nd,cont }}=$ demanda mensual o estacional de refrigeración continua en MJ

$\mathrm{Q}_{\mathrm{c}, \mathrm{gn}}=$ ganancias internas y solares en $\mathrm{MJ}$

$\eta_{c, l s}=$ factor de utilización de pérdidas térmicas

$\mathrm{Q}_{\mathrm{c}, \mathrm{ht}}=$ ganancias por conducción de la envolvente y por ingreso de aire exterior en MJ 
No se calcula el calor latente (deshumidificación).

La Norma desarrolla en detalle los métodos de cálculo mencionados y provee tablas con datos normalizados para dichos cálculos.

\subsubsection{CIBSE TM41: 2006. Teoría de los grados días y aplicación}

The Chartered Institution of Building Services Engineers (CIBSE) se origina en 1897 cuando emergen las soluciones tecnológicas para lograr el confort en edificios, en el Reino Unido. Promueve la carrera de ingeniero en servicios edilicios, publica Guías y Códigos, es consultada por el gobierno en materia de construcción, ingeniería y sustentabilidad e integra asociaciones del Reino Unido y Europa.

Esta norma (CIBSE, 2006) provee la teoría y la metodología de cálculo de los grados días aplicados a la calefacción y la refrigeración a los fines de calcular el consumo de energía. Esta práctica es introducida por Sir Richard Strachey en 1798 para predecir la temporada de crecimiento de los cultivos en el Reino Unidoyluego se extiende al ámbito del consumo energético edilicio. El primer registro de aplicación a edificios es de la American Gas Association en los '20s en los Estados Unidos. En el Reino Unido, la primera en aplicarlos en 1938 es la London and Counties Coke Association. El método siguió desarrollándose e incorporó la idea de uso intermitente del edificio hasta que en los '80s, Holmes introdujo el concepto de capacidad térmica y los efectos de las ganancias variables. La intermitencia en el uso del edificio introdujo la necesidad de incorporar el método de admitancia y con éste, la inercia térmica. Utiliza un procedimiento similar a la BS EN ISO 13790.

No es un método rigurosamente exacto pero sí sencillo y rápido. A diferencia de las simulaciones, este método es completamente transparente y puede realizarse con una planilla de cálculo. El balance de calefacción se expresa en la fig. 4.7.

El cálculo de la demanda instantánea de calefacción se expresa en la ecuación [Ec. 4.25]:

$$
Q_{E}=U^{\prime}\left(\theta_{S}-\theta_{o}\right)+Q_{C}-Q_{G} ; \text { para } Q_{E}>0
$$

siendo:

$\theta_{\mathrm{sp}}=$ temperatura de confort interior

$\theta_{0}=$ temperatura exterior

$Q_{C}=$ factor de efecto del almacenamiento térmico del edificio en caso de uso intermitente del edificio, si el uso es continuo es igual a 0 


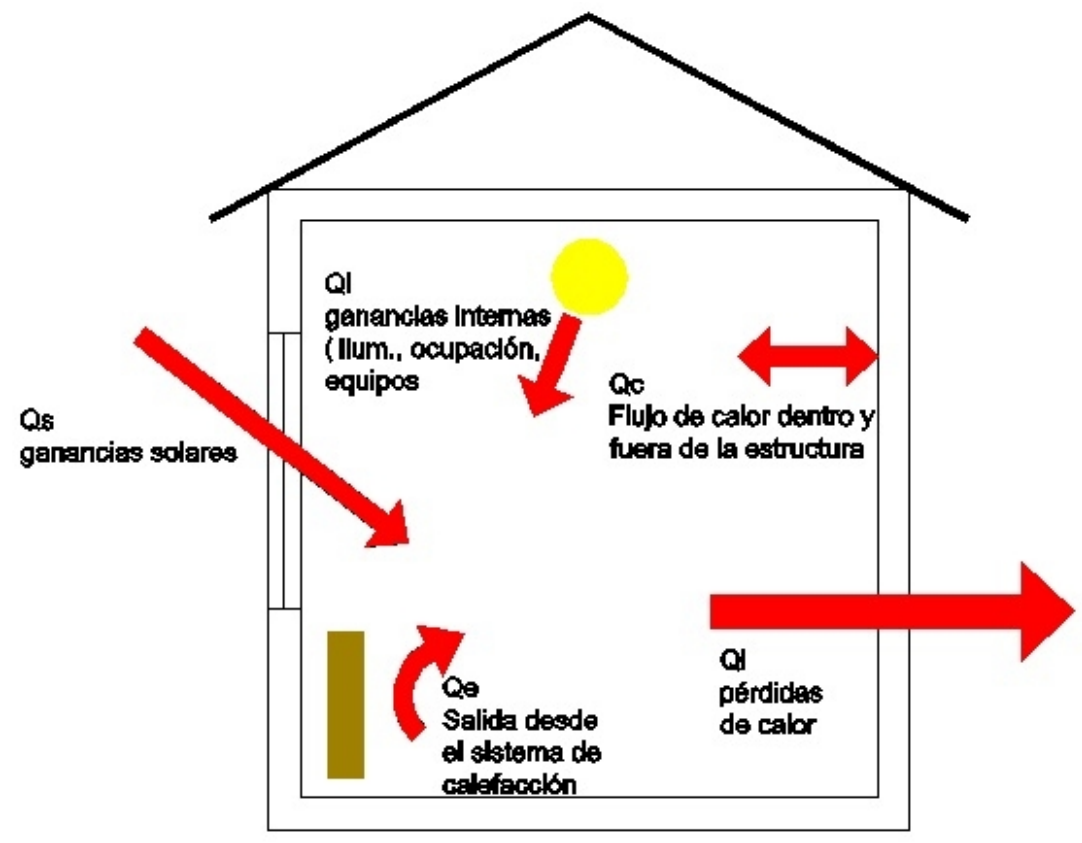

Fig. 4.7. Ganancias y pérdidas de calor en la envolvente. Fuente:la autora

U'= es el coeficiente de pérdidas térmicas globales en kW/K [Ec. 4.26]:

$$
U^{\prime}=\frac{\sum A U+\frac{1}{3} N}{1}
$$

siendo:

$\mathrm{U}=$ transmitancia del elemento en $\mathrm{W} / \mathrm{m}^{2} \mathrm{~K}$

$\mathrm{A}=$ área del elemento en $\mathrm{m}^{2}$

$\mathrm{N}=$ número de renovaciones horarias en $\mathrm{h}^{-1}$

$1 / 3=$ calor específico del aire

$V=$ volumen de aire interior del edificio

La demanda energética $\mathrm{E}$ se obtiene mediante la suma de estas cargas instantáneas a lo largo del tiempo, o sea, a integración de [Ec. 4.27]:

$$
E=\int Q_{E} d=\int U^{\prime}\left(\theta_{S}-\theta_{0}\right) d+\int Q_{C} d-Q_{G} d ; \text { para } Q_{E}>0
$$

Si se trata de un edificio con calefacción continua, entonces $Q_{c}=0$.

Para el cálculo de la demanda de energía para refrigeración, el cálculo es más complejo porque varía de acuerdo al tipo de equipo: por conductos, tipo ventilador serpentín o difusores de inducción de techo (chilledbeams). Los factores que deben considerarse para un cálculo aplicando el método de los grados días deberían considerar además la presencia 
de cargas latentes, la posibilidad de grandes cargas de aire fresco, el uso de recuperación de calor sea solamente sensible o la suma de sensible y latente, la variación en los flujos de aire y la dependencia de la temperatura respecto del coeficiente de performance del equipo refrigerante.

Veamos el cálculo de la demanda energética para refrigeración por conductos. La energía extraída del aire se expresa en [Ec. 4.28]:

$$
Q_{E}=m c_{p}\left(\theta_{a}-\theta_{c}\right)+m h_{f}\left(g_{o}-g_{s}\right)
$$

$\mathrm{Q}_{\mathrm{E}}=$ es la cantidad de calor removida del aire $(\mathrm{kW})$

$\mathrm{m}=$ es la flujo de la masa de aire $(\mathrm{kg} / \mathrm{s})$

$\mathrm{C}_{\mathrm{p}}=$ calor específico del aire $(\mathrm{kJ} / \mathrm{kg} \mathrm{K})$

$\theta_{\mathrm{ao}}=$ temperatura del aire exterior $(\mathrm{K})$

$\theta c=$ temperatura del aire interior $(\mathrm{K})$

$g_{\circ}=$ humedad del aire exterior ( $\mathrm{kg}$ vapor de agua $/ \mathrm{kg}$ aire seco)

$\mathrm{g}_{\mathrm{s}}=$ humedad del aire interior ( $\mathrm{kg}$ vapor de agua/kg aire seco)

A la vez podemos descomponer $Q_{E}[$ Ec. 4.29]:

$$
Q_{E}=Q_{e}+Q_{S}+Q_{I}+Q_{v}+Q_{f(S)}+Q_{f(L)}+Q_{L}
$$

$Q_{\mathrm{e}}=$ carga térmica de la envolvente $(\mathrm{kW})$

$\mathrm{Q}_{\mathrm{s}}=$ ganancia solar $(\mathrm{kW})$

$Q_{1}=$ ganancias internas calor sensible $(\mathrm{kW})$

$Q_{\text {vent }}=$ calor enviado al ambiente por el ventilador $(\mathrm{kW})$

$\mathrm{Q}_{\mathrm{fa}(\mathrm{S})}=$ calor sensible del aire exterior $(\mathrm{kW})$

$\mathrm{Q}_{\mathrm{fa}(\mathrm{L})}=$ calor latente del aire exterior $(\mathrm{kW})$

$\mathrm{Q}_{\mathrm{L}}=$ carga de calor latente del ambiente $(\mathrm{kW})$

Desglosando cada término tenemos que [Ec. 4.30, 31, 32, 33 y 34]:

$$
Q_{e}=U^{\prime}\left(\theta_{e} \cdot \theta_{a}\right)
$$

$\theta_{\mathrm{eo}}=$ temperatura sol-aire $(\mathrm{K})$ 
$\theta_{\mathrm{ai}}=$ temperatura del aire interior $(\mathrm{K})$

$$
Q_{v} \quad=\frac{v}{\eta_{v}}=m c_{p}\left(\theta_{s}-\theta_{C}\right)
$$

$v=$ volumen del flujo de aire $\left(\mathrm{m}^{3} / \mathrm{s}\right)$

$\Delta \mathrm{P}=$ incremento de la presión dentro del ventilador $(\mathrm{kPa})$

$\eta_{\text {vent }}=$ eficiencia del ventilador

$\theta s=$ temperatura del aire provisto

$$
Q_{f(S)}=m c_{p}\left(\theta_{a}-\theta_{a}\right)
$$

$\mathrm{m}=$ flujo de la masa de aire $(\mathrm{kg} / \mathrm{s})$

$\mathrm{C}_{\mathrm{p}}=$ calor específico del aire $(\mathrm{kJ} / \mathrm{kg} \mathrm{K})$

La carga de calor latente del aire fresco puede sumarse a la carga de calor latente del ambiente, obteniéndose el calor latente extraído del aire [1.4.41]:

$$
Q_{f(L)}+Q_{L}=m h_{f}\left(g_{o}-g_{\mathrm{s}}\right)
$$

Si:

$$
m h_{f}\left(g_{o}-g_{\mathrm{s}}\right)=m c_{p} \Delta \theta_{L}^{\prime}
$$

donde $\Delta \theta^{\prime}$ L es la diferencia teórica de temperatura latente.

Si reacomodamos la ecuación X obtenemos [Ec. 4.35]:

$$
\Delta \theta_{L}^{\prime}=\frac{h_{f}}{c_{p}}\left(g_{o}-g_{\mathrm{s}}\right)
$$

Reemplazando $\mathrm{h}_{\mathrm{fg}}=2450 \mathrm{~kJ} / \mathrm{kg}$ y $\mathrm{c}_{\mathrm{p}}=1.02 \mathrm{~kJ} / \mathrm{kg} \mathrm{K}$, tenemos [Ec. 4.36]:

$$
\Delta \theta_{L}^{\prime}=2400\left(g_{o}-g_{\mathrm{s}}\right)
$$

Si expresamos todas las cargas en función de la diferencia de temperaturas, tenemos [Ec.4.37]:

$$
Q_{E}=m c_{p}\left[\theta_{a}-\theta_{a}+\frac{v}{m c_{p} \eta_{v}}+\frac{Q_{s}}{m c_{p}}+\frac{u^{\prime}}{m c_{p}}\left(\theta^{\prime}{ }_{a}(d \quad)-\theta_{a}\right)+2400\left(g_{o}-g_{s}\right)\right][\text { Ec. 4.37] }
$$

siendo $Q_{s}=Q_{\text {solar }}+Q_{1}$

En términos de energía extraída a lo largo del tiempo lo expresamos con la siguiente integral [Ec. 4.38]: 


$$
\int Q_{E} d=m c_{p} \int\left\{\theta_{a}-\left[\theta_{a}+\frac{v}{m c_{p} \eta_{v}}+\frac{Q_{s}}{m c_{p}}+\frac{U^{\prime}}{m c_{p}}\left(\theta^{\prime}{ }_{a(d)}-\theta_{a}\right)+2400\left(g_{o}-g_{\mathrm{s}}\right)\right]\right\} d
$$

siendo la expresión entre corchetes, la temperatura base y la expresión entre llaves, los grados días de refrigeración.

La norma también desarrolla el método para otros tipos de sistema refrigerante y para edificios de uso intermitente.

\subsection{Normativa en EEUU}

\subsubsection{ASHRAE Handbook Fundamentals SI. Cálculo de las cargas térmicas por calefacción y refrigeración}

La American Society of Heating, Refrigerating and Air-ConditioningEngineers (ASHRAE) fue fundada en 1894 y se focaliza en las instalaciones edilicias, eficiencia energética, calidad del aire interior, refrigeración y sostenibilidad. Desarrolla investigación, redacción de normativa y educación, entre otras actividades.

En el capítulo 17 de ASHRAE Fundamentals (ASHRAE, 2013) se detallan los cálculos para determinar las cargas térmicas para calefacción y refrigeración

Para el cálculo de la carga térmica de calefacción no se consideran ganancias solares o internas así como tampoco almacenamiento de calor debido a la inercia térmica de la envolvente. La temperatura de confort interior se fija en $20^{\circ} \mathrm{C}$.

La sumatoria de todas las pérdidas $\mathrm{q}_{\mathrm{h}}$ nos da la demanda energética de calefacción en $\mathrm{W}$ [Ec. 4.39]

$$
\sum q_{h}=q_{e}+q_{v}+q_{f}
$$

El cálculo de las pérdidas por conducción de la envolvente es el siguiente [Ec. 4.40]:

$$
q_{e}=A \cdot H
$$

siendo:

$q_{e}=$ pérdidas térmicas de los elementos opacos y no opacos de la envolvente en $W$

$A=$ el área del elemento exterior de la envolvente

$\mathrm{HF}=$ factor de calefacción que es igual a [Ec. 4.41]:

$$
H=U
$$


siendo:

$\mathrm{U}$ : transmitancia térmica del elemento en $\mathrm{W} / \mathrm{m} 2 \mathrm{~K}$

$\Delta t=$ diferencia de temperatura exterior e interior (bulbo seco)

La pérdida térmica por infiltración de aire se calcula así [Ec. 4.42]:

$$
q=C
$$

siendo:

$\mathrm{Cs}=$ calor sensible del aire a nivel del mar, $23 \mathrm{~W} / \mathrm{L} \mathrm{s} \mathrm{K}$

$\mathrm{Q}=$ flujo de aire en $\mathrm{L} / \mathrm{s}$

La pérdida térmica por piso se calcula según [Ec. 4.43]:

$$
q_{f}=F_{p} p
$$

siendo:

$\mathrm{q}_{\mathrm{f}}=$ pérdidas térmicas por piso en $\mathrm{W}$

$F_{p}=$ coeficiente de pérdida pormetro de perímetro en $\mathrm{W} /(\mathrm{m} \cdot \mathrm{K})$

$p=$ perímetro del edificio en $m$

La carga térmica de refrigeración por calor sensible se calcula mediante la suma de las ganancias por los elementos opacos y transparentes de la envolvente, ventilación e infiltración y ocupación. La parte de carga térmica por calor latente se evalúa separadamente. Se considera una temperatura de confort de $24^{\circ} \mathrm{C}$ y $50 \%$ de humedad relativa.

La sumatoria de las ganancias por calor sensible son las siguientes [Ec. 4.44]:

$$
\sum q_{c}=q_{o}+q_{f}+q_{v, \mathrm{~s}}+q_{i_{1}, \mathrm{~s}}+q_{d}
$$

La sumatoria de las ganancias por calor latente son las siguientes [Ec. 4.45]:

$$
\sum q_{C}=q_{v, l}+q_{i, l}
$$

Las ganancias por elementos opacos se calculan en la ecuación [Ec. 4.46]:

$$
q_{o}=A . C_{o}
$$

$\mathrm{A}=$ área del elemento en $\mathrm{m}^{2}$ 
$\mathrm{CF}_{\mathrm{opq}}=$ coeficiente de refrigeración, que se detalla a continuación [Ec. 4.47]:

$$
C_{o}=U\left(O_{t} \cdot \Delta+O F_{b}+O_{r} D\right)
$$

$\mathrm{OF}_{\mathrm{t}}=$ valor inferior a 1 que captura el efecto amortiguador de áticos y cámaras de aire bajo piso.

$\mathrm{OF}_{\mathrm{b}}=$ ganancia solar por radiación incidente, considerando la absorptancia solamente para las cubiertas

$\mathrm{OF}_{\mathrm{r}}=$ efecto de almacenamiento de calor que reduce la diferencia de temperatura

$\mathrm{DR}=$ amplitud térmica diaria de la temperatura exterior (bulbo seco) en $\mathrm{K}$

Los valores de los factores de refrigeración OF están provistos en la Tabla 7 de la pág. 9 del capítulo 17 (ASHRAE, 2013).

Las ganancias por los elementos transparentes se calculan así [Ec. 4.48]:

$$
q_{f} \quad=A \cdot C_{f}
$$

siendo:

$\mathrm{q}_{\mathrm{fen}}=$ carga térmica por refrigeración de elementos transparente en $\mathrm{W}$

$\mathrm{A}=$ área del elemento transparente en $\mathrm{m}^{2}$

$\mathrm{CF}_{\text {fen }}=$ factor superficial de refrigeración de elementos transparentes en $\mathrm{W} / \mathrm{m} 2$ [Ec. 4.49]:

$$
C_{f}=U(\Delta-0,46 D)+P \quad . S \quad . L_{\Lambda} \quad . F
$$

siendo:

$\mathrm{U}=$ coeficiente $\mathrm{U}$ de calor de la ventana provisto por Consejo Nacional de Clasificación de Ventanas en $\mathrm{W} / \mathrm{m}^{2} \mathrm{~K}$

$\Delta \mathrm{t}=$ diferencia de temperatura exterior e interior en $\mathrm{K}$

$\mathrm{DR}=$ amplitud térmica diaria temperatura exterior de bulbo seco en $\mathrm{K}$

$\mathrm{PXI}=$ irradiancia exterior pico incluyendo modificaciones por sombreado en $\mathrm{W} / \mathrm{m}^{2}$

SHGC = coeficiente de ganancia solar de las ventanas

$I A C=$ coeficiente de atenuación de sombra interior

$F F s=$ factor solar de carga de la ventana (ASHRAE, 2013- Tabla 13, pág. 10) 
Las ganancias por infiltración y ventilación se calculan así [Ec. 4.50, 51, 52 y 53]:

$$
\begin{aligned}
& q_{v, \mathrm{~s}}=C_{S}\left[Q_{v}+\left(1-\varepsilon_{\mathrm{S}}\right) Q_{b}, h r+Q_{b}, o h\right] \Delta \\
& q_{v, l}=C_{l}\left[Q_{v}+Q_{b},{ }_{,} h\right] \Delta \quad \text { no HRV/ERV } \\
& q_{v, t}=C_{t}\left[Q_{v}+\left(1-\varepsilon_{t}\right) Q_{b}, h r+Q_{b}, o h\right] \Delta h \\
& q_{v, l}=q_{v, t}-q_{v, s}
\end{aligned}
$$

$q_{v i, s}=$ carga térmica sensible por ventilación e infiltración en W

$\mathrm{C}_{\mathrm{s}}=$ coeficiente de calor sensible del aire: $23 \mathrm{~W} / \mathrm{L} \cdot \mathrm{s} \cdot$ ) a nivel del mar

$\varepsilon_{s}=H R V / E R V$ eficiencia sensible

$\varepsilon_{\mathrm{t}}=\mathrm{HRV} / \mathrm{ERV}$ eficiencia total

$Q_{\text {bal,hr }}=$ flujo de ventilación balanceado a través del equipo HRV/ERV en L/s

HRV (heatrecoveryventilation)=ventilación con recuperación decalor

ERV (enthalpyrecoveryventilation)= ventilación con recuperación de entalpía

$\mathrm{Q}_{\mathrm{bal}, \text { oth }}=$ otro flujo de ventilación balanceado adicional en L/s

$\Delta \mathrm{t}=$ diferencia de temperatura interior/exterior en $\mathrm{K}$

$\Delta \mathrm{W}=$ diferencia de humedad interior/exterior

$\mathrm{q}_{\mathrm{v}, \mathrm{t}}=$ carga térmica total de ventilación/infiltración en W

$\Delta \mathrm{h}=$ diferencia de entalpía interior/exterior en $\mathrm{kJ} / \mathrm{kg}$

$\mathrm{q}_{\mathrm{v}, \mathrm{l}}=$ carga latente por ventilación/infiltración en W

Las ganancias internas por ocupación se calculan así [Ec. 4.54 y 55]:

$$
\begin{aligned}
& q_{i_{1}, s} 136+2,2 A_{c}+22 N_{o} \\
& q_{i_{1}, l} 20+0,22 A_{C}+12 N_{o}
\end{aligned}
$$

siendo

$q_{i g, s}=$ carga de refrigeración de calor sensible por ganancias internas (ocupación, iluminación y equipos) en $\mathrm{W}$

$\mathrm{q}_{\mathrm{ig}}, \mathrm{l=}$ carga de refrigeración de calor sensible por ganancias internas (ocupación, iluminación y equipos) en $\mathrm{W}$ 
$\mathrm{A}_{\mathrm{cf}}=$ área de edificio refrigerado en $\mathrm{m}^{2}$

$\mathrm{N}_{\mathrm{oc}}=$ número de personas

Las ganancias por conductos se calculan así [Ec. 4.56]:

$$
q_{d}=F_{d} \cdot q_{b}
$$

$q_{d}=$ ganancias por ductos en $\mathrm{W}$

$F_{d l}=$ factor de pérdida/ganancia (Tabla 6, pág. 8) (ASHRAE, 2013)

$\mathrm{q}_{\mathrm{bl}}=$ carga térmica total del edificio en $\mathrm{W}$

\subsubsection{Norma ANSI-ASHRAE/IES 90.1-2010: Normativa para edificios excepto edificios residenciales bajos (Edición I-P)}

El propósito de esta norma es fijar los requisitos mínimos de eficiencia energética en edificios que no sean residenciales de hasta tres pisos, para el diseño, construcción y plan de mantenimiento y operación, así como también la utilización de fuentes de energías renovables in situ. Es aplicable a edificios nuevos y ampliaciones de edificios existentes con sus correspondientes instalaciones (ASHRAE, 2000).

Se definen los requisitos que debe cumplir la envolvente tales como: aislación térmica, elementos no opacos, cargas térmicas por infiltración. Se proveen tablas con las resistencias térmicas mínimas exigibles según el tipo de construcción para cada zona climática. También se especifican los coeficientes de ganancia solar para las aberturas y las áreas vidriadas por orientación.

Se establecen requisitos mínimos de eficiencia energética para el equipamiento mecánico de calefacción, refrigeración y ventilación. Se regula la eficiencia del sistema de provisión de agua caliente y piscinas climatizadas.

La norma especifica los requisitos que deben cumplir las instalaciones de iluminación de un edificio, tanto las interiores como las exteriores y los métodos para calcular su consumo energético.

Se detalla el método para el cálculo del costo de diseño de la energía y el presupuesto del costo de la energía.

Se detallan las zonas climáticas de EEEUU y sus características en un apéndice, y se comparan las equivalencias con las definiciones internacionales climáticas. 


\subsubsection{Norma ANSI-ASHRAE/IES 90.2-2010: Normativa para edificios residenciales bajos (Edición I-P)}

El propósito de esta norma es proveer requisitos mínimos de diseño energéticamente eficiente para edificios residenciales bajos (igual o menos de tres pisos). Se aplica a edificios nuevos y ampliaciones de edificios existentes y sus instalaciones, y también a las instalaciones nuevas de edificios existentes. Comprende viviendas unifamiliares, multifamiliares y casas modulares. La norma se aplica a la envolvente edilicia, equipamiento y sistemas de calefacción, refrigeración y agua caliente sanitaria. No se aplica a los requisitos del servicio eléctrico residencial o de iluminación (ASHRAE, 2007).

Establece las máximas transmitancias térmicas admisibles para los diferentes materiales que conforman la envolvente y la máxima cantidad de renovaciones de aire

Se proveen perfiles de ganancias internas y se calculan las cargas debidas al calor latente y sensible. También se prevé una mínima masa térmica, relacionada con la ocupación.

Según la zona climática, esta norma regula los sistemas de calefacción y su alimentación.

Al igual que la norma ASHRAE 90.1, provee la zonificación del país y los datos climáticos detallados de cada zona, como asimismo, da un listado de ciudades de todo el mundo, clasificadas según la zona climática a la que pertenecen.

\subsection{Conclusiones}

Luego de realizado este estudio pormenorizado de la normativa y legislación existentes tanto en Argentina como en España, Europa y EEUU, se evalúan críticamente los diferentes métodos para medir la demanda de calefacción y refrigeración de los edificios con sus aspectos a favor y en contra, los parámetros que se consideran para dichos cálculos y las limitaciones que condicionan cada clima de referencia. En atención al posterior desarrollo de este trabajo, se consideran con particular interés, las recomendaciones para aquellos climas templados a los que está destinada la herramienta digital, específicamente el área metropolitana de Buenos Aires (Argentina) y la ciudad de Sevilla (España) junto con los métodos simplificados de cálculo, aplicables a las primeras etapas del diseño arquitectónico. 
II. Objetivos, metodología y desarrollo de la investigación 
El uso de algoritmos genéticos aplicados al diseño bioambiental paramétrico 
5. Objetivos 
El uso de algoritmos genéticos aplicados al diseño bioambiental paramétrico 
Como ya lo mencionáramos en la introducción, el objetivo principal de este trabajo, es desarrollar un modelo ambiental digital, basado en la performance energética, que optimice el prediseño de morfologías edilicias mediante algoritmos genéticos (AGs), en las fases iniciales del proyecto arquitectónico en el caso de edificios de nueva planta o en el de rehabilitación energética de edificios existentes.

A continuación, se enuncian los objetivos secundarios que permitirán alcanzar el objetivo principal (Fig. 5.1):

El Objetivo 1 consiste en la creación de un modelo digital para resolver morfologías y/o envolventes sostenibles, en climas templados: Buenos Aires y Sevilla.

El Objetivo 2 propone el desarrollo de un caso de estudio, aplicando el modelo a un edificio de nueva planta en torre, situado en Buenos Aires, mediante la parametrización de las variables geométricas, materiales (composición de la envolvente), climáticas, operativas (ocupación) y normativas, que permita la optimización de la morfología edilicia.

El Objetivo 3 plantea la aplicación del modelo a un caso de rehabilitación energética de un edificio en tira: Barriada RENFE, Sevilla, optimizando no sólo el desempeño energético de la envolvente sino también su factibilidad financiera.

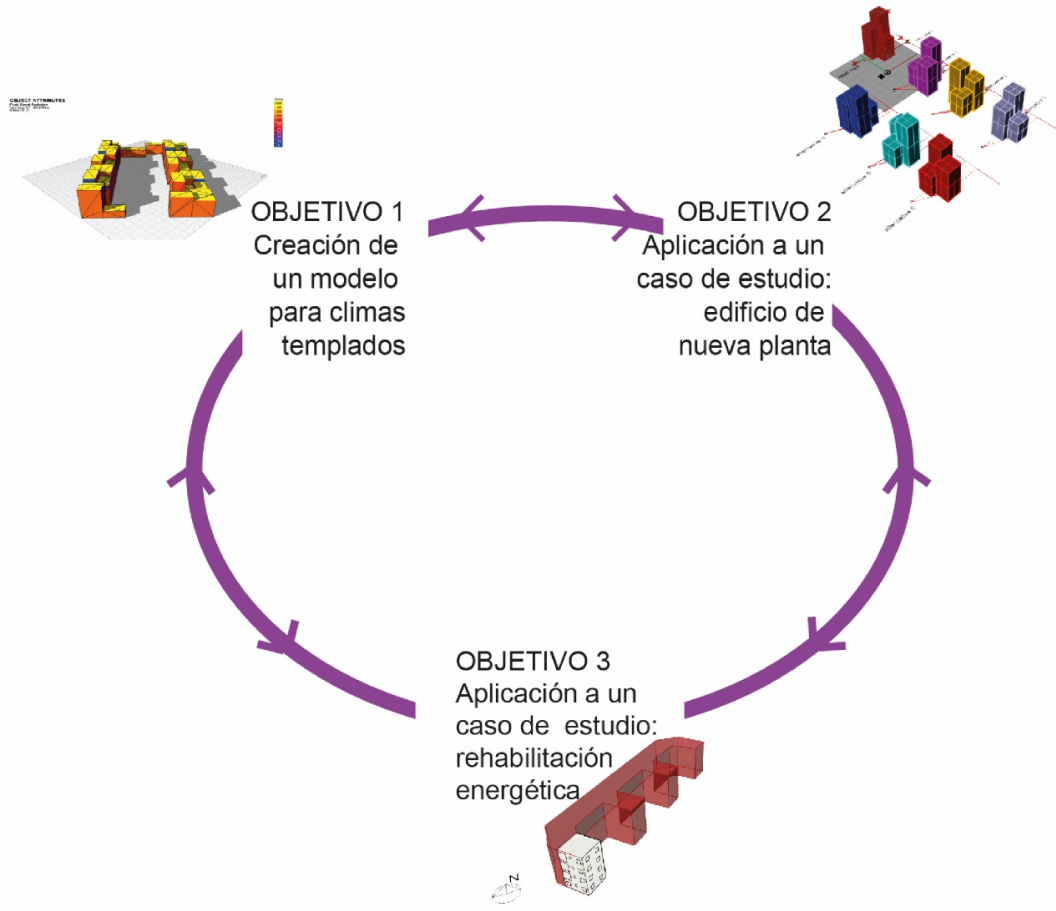

Fig. 5.1: Objetivos de cada etapa de la investigación. Fuente: la autora 
Ampliamos a continuación, el contenido de los objetivos:

- El Objetivo 1 define qué tipo de modelo digital es necesario diseñar al momento de proyectar morfologías arquitectónicas ambientalmente sostenibles situadas en climas templados, en las primeras instancias del proyecto. Asimismo, plantea que la forma y la envolvente son variables, por lo cual serán parametrizables, integrándose en operaciones geométricas, matemáticas y lógicas, en un único entorno 3D. El modelo incorpora la normativa argentina, española y europea, referente a la eficiencia energética en edificios.

- El Objetivo 2 es un caso de estudio de un edificio en torre de nueva planta, situado en Buenos Aires. Se busca obtener una multiplicidad de soluciones formales energéticamente eficientes, que permitan al diseñador evaluar más alternativas que las que podría conseguir mediante un procedimiento manual. Se considera la normativa vigente para la localización particular del caso de estudio.

- El Objetivo 3 propone optimizar la envolvente de un bloque de viviendas, existente en Sevilla para su rehabilitación energética relacionando el ahorro energético, el costo de la inversión y el período de amortización de la misma, adecuándose a la normativa dictada por España y la Unión Europea. Se elige uno de los edificios que integran la barriada RENFE, dando continuidad a las investigaciones ya realizadas sobre el mismo en la Universidad de Sevilla. 
6. Metodología 
El uso de algoritmos genéticos aplicados al diseño bioambiental paramétrico 
El modelo, de tipo bottom-up (Schweers, R., 2002) (ver apartado 2.1), se genera a partir de las variables paramétricas bioambientales que determinan un edificio (o conjunto de edificios) : características materiales de la envolvente, condiciones de uso, normativa y clima locales, con el objetivo de obtener morfologías optimizadas, energéticamente eficientes, en correspondencia con el objetivo general de la investigación (ver apartado 5).

No se trata de una estructura diseñada a priori, impuesta sobre el objeto de estudio, sino que se va construyendo a partir de los datos parametrizados de entrada, vinculándolos entre sí mediante procedimientos matemáticos e informáticos. El proceso de generación se asemeja al tipo design research (Sevaldson, B., 2005) (Laurel, 2003), donde se hace hincapié en la investigación a través del proceso de diseño. Cuando este proceso es el resultado de la interacción entre el diseñador y el ordenador, surgen nuevas estrategias que vinculan al diseñador con el potencial de la tecnología computacional.

El modelo es adaptativo y depende del problema a resolver. En el caso el edificio en torre de nueva planta en el Área Metropolitana de Buenos Aires (AMBA), se pretende optimizar la demanda energética. Para ello, se definen una implantación, una normativa local, un programa de necesidades que cuantifique las superficies, los usos de los ocupantes del proyecto, el clima del lugar, la resolución material de la envolvente y su comportamiento térmico. De la autoorganización del conjunto de las variables, a través del proceso de optimización, va a depender el resultado final (ver apartado 2.2).

El mismo modelo se adapta a la rehabilitación energética de un edificio en tira, situado en Sevilla, optimizando la envolvente a los efectos de disminuir la demanda energética y la factibilidad financiera de la inversión necesaria en eficiencia.

Ambos casos se encuentran en climas templados con una latitud, altitud y condiciones climáticas bastante similares, lo que compatibiliza dicha adaptación (Fig. 6.1).

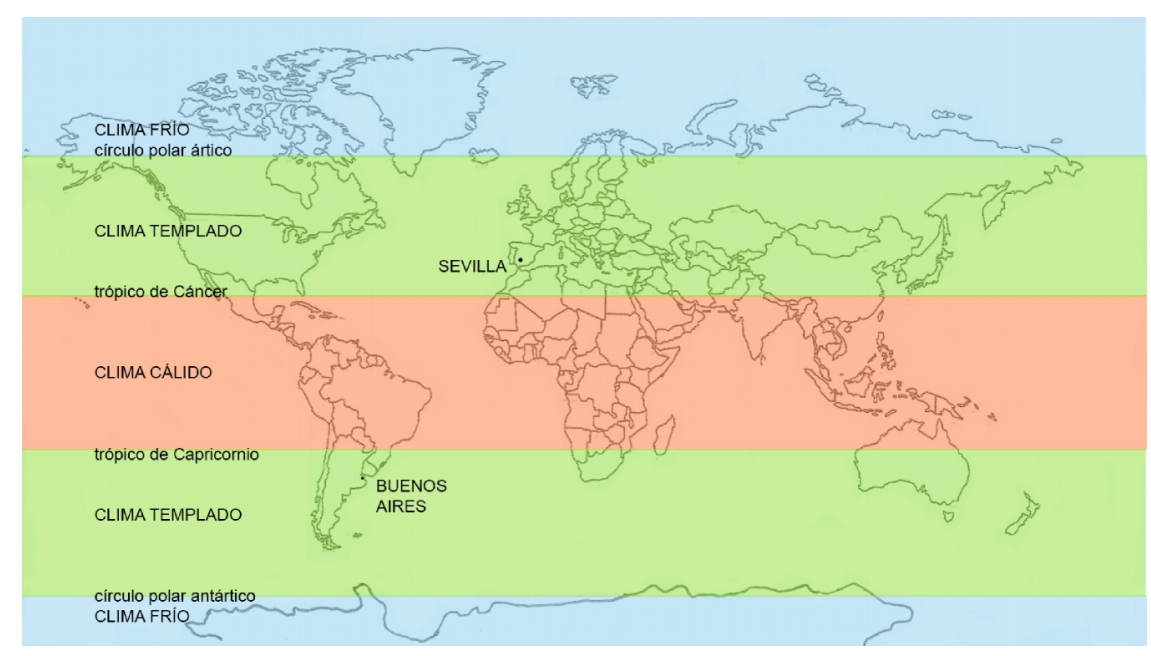

Fig.6.1. Clasificación general de los climas. Fuente: Strahler A. reelaborado por la autora 
Las etapas metodológicas se relacionan entre sí de manera consecutiva, dando lugar cada una a la siguiente y retroaliméntadose. Detallamos a continuación las etapas y las subetapas metodológicas que surgieron a medida que se desarrollaba la investigación en correspondencia con los objetivos planteados en el apartado 5 (Fig. 6.2 y 3).

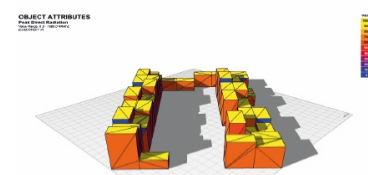

ETAPA 1:

Diseño del modelo bioambiental paramétrico

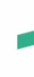
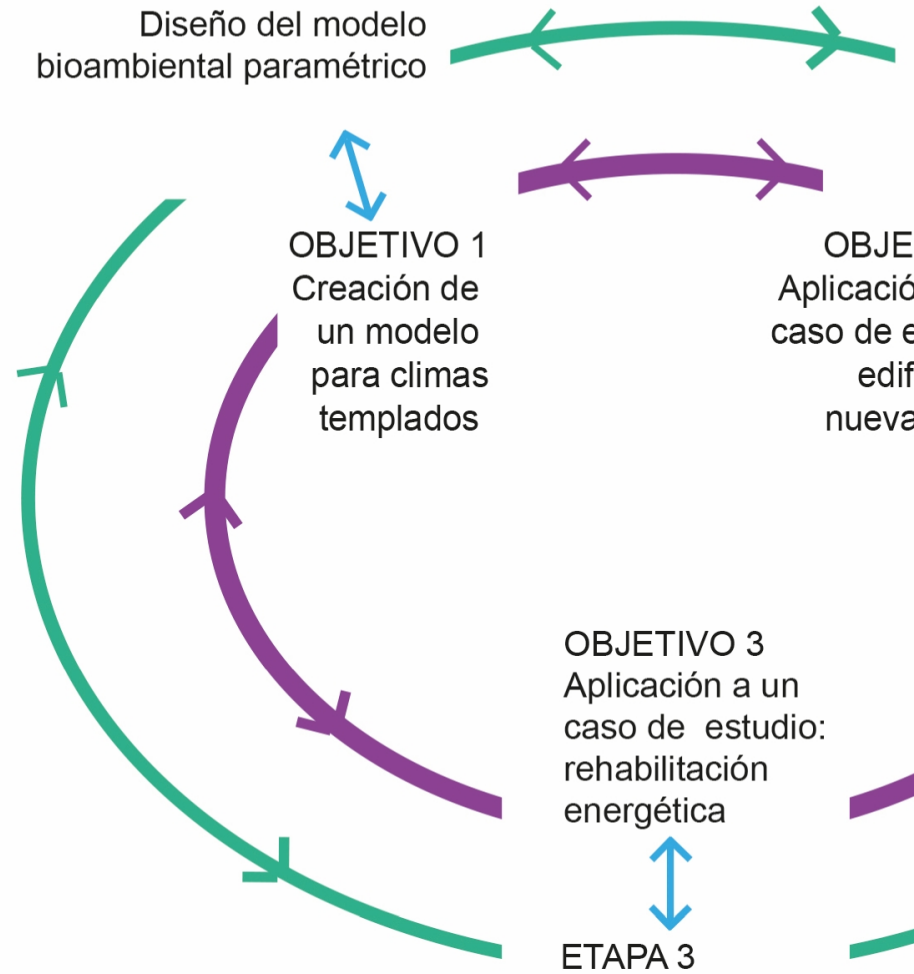

ETAPA 3

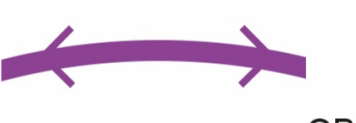

\section{OBJETIVO 2}

Aplicación a un

caso de estudio:

edificio de

nueva planta
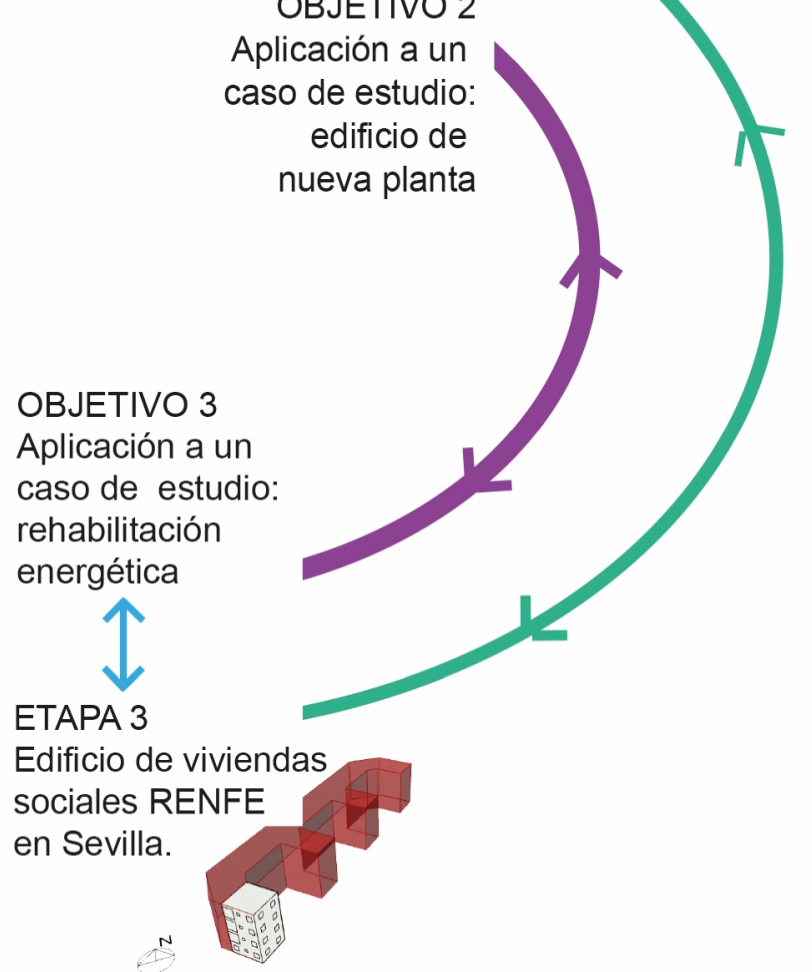

sociales RENFE

en Sevilla.

Edificio en torre

Área Metropolitana

de Buenos Aires

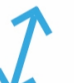

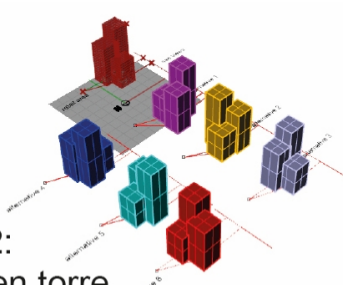

Fig. 6.2: Objetivos y etapas metodológicas en la retroalimentación de las etapas de la investigación.

Fuente: la autora

- Etapa 1: Diseño de un modelo bioambiental paramétrico para climas templados que integre las variables en un programa adaptativo, que se conforma de dos instancias: y estructura.

- Subetapa 1.1: Génesis del modelo del modelo bioambiental paramétrico.

- Subetapa 1.2: Estructuración de los datos en un flujo de trabajo. 
- Etapa 2: Aplicación del modelo a un edificio de nueva planta: Torre en el Área Metropolitana de Buenos Aires. Se organiza de la siguiente manera:

- Sub-etapa 2.1: Datos de entrada climáticos, normativos, operativos y materiales: se incorporaron los datos de entrada y se implementaron los procesos de cálculo de los rangos de dichas variables. Estos datos eran heterogéneos en su naturaleza y exigían una sistematización; por ello se los dividió en las siguientes categorías:

- físicos: dimensiones y características de la parcela de terreno donde se implanta el edificio, orientación, relieve, factores del entorno que incidan sobre el edificio

- funcionales: usos y programa de necesidades

- normativos: restricciones normativas, que afectan a dicha parcela: superficie construible permitida, altura máxima, retiros perimetrales, densidad de habitantes/ha, usos permitidos, normas de eficiencia energética: límites de transmitancia térmica de la envolvente, infiltración, ocupación, iluminación, temperaturas de confort de invierno y verano.

- geométricos: tipología edilicia. número y altura de las plantas, relación vidriado/opaco

- climáticos: temperaturas horarias medias de invierno y verano y radiación solar, viento, humedad,

- materiales: composición de los cerramientos opacos y vidriados, transmitancias térmicas, absortancia de las superficies, estanqueidad de las aberturas

- equipamiento: iluminación, sistemas de refrigeración y calefacción.

- Sub-etapa 2.2.: Estructuración del modelo a los efectos del cálculo de los coeficientes e índices:

- determinación geométrica: la forma del edificio en planta y topológica: las leyes de agrupamiento de los diferentes volúmenes que lo componen

- cálculo de la infiltración de aire según la altura de los pisos del edificio, en función de la variación del viento

- integración de los datos de entrada del cálculo de los coeficientes volumétricos de calefacción y refrigeración (IRAM, 2001) (IRAM, 2004) (IRAM, 2007) e índices bioclimáticos diseñados ad hoc: demanda de calefacción para un día típico de invierno y de refrigeración para un día típico de verano, además de la demanda de calefacción para la hora pico solar. Los índices se calcularon por unidad de volumen y de superficie del edificio.

- Sub-etapa 2.3. Determinación de los parámetros internos del algoritmo genético en función de la morfología edilicia, la composición de la envolvente y el área de 
acristalamiento según la orientación de cada fachada. Se obtuvieron los siguientes resultados:

- coeficientes volumétricos de calefacción según la norma IRAM 11604 (IRAM, 2001) y refrigeración según las normas 116591 y 2 (IRAM, 2004) (IRAM, 2007).

- índice bioclimático de refrigeración que computa la demanda energética horaria de un día típico de verano: ganancias de los cerramientos opacos, utilizando la temperatura sol-aire, ganancias internas y ganancia solar de los cerramientos transparentes.

- índice bioclimático de calefacción que computa la demanda energética horaria de un día típico de invierno: ganancias de los cerramientos opacos, utilizando la temperatura sol-aire, y ganancias internas, de las que se deducen las ganancias solares de los cerramientos transparentes.

- carga térmica de la hora pico solar en invierno para verificar la posibilidad de excedente de calor para almacenamiento en masa térmica.

Asimismo, se validaron los resultados mediante la simulación de un sector edilicio con EnergyPlus. Este software de libre descarga fue elegido luego de una exhaustiva búsqueda bibliográfica que mostró su uso por parte de destacados grupos de investigación pertenecientes a las siguientes instituciones: Massachussets Institute of Technology (MIT), Portugal Sustainable Energy Systems (Granadeiro, Correia, Leal, \& Duarte, 2013), Harvard Graduate School of Design (GSD) (Jakubiec, A. \& Reinhardt, C., 2011), Cornell University (Dogan, Reinhart, \& Michalatos, 2016), Ecole Polytechnique Fédérale de Lausanne (Nembrini, Samberger, \& Labelle, 2014) y (Universidad Politécnica de Catalunya (Fonseca i Casas, Fonseca i Casas, GarridoSoriano, \& Casanovas, 2014) entre otras.

- Etapa 3: Aplicación del modelo a un edificio existente: bloque de viviendas RENFE en Sevilla. Al igual que en el apartado anterior, comprende los datos de entrada del modelo y su procesamiento a los efectos de obtener las mejores soluciones desde el punto de vista energético, agregando la factibilidad financiera. Se ingresan los datos de entrada climáticos, normativos, operativos y materiales. Se adaptó el modelo a esta localización con sus condiciones climáticas, temperatura ${ }^{123}$, radiación solar ${ }^{4}, y$

\footnotetext{
${ }^{1}$ Agencia Estatal de Meteorología. Ministerio de Agricultura y Pesca, Alimentación y Medio Ambiente. Gobierno de España. Consultado el 2/2/17:

http://www.aemet.es/es/serviciosclimaticos/datosclimatologicos/valoresclimatologicos

2 Datos horarios de la estación Sevilla Aeropuerto de Weather Underground. Consultado el 10/2/17:https://www.wunderground.com/history/airport/LEZL/2015/7/2/DailyHistory.html?req_city=\&req state $=\&$ req statename $=\&$ reqdb.zip $=\&$ reqdb. magic $=\&$ reqdb. $w m o=\& M R=1$

${ }^{3}$ Guía 007 Frecuencias horarias de repetición en temperaturas. Intervalo 24horas. Instituto para la Diversificación y Ahorro de la Energía. Ministerio de Energía, Turismo y Agenda Digital. Gobierno de 114
} 
morfología de la envolvente del edificio existente. Para el cálculo de la rehabilitación, se utilizaron los datos de la Base de Costes de la Construcción de Andalucía ${ }^{5}$. Luego se procede a la obtención de la envolvente edilicia optimizada (AG) (Granadeiro, Pina, Duarte, Correia, \& Leal, 2013), mediante un AG, minimizando su demanda energética a través de índices bioclimáticos y calculando la misma mediante el programa de simulación térmica EnergyPlus. Luego se optimizaron las soluciones obtenidas, a través de un ranking de Pareto (Karmellos, Kiprakis, y Mavrotas 2015), compatibilizando la eficiencia energética y la factibilidad financiera.

Españahttp://www.idae.es/uploads/documentos/documentos_Guia_007_Frecuencias_horarias_repeti cion_en_temperatura_Intervalo_24_h_a7945051.pdf

${ }^{4}$ Datos horarios de radiación de la Estación Lebrija 2. Consultado el 10/2/17:

http://www.agenciaandaluzadelaenergia.es/Radiacion/radiacion1.php

${ }^{5}$ BCCA. Base de Costes de la Construcción de Andalucía consultado el 5/12/16:

http://www.juntadeandalucia.es/fomentoyvivienda/portal-web/web/areas/vivienda/texto/706e4686-

1fbd-11e0-89b8-998a90d310ed 


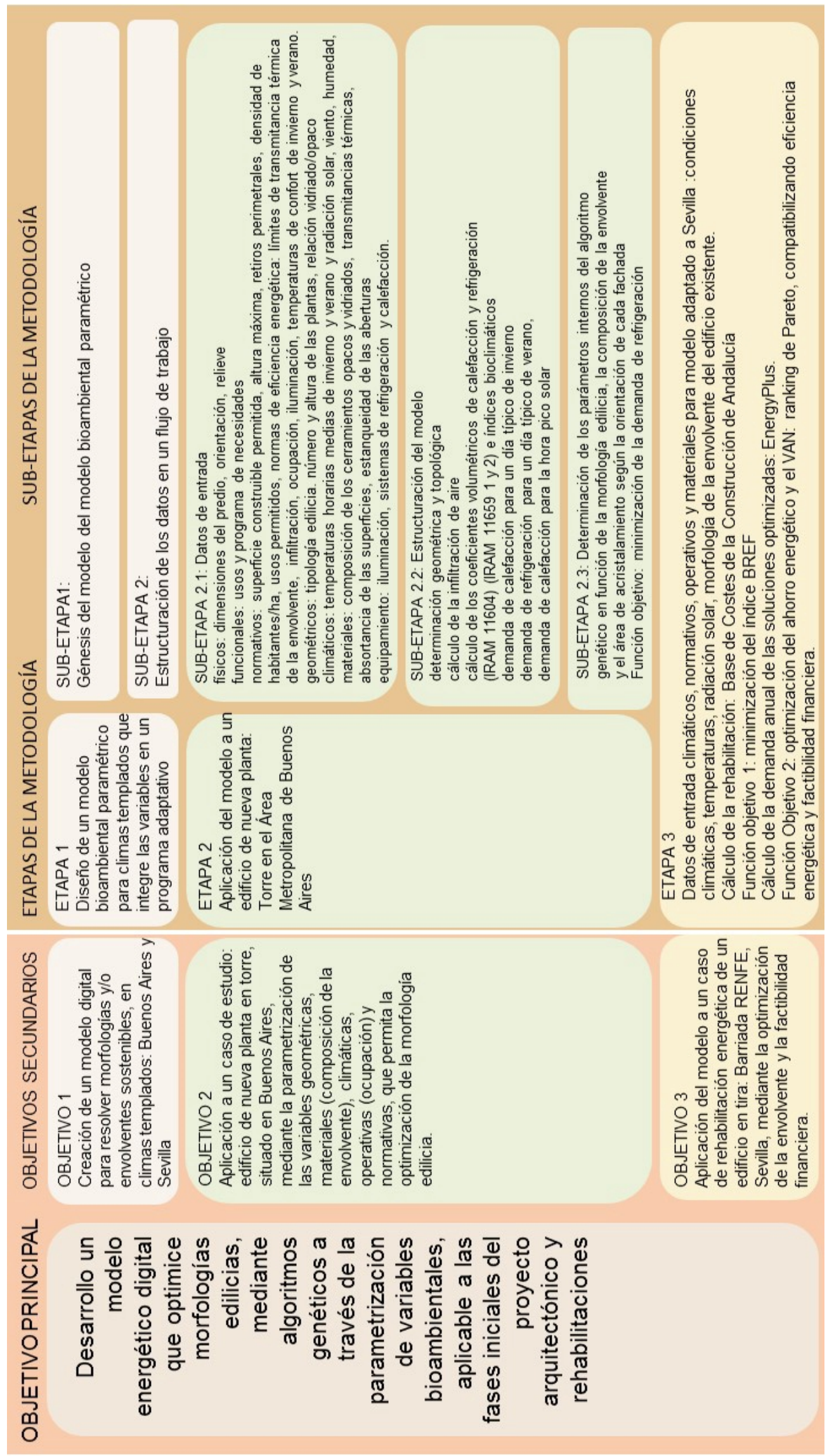

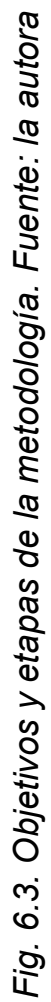


7. Etapa 1: Diseño del modelo bioambiental paramétrico 
El uso de algoritmos genéticos aplicados al diseño bioambiental paramétrico 


\subsection{Génesis del modelo bioambiental paramétrico}

Los objetivos fueron definiéndose a medida que el desarrollo del modelo avanzaba. Una vez elegido el software a emplear, se comenzó por parametrizar las variables geométricas de una morfología edilicia, implantada en un terreno urbano y sujeta a las normas de edificación vigentes. De esta manera, se buscó continuar con la línea de investigación iniciada con el programa EnergoCad (Czajkowski, J. \& Rosenfeld, E., 1992) trabajando con la morfología edilicia urbana pero, en este caso, sin una base de tipologías.

Se pretendía un indicador de eficiencia energética que vinculara morfología edilicia y demanda energética, y se decidió la parametrización del cálculo del Coeficiente Volumétrico de Calefacción $\mathrm{G}_{\mathrm{CAL}}(\mathrm{IRAM}, 2001)$. Este coeficiente considera un estado estacionario y calcula la demanda energética anual de calefacción por el método de los grados-días. Otros autores ya habían utilizado un modelo similar y su optimización mediante un AG (Murray, Walsh, Kelliher, \& O’Sullivan, 2014), demostrando la viabilidad de ese procedimiento.

A continuación, se incorporó el cálculo del Coeficiente volumétrico de Refrigeración $\mathrm{G}_{\mathrm{R}}$ (IRAM, 2004) (IRAM, 2007). El problema se planteaba al querer vincularlos ya que, éstos no son comparables entre sí porque mientras el $\mathrm{G}_{\mathrm{CAL}}$ no considera las ganancias internas y solares, el $\mathrm{G}_{\mathrm{R}}$, calcula la demanda de refrigeración para la hora pico solar, considerando dichas ganancias. No se podía vincularlos como un cociente (Turrin, von Buelow, \& Stouffs, 2011) entre ambos porque se buscaba la minimización de los dos coeficientes A su vez, no había un registro de los

grados días de refrigeración para el cálculo de la demanda. Ninguno de los coeficientes GAL $_{\text {y }}$ $G_{R}$ tomaba en cuenta la incidencia de la radiación solar sobre la superficie de los elementos opacos - considerando su absortancia- y su incremento en la temperatura exterior (temperatura sol-aire).

Conceptualmente, $G_{C A L}$ y $G_{R}$ no son comparables. Para poder evaluar la sostenibilidad de un edificio era necesario poder considerar la condición de invierno y verano simultáneamente, ya que un desempeño óptimo para el invierno podría no serlo para el verano. También se buscaba determinar si una de las condiciones primaba sobre la otra, transformando una de las variables en dependiente de la otra.

Fue por los motivos antes enunciados, que se decidió confeccionar nuevos índices de demanda de calefacción y refrigeración que consideraran la temperatura sol-aire, las ganancias solares e internas para el cálculo de la demanda, tomando como período de estudio un día típico de invierno y otro de verano. Esto permite la comparación de ambas demandas y la obtención de indicadores para mejorar aquellos aspectos que mayor incidencia tengan sobre la demanda 
energética. La definición de los parámetros es determinante para el funcionamiento del modelo y dependerá del objetivo propuesto en cada caso, al igual que el rango.

Esta parametrización permite que el diseñador pueda así obtener alternativas formales, sin salir del entorno CAD elegido. Se opera sobre la definición morfológica y material de la envolvente arquitectónica, a través de su optimización mediante algoritmos genéticos (AGs). La posibilidad de cuantificación de la demanda energética es lo que la convierte en un objetivo alcanzable, en un proceso de optimización. El programa itera, manteniendo constante la materialidad de la envolvente y el porcentaje de elementos vidriados, solo sobre la morfología edilicia. Esto diferencia este trabajo de otros, donde la optimización es aplicada a varias morfologías definidas en una etapa anterior (Caldas \& Norford, 2002).

\subsection{Estructura del modelo}

El modelo digital se divide en tres instancias: (Fig. 5.1):

- los datos de entrada o inputs:

- el procesamiento de los datos y su optimización

- los datos de salida u outputs

Cada uno de los tipos de datos o procesos están representados de acuerdo a la convención para diagramas de flujos: para el inicio y finalización del proceso: elipses, datos de entrada: paralelogramos, círculos: conectores entre pasos alejados del diagrama, rectángulos: procesos computacionales, decisiones alternativas: rombos, datos de salida: rectángulos de borde inferior curvo. Se le ha asignado un color diferente a cada forma geométrica para una mejor visualización según las referencias de la Fig.7.1.

\subsubsection{Datos de entrada}

Los datos de entrada se van introduciendo a lo largo del proceso de cálculo, indicados en el diagrama de flujo con paralelogramos de color azul, como se especificara en el apartado anterior. Dentro de los datos de entrada, que se van introduciendo en distintas etapas del proceso, podemos distinguir: 


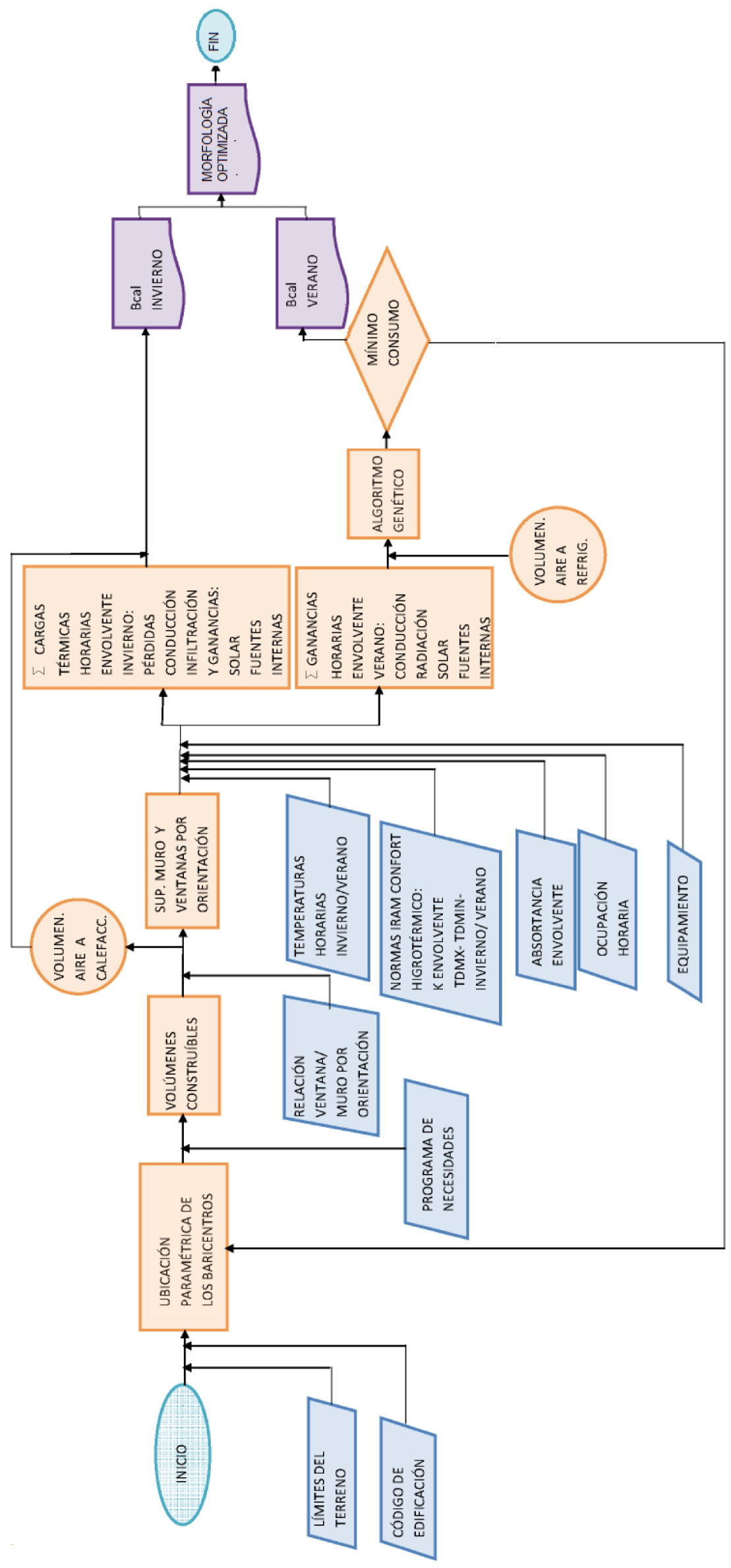


- Constantes

- dimensiones del terreno

- restricciones normativas

- programa de necesidades: usos, ocupación

- datos climáticos

- Variables

- relación vidriado/opaco por fachada

- características térmicas de los componentes de la envolvente

- dimensiones de las masas que conforman el edificio manteniendo un rango de superficie útil efectiva

- ubicación de las masas en el terreno, respetando las restricciones normativas

Durante el proceso se generan nuevos datos que se utilizarán para obtener los resultados optimizados, como la infiltración, las ganancias internas, solares y por transmisión de la envolvente. Se pueden, asimismo, clasificar los parámetros de acuerdo a su función dentro del proceso de optimización. Existen parámetros que alimentan el algoritmo genético, los genes, que son los datos de entrada variables enunciados. Los parámetros dependientes de los procesos de cálculo son aquéllos derivados del empleo de los genes y los datos constantes. Estos últimos constituyen los parámetros fijos.

Dentro de los datos de entrada, están las normas y códigos locales que determinan los niveles mínimos de eficiencia para cada elemento que constituye la envolvente, así como la observación de las reglas del arte en los aspectos constructivos. Asimismo, en el caso de un edificio de nueva planta, deben incorporarse las restricciones de ocupación del terreno: máxima altura, máximo volumen edificable, máxima superficie edificable por planta, retiros perimetrales, máxima densidad habitacional y otras que dependerán de cada caso en particular.

Otros datos son los climáticos locales, que incluyen temperaturas medias horarias, velocidad media del viento, humedad relativa media mensual y radiación media horaria par los meses de julio y enero, tanto para el caso de Buenos Aires como para el de Sevilla, correspondiéndose con los meses típicos de invierno y verano.

Los datos del edificio son las superficies asignadas a cada uso, la densidad habitacional, los horarios de ocupación, la intensidad lumínica, y el equipamiento a considerar. Los datos referentes a la envolvente comprenden la transmitancia térmica de los diferentes elementos que la integran, el porcentaje de vidriado-opaco de las fachadas, la estanqueidad y el factor solar de las carpinterías, y la absortancia de los elementos opacos. Los datos geométricos del edificio 
7. Etapa 1: Diseño del modelo bioambiental paramétrico son las dimensiones de cada sólido, las alturas de cada uno de ellos, la altura de cada planta, la situación en el terreno y su agrupamiento. En el caso de rehabilitación energética de un edificio existente, se opera sobre la aislación a adicionar a la envolvente y el reemplazo de sus carpinterías por otras eficientes, sin variar la relación vidirado-opaco ni las dimensiones del edificio y su situación relativa al terreno o entre los sólidos que lo compusieran.

\subsubsection{Procesamiento de los datos}

Con los datos de entrada, se dibuja la morfología edilicia de manera paramétrica, determinando los rangos que permitan la ocupación por planta y la altura deseadas, la implantación en el terreno y el agrupamiento de los sólidos, para edificios de nueva planta. Si se trata de una rehabilitación energética, se dibuja la morfología del edificio existente.

Se calculan los coeficientes volumétricos y los índices bioclimáticos de calefacción y refrigeración (Camporeale, P. \& Czajkowski, J., 2016), mediante la iteración de un algoritmo genético que minimiza la demanda energética y se varía la morfología edilicia y la relación vidriado/opaco, dentro de los límites previamente establecidos. En las rehabilitaciones energéticas, se itera el espesor de las aislaciones de muros y techo, junto con diferentes tipos de carpinterías.

Se incorpora la factibilidad financiera en el caso de estudio de rehabilitación energética ampliando así la optimización a este aspecto.

\subsubsection{Resultados}

Se obtienen alternativas morfológicas de desempeño energético equivalente que facilitan la tarea del diseñador al proporcionar un número mayor de opciones al que obtendría a través de un procedimiento tradicional. En una segunda instancia, se optimizan las alternativas de acuerdo a su desempeño financiero, habiéndolo experimentado solamente, para el caso de estudio de la rehabilitación energética. 
El uso de algoritmos genéticos aplicados al diseño bioambiental paramétrico 


\section{Etapa 2. Edificio de nueva planta en el área metropolitana de Buenos Aires. Sub-etapa 2.1: Datos de entrada}


8. Etapa 2. Edificio de nueva planta en el área metropolitana de Buenos Aires. Sub-etapa 2.1: Datos de entrada 


\subsection{El edificio}

\subsubsection{Implantación}

El edificio está implantado en una parcela de terreno del Área Metropolitana de Buenos Aires (AMBA). Este área alberga el 36,75 \% de la población del país y junto con la Ciudad de Buenos Aires forman la tercera megalópolis de Latinoamérica. Su población asciende a 14.839.746habitantes (INDEC, 2010) (Fig. 8.1). Está formada por CABA y 24 partidos o departamentos.

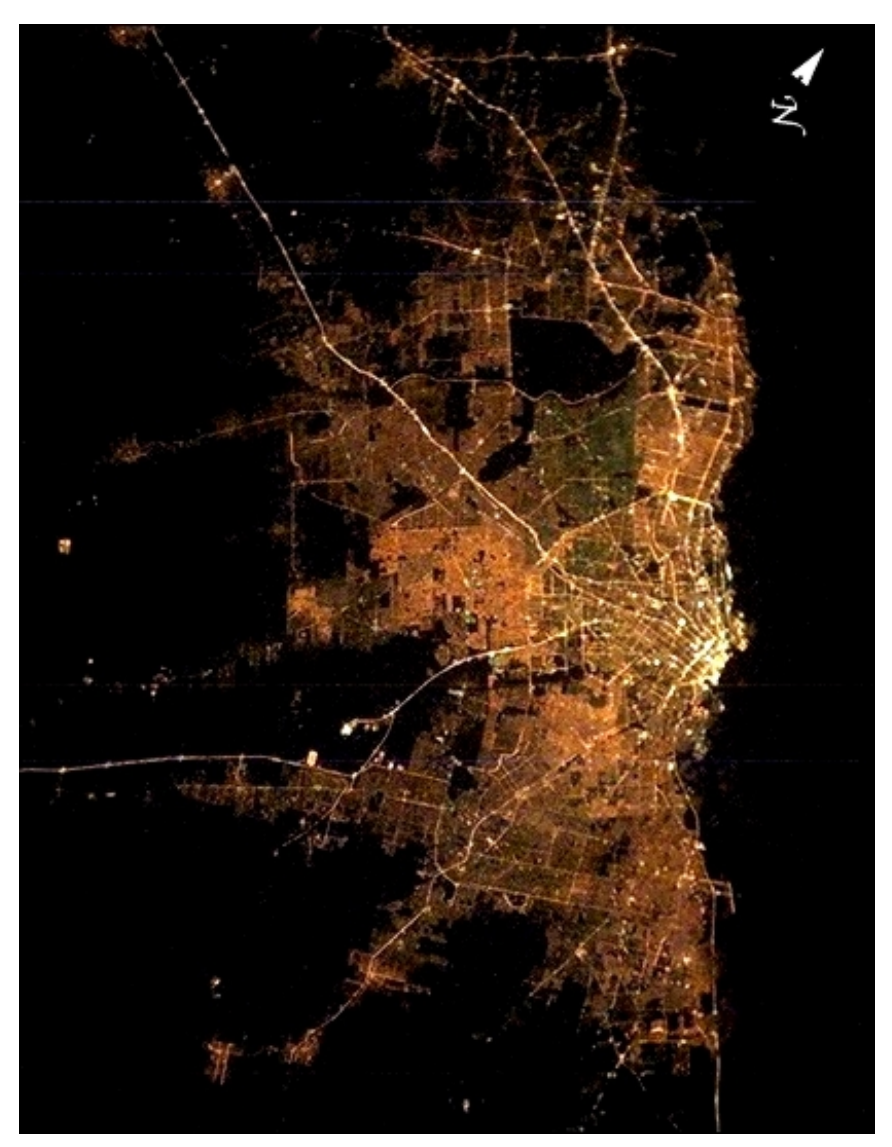

Fig.8.1. Área metropolitana de Buenos Aires. Fuente: Image Science \& Analysis Laboratory, NASA Johnson Space Center - ${ }^{1}$

El Código de Planeamiento Urbano de la Ciudad de Buenos Aires (Gobierno de la Ciudad Autónoma de Buenos Aires, 2016), así como también las ordenanzas de los municipios que integran el Área Metropolitana de Buenos Aires (AMBA), regulan la ocupación del suelo en función de la zonificación del territorio. El Factor de Ocupación del Suelo (FOS) determina la

\footnotetext{
${ }^{1}$ Disponible en http://eoimages.gsfc.nasa.gov/images/imagerecords/3000/3295/ISS006-E-24987.JPG NASA - http://eol.jsc.nasa.gov/, Dominio público, https://commons. wikimedia.org/w/index. php?curid=3473857 128
} 
8. Etapa 2. Edificio de nueva planta en el área metropolitana de Buenos Aires. Sub-etapa 2.1: Datos de entrada

superficie máxima en planta del edificio, incluyendo las proyecciones y superficies semicubiertas (galerías, balcones). El Factor de Ocupación Total (FOT) determina la superficie total del edificio, sumando todas las plantas. La zona donde se implanta el caso de análisis posee un FOS igual a $60 \%$ de la parcela y un FOT, de $500 \%$. La densidad es de 1000 hab/ha para vivienda y 2000 hab/ha para uso comercial/terciario. El coeficiente de hacinamiento es de $25 \mathrm{~m} 2 /$ hab para vivienda, $12 \mathrm{~m} 2 /$ hab para oficina y $18 \mathrm{~m} 2 /$ hab para el uso mixto de vivienda y oficina.

El terreno tiene 50m de lado, orientación Norte, rodeado por tres calles y junto al Río de la Plata (Fig. 8.2), en un área de futuro desarrollo urbano en el AMBA. Los retiros perimetrales de la línea de edificación son de $4 \mathrm{~m}$, así como también el retiro de fondo.

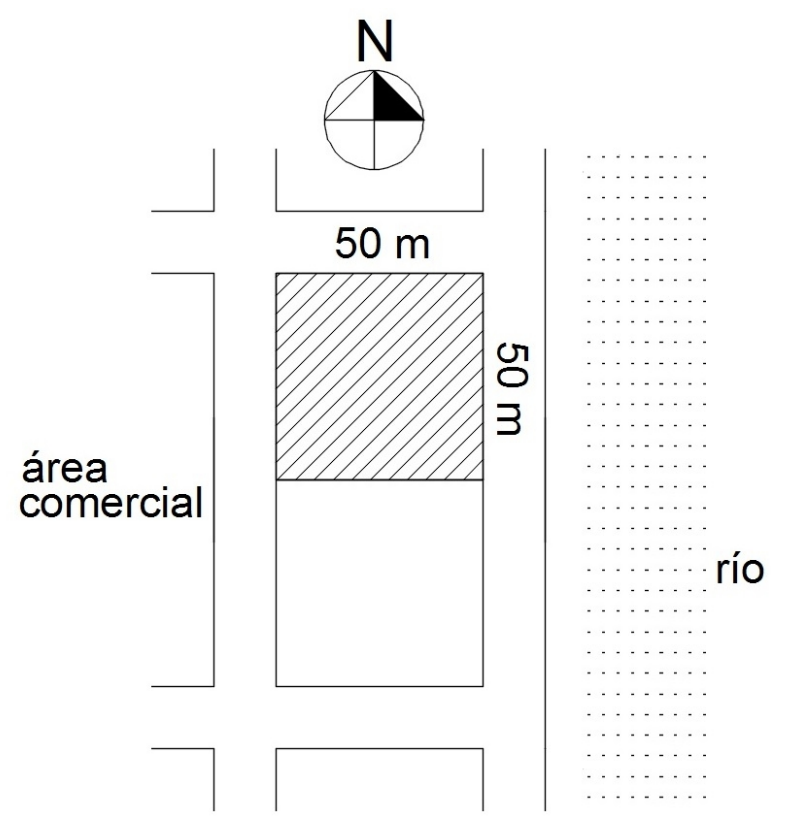

Fig. 8.2: Implantación del edificio. Fuente: la autora

En la Tabla 8.1, se pueden observar los indicadores urbanísticos según la zona y según el proyecto.

\begin{tabular}{|c|c|c|c|c|c|c|c|c|c|c|c|}
\hline \multirow{3}{*}{\multicolumn{2}{|c|}{$\begin{array}{c}\text { sup. } \\
\text { terreno } \\
\text { m2 }\end{array}$}} & \multirow{3}{*}{$\begin{array}{c}\text { FOS } \\
\%\end{array}$} & \multicolumn{3}{|c|}{ FOT } & \multirow{2}{*}{\multicolumn{3}{|c|}{$\begin{array}{l}\text { densidad } \\
\text { hab/ha }\end{array}$}} & \multirow{2}{*}{\multicolumn{3}{|c|}{$\begin{array}{l}\text { hacinamiento } \\
m^{2} / h a b\end{array}$}} \\
\hline & & & \multirow[t]{2}{*}{$m 2$} & \multirow[t]{2}{*}{$\%$} & \multirow[t]{2}{*}{$m 2$} & & & & & & \\
\hline & & & & & & vivienda & oficina & $\begin{array}{c}\text { uso } \\
\text { mixto }\end{array}$ & vivienda & oficina & uso mixto \\
\hline s/zona & 2500 & 60 & 1500 & 500 & 12500 & 1000 & 2000 & 1500 & 25 & 12 & 18,5 \\
\hline s/proy & 2500 & 32 & 800 & 470 & 11750 & 1000 & 2000 & 1500 & 25 & 12 & 18,5 \\
\hline
\end{tabular}




\subsubsection{Programa funcional}

Se elaboró un programa de necesidades que contemplara usos diversos. Por tal motivo, éste se compone de viviendas y oficinas, con una superficie asignada a las viviendas de $3000 \mathrm{~m}^{2}$, a las oficinas de $5000 \mathrm{~m}^{2}$ y uso mixto de oficinas y viviendas de $3750 \mathrm{~m}^{2}$. Se decidió una tipología de torre, distribuyendo las actividades en tres volúmenes edilicios agrupados de acuerdo a la Tabla 8.2. Con esta tipología, la ocupación del terreno (FOS) es del $32 \%$ y la ocupación total (FOT) del $470 \%$. Dichos valores no superan los máximos permitidos según la zonificación (Tabla 8.1).

\begin{tabular}{|c|c|c|c|c|}
\hline Usos & $\begin{array}{c}n^{\circ} \text { plantas } \\
u\end{array}$ & $\begin{array}{c}\text { superficie / planta } \\
m^{2}\end{array}$ & $\begin{array}{c}\text { H planta } \\
\text { m }\end{array}$ & $\begin{array}{c}\text { H volumen } \\
\text { m }\end{array}$ \\
\hline vivienda & 10 & 300 & 2,80 & 27,5 \\
\hline oficina & 20 & 250 & 2,80 & 55 \\
\hline mixto & 15 & 250 & 2,80 & 41,25 \\
\hline sup. total & & 11750 & & \\
\hline
\end{tabular}

Tabla 8.2. Programa funcional. Fuente la autora

\subsubsection{Transmitancia térmica de la envolvente}

La ley de Eficiencia Energética de la Provincia de Buenos Aires exige que la envolvente del edificio cumpla con el nivel B de la Norma IRAM 11605 (ver apartado 4.2.1.5) para una temperatura de diseño mayor a $0^{\circ} \mathrm{C}$ en invierno. Para el verano, que no es exigible para la ley 13059, adoptamos el mismo nivel B (IRAM 11605) (Tabla 8.3). En cuanto a las carpinterías, consideramos el mayor nivel exigido que es, para alturas mayores a $10 \mathrm{~m}$, (K4) de la Norma IRAM .11507-4 (IRAM, 2010) (ver apartado 4.2.1.1) (Tabla 8.3).

\begin{tabular}{l|c|c}
\multicolumn{1}{c}{ Elemento } & Nivel B IRAM 11605 & K adoptado \\
& $W / \mathbf{m}^{2} \mathbf{K}$ & $W / \mathbf{m}^{2} \mathbf{K}$ \\
\hline Muro (invierno) & $0,38<\mathrm{B} \leq 1$ & 0,71 \\
\hline Muro (verano) & $0,50<\mathrm{B} \leq 1,25$ & 0,71 \\
Cubierta (invierno) & $0,32<\mathrm{B} \leq 0,83$ & 0,51 \\
Cubierta (verano) & $0,19<\mathrm{B} \leq 0,48$ & 0,46 \\
Ventanas & $2<\mathrm{B} \leq 3$ (IRAM 11507-4) & 2,61 \\
\hline Pisos & 1,08 & 1,08 \\
\hline
\end{tabular}

Tabla 8.3. Transmitancia térmica de la envolvente. Fuente: la autora 
La composición de muros y cubiertas para invierno y verano se detallan en las Tablas 8.4, 5, 6 y 7.

\begin{tabular}{|c|c|c|c|}
\hline Norma IRAM 11601 & \multicolumn{3}{|c|}{ CÁLCULO K } \\
\hline PROYECTO & \multicolumn{3}{|c|}{ edificio en altura } \\
\hline ELEMENTO & \multicolumn{3}{|c|}{ muro } \\
\hline ÉPOCA DEL AÑO & invierno & \multicolumn{2}{|c|}{ flujo calor horiz. } \\
\hline ZONA BIOAMBIENTAL & \multicolumn{3}{|c|}{ IIIb } \\
\hline Nivel de confort según IRAM 11605 & \multicolumn{3}{|c|}{ Tmín.D: $1,7^{\circ} \mathrm{C}$} \\
\hline Capa del elemento constructivo & $\begin{array}{c}\text { espesor } \\
\mathrm{m}\end{array}$ & $\begin{array}{c}\text { I } \\
\mathrm{W} / \mathrm{mK}\end{array}$ & $\begin{array}{c}\boldsymbol{R} \\
\mathrm{m}^{2} \mathrm{~K} / \mathrm{W}\end{array}$ \\
\hline Resistencia superficial exterior & & & 0,04 \\
\hline revoque exterior & 0,03 & 1,16 & 0,03 \\
\hline poliestireno expandido dens.: $30 \mathrm{~kg} / \mathrm{m}^{3}$ & 0,025 & 0,032 & 0,78 \\
\hline \multicolumn{4}{|l|}{ barrera de vapor } \\
\hline ladrillo hueco tipo Klimablock & 0,18 & & 0,41 \\
\hline placa de yeso & 0,0125 & 0,45 & 0,03 \\
\hline Resistencia superficial interior & & & 0,13 \\
\hline TOTAL & & & 1,41 \\
\hline $\begin{array}{l}\text { Transmitancia térmica del componente } \\
K\left(W / m^{2} K\right)\end{array}$ & \multicolumn{3}{|c|}{0,71} \\
\hline $\begin{array}{l}\text { Transmitancia térmica K IRAM } 11605 \\
\left(W / m^{2} K\right) \text { nivel B }\end{array}$ & \multicolumn{3}{|c|}{1} \\
\hline
\end{tabular}

Adoptamos valores porcentuales para los vanos según la orientación: $50 \%$ al Norte, $10 \%$ al Sur, $40 \%$ al Este y $30 \%$ al Oeste, de acuerdo a las recomendaciones del Anexo B de la Norma IRAM 11603 (IRAM 11603, 2011). Las carpinterías son de doble vidriado hermético (DVH) de 6mm y cámara de aire de $12 \mathrm{~mm}$ con marco de PVC de cámara simple. La transmitancia térmica (K) es $2.61 \mathrm{~W} / \mathrm{m}^{2} \mathrm{~K}$ y el factor de protección solar es de 0,35.

La absortancia de los materiales (Yañez Parareda, 2008) de la envolvente es la sig.: muros con revoque texturado color blanco: 0.3 , y cubiertas con membrana asfáltica y aluminio: 0.15 . El 
Factor Solar de las ventanas elegidas es de 0,35 y corresponde a doble vidriado hermético de baja emisividad. ${ }^{2}$

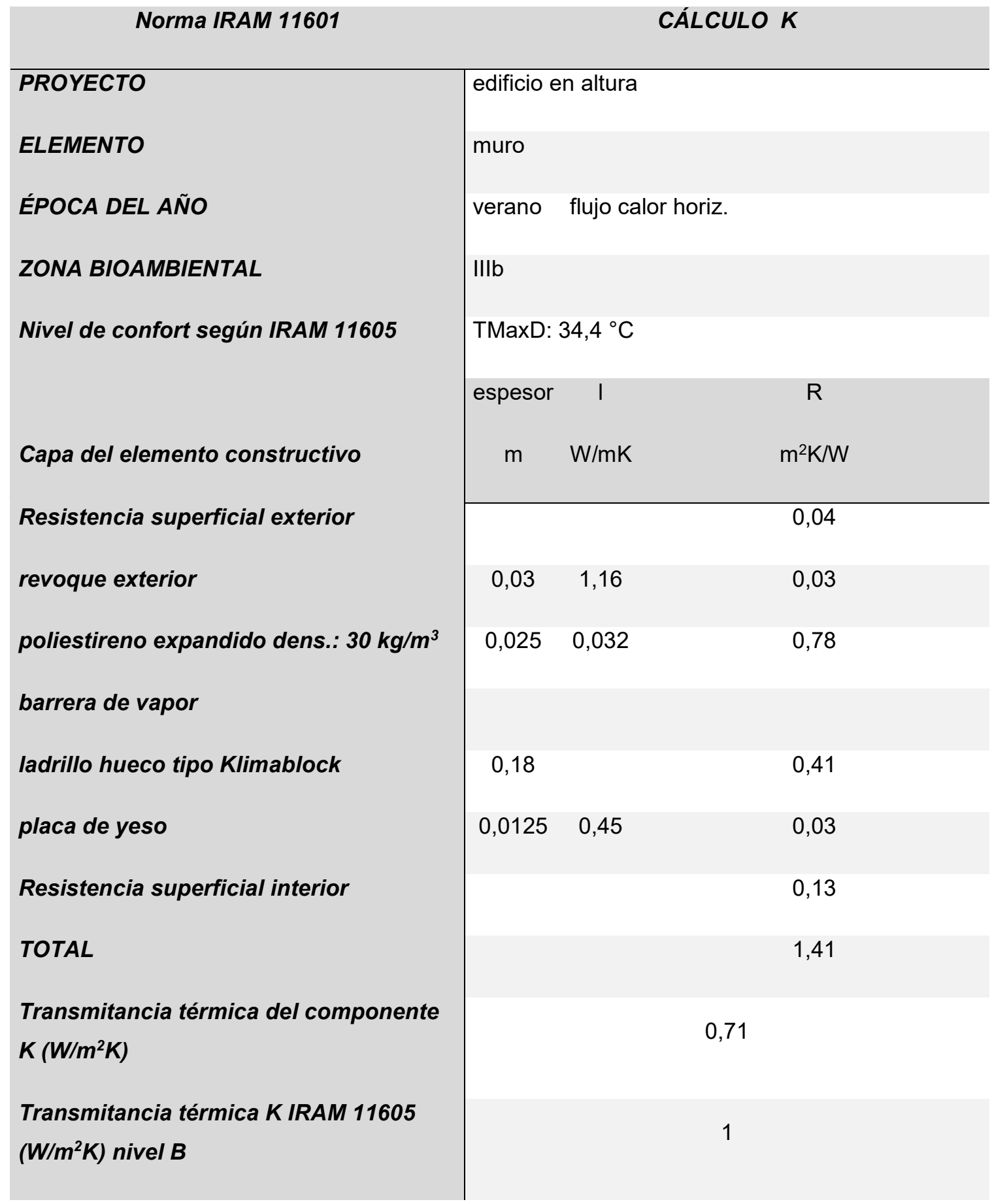

Tabla 8.5: Composición y transmitancia térmica de muro en verano. Fuente: la autora

\footnotetext{
${ }^{2}$ VASA Low-e clima cálido. Consultado el 16/6/16 en: http://www.vasa.com.ar/DocVasa/pdf/Low-E-Flyerv2.pdf 
8. Etapa 2. Edificio de nueva planta en el área metropolitana de Buenos Aires.

Sub-etapa 2.1: Datos de entrada

\begin{tabular}{|c|c|c|c|}
\hline Norma IRAM 11601 & \multicolumn{3}{|c|}{ CÁLCULOK } \\
\hline PROYECTO & \multicolumn{3}{|c|}{ edificio en altura } \\
\hline ELEMENTO & \multicolumn{3}{|c|}{ cubierta } \\
\hline ÉPOCA DEL AÑO & invierno & \multicolumn{2}{|c|}{ flujo calor ascend. } \\
\hline ZONA BIOAMBIENTAL & \multicolumn{3}{|c|}{ IIIb } \\
\hline \multirow[t]{2}{*}{ Nivel de confort según IRAM 11605} & \multicolumn{3}{|c|}{ T.míx.D: $1,7^{\circ} \mathrm{C}$} \\
\hline & espesor & I & $\mathrm{R}$ \\
\hline Capa del elemento constructivo & $\mathrm{m}$ & $\mathrm{W} / \mathrm{mK}$ & $\mathrm{m}^{2} \mathrm{~K} / \mathrm{W}$ \\
\hline Resistencia superficial exterior & & & 0,04 \\
\hline membrana asfáltica & 0,05 & 58 & 0,00 \\
\hline espuma de poliuretano celda ab. & 0,03 & 0,022 & 1,36 \\
\hline carpeta de asiento & 0,05 & 1,13 & 0,09 \\
\hline contrapiso $H^{\circ} P^{\circ}$ & 0,10 & 0,76 & 0,07 \\
\hline capa de compresión $H^{\circ} A^{\circ}$ & 0,05 & 0,97 & 0,12 \\
\hline losa de $H^{\circ}$ alivianado con EPS & 0,12 & 0,44 & 0,11 \\
\hline cielorraso suspendido & 0,03 & 0,49 & 0,06 \\
\hline Resistencia superficial interior & & & 0,10 \\
\hline TOTAL & & & \\
\hline $\begin{array}{l}\text { Transmitancia térmica del } \\
\text { componente } K\left(W / m^{2} K\right)\end{array}$ & & & \\
\hline $\begin{array}{l}\text { Transmitancia térmica K IRAM } 11605 \\
\left(W / m^{2} K\right) \text { nivel B }\end{array}$ & & & \\
\hline
\end{tabular}

Tabla 8.6: Composición y transmitancia térmica de la cubierta en invierno. Fuente: la autora 


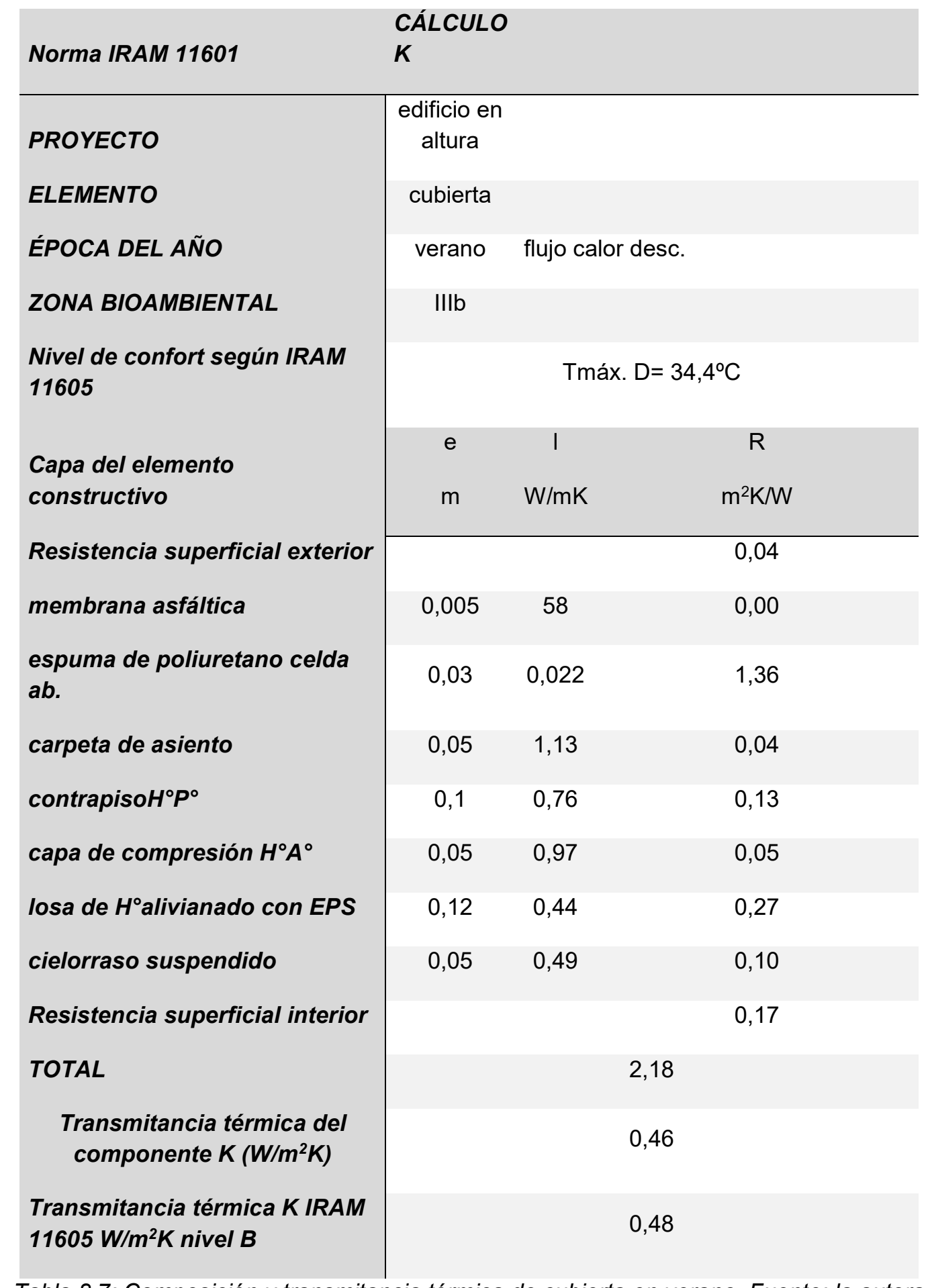

Tabla 8.7: Composición y transmitancia térmica de cubierta en verano. Fuente: la autora 


\subsubsection{Ocupación}

El número de habitantes el edificio fue calculado considerando los índices de hacinamiento previstos en el Código Ambiental vigente en el sector del AMBA: $12 \mathrm{~m}^{2} / \mathrm{hab}$ para oficinas, 25 $\mathrm{m}^{2} / \mathrm{hab}$ para vivienda y $18.5 \mathrm{~m}^{2} / \mathrm{hab}$ para uso mixto (oficinas/ viviendas), lo cual da una densidad de 1392 hab/ha, calculando un promedio ponderado de habitantes.

La ocupación del edificio se discriminó según los usos. Para ello se consideró la jornada laboral de 9 a 18 horas para las oficinas con una ocupación del 100\% y el resto del día sin ocupación. Para las viviendas, se consideró $100 \%$ de ocupación de 18 a 9 horas y un $50 \%$ de ocupación. El sector de uso mixto - viviendas y oficinas - se consideró con una ocupación del $50 \%$ durante todo el día (Tabla 8.8).

El calor sensible para un trabajo de oficina con cierta actividad es igual a $47 \mathrm{~W} /$ persona y el calor latente para la misma actividad, 52 W/persona (Tabla 13, IRAM 11659-1).

\subsubsection{Equipamiento}

Su funcionamiento está relacionado con la ocupación: iluminación y climatización dependerán del número de usuarios que se encuentren en el edificio a cada hora del día.

No se consideran artefactos dentro del equipamiento. La pérdida por conductos de aire acondicionado se fija en el $5 \%$. La energía térmica por unidad de superficie es de $12 \mathrm{~W} / \mathrm{m}^{2}$ para un nivel de 300 lux $/ \mathrm{m}^{2}$ (vivienda y oficina) (Tabla 4, IRAM 11659-1). El coeficiente térmico adoptado es 1,25 correspondiente a iluminación fluorescente (Tabla 5, IRAM 11659-1).

\subsection{Datos climáticos}

\subsubsection{Temperatura}

La temperatura de diseño es la del aire exterior definida para un día típico de diseño de la estación correspondiente que se obtiene estadísticamente sobre la base de un período de diez años y que será superada en severidad en ocho días por año en promedio según lo expresa la norma IRAM 11549 (IRAM, 2002). 


\begin{tabular}{|c|c|c|c|c|c|c|c|}
\hline OCUPACIÓN & & & & & & & \\
\hline tipo & VIVENDA & OFICINA & USO MIXTO & & & & \\
\hline hacinamiento $\mathrm{m} 2 / \mathrm{hab}$ & 25 & 12 & 18,5 & TOTAL & & & \\
\hline superficie & 2819 & $m 2$ & 4698 & $m 2$ & 3524 & $m 2$ & \\
\hline hora & $\%$ & hab. & $\%$ & hab. & $\%$ & hab. & \\
\hline 1 & 100 & 113 & 0 & 0 & 50 & 95 & 208 \\
\hline 2 & 100 & 113 & 0 & 0 & 50 & 95 & 208 \\
\hline 3 & 100 & 113 & 0 & 0 & 50 & 95 & 208 \\
\hline 4 & 100 & 113 & 0 & 0 & 50 & 95 & 208 \\
\hline 5 & 100 & 113 & 0 & 0 & 50 & 95 & 208 \\
\hline 6 & 100 & 113 & 0 & 0 & 50 & 95 & 208 \\
\hline 7 & 100 & 113 & 0 & 0 & 50 & 95 & 208 \\
\hline 8 & 100 & 113 & 0 & 0 & 50 & 95 & 208 \\
\hline 9 & 50 & 56 & 100 & 392 & 50 & 95 & 543 \\
\hline 10 & 50 & 56 & 100 & 392 & 50 & 95 & 543 \\
\hline 11 & 50 & 56 & 100 & 392 & 50 & 95 & 543 \\
\hline 12 & 50 & 56 & 100 & 392 & 50 & 95 & 543 \\
\hline 13 & 50 & 56 & 100 & 392 & 50 & 95 & 543 \\
\hline 14 & 50 & 56 & 100 & 392 & 50 & 95 & 543 \\
\hline 15 & 50 & 56 & 100 & 392 & 50 & 95 & 543 \\
\hline 16 & 50 & 56 & 100 & 392 & 50 & 95 & 543 \\
\hline 17 & 50 & 56 & 100 & 392 & 50 & 95 & 543 \\
\hline 18 & 50 & 56 & 100 & 392 & 50 & 95 & 543 \\
\hline 19 & 100 & 113 & 0 & 0 & 50 & 95 & 208 \\
\hline 20 & 100 & 113 & 0 & 0 & 50 & 95 & 208 \\
\hline 21 & 100 & 113 & 0 & 0 & 50 & 95 & 208 \\
\hline 22 & 100 & 113 & 0 & 0 & 50 & 95 & 208 \\
\hline 23 & 100 & 113 & 0 & 0 & 50 & 95 & 208 \\
\hline 24 & 100 & 113 & 0 & 0 & 50 & 95 & 208 \\
\hline
\end{tabular}


La temperatura mínima de diseño es la obtenida para el invierno y elaborada a partir de las temperaturas mínimas correspondientes a los meses de mayo, junio, julio y agosto, que será superada en severidad en ocho días por año en promedio (Fig. 8.3 y 4) (Anexo 1, tabla A 1.1). La temperatura máxima de diseño es la obtenida para el verano y elaborada a partir de las temperaturas máximas correspondientes a los meses de diciembre, enero, febrero y marzo, que será superada en severidad en ocho días por año en promedio (Fig. 8.5 y 6) (Anexo 1, tabla A 1.2). Las temperaturas mínima y máxima de diseño adoptadas son para invierno, $1,7^{\circ} \mathrm{C}$ y para verano, $34.4^{\circ} \mathrm{C}$ (IRAM, 2012), respectivamente.

Para el cálculo de las temperaturas horarias, se utilizó la base de datos climáticos de la estación meteorológica David Vantage Pro 2, que el LAyHS posee en la localidad de Gonnet conectada - vía internet- a la red de la Universidad de La Plata. Se consideraron los datos de temperatura para los meses de enero y julio desde el año 2009 al 2012 de las horas 6 y 14 y se calcularon las medias máximas y mínimas para los meses de julio y enero de 2009 a 2012, para utilizarlas en el cálculo de la temperatura horaria de un día típico de invierno y otro de verano. Para invierno se obtuvo una media máxima de $12,7^{\circ} \mathrm{C}$ y una media mínima de $5,65^{\circ} \mathrm{C}$. Para verano se obtuvo una media máxima de $28,14^{\circ} \mathrm{C}$ y una media mínima de $20,22^{\circ} \mathrm{C}$.

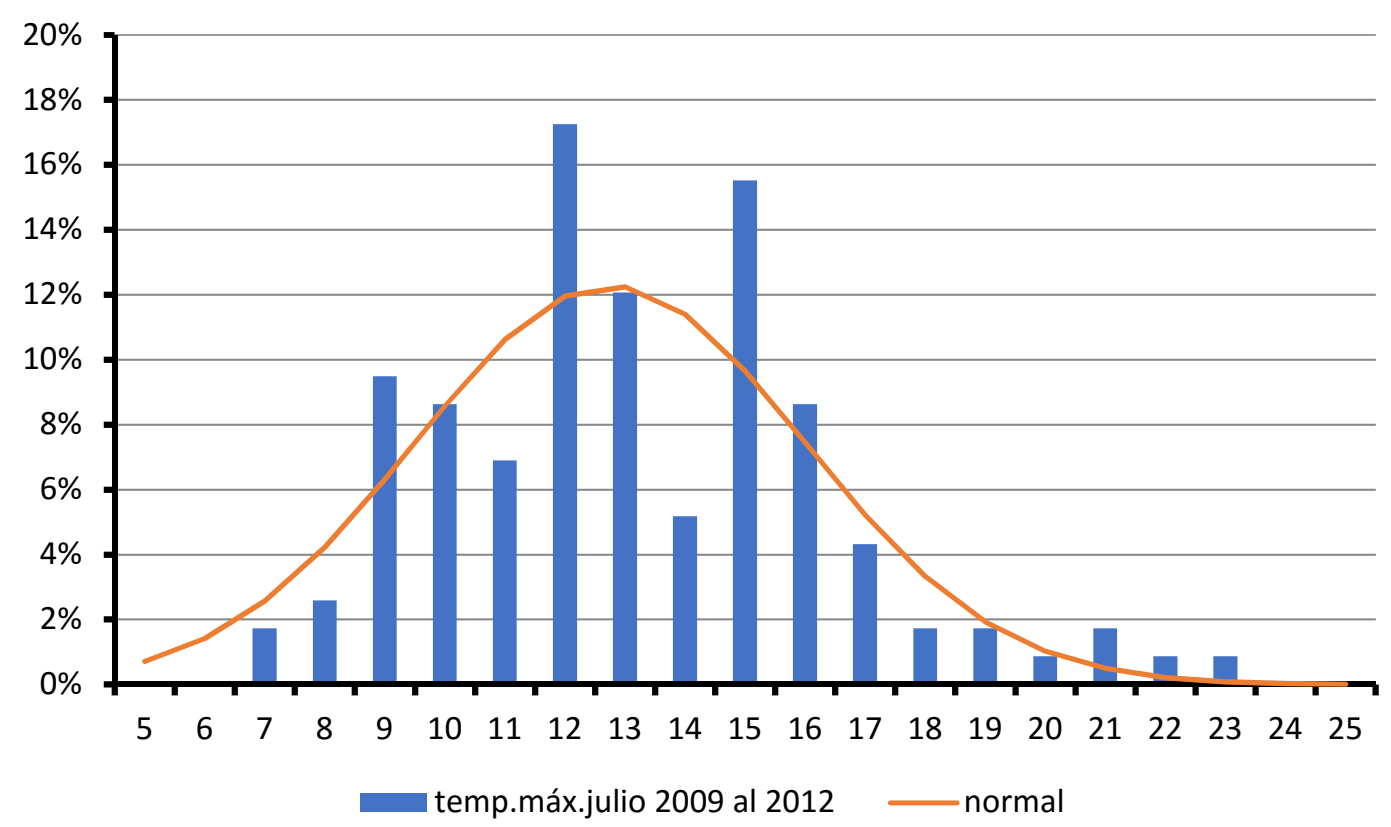

Fig. 8.3. Temperaturas máximas (hora 14) de julio 2009 al 2012. Fuente: la autora 
El uso de algoritmos genéticos aplicados al diseño bioambiental paramétrico

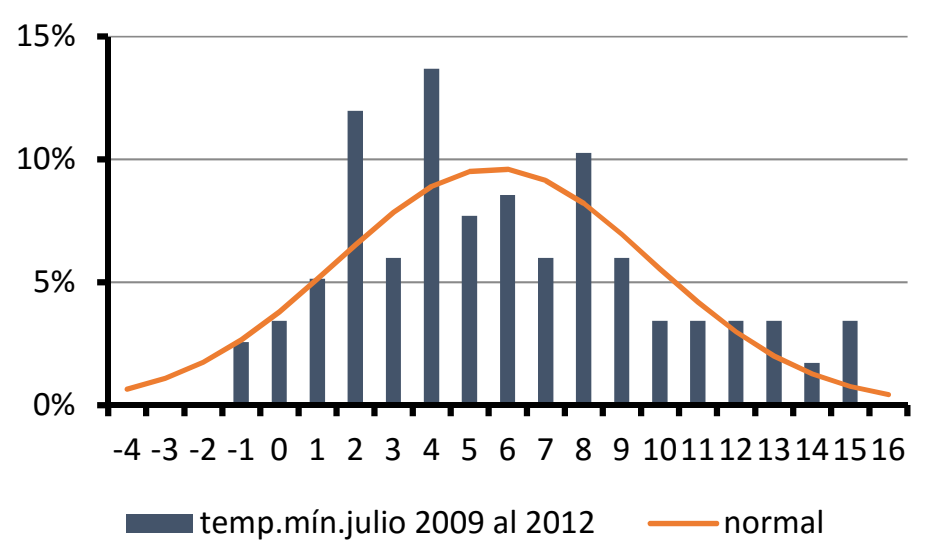

Fig. 8.4: Temperaturas mínimas (hora 6) de julio 2009 al 2012. Fuente: la autora

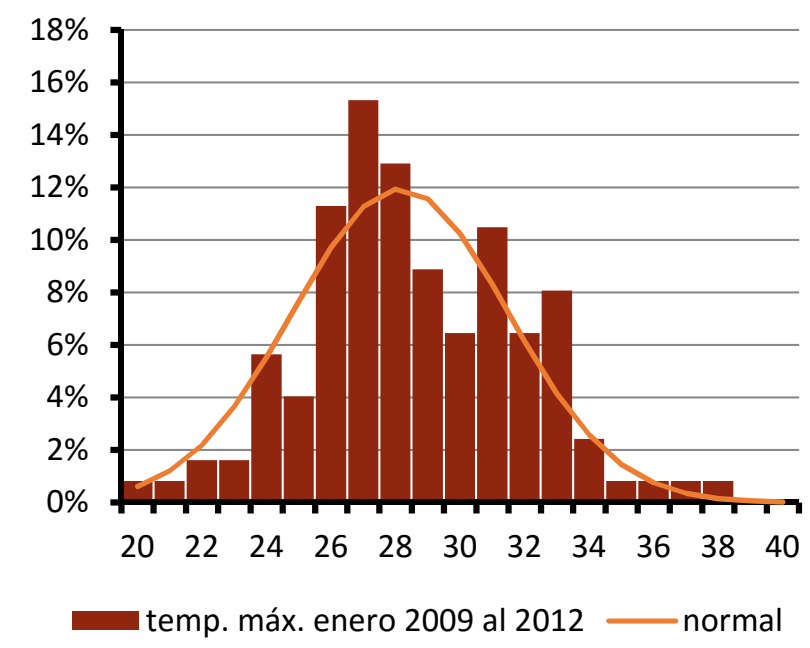

Fig. 8.5: Temperaturas máximas (hora 14) de enero 2009 al 2012. Fuente: la autora

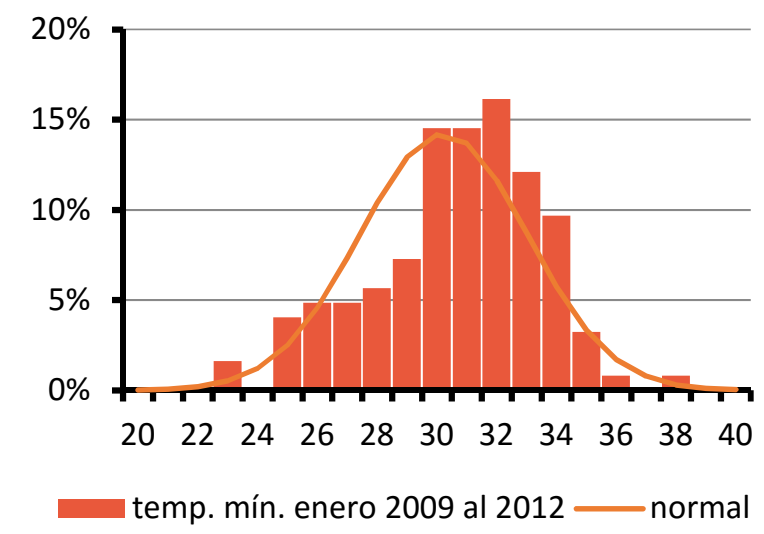

Fig. 8.6: Temperaturas mínimas (hora 6) de enero 2009 al 2012. Fuente: la autora

\subsubsection{Viento}


El viento tiene una incidencia importante cuando se diseñan edificios en altura, ya que, a medida que se asciende, aumenta su velocidad y, por consiguiente, la infiltración a través de las carpinterías. La velocidad del viento para el caso de estudio es de3. $9 \mathrm{~m} / \mathrm{s}(14.1 \mathrm{~km} / \mathrm{h})$ a $10 \mathrm{~m}$ de altura de acuerdo a los datos de la Estación Aeroparque, Bs. As. (IRAM, 2012) para invierno. Se eligieron los datos de esta estación por hallarse al igual que el terreno elegido, frente al Río de la Plata.

\subsubsection{Humedad}

La humedad relativa exterior es de $45 \%$ para una temperatura de diseño de $34.4^{\circ} \mathrm{C}$ y la interior, de $50 \%$ para una temperatura de diseño de $25^{\circ} \mathrm{C}$, en verano. Esto representa una humedad absoluta exterior de $14,9 \mathrm{~g} / \mathrm{Kg}$ de aire seco y una humedad absoluta interior de $10 \mathrm{~g} / \mathrm{Kg}$ de aire seco, según el diagrama psicrométrico, que corresponde a la Fig. 1 de la Norma IRAM 11659-1 (IRAM, 2004). Estos valores de humedad se mantienen para todas las horas del día.

\subsubsection{Radiación solar}

La radiación solar horaria se calcula con el programa ISOL (Evans, J.M. \& Reyes, J., 1995) para invierno y verano, considerando un índice de claridad atmosférica igual a 0,5 (Czajkowski, J. \& Rosenfeld, E., 1992) (Anexo 1, tablas A1.3 y A1.4) (Fig. 8.7 y 8).

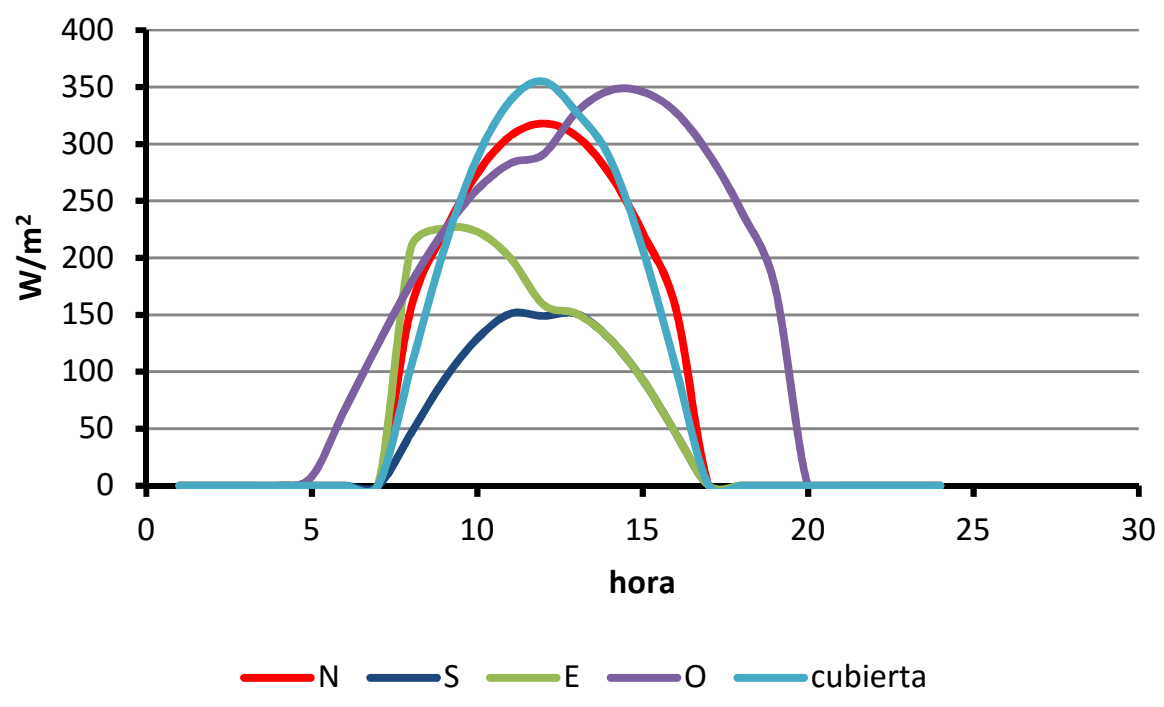

Fig. 8.7: Radiación solar para un día típico de invierno. Fuente: la autora 
El uso de algoritmos genéticos aplicados al diseño bioambiental paramétrico

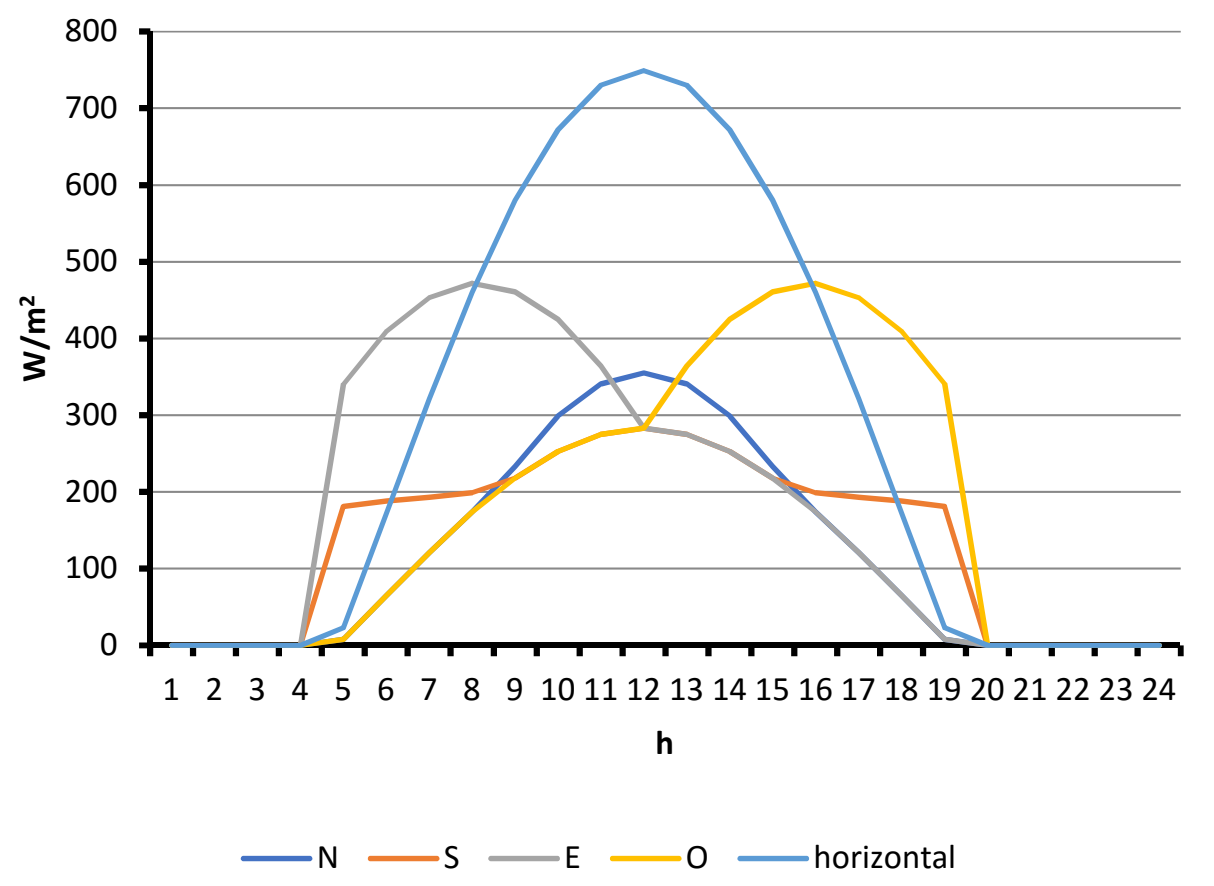

Fig. 8.8: Radiación solar para un día típico de verano. Fuente: la autora 
9. Etapa 2

Edificio de nueva planta en el Área Metropolitana de Buenos Aires. Sub-etapa 2.2. Estructuración del modelo 
El uso de algoritmos genéticos aplicados al diseño bioambiental paramétrico 


\subsection{Determinación de la implantación y la geometría edilicia}

Las dimensiones y orientación del lote son datos invariables que se dibujan en Rhinoceros para luego ser adquiridos por Grasshopper (Fig. 9.1). Las plantas de cada volumen son cuadradas y el número de pisos surge del cociente entre la superficie total del volumen y la superficie de la planta de cada volumen (ver Tabla 8.2).

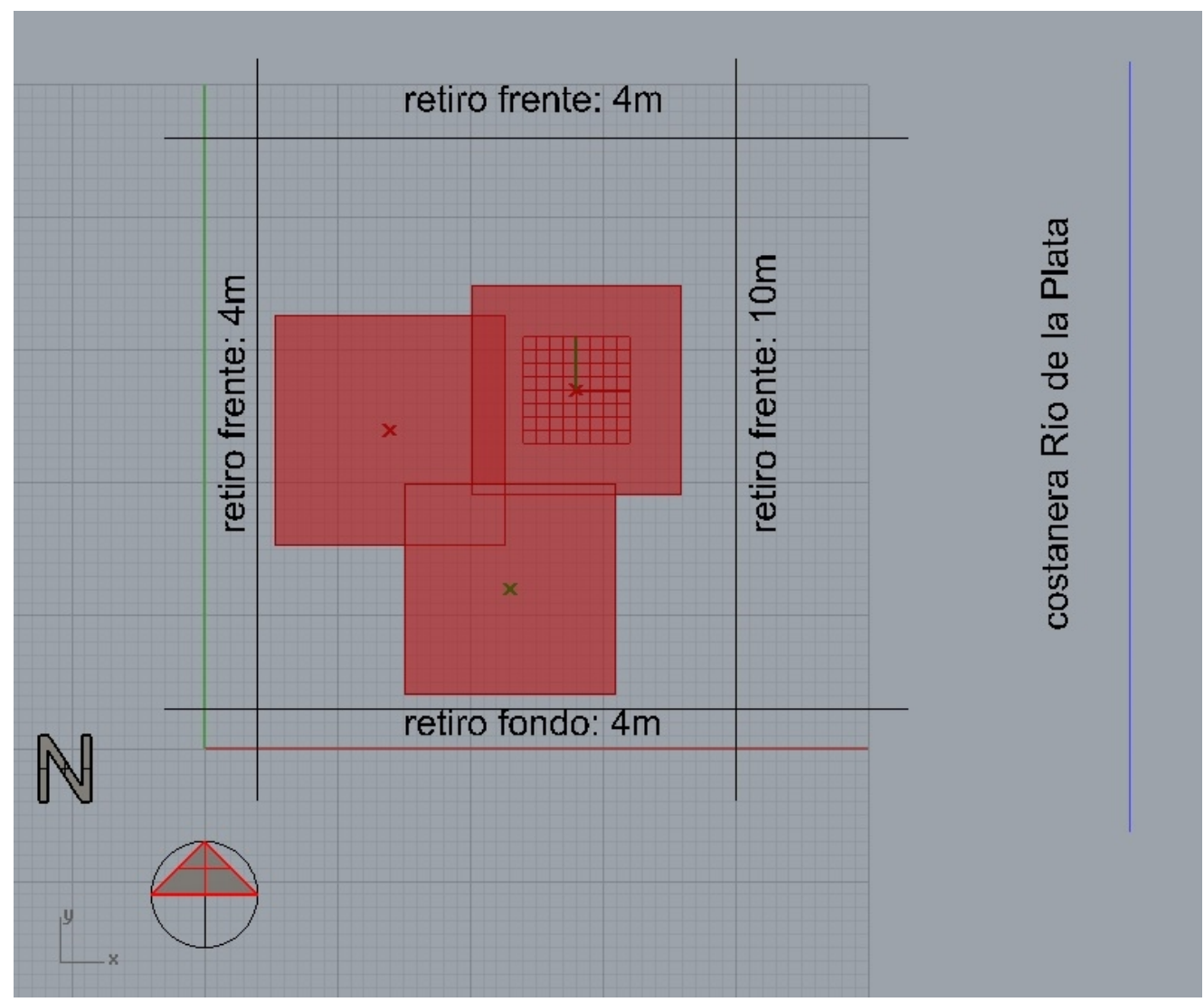

Fig. 9.1. Elementos definidos en Rhinoceros (terreno y orientación). Fuente: la autora

Se cumplen entonces las siguientes condiciones [Ec. 9.1 y 2]:

$A_{1}+A_{2}+A_{3} \leq F O S$.sup. terreno

[Ec. 9.1]

$A_{1} \times n^{\circ}$ pisos $_{1}+A_{2} \times n^{\circ}$ pisos $_{2}+A_{3} \times n^{\circ}$ pisos $\leq$ FOT.sup.terreno

[Ec. 9.2]

siendo:

$\mathrm{A}_{\mathrm{i}}=$ área de la planta del volumen $\mathrm{i}$

FOS factor de ocupación del suelo $=0.6$

FOT factor de ocupación total $=5$

Luego, se determina un rango de $\mathrm{x}$ e y para las coordenadas de los centros de cada uno de los tres volúmenes, de manera tal, que el edificio se ubique respetando el retiro mínimo de 
$4 \mathrm{~m}$ para la tipología torre sobre los lados Norte, Sur y Oeste y el retiro de fondo de $10 \mathrm{~m}$ sobre el lado Este. Las coordenadas paramétricas de los centros cumplen la siguiente condición (Ecs. 9.3 a 5):

$$
\begin{gathered}
4+\frac{1}{2} l_{i} \leq x_{i} \leq 46-\frac{1}{2} l_{i} \\
10+\frac{1}{2} l_{i} \leq y_{i} \leq 46-\frac{1}{2} l_{i} \\
l_{i}=\sqrt{A_{i}}
\end{gathered}
$$

siendo:

$\mathrm{x}_{\mathrm{i}}=$ coordenada sobre el eje de las abcisas del centro del volumen $\mathrm{i}$

$\mathrm{y}_{\mathrm{i}}=$ coordenada sobre el eje de las ordenadas del centro del volumen $\mathrm{i}$

$\mathrm{l}_{\mathrm{i}}=$ lado de la planta del volumen $\mathrm{i}$

$\mathrm{A}_{\mathrm{i}}=$ área de la planta del volumen $\mathrm{i}$

$\mathrm{i}=1$ a 3

En el entorno de Grasshopper, la planta de cada volumen se define paramétricamente, asignando un rango a la ubicación de cada centro, determinando el lado de la base a partir de la superficie de cada planta (Tabla 8.2) (Fig. 9.2)

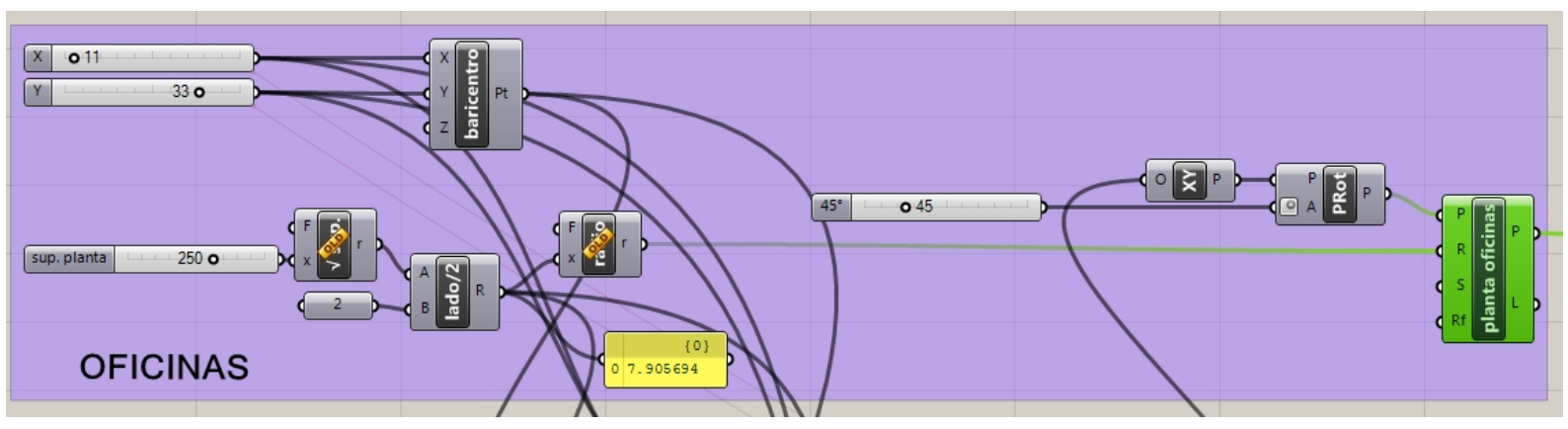

Fig. 9.2. Definición paramétrica del baricentro de la base del volumen de oficinas en Grasshopper.

Fuente: la autora

Se determinan las coordenadas de los centros de las 3 bases:

$$
\begin{aligned}
& C_{1}=\left(x_{1} ; y_{1}\right) \\
& C_{2}=\left(x_{2} ; y_{2}\right) \\
& C_{3}=\left(x_{3} ; y_{3}\right)
\end{aligned}
$$


Luego, se trazan los segmentos que unen entre sí dichos centros:

$$
\begin{aligned}
& S_{1 ; 2} \\
& S_{2 ; 3} \\
& S_{3 ; 1}
\end{aligned}
$$

Se determinan las normales $S_{x, y}$ respecto de la distancia entre los centros $C_{i}$ [Ec. 9.6 al 11]

$$
\begin{aligned}
& S_{1 ; 2}=\frac{1}{2}\left(l_{\nu_{1}}+l_{\partial_{2}}\right) \\
& S_{1 ; 2}=\frac{1}{2}\left(l_{1}+l_{2}\right) \\
& S_{1 ; 3}=\frac{1}{2}\left(l_{1}+l_{3}\right) \\
& S_{1 ; 3}=\frac{1}{2}\left(l_{1}+l_{3}\right) \\
& S_{2 ; 3}=\frac{1}{2}\left(l_{2}+l_{3}\right) \\
& S_{2 ; 3}=\frac{1}{2}\left(l_{2}+l_{3}\right)
\end{aligned}
$$

La longitud de estos segmentos $S$ cumple la condición de ser $S \leq 1,25 S_{x, y}$, que es la longitud de las normales $\mathrm{N}_{\mathrm{i}}$ entre 2 centros Ec. 9.12 al 16 (Fig. 9.3) para impedir la separación de los sólidos:

$$
\begin{aligned}
& S_{1 ; 2} \leq 1.25 S_{1 ; 2} \\
& S_{1 ; 2} \leq 1.25 S_{; ; 2} \\
& S_{1 ; 2} \leq 1.25 S_{2 ; 3} \\
& S_{2 ; 3} \leq 1.25 S_{2 ; 3} \\
& S_{3 ; 1} \leq_{3 ; 1} S_{3 ; 1} \\
& S_{3 ; 1} \leq 1.25 S_{3 ; 1}
\end{aligned}
$$




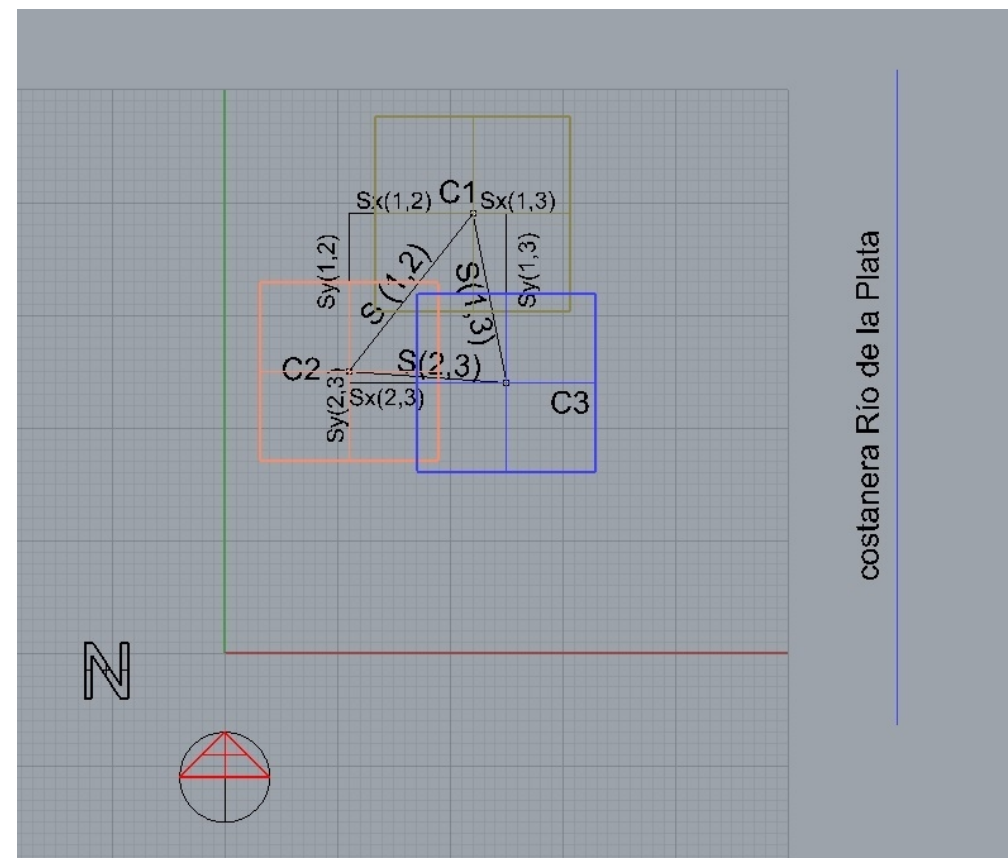

Fig. 9.3: Visualización del agrupamiento de las bases en Rhinoceros. Fuente: la autora

Una vez definida la posición de las bases dentro del conjunto de posiciones paramétricamente posibles, se las extruye de acuerdo a la altura de cada volumen y se ejecuta una unión booleana (Fig. 9.4).

Se generan los planos de cada planta de este nuevo volumen (Fig. 9.5) y se calcula el perímetro en contacto con el terreno, que será utilizado para el cálculo de las pérdidas térmicas por piso en el índice $\mathrm{G}_{\mathrm{CAL}}$. Asimismo, se calcula el volumen neto de aire de cada planta con la altura libre, descontando las losas y demás elementos constructivos que integran los forjados - pisos, contrapisos, espacio entre cielorraso y losa, instalaciones etc. que suman $0,25 \mathrm{~m}$ - , siendo la altura libre de piso a cielorraso de 2,50m. Con estos datos, se calcula el volumen neto de aire del edificio.

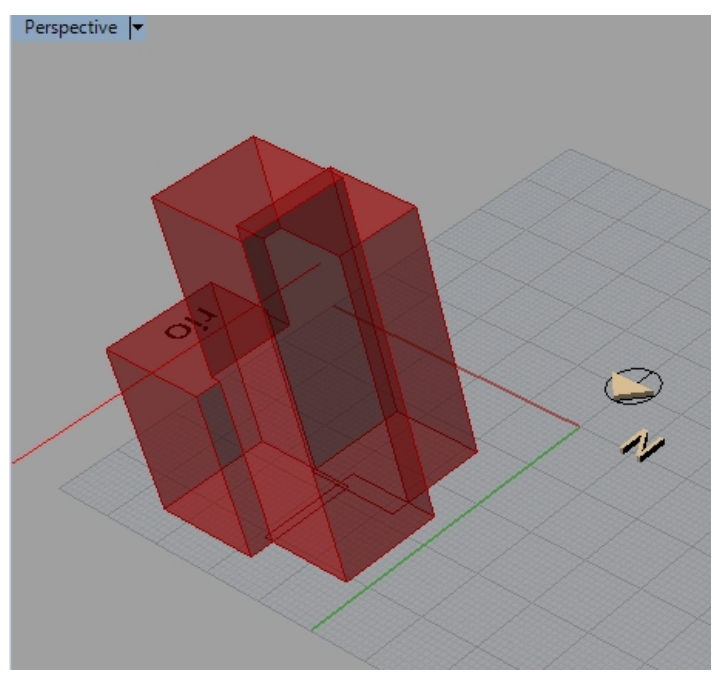

Fig. 9.4: Extrusión de las bases. Fuente: la autora 


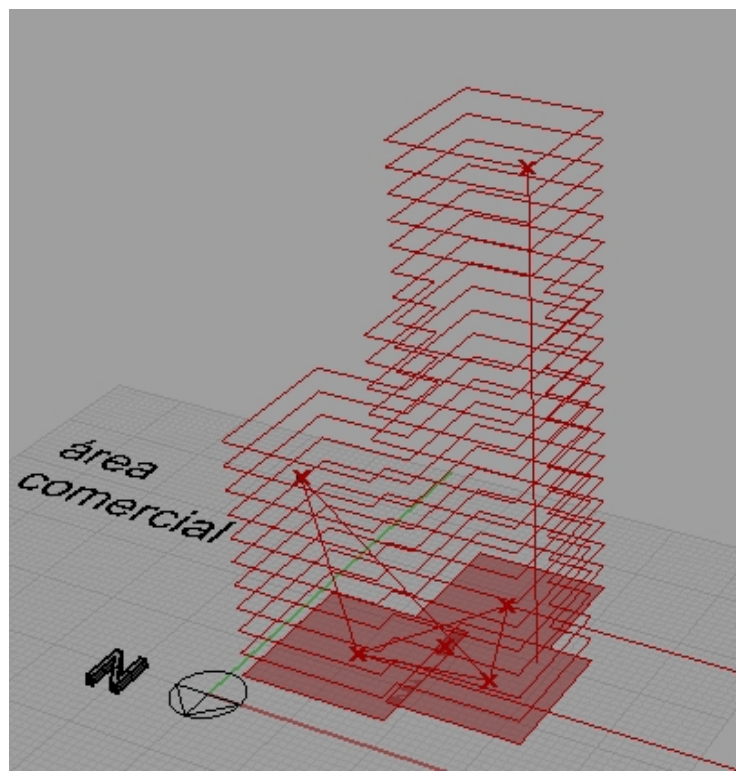

Fig. 9.5: Generación de los planos de cada plantas a partir del sólido booleano. Fuente: la autora

El volumen paramétrico obtenido de la unión booleana se descompone por fachadas según su orientación (Fig. 9.6). La superficie de las mismas varía según la configuración espacial de cada alternativa que se obtenga.

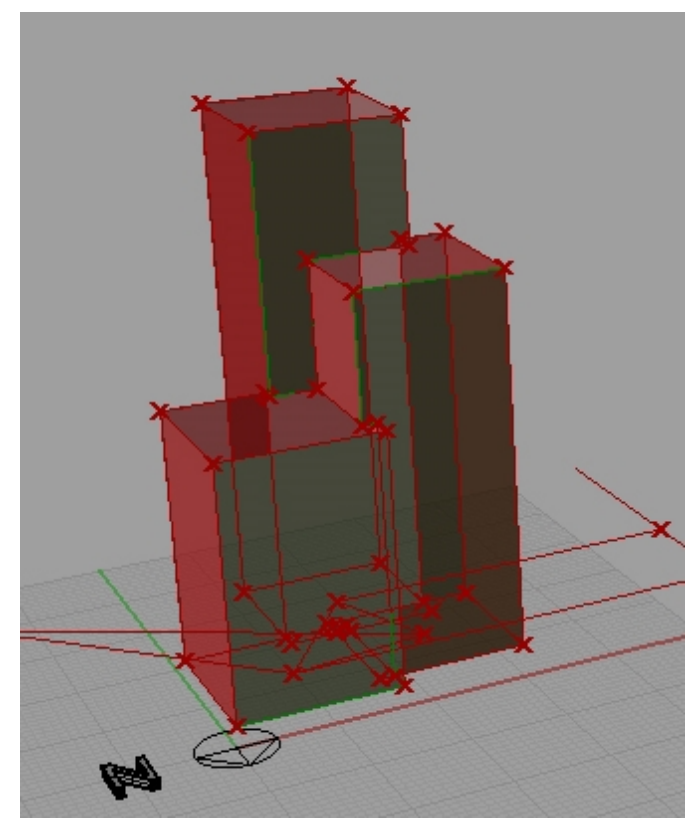

Fig. 9.6: Fachadas al Norte seleccionadas del edificio paramétrico. Fuente: la autora

A continuación, se suman las superficies de las fachadas por orientación y se define paramétricamente el rango porcentual de superficie vidriada por unidad de superficie de muro, para cada orientación (Fig. 9.7). Este valor se ajusta manualmente, siguiendo las recomendaciones de la norma IRAM 11603 Anexo B (IRAM, 2012) para la zona 
bioambiental templada cálida IIIb. En nuestro caso, adoptamos: $50 \%$ al Norte, $10 \%$ al Sur, $40 \%$ al Este y $30 \%$ al Oeste.

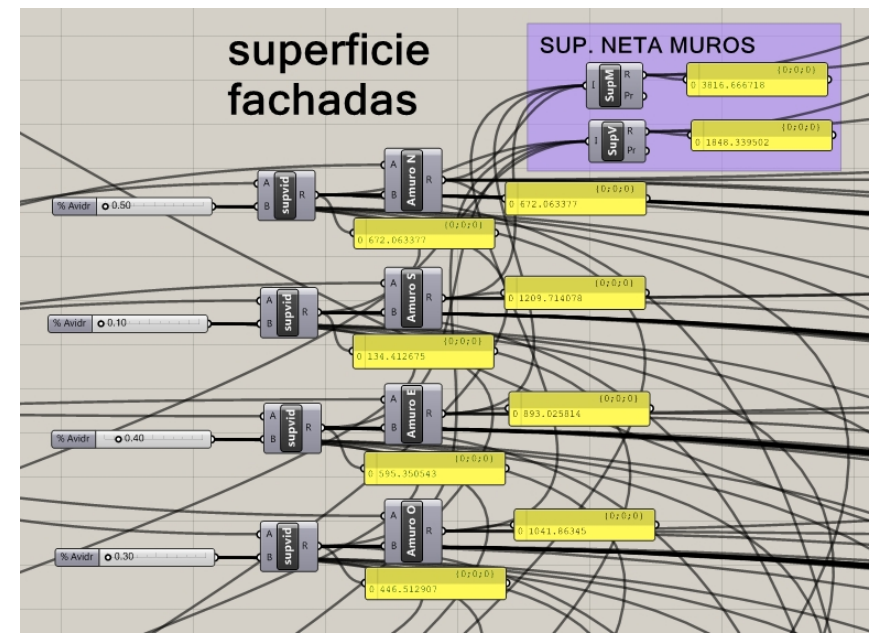

Fig. 9.7: Relación paramétrica entre superficies de muro y vidrio. Fuente: la autora

\subsection{Temperaturas de diseño y horarias}

Para el cálculo de $\mathrm{G}_{\mathrm{CAL}}$ y $\mathrm{G}_{\mathrm{REF}}$, se toman en cuenta las temperaturas de diseño —para invierno, $1,7^{\circ} \mathrm{C}$ y para verano, $34.4^{\circ} \mathrm{C}$ (IRAM, 2012) - como se dijo en el apartado 3.2.1. Pero para el cálculo de $\mathrm{B}_{\mathrm{CAL}}$ y $\mathrm{B}_{\mathrm{REF}}$, se consideran las temperaturas sol-aire (TSA) que incluye el efecto de la radiación solar en los cerramientos opacos del edificio.

Para el cálculo de $B_{C A L}$ y $B_{R E F}$ se emplean registros de la base de datos de la estación Gonnet, que posee el Laboratorio de Arquitectura y Hábitat Sustentable (LAyHS) de la Facultad de Arquitectura y Urbanismo de la Universidad Nacional de La Plata, donde se halla radicada esta tesis. Las temperaturas de un día típico de invierno se obtienen calculando la media de las temperaturas máximas (hora14) y las mínimas (hora 6) del mes de julio para los años 2009 al 2012 inclusive (Tabla Anexo 1.1). Para el día típico de verano, hacemos lo propio considerando la media de las temperaturas máximas (hora 14) y mínimas (hora 6), de los meses de enero de 2009 al 2012 inclusive (Tabla Anexo 1.2). Con estos datos confeccionamos las tablas de temperaturas horarias (Anexo 1, Tablas A1.5 y A1.6) (Gonzalo \& Nota, 2003).

\subsection{Infiltración y renovaciones de aire}

Para el cálculo de las pérdidas térmicas de invierno, debemos considerar las renovaciones de aire debidas a la infiltración en carpinterías. El número de renovaciones $(n)$ indicado por la Ley 13059/03 (Gobierno de la Provincia de Buenos Aires, 2010), tomado a su vez de la norma IRAM 11604 (IRAM, 2001) es igual a 2, lo cual significa que el volumen de aire de todo el edificio se renueva 2 veces por hora. Como este valor es excesivo para un edificio 
eficiente, adoptaremos el método analítico indicado por la norma IRAM 11604 para estos casos, utilizando la fórmula siguiente [Ec. 9.8]:

$$
N=\frac{\left.\Sigma 0,4 \quad l i q[0,5 \quad(c v))^{2}\right]^{0,8}}{V}
$$

donde:

$\mathrm{N}=$ número de renovaciones por hora

li= largo de las juntas de contacto de cada tipo de carpintería en m

qi= caudal de infiltración por metro lineal de junta (Norma IRAM 11507-1). Para la carpintería adoptada (categoría A3 reforzada), es igual a 2, con una presión de ensayo de $100 \mathrm{~Pa} x$ $\mathrm{m}^{2} / \mathrm{h}$.

cl= coeficiente de corrección; se calcula con una variación cada $10 \mathrm{~m}$ de altura del edificio y una rugosidad del terreno tipo suburbana. (IRAM 11604, Anexo B, Tabla B1)

$\mathrm{vl}=$ velocidad del viento de la localidad considerada (IRAM 11603) en m/seg. Adoptamos $14.1 \mathrm{~km} / \mathrm{h}=3.9 \mathrm{~m} / \mathrm{s}$ a $10 \mathrm{~m}$ de altura (datos de la Estación Aeroparque, Bs. As.) (IRAM, 2012). $V=$ volumen del edificio, para la alternativa analizada es de $26324 \mathrm{~m}^{3}$.

Este valor $\mathrm{n}$ dependerá de la superficie de cada fachada, que es diferente en cada alternativa morfológica; y está relacionada con el grado de superposición de los volúmenes. Las ventanas de cada fachada representan un porcentaje de la superficie de la misma, según la orientación, como se indicó en más arriba.

A medida que el edificio va ascendiendo, la velocidad del viento aumenta, como se observa en la Fig. 6.18, con lo cual, la necesidad de reducir la apertura de las carpinterías se torna imprescindible. Para la confección de dicho gráfico empleamos la fórmula detallada a continuación [Ec.9.9] (Swiss Federal Office of Energy, 2017) ${ }^{1}$, considerando una rugosidad del suelo de tipo suburbano igual a 0.4 , debido a la proximidad con el río y una velocidad media del viento de $3.9 \mathrm{~m} / \mathrm{s}$ a $10 \mathrm{~m}$ de altura (IRAM, 2012):

$$
v_{2}=v_{1} \frac{1\left(\frac{h_{2}}{z_{0}}\right)}{l_{1} \frac{h_{1}}{z_{0}}}
$$

donde:

$\mathrm{V}_{2}$ : velocidad del viento a la altura especificada

\footnotetext{
${ }^{1}$ Consultado el 20/10/15 en http://wind-data.ch/tools/profile.php?lng=en
} 
$\mathrm{V}_{1}$ : velocidad del viento a $10 \mathrm{~m}$ de altura

$\mathrm{h}_{2}$ : altura especificada

$h_{1}: 10 m$

$\mathrm{z}_{0}$ : rugosidad del suelo igual a 0.4

Con esos valores podemos calcular el decremento del largo de las juntas en relación inversamente proporcional al incremento de la velocidad del viento, obteniendo la (Anexo 1 , Tabla A1.18) (Fig. 9.8 y 9.9). El diseño de las carpinterías se observa en la Fig. 9.10.

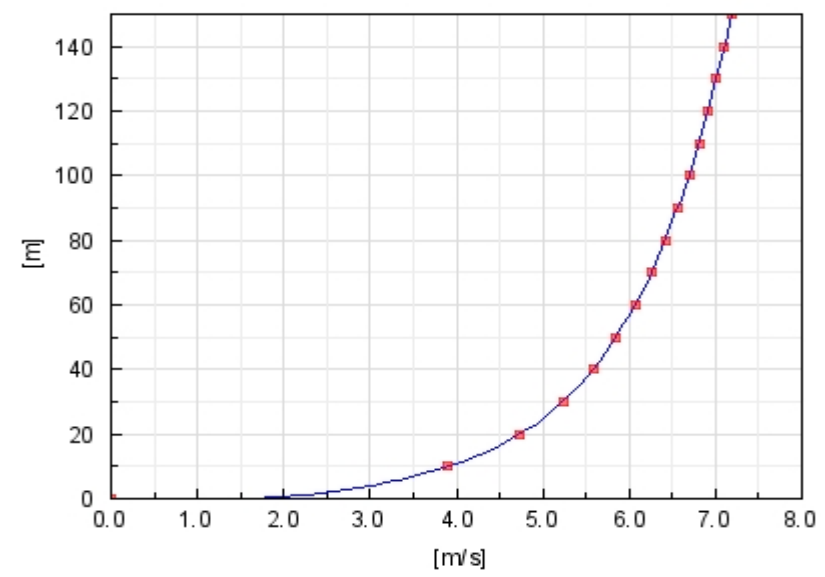

Fig. 9.8: Incremento de la velocidad del viento con la altura para una rugosidad=0.4. Fuente: la autora

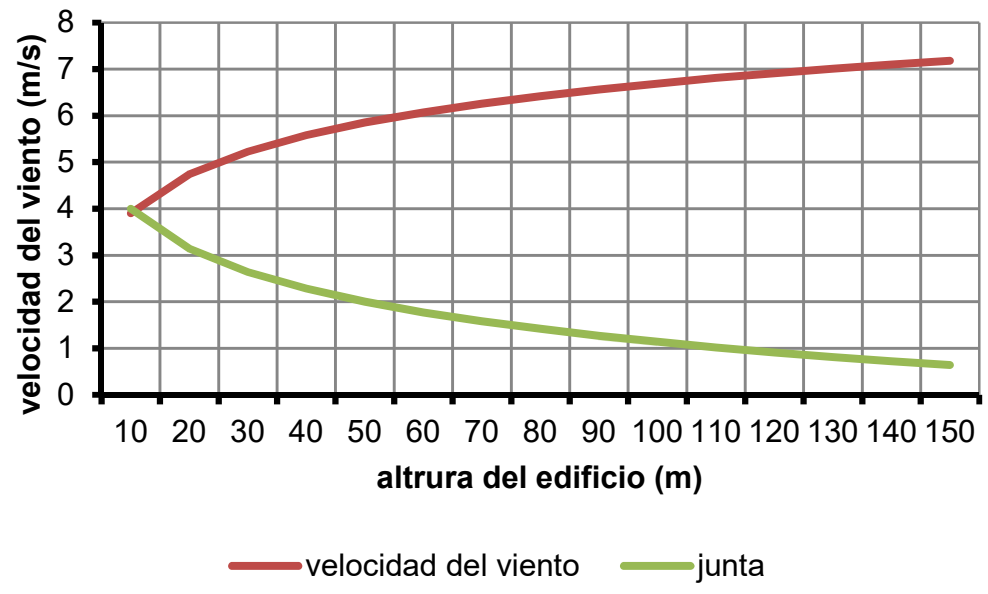

Fig. 9.9: Decremento del largo de junta de carpintería con el aumento de la velocidad del viento Fuente: la autora 
9. Etapa 2. Edificio de nueva planta en el Área Metropolitana de Buenos Aires.

Sub-etapa 2.2. Estructuración del modelo

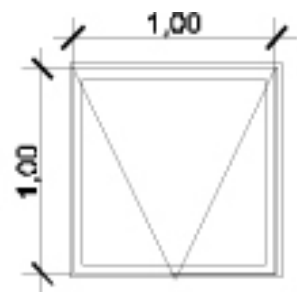

Hedificio: hasta $10 \mathrm{~m}$ largo junta: $4 \mathrm{~m}$

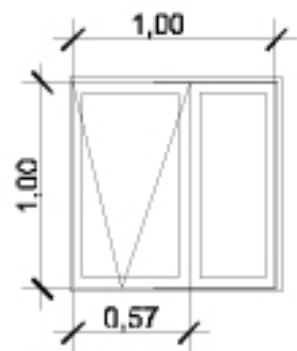

H odificio: 10 a $20 \mathrm{~m}$ largo junta: $3.14 \mathrm{~m}$

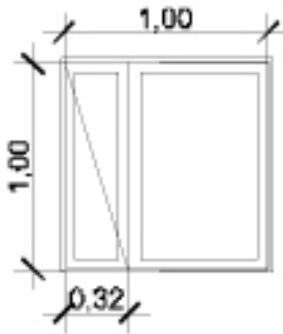

$\mathrm{H}$ edificio: 20 a $30 \mathrm{~m}$ largo jurta: $2.64 \mathrm{~m}$

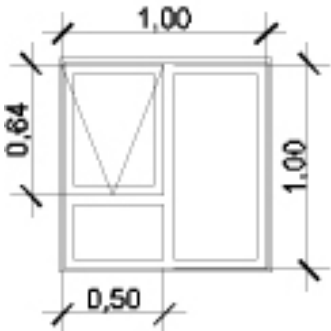

$\mathrm{H}$ edificio: 30 a $40 \mathrm{~m}$ largo junta: $2.28 \mathrm{~m}$

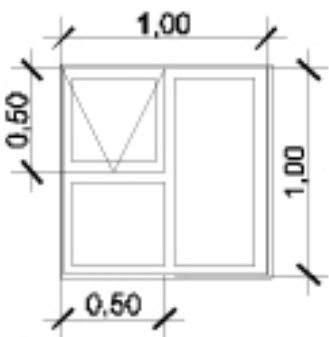

Hodificio: $\mathbf{4 0}$ a $\mathbf{5 0 m}$ largo jurtta: $2 \mathrm{~m}$

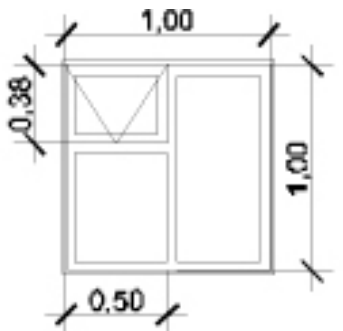

$\mathrm{H}$ edificio: 50 a $60 \mathrm{~m}$ largo junta: $1.77 \mathrm{~m}$

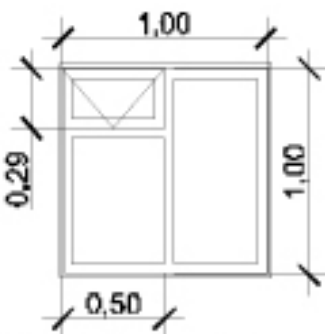

$\mathrm{H}$ edificio: 60 a $70 \mathrm{~m}$ largo junta: $1.58 \mathrm{~mm}$

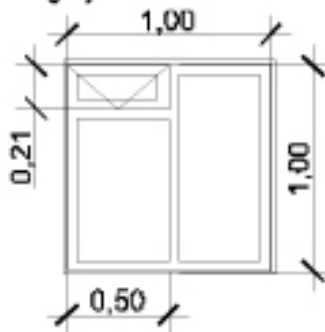

$H$ edificio: 70 a $80 \mathrm{~m}$ largo junta: $1.42 m$

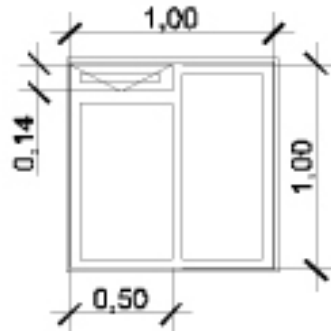

$H$ edificio: 80 a $90 \mathrm{~m}$ largo junta: $1.27 \mathrm{~m}$

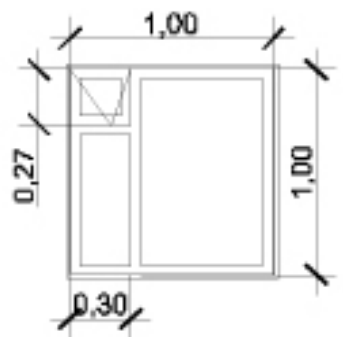

$H$ odificio: 90 a $100 \mathrm{~m}$ largo junta: $1.14 \mathrm{~m}$

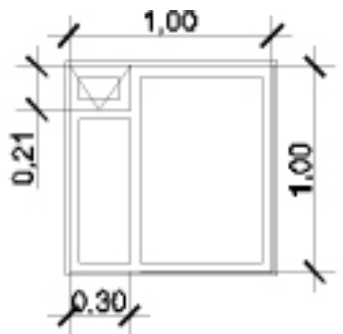

$H$ edificia: 100 a $110 \mathrm{~m}$ Iargo junte: $1.02 \mathrm{~m}$

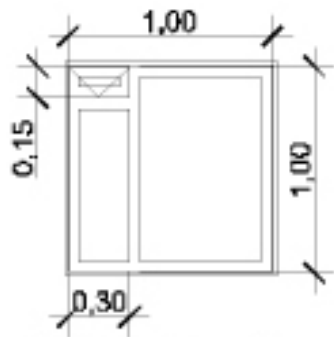

Hedficio: 110 a $120 \mathrm{~m}$ largo junta: $0.91 \mathrm{~m}$

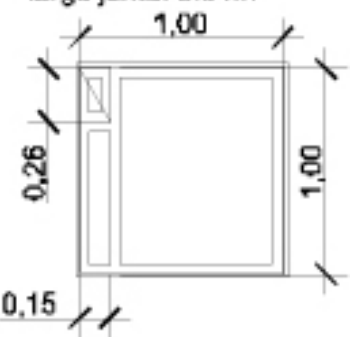

$\mathrm{H}$ codificio: 120 a $130 \mathrm{~m}$ largo junta: $0.81 \mathrm{~m}$

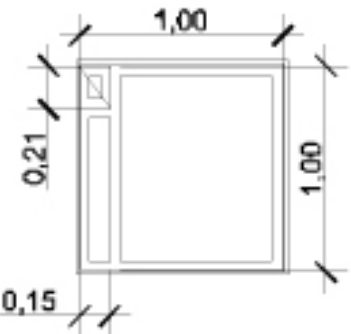

$H$ edificio: 130 a $140 \mathrm{~m}$ largo junta: $0.72 \mathrm{~m}$

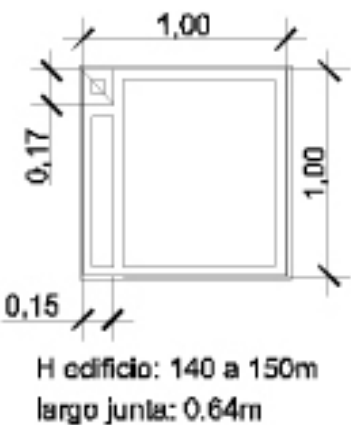

Fig. 9.10: Variación del largo de junta de carpintería en función de la altura del edificio. Fuente: la autora 


\subsection{Cálculo del coeficiente global de pérdidas de calor ( $\left.\mathrm{G}_{\mathrm{CAL}}\right)$}

Aplicando la fórmula de $\mathrm{G}_{\mathrm{CAL}}$ (IRAM, 2001) [Ec. 9.10], se tiene que:

$$
G_{C}=\frac{\Sigma K_{m} \cdot S_{m}+\Sigma K_{v} \cdot S_{v}+P \quad \cdot P_{p}}{V}+0,3
$$

siendo:

$\mathrm{G}_{\mathrm{CAL}}=$ coeficiente volumétrico de calefacción en $\mathrm{W} / \mathrm{m}^{3} \mathrm{~K}$

$\mathrm{K}_{\mathrm{m}}$ : transmitancia térmica de los elementos opacos exteriores (muros y cubiertas) en $\mathrm{W} / \mathrm{m}^{2} \mathrm{~K}$

$\mathrm{S}_{\mathrm{m}}$ : área interior de los elementos opacos en metros cuadrados

$\mathrm{K}_{\mathrm{v}}$ : transmitancia térmica de los elementos no opacos exteriores en $\mathrm{W} / \mathrm{m}^{2} \mathrm{~K}$

$S_{v}$ : área interior de los elementos no opacos interiores en metros cuadrados.

Per: perímetro del edificio

$\mathrm{P}_{\mathrm{p}}$ : perdidas por piso en contacto con el terreno en $\mathrm{W}$.

$V=$ volumen de aire del edificio.

0.35: capacidad específica del aire en $\mathrm{Wh} / \mathrm{m}^{3} \mathrm{~K}$

n: número de renovaciones de aire promedio por hora del edificio

Para calcular la variación de la infiltración con la altura, partimos el edificio en seis subvolúmenes según la variación de la velocidad del viento (Fig. 9.11). Se reemplaza n por el promedio ponderado de $\mathrm{n}_{\mathrm{i}}$ en relación al volumen total [Ec. 9.11]:

$$
G_{c}=\frac{\Sigma K_{m} \cdot S_{m}+\Sigma K_{v} \cdot S_{v}+P \quad \cdot P_{p}}{V}+0,3 \cdot \frac{\sum_{i=1}^{n} N_{i} \cdot V_{i}}{V}
$$

siendo:

$\mathrm{G}_{\mathrm{CAL}}=$ coeficiente volumétrico de calefacción en $\mathrm{W} / \mathrm{m}^{3} \mathrm{~K}$

$\mathrm{N}_{\mathrm{i}}=$ de 1 a 6 número de renovaciones de cada subvolumen edilicio en $1 / \mathrm{h}$

$V_{i}=$ subvolúmenes del edificio según la subdivisión cada $10 \mathrm{~m}$ de altura.

Este coeficiente $\mathrm{G}_{\mathrm{CAL}}$ deberá ser inferior al $\mathrm{G}_{\text {CALADM CORREGIDO indicado por la norma IRAM }}$ 11604 pág. 14 para edificios con más de un $20 \%$ de área vidriada. Adoptamos el valor de $\mathrm{G}_{\text {CALADM CORREGIDO }}=1,096 \mathrm{~W} / \mathrm{m}^{3} \mathrm{~K}$ que corresponde a un volumen de $27.000 \mathrm{~m}^{3}$ y 1.256 grados días según la Tabla 3 de la norma IRAM 1603 (IRAM, 2012) para una temperatura de 
confort de $20^{\circ} \mathrm{C}$. Si bien cada alternativa presenta leves variaciones de superficie de envolvente- que dependen de cada configuración- no presentan diferencias que alteren el cumplimiento de la norma de referencia. El programa calcula el $\mathrm{G}_{\text {CAL }}$ para cada alternativa según la fórmula descripta a continuación (Ec. 9.12), obteniendo un valor aproximado para todas las alternativas de $0.61 \mathrm{~W} / \mathrm{m}^{3} \mathrm{~K}$, el cual es sensiblemente inferior al valor admisible corregido, cuya media es de aproximadamente $1.38 \mathrm{~W} / \mathrm{m}^{2} \mathrm{~K}$, ya que varía según la superficie de muro y vidriada:

$$
G_{a \iota} \quad \quad=G_{a 1}+\left(1.7 \cdot \frac{S_{V}}{S_{E}}-0.3\right)
$$

siendo:

$\mathrm{G}_{\mathrm{adm}}=1.096 \mathrm{~W} / \mathrm{m}^{3} \mathrm{~K}$

$\mathrm{S}_{\mathrm{V}}=$ superficie vidriada en $\mathrm{m}^{2}$

$S_{E}=$ superficie de la envolvente del edificio en $\mathrm{m}^{2}$

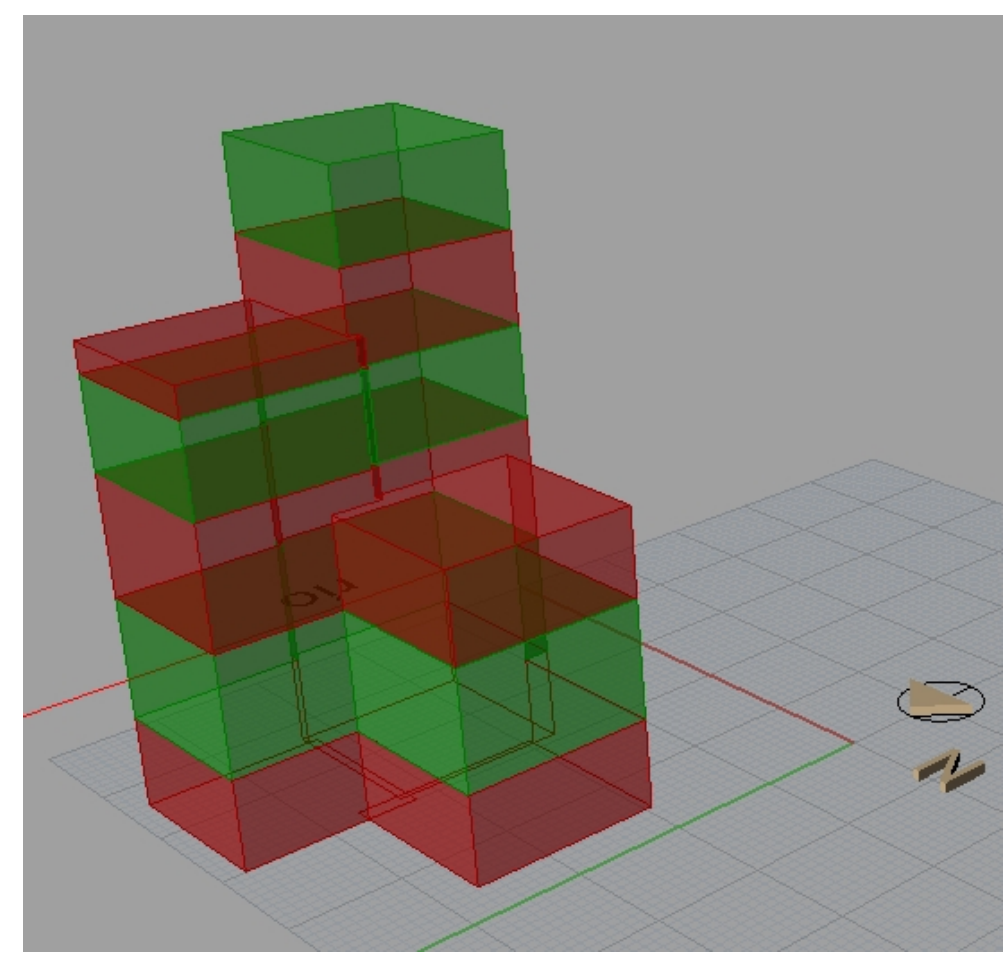

Fig. 9.11: Sectorización del edificio en subvolúmenes para los distintos n. Fuente: la autora

\subsection{Cálculo del coeficiente volumétrico de refrigeración ( $\left.G_{R E F}\right)$}

De acuerdo a la norma IRAM 11659-2 (IRAM, 2007), este coeficiente es el cociente entre la carga térmica del edificio en cuestión y el volumen de aire a refrigerar del mismo [Ec. 9.13]: 


$$
G_{R}=\frac{Q_{\mathrm{R}}(\mathrm{W})}{V\left(m^{3}\right)}
$$

siendo:

$\mathrm{G}_{\mathrm{REF}}=$ coeficiente volumétrico de refrigeración en $\mathrm{W} / \mathrm{m}^{3} \mathrm{~K}$

$\mathrm{Q}_{\mathrm{REF}}=$ carga térmica total en $\mathrm{W}$

$V=$ volumen de aire del edificio en $\mathrm{m}^{3}$

La carga térmica $Q_{R E F}$ se compone de los siguientes términos [9.14]:

$$
\boldsymbol{Q}_{\boldsymbol{R}}=\sum \boldsymbol{Q}_{C}+\boldsymbol{Q}_{A}+\boldsymbol{Q}_{S}+\boldsymbol{Q}_{o}
$$

siendo:

$Q_{R E F}=$ carga térmica de refrigeración en $\mathrm{W}$

$Q_{C}=$ carga térmica por conducción en W

$Q_{A}=$ carga térmica del aire en $\mathrm{W}$

$\mathrm{Qs}_{\mathrm{s}}$ carga térmica solar en $\mathrm{W}$

$Q_{0}=$ carga térmica por fuentes internas

Analizando cada término de la Ec. 9.14 por separado, tenemos que la carga térmica por conducción en W correspondiente a la envolvente del edificio es [9.15]:

$$
Q_{C}=\Sigma A_{i} \cdot K_{i} \cdot\left(T_{D}-T_{I}\right)
$$

siendo:

$Q_{C}=$ carga térmica por conducción en W

$A_{i}=$ área de los elementos que integran la envolvente en $\mathrm{m}^{2}$

$\mathrm{K}_{\mathrm{i}}=$ transmitancia térmica de los elementos que integran la envolvente en $\mathrm{W} / \mathrm{m}^{2} \mathrm{~K}$

$\mathrm{T}_{\mathrm{DMX}}=$ temperatura máxima de diseño, $34.4^{\circ} \mathrm{C}($ IRAM 11603,2012$)$

$\mathrm{T}_{1}=$ temperatura interior de confort, $25^{\circ} \mathrm{C}$

En nuestro caso, la transmitancia térmica adoptada tiene un valor paramétrico de ajuste manual que supera el nivel $B,-$ a fin de cumplir con la ley 13059 - sin alcanzar el nivel A de la norma IRAM 11605 (Tabla 5.2 de la Norma IRAM 11605, 1996) para una temperatura 154 
9. Etapa 2. Edificio de nueva planta en el Área Metropolitana de Buenos Aires. Sub-etapa 2.2. Estructuración del modelo

máxima de diseño de $34.4^{\circ} \mathrm{C}$ (IRAM 11603,2012 ) y una temperatura de confort de $25^{\circ} \mathrm{C}$ (IRAM 11659-1, 2012).

Luego se obtiene el calor sensible del aire exterior [Ec 9.16]:

$$
Q_{A}=C_{A} \cdot(0,2 \Delta t+0,6 \Delta w)
$$

donde:

$Q_{A}=$ carga térmica del aire en $W$

$\mathrm{C}_{\mathrm{AR}}=$ caudal de aire a renovar en $\mathrm{m}^{3} / \mathrm{h}$

$0.25=$ constante entre el cociente del calor específico del aire a $21^{\circ} \mathrm{C}$ y $50 \%$ de humedad relativa $\mathrm{HR}$ y su volumen específico en $\mathrm{W} / \mathrm{m}^{3 \circ} \mathrm{C}$

$\Delta \mathrm{t}=$ diferencia entre la temperatura exterior y la interior en ${ }^{\circ} \mathrm{C}$.

0.61 $=$ constante entre el cociente del valor medio de la cantidad de calor cedida por la condensación de un gramo de vapor de agua y el volumen específico de la misma mezcla de aire en $\mathrm{W} / \mathrm{m}^{3} \mathrm{~g}$

$\Delta \mathrm{w}=$ diferencia entre la humedad específica del aire exterior y el interior en $\mathrm{g} / \mathrm{kg}$, obtenidas mediante el diagrama psicrométrico que se encuentra en la norma IRAM 11659.

La ecuación 6.10 muestra el cálculo de $\mathrm{C}_{\mathrm{AR}}$ [Ec. 9.17]:

$$
C_{A}=N_{p} \quad . C_{A}
$$

siendo:

$\mathrm{N}_{\text {pers }}=$ el número de personas que ocupan el edificio

$\mathrm{C}_{\mathrm{ARP}}=$ el caudal de aire a renovar por persona en $\mathrm{m}^{3} / \mathrm{h}$.persona

Luego se tiene la carga térmica solar en W [Ec.9.18]:

$$
Q_{s}=F_{s} \cdot K_{v} \cdot \sum_{o \in O} A{ }_{o} \cdot I_{0} \cdot \Delta t
$$

$Q_{s}=$ ganancias solares por vidrios en $\mathrm{W}$.

Fs: es el factor de exposición solar que, en nuestro caso es de 0.35 y corresponde a DVH $6+12+6$ de baja emisividad

$\mathrm{K}_{\mathrm{v}}$ : transmitancia térmica en $\mathrm{W} / \mathrm{m}^{2} \mathrm{~K}$

$A v_{0}$ : área de ventanas por cada orientación en $\mathrm{m}^{2}$ 
$\mathrm{O}=\{$ Norte, Sur, Este, Oeste $\}$

Iso: radiación sobre el plano según su orientación (Anexo 1-Tabla A1.3)

$\Delta \mathrm{t}=$ variación de la temperatura exterior/interior en ${ }^{\circ} \mathrm{C}$

La carga por fuentes internas está compuesta de la sig. Forma: [Ec. 9.19]:

$$
Q_{o}=Q_{p}+Q_{p}+Q_{i i}+Q_{e}+Q_{c}
$$

Analizando cada término se tiene la carga térmica discriminada por fuente [Ec. 9.20]:

$$
Q_{p} \quad=N_{p} \cdot M_{S}
$$

$Q_{\text {pers }}$ es la carga térmica sensible debida a las personas en w

$\mathrm{N}_{\text {per: }}$ número de personas, que según la Tabla 5.8 es de 543 habitantes, en la hora pico solar Ms: es calor sensible producido por una actividad de oficina, para el cual adoptamos $47 \mathrm{~W}$ (ver Apartado 8.3) (Tabla 13- IRAM11659-1)

El segundo término corresponde a [Ec. 9.21]:

$$
Q_{p} \quad=N_{p} \cdot M_{L}
$$

$Q_{\text {perL }}$ es la carga térmica latente debida a las personas

$\mathrm{M}_{\mathrm{L}}$ :es el calor latente delas personas que se fija en 52W (ver Apartado 8.3) (Tabla 13 IRAM 11659-1)

El tercer término corresponde a [Ec. 9.22]:

$$
Q_{i i}=A \cdot q_{i l} \quad C_{t}
$$

donde:

Qilums $=$ carga térmica sensible por iluminación

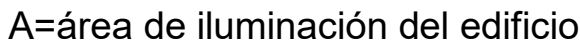

qilum= energía térmica por unidad de superficie (Tabla 4, IRAM11659-1).En nuestro caso, adoptamos $12 \mathrm{~W} / \mathrm{m}^{2}$ para un nivel de 300 lux (vivienda y oficina) (ver Apartado 2.3.1)

$\mathrm{C}_{\mathrm{t}}$ : coeficiente térmico según el tipo de iluminación. En nuestro caso, por ser fluorescente le corresponde 1,25 (ver Apartado 2.3.1) (Tabla 5, IRAM 11659-1). 
El cuarto término Qequip corresponde al calor sensible y latente, aportados por el equipamiento que, en este caso, no serán considerados.

El quinto término corresponde a [Ec. 9.23]:

$$
Q_{c}=\left(Q_{p}+Q_{i 1}+Q_{e}\right) \cdot C_{S}
$$

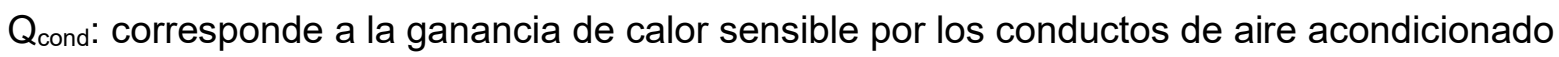

Qpers: es el calor sensible debido a la ocupación

$\mathrm{CA}_{S}$ : coeficiente de aporte de calor sensible que para nuestro caso es de 0.05 (conductos aislados entre 30 y $100 \mathrm{~m}$ en espacios a $35^{\circ} \mathrm{C}$ ) (ver Apartado 2.3.1) (Tabla 4- IRAM11659-2) (IRAM, 2007).

Una vez obtenido el $Q_{R}$, (Ec.6.7) se divide por el volumen del edificio y se obtiene un valor que debe ser inferior al coeficiente volumétrico de refrigeración admisible ( $G_{R E F} A D M$ ). EI $G_{R E F}$ ADM para un edificio de hasta $10.000 \mathrm{~m} 3$ de volumen de aire y una temperatura máxima de diseño de $34,4^{\circ} \mathrm{C}$ según la norma IRAM 11603 , es de $16,25 \mathrm{~W} / \mathrm{m}^{3}$ (IRAM, 2012). Podemos inferir que la curva se aproxima a 16,20W/m3a medida que aumenta el volumen edilicio (Fig. 2c- IRAM 11659-2) (IRAM, 2007), por lo que adoptaremos ese valor para nuestro caso.

\subsection{Cálculo del índice bioclimático de calefacción para un día típico de invierno (BCAL)}

Cuando calculamos el $\mathrm{G}_{\mathrm{CAL}}$, consideramos una envolvente sin ganancia solar, solamente con pérdidas. Existen otros métodos de cálculo como el llamado Cociente Carga Colector (Solar Load Ratio) (Balcomb, 1992) y el programa Optimix (Yarke, E. \& Alonso, P., 2002) que incorporan las ganancias solares al balance térmico del edificio. Este tipo de programas surgieron con el fin de poder evaluar el aporte solar no sólo de las ventanas, sino también de los sistemas solares pasivos, como el muro Trombe o el invernadero adosado, entre otros. También se investigó el método LT (Baker \& Steemers, 1996), orientado a las primeras fases del diseño arquitectónico que calcula la demanda mensual de un edificio empleando un método cuasi-estacionario.

Para obtener un cálculo de la demanda energética de un día típico de invierno, aplicamos un método similar al de las ganancias térmicas $Q_{\mathrm{REF}}$ para refrigeración Ec. 9.5 pero para cada hora del día, sumando el total de las pérdidas y las ganancias, obteniendo así un coeficiente bioclimático de calefacción $\mathrm{B}_{\mathrm{CAL}}\left(\mathrm{W} / \mathrm{m}^{3}\right.$. día invierno) [Ec.9.24].

$$
B_{C}=\frac{1}{V}\left(Q_{c}+Q_{r}+Q_{a}-Q_{s}+Q_{o}\right)
$$


siendo:

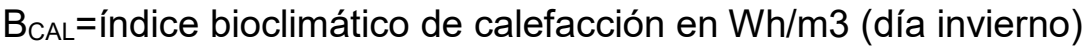

$V=$ volumen efectivo de aire del edificio en $\mathrm{m}^{3}$

Analizamos cada término [Ec. 9.25]:

$$
\left.Q_{c}=\sum_{i=0}^{n} \Delta t_{i:} \quad\left(K_{m} S_{m}\right)+\sum_{i=0}^{n} \Delta t_{i}\left(K_{v} S_{v}\right)+\sum_{i=0}^{n} \Delta t_{i:} \quad\left(K_{c} S_{c}\right)+P \quad P_{p}\right) . \quad[\text { Ec. 9.25] }
$$

siendo:

$\mathrm{Q}_{\mathrm{c}}=$ pérdidas térmicas por conducción de la envolvente en $\mathrm{W}$ de la sumatoria de cada hora del día

$\mathrm{n}=1$ a 24

$\mathrm{K}_{\mathrm{m}}=$ transmitancia térmica del muro en $\mathrm{W} / \mathrm{m}^{2} \mathrm{~K}$

$S_{m}=$ superficie de muros en $m^{2}$

$\mathrm{K}_{\mathrm{v}}=$ transmitancia térmica de las ventanas en $\mathrm{W} / \mathrm{m}^{2} \mathrm{~K}$

$\mathrm{S}_{\mathrm{v}}=$ superficie de las ventanas en $\mathrm{m}^{2}$

$\mathrm{K}_{\mathrm{c}}=$ transmitancia térmica de la cubierta en $\mathrm{W} / \mathrm{m}^{2} \mathrm{~K}$

$\mathrm{S}_{\mathrm{c}}=$ superficie de las cubiertas en $\mathrm{m}^{2}$

$\mathrm{P}_{\mathrm{p}}$ : perdidas por piso en contacto con el terreno en $\mathrm{W}$

$\Delta \mathrm{t}_{\mathrm{iSA}}=$ diferencia entre temperatura sol-aire y de confort en muros y cubiertas para cada hora del día

$\Delta \mathrm{t}_{\mathrm{i}}=$ diferencia de temperatura exterior y de confort para cada hora del día en ${ }^{\circ} \mathrm{C}$

$\mathrm{n}=1$ a 24

Las temperaturas horarias de julio se muestran en la Tabla 3.3 del Anexo 3. Las $T_{S A}$ horarias se muestran en las Tablas 3.4 al 3.10 del Anexo 3. El cálculo de la TSA se obtiene a partir de la Ec. 9.26:

$$
T_{S}=T_{e}+\text { I. } \alpha \cdot R_{S}
$$

$\mathrm{T}_{\text {ext }}=$ temperatura de bulbo seco exterior 
9. Etapa 2. Edificio de nueva planta en el Área Metropolitana de Buenos Aires. Sub-etapa 2.2. Estructuración del modelo

I= radiación solar total horaria I (directa+ difusa+ reflejada) (ver Apartado 3.2.1) (Anexo1. Tabla A14)

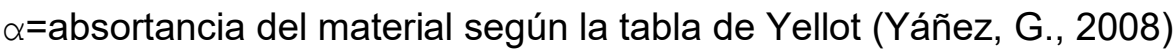

$R_{\mathrm{se}}=$ resistencia superficial del aire exterior $0.04 \mathrm{~m}^{2} \mathrm{~K} / \mathrm{W}$ para flujo horizontal o ascendente para la condición de invierno.

El siguiente es el cálculo de las pérdidas por infiltración [Ec. 9.27]:

$$
Q_{r}=\left(0,3 \cdot \frac{\sum_{i=1}^{m} \cdot N_{i_{1}}}{V} \cdot v_{i}\right) \cdot V \cdot \sum_{i=1}^{n} \Delta t_{i}
$$

$Q_{r}=$ pérdidas térmicas por infiltración en $\mathrm{W}$

0.35: capacidad específica del aire en $\mathrm{Wh} / \mathrm{m}^{3} \mathrm{~K}$

$N_{\text {iren }}=$ número de renovaciones de aire por hora para cada subvolumen edilicio en $1 / \mathrm{h}$

$V_{i}=$ subvolúmenes del edificio según la velocidad del viento en $\mathrm{m}^{3}$

$m=1$ a 6

$V=$ volumen de aire del edificio en $\mathrm{m}^{3}$

$\Delta \mathrm{t}_{\mathrm{i}}=$ diferencia de temperatura exterior/interior en ${ }^{\circ} \mathrm{C}$ para cada hora del día

$\mathrm{n}=1$ a 24

Simplificando obtenemos [Ec. 9.28]:

$$
Q_{r}=\mathbf{0 , 3} \cdot \sum_{i=1}^{m} \cdot N_{i 1} \quad \cdot V_{i} \cdot \sum_{i=1}^{n} \Delta t_{i}
$$

Calculamos las ganancias por ventilación [Ec. 9.29]

$$
Q_{a}=\sum_{i=1}^{n} C_{A} \cdot\left(0,2 \cdot \Delta t_{i}+0,6 \Delta w\right)
$$

$Q_{a}=e s$ el calor sensible del aire interior, en $\mathrm{W}$

$\mathrm{C}_{\mathrm{AR}}=$ caudal de aire a renovar en $\mathrm{m}^{3} / \mathrm{h}$

$0.25=$ constante entre el cociente del calor específico del aire a $21^{\circ} \mathrm{C}$ y $50 \%$ de humedad relativa $\mathrm{HR}$ y su volumen específico en $\mathrm{W} / \mathrm{m}^{3 \circ} \mathrm{C}$

$\Delta \mathrm{t}_{\mathrm{i}}=$ diferencia entre la temperatura exterior y la interior en ${ }^{\circ} \mathrm{C}$ para cada hora del día.

$\mathrm{n}=1$ a 24 
El uso de algoritmos genéticos aplicados al diseño bioambiental paramétrico

$0,61=$ la constante que resulta del cociente entre el valor medio de la cantidad de calor cedida por la condensación de un gramo de vapor de agua y el volumen específico de la misma mezcla de aire en $\mathrm{W} / \mathrm{m}^{3} . \mathrm{g}$

$\Delta \mathrm{w}=$ diferencia entre la humedad específica del aire exterior y la humedad específica del aire interior en $\mathrm{g} / \mathrm{kg}$

Se calculan a continuación las ganancias solares [Ec. 9.30]:

$$
Q_{s}=F_{s} \cdot K_{v} \cdot \sum_{o \in O} A A_{o} \cdot \sum_{i=1}^{n} I \cdot o \cdot \Delta t_{i}
$$

$Q_{s}=$ ganancias solares por vidrios en $W$.

Fs: es el factor de exposición solar que, en nuestro caso es de 0.35 y corresponde a DVH $6+12+6$ de baja emisividad

$\mathrm{K}_{\mathrm{v}}$ : transmitancia térmica en $\mathrm{W} / \mathrm{m}^{2} \mathrm{~K}$

$A v_{0}:$ área de ventanas en $\mathrm{m}^{2}$

$\mathrm{O}=\{$ Norte, Sur, Este, Oeste $\}$

IS $\mathrm{S}_{\mathrm{o}}$ : radiación sobre el plano según su orientación y para cada hora del día (Tabla Anexo 33)

$\Delta \mathrm{t}_{\mathrm{i}}=$ variación de la temperatura exterior/interior para cada hora del día en ${ }^{\circ} \mathrm{C}$

$\mathrm{n}=1$ a 24 horas

Se calculan las ganancias internas [Ec. 9.31]:

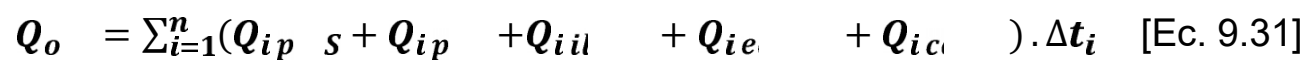

$Q_{o S L}=$ ganancias por fuentes internas: personas, equipamiento, iluminación. A cada hora del día corresponde una ocupación (Tabla 8.8).

$\Delta \mathrm{t}_{\mathrm{i}}=$ diferencia de temperatura exterior/interior para cada hora del día en ${ }^{\circ} \mathrm{C}$

$\mathrm{n}=1$ a 24

Analizamos, a continuación, cada término [Ecs. 9.32 a 35)

$$
Q_{i p} \quad=M_{S} \cdot \sum_{i=1}^{n} N_{i p}
$$

$Q_{\text {ipers }}=$ es el calor sensible de las personas en $\mathrm{W}$

$\mathrm{n}=1$ a 24 horas 
$M_{s}=e s$ el calor sensible por persona en $\mathrm{W}$

$\mathrm{N}_{\text {ipers}}=$ número de personas según la hora del día

$$
Q_{i p}=M_{L} \cdot \sum_{i=1}^{n} N_{p}
$$

$Q_{\text {iperL }}=$ es el calor latente de las personas en W

$\mathrm{n}=1$ a 24 horas

$\mathrm{M}_{\mathrm{L}}=\mathrm{e}$ el calor latente por persona en $\mathrm{W}$

$\mathrm{N}=$ número de personas según la hora del dia

$$
Q_{i i l}=q_{i l} \quad C_{t} \cdot \sum_{i=1}^{n} A_{i}
$$

$Q_{\text {iilums }}$ es la carga térmica producida por la iluminación en $W$. Se obtiene del mismo modo que para $\mathrm{G}_{\mathrm{REF}}$ (ver Ec. 9.13) pero considerando la variación del área ocupada para cada hora del día $\left(A_{i}\right)$

qilum= energía térmica por unidad de superficie en $\mathrm{W} / \mathrm{m}^{2}$ (ver Ec. 9.13)

$\mathrm{Ct}=$ coeficiente térmico según el tipo de iluminación

Como ya fuera expresado más arriba, Qiequips no será considerada.

$$
Q_{c}=\sum_{i=1}^{n}\left(Q_{i p}+Q_{i i l}+Q_{i e}\right) \cdot C_{s} \cdot \Delta t_{i}
$$

$Q_{\text {cond }}=$ carga térmica de los conductos de aire acondicionado en W (ver Ec. 6.32)

$\mathrm{CA}_{s}=$ coeficiente de aporte de calor sensible en W (Ec. 6.32)

$\Delta \mathrm{t}_{\mathrm{i}}=$ diferencia de temperatura exterior/ interior en ${ }^{\circ} \mathrm{C}$

$\mathrm{n}=1$ a 24

El índice $B_{C A L}$ obtenido expresa la demanda energética $(W)$ por unidad de volumen de aire $\left(\mathrm{m}^{3}\right)$ para las 24 horas de un día típico de invierno. Es usual expresar la intensidad energética de un edificio $\left(\mathrm{Wm}^{2}\right)$ para lo cual dividimos el total de las cargas obtenidas para un día típico de invierno por la superficie del edificio (Ec. 9.36):

$$
B_{C}=\frac{1}{s} Q_{c}+Q_{r}-Q_{a}-Q_{s}-Q_{o}
$$

$\mathrm{BS}_{\mathrm{CAL}}=$ índice bioclimático de calefacción en $\mathrm{Wh} / \mathrm{m}^{2}$

$\mathrm{S}=$ superficie del edificio en $\mathrm{m}^{2}$ 
El uso de algoritmos genéticos aplicados al diseño bioambiental paramétrico

\subsection{Cálculo del índice bioclimático de refrigeración para un día típico de verano (BREF)}

Asì como se mencionan en el apartado 9.3, los métodos para el cálculo de la carga térmica para calefacción, también existen métodos para medir la carga térmica de refrigeración (Santamouris \& Asimakopoulos, 2013). El análisis térmico edilicio se puede dividir en dos tipos de métodos: el de la red térmica y el de transferencia. El primero considera al edificio como una red eléctrica de elementos interconectados, donde el calor se asimila a un flujo eléctrico. El segundo es más simple y considera las funciones de transferencia de calor.

Para obtener este índice, calculamos las ganancias térmicas hora a hora para un día típico de verano, de manera similar al método empleado para el cálculo del $\mathrm{G}_{\mathrm{REF}}$.

Las temperaturas horarias se calculan como se explica en el capítulo 5 apartado 5.1 (Anexo 3, Tabla 3.4).Si lo multiplicamos por la diferencia entre la temperatura exterior y la temperatura de confort interior $\Delta \mathrm{t}_{\mathrm{i}}$ para cada hora del día, obtenemos la demanda de refrigeración de un día típico de verano (enero) (Tablas Anexo 3-11 al 17).

La humedad se mantiene constante a largo del día para no complejizar innecesariamente una herramienta que se utiliza en las fases iniciales del diseño del edificio, considerando la misma que para $G_{R}$.

La ocupación del edificio de los diferentes varía según usos (vivienda, oficinas, uso mixto) y horarios. En este análisis, las ganancias varían hora a hora, según sea la temperatura exterior mayor o menor a la interior, considerando la máxima y mínima medias. La suma algebraica de dichas ganancias da como resultado el aporte de calor debido a la ocupación edilicia.

Este índice bioclimático de refrigeración representa la demanda de refrigeración de un día típico de verano en $\mathrm{Wh} / \mathrm{m}^{3}$ [Ec. 9.37].

$$
B_{R}=\frac{1}{V}\left(Q_{c}+Q_{a}+Q_{s}+Q_{o}\right)
$$

Analizamos los términos de la Ec. 9.38:

$$
Q_{c}=\sum_{i=0}^{n} \Delta t_{i:} \quad\left(K_{m} S_{m}\right)+\sum_{i=0}^{n} \Delta t_{i}\left(K_{v} S_{v}\right)+\sum_{i=0}^{n} \Delta t_{i:} \quad\left(K_{c} S_{c}\right)
$$

$\mathrm{Q}_{\mathrm{c}}=$ ganancias térmicas por conducción de la envolvente en W para cada hora del día

$\mathrm{K}_{\mathrm{m}}=$ transmitancia térmica del muro en $\mathrm{W} / \mathrm{m}^{2} \mathrm{~K}$

$\mathrm{S}_{\mathrm{m}}=$ superficie de muros en $\mathrm{m}^{2}$

$\mathrm{K}_{\mathrm{v}}=$ transmitancia térmica de las ventanas en $\mathrm{W} / \mathrm{m}^{2} \mathrm{~K}$ 
9. Etapa 2. Edificio de nueva planta en el Área Metropolitana de Buenos Aires. Sub-etapa 2.2. Estructuración del modelo

$\mathrm{S}_{\mathrm{v}}=$ superficie de las ventanas en $\mathrm{m}^{2}$

$\mathrm{K}_{\mathrm{c}}=$ transmitancia térmica de la cubierta en $\mathrm{W} / \mathrm{m}^{2} \mathrm{~K}$

$\mathrm{S}_{\mathrm{c}}=$ superficie de las cubiertas en $\mathrm{m}^{2}$

$\Delta \mathrm{t}_{\mathrm{iSA}}=$ diferencia entre temperatura sol-aire y de confort en muros y cubiertas para cada hora del día

$\Delta \mathrm{t}_{\mathrm{i}}=$ diferencia de temperatura exterior $\mathrm{y}$ de confort para cada hora del día

$\mathrm{n}=1$ a 24

Se analiza el siguiente término [Ec. 9.39]

$$
Q_{a}=\sum_{i=1}^{n} C_{A} \cdot\left(0,2 \cdot \Delta t_{i}+0,6 \Delta w\right)
$$

$Q_{a}=e s$ el calor sensible del aire interior, en $\mathrm{W}$

$\mathrm{C}_{\mathrm{AR}}=$ caudal de aire a renovar en $\mathrm{m}^{3} / \mathrm{h}$

$0.25=$ constante entre el cociente del calor específico del aire a $21^{\circ} \mathrm{C}$ y $50 \%$ de humedad relativa $\mathrm{HR}$ y su volumen específico en $\mathrm{W} / \mathrm{m}^{3 \circ} \mathrm{C}$

$\Delta \mathrm{t}_{\mathrm{i}}=$ diferencia entre la temperatura exterior y la interior en ${ }^{\circ} \mathrm{C}$ para cada hora del día.

$\mathrm{n}=1$ a 24

$0,61=$ la constante que resulta del cociente entre el valor medio de la cantidad de calor cedida por la condensación de un gramo de vapor de agua y el volumen específico de la misma mezcla de aire en $\mathrm{W} / \mathrm{m}^{3} . \mathrm{g}$

$\Delta \mathrm{w}=$ diferencia entre la humedad específica del aire exterior y la humedad específica del aire interior en $\mathrm{g} / \mathrm{kg}$

El siguiente término se compone así [Ec. 9.40]:

$$
Q_{s}=F \cdot K_{V} \cdot \sum_{o \in O} A_{v} \cdot \sum_{i=1}^{n} I \cdot o \cdot \Delta t_{i}
$$

$Q_{s}=$ ganancias solares a través de los elementos vidriados exteriores en W

Fs: es el factor de exposición solar

$\mathrm{K}_{\mathrm{v}}$ : transmitancia térmica en $\mathrm{W} / \mathrm{m}^{2} \mathrm{~K}$

$A_{V_{0}}:$ área de ventanas en $\mathrm{m}^{2}$ 
El uso de algoritmos genéticos aplicados al diseño bioambiental paramétrico

$\mathrm{O}=\{$ Norte, Sur, Este, Oeste $\}$

ISoi: radiación sobre el plano según su orientación (Anexo 1- Tabla A1.4)

$\Delta \mathrm{t}_{\mathrm{i}}=$ diferencia de temperatura exterior/interior en ${ }^{\circ} \mathrm{C}$ en cada hora del día

$\mathrm{n}=1$ a 24

El siguiente término corresponde a las ganancias internas [Ec. 9.50]

$$
\boldsymbol{Q}_{\boldsymbol{o}}=\sum_{\boldsymbol{i}=1}^{\boldsymbol{n}}\left(\boldsymbol{Q}_{\boldsymbol{i} \boldsymbol{p}}+\boldsymbol{Q}_{\boldsymbol{i} \boldsymbol{p}}+\boldsymbol{Q}_{\boldsymbol{i} i \mathrm{i}}+\boldsymbol{Q}_{\boldsymbol{i} \boldsymbol{e}}+\boldsymbol{Q}_{\boldsymbol{i} \boldsymbol{c}}\right) . \Delta \boldsymbol{t}_{\boldsymbol{i}} \quad \text { [Ec. 9.50] }
$$

$Q_{o s L}=$ calor latente y sensible por fuentes internas: personas, equipamiento, iluminación y conductos en $\mathrm{W}$.

$Q_{\text {ipers }}=$ calor sensible de las personas en W (ver Ec. 2.3.2.29)

$Q_{\text {iperL }}=$ calor latente de las personas en W (ver. Ec. 2.3.2.30)

$Q_{\text {iilum }}=$ ganancias internas por iluminación en W (ver. Ec. 2.3.2.31)

$Q_{\text {iequip }}=$ ganancias internas del equipamiento en W, que no serán consideradas en este caso.

$Q_{\text {iconds }}=$ ganancias internas por conductos en W (ver 2.3.2.32)

$\mathrm{Al}$ igual que sucede con $\mathrm{B}_{\mathrm{CAL}}$, el $\mathrm{B}_{\mathrm{REF}}$ representa la demanda energética de un día típico de verano por unidad de volumen. Si lo expresamos por unidad de superficie la ecuación es la sig. [Ec. 9.51].

$$
B_{r}=\frac{1}{s} \cdot \sum_{i=1}^{n} Q_{c}+Q_{a}+Q_{s}+Q_{o}
$$

\subsection{Cálculo de la demanda de calefacción para la hora pico solar: $\mathbf{Q}_{\mathrm{h} 14}$}

Simultáneamente con los índices y coeficientes mencionados más arriba, el programa calcula la demanda de invierno a la hora pico solar. La aislación térmica del edificio disminuye la demanda energética tanto de calefacción como de refrigeración, pero al mismo tiempo, aparecen fenómenos de exceso de calor debido a las ganancias solares y las ganancias internas, en invierno superando la temperatura de confort $\left(20^{\circ} \mathrm{C}\right)$. Al contar con el cálculo horario de dicha demanda, solamente se deben sumar algebraicamente las ganancias y pérdidas a la hora pico solar, a los efectos de verificar si se produce dicho exceso de calor [Ec. 9.52]. Para evitar dicho fenómeno, deberá proveerse masa térmica que pueda absorberlo y devolverlo al ambiente con un retraso tal que sirva como aporte a la reducción de la demanda de calefacción.

$$
Q_{h}=Q_{c h}+Q_{a h}-Q_{s h}-Q_{o} h
$$


9. Etapa 2. Edificio de nueva planta en el Área Metropolitana de Buenos Aires.

donde:

$\mathrm{Q}_{\mathrm{h} 14}=$ carga térmica de calefacción para la hora pico solar (14h) de un día típico de invierno en W.

$Q_{\text {ch14}}=$ carga térmica por conducción de la envolvente en W

$\mathrm{Q}_{\mathrm{ah14}}=$ carga térmica del aire en $\mathrm{W}$

$\mathrm{Q}_{\mathrm{sh} 14}=$ carga solar en W

$Q_{0 S L h 14}=$ carga térmica por fuentes internas en W

Analizamos los términos por separado [Ecs. 9.53, 54,.55 y.56]

$$
Q_{c h}=\Delta t_{S h}\left(K_{m} S_{m}\right)+\Delta t_{h 4}\left(K_{v} S_{v}\right)+\Delta t_{S h}\left(K_{c} S_{c}\right)
$$

donde:

$\mathrm{Q}_{\mathrm{ch14}}=$ carga térmica por conducción de la envolvente en W

$\mathrm{K}_{\mathrm{m}}=$ transmitancia térmica del muro en $\mathrm{W} / \mathrm{m}^{2} \mathrm{~K}$

$\mathrm{S}_{\mathrm{m}}=$ superficie de muros en $\mathrm{m}^{2}$

$\mathrm{K}_{\mathrm{v}}=$ transmitancia térmica de las ventanas en $\mathrm{W} / \mathrm{m}^{2} \mathrm{~K}$

$\mathrm{S}_{\mathrm{v}}=$ superficie de las ventanas en $\mathrm{m}^{2}$

$\mathrm{K}_{\mathrm{c}}=$ transmitancia térmica de la cubierta en $\mathrm{W} / \mathrm{m}^{2} \mathrm{~K}$

$\mathrm{S}_{\mathrm{c}}=$ superficie de las cubiertas en $\mathrm{m}^{2}$

$\Delta t_{\mathrm{SAh} 14}=$ diferencia entre temperatura sol-aire y de confort en muros y cubiertas para la hora 14 en ${ }^{\circ} \mathrm{C}$

$\Delta t_{h 14}=$ diferencia de temperatura exterior y de confort para la hora 14 en ${ }^{\circ} \mathrm{C}$

$$
Q_{a h}=C_{A} \cdot\left(0,2 \Delta_{h}+0,6 \Delta w\right)
$$

donde:

$Q_{a h 14}=$ carga térmica del aire a la hora 14 en $\mathrm{W}$

$\mathrm{C}_{\mathrm{AR}}=$ caudal de aire a renovar en $\mathrm{m}^{3} / \mathrm{h}($ Ec. 6.10$)$ 
El uso de algoritmos genéticos aplicados al diseño bioambiental paramétrico

$0.25=$ constante entre el cociente del calor específico del aire a $21^{\circ} \mathrm{C}$ y $50 \%$ de humedad relativa $(H R)$ y su volumen específico en $\mathrm{W} / \mathrm{m}^{3 \circ} \mathrm{C}$

$$
Q_{s}=F_{s} \cdot \sum_{i=0}^{n} A_{v} \cdot K_{v} \cdot I_{s}
$$

Las ganancias internas de la hora pico solar se calculan de la misma forma que para $B_{\text {REF }}$ [Ec. 55]

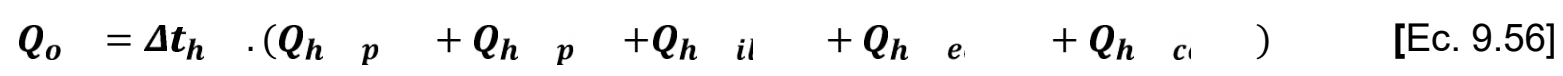

Los términos se componen de la misma manera que en la Ec. 9.50. 
10. Etapa 2

Edificio de nueva planta en el Área Metropolitana de Buenos Aires. Sub-etapa 2.3: Optimización de la morfología 
El uso de algoritmos genéticos aplicados al diseño bioambiental paramétrico 


\subsection{Integración de las variables a optimizar. El uso del AG}

La herramienta digital calcula en tiempo real: $G_{C A L}, G_{R E F}, B_{C A L}, B_{C A L}, B_{R E F}$ y $B S_{R E F}$, para la morfología edilicia que hemos definido paramétricamente, integrando todas sus variables en una única rutina.

La optimización del agrupamiento de los tres volúmenes que componen el edificio se realiza a través de un algoritmo genético de GH: Galápagos (Granadeiro, Correia, Leal, \& Duarte, 2013). Este algoritmo busca luego de una determinada cantidad de generaciones, aquellos individuos que presenten el mínimo $B_{\text {REF }}$ a la vez que no superen el $G_{R A D M}$, que sirve como parámetro para determinar la demanda enérgetica instantánea para refrigeración.

Se fijan los parámetros internos del AG (fig. 10.1):

- Valor adecuado (fitness): se determina para cada proceso, se puede maximizar, minimizar.

- Umbral (thereshold): surge de la estimación de un valor mínimo o máximo posible donde el $A G$ se desempeña correctamente y está relacionado con el espacio de búsqueda. Se lo debe ajustar para cada proceso.

- Población (population): $\mathrm{n}^{\circ}$ de individuos que la integran, adoptamos 75

- Máximo remanente (maximum stagnant): máxima cantidad individuos a mantener en cada generación, que lo fijamos en 50 .

- Población inicial (population): $\mathrm{n}^{\circ}$ de individuos que originan la población: 2

- Porcentaje de individuos a mantener en todas las generaciones (maintain): $5 \%$

- Porcentaje de endogamia (inbreeding): cruzamiento entre individuos de parentesco cercano: $75 \%$

Es posible incorporar mutaciones durante el proceso de reproducción, pero este recurso no fue utilizado manualmente, las mutaciones fueron aleatoriamente realizadas por el AG.

\subsection{Iteración del AG: Optimización de la morfología}

Los datos de entrada del AG son las coordenadas de los centros de las bases de los volúmenes en el terreno. Se itera sobre la forma y no sobre el porcentaje vidriado/opaco, ya que el algoritmo sólo buscaría minimizarlo, sin explorar suficientemente las posibilidades formales. 
El fitness se fija para alcanzar el mínimo $B_{R E F}$ buscando, a su vez, no superar el $G_{R}$ ADM $\left(19,33 \mathrm{~W} / \mathrm{m}^{3} \mathrm{~K}\right)$. No necesariamente un menor $B_{\text {REF }}$ implica un menor $\mathrm{G}_{\mathrm{REF}}$. El AG itera hasta encontrar las alternativas que ofrezcan los mínimos valores de $B_{R E F}$, calculando en tiempo real, los índices $B S_{R E F}, B_{C A L}$ y $B S_{C A L}$ y los coeficientes $G_{R E F}$ y $G_{C A L}$.

Las soluciones obtenidas cumplen el requisito de no superar el $G_{R}$ ADM admisible. El cumplimiento de $G_{R E F}$ lleva implícito el cumplimiento de $G_{C A L}$ ADM, ya que en la zona bioambiental elegida, las exigencias de aislación para verano superan a las de invierno.

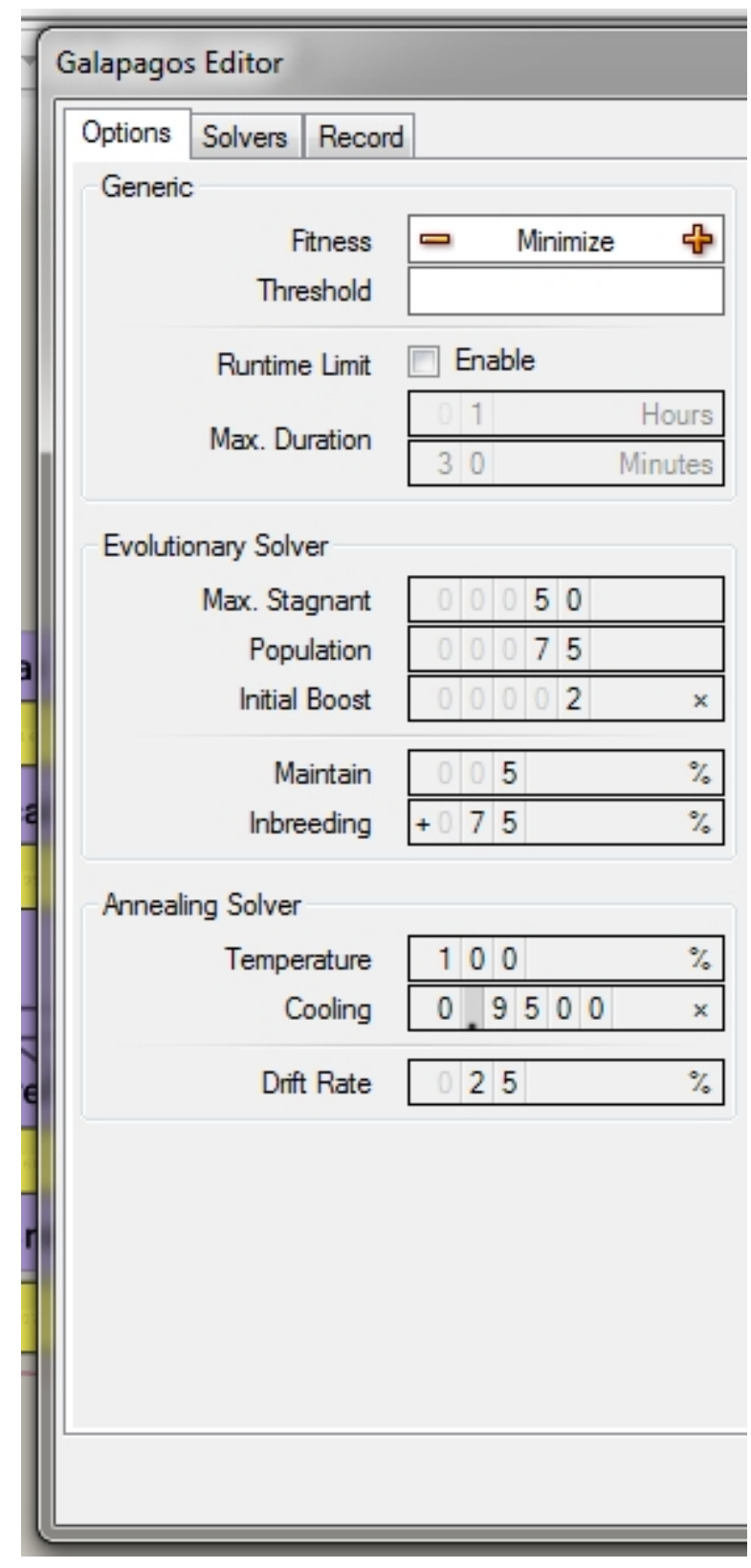

Fig. 10.1: Editor de Galapagos en GH. Fuente: la autora

Se seleccionaron dieciocho alternativas morfológicas que se analizan a continuación (Fig. 10.2 y 10.3). Se pueden apreciar las diferentes configuraciones de volúmenes y su grado de 
10. Etapa 2. Edificio de nueva planta en el Área Metropolitana de Buenos Aires. Sub-etapa 2.3: Optimización de la morfología

superposición. En todas ellas, se observa la compacidad del resultado formal, debido a las restricciones geométricas impuestas en la definición del agrupamiento (Apartado 9.1)

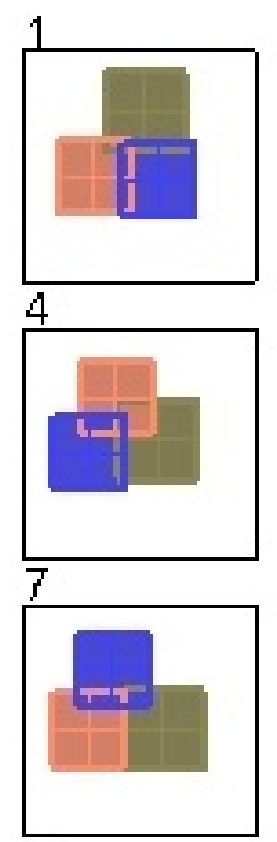

10

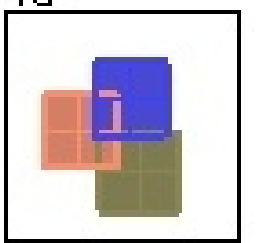

13

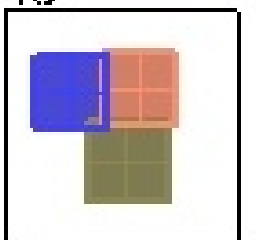

16

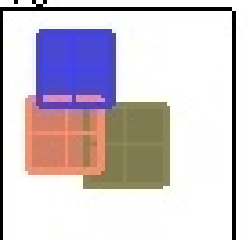

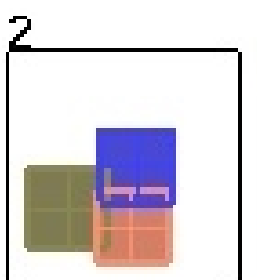

5
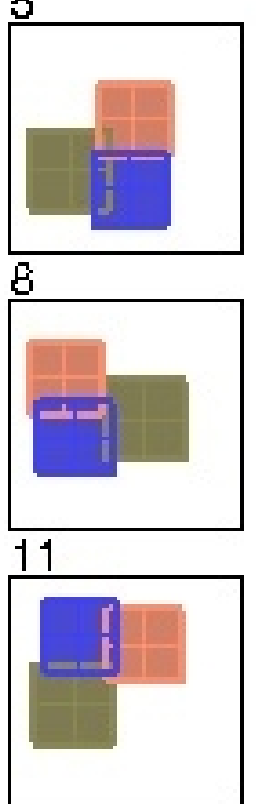

14

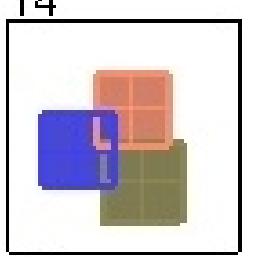

17

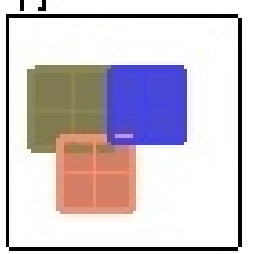

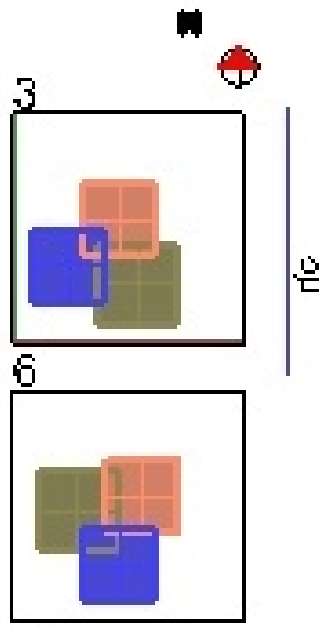
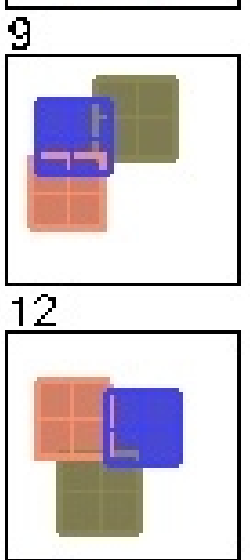

15

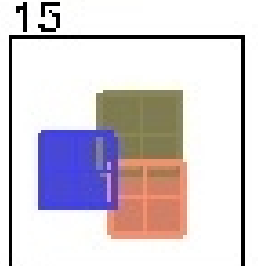

18

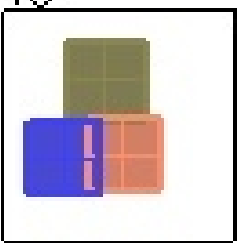

Referencias: azul: oficinas, verde: viviendas, naranja: uso mixto

Fig. 10.2. Planta de las morfologías optimizadas. Fuente: la autora 


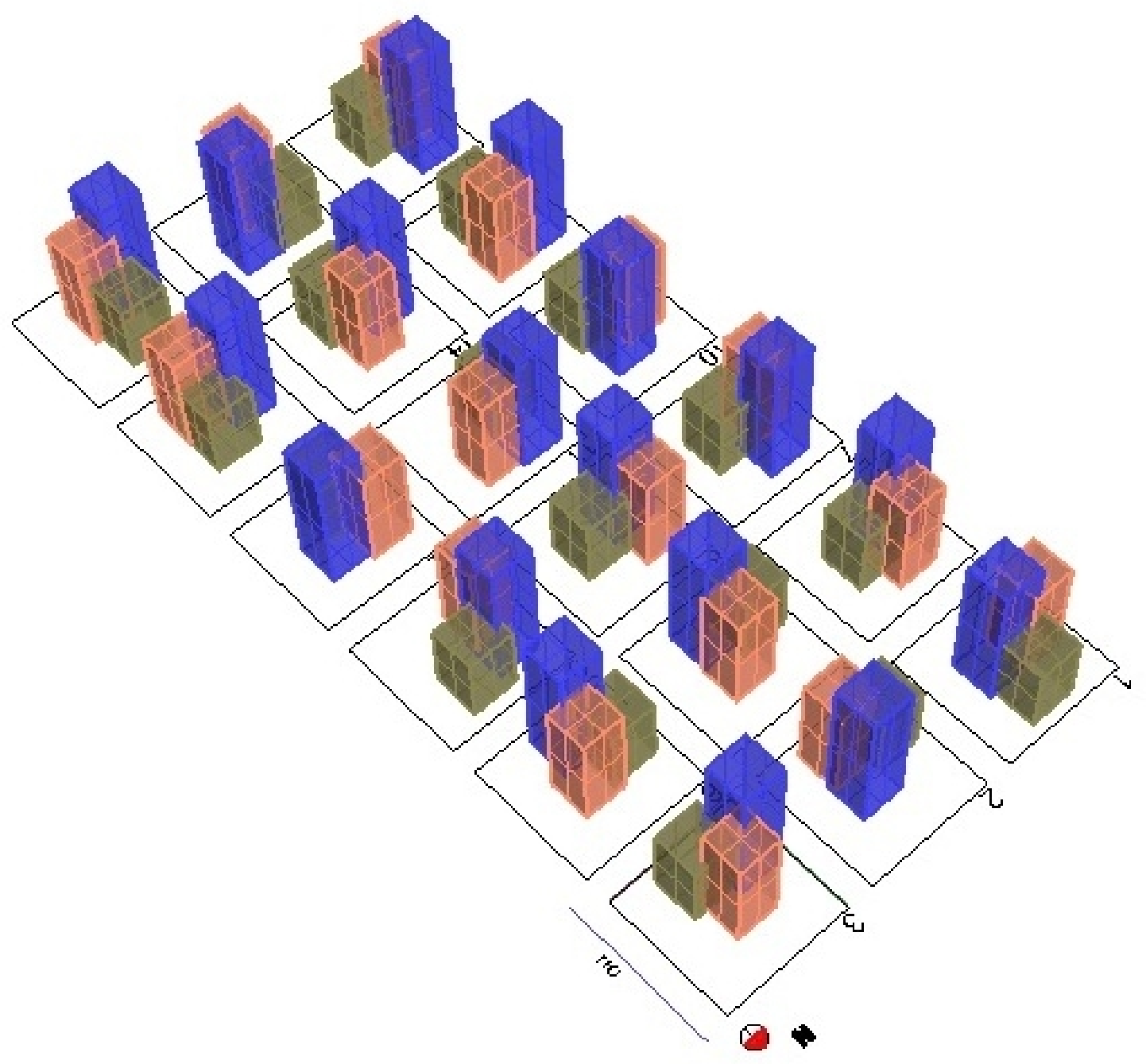

Fig. 10.3. Vista NE de las alternativas morfológicas optimizada. Fuente: la autora

En la Tabla 10.1 se observan los datos de los coeficientes volumétricos de refrigeración $\left(G_{R E F}\right)$ y calefacción $\left(G_{C A L}\right)$, junto con los índices bioclimáticos de refrigeración $\left(B_{R E F}\right)$ y calefacción ( $\left.\mathrm{B}_{\mathrm{CAL}}\right)$ y su expresión por unidad de superficie $\left(\mathrm{BS}_{\mathrm{REF}}\right.$ y $\left.\mathrm{BS}_{\mathrm{CAL}}\right)$, optimizados de acuerdo al índice bioclimático de refrigeración, $B_{R E F}$. Todos los datos obtenidos de cada alternativa morfológica están volcados en la Tabla A 2.1 y A 2.2 del Anexo 2.

La relación entre las variables $\mathrm{G}_{\mathrm{REF}}, \mathrm{B}_{\mathrm{REF}}, \mathrm{G}_{\mathrm{CAL}}$ y $\mathrm{B}_{\mathrm{CAL}}$ se muestra en la Fig. 10.4. Las alternativas están ordenadas de menor a mayor $B_{R E F}$.

\subsection{Iteración del AG: Optimización de los elementos vidriados}

Una vez obtenidas las alternativas optimizadas de $B_{R E F}$, se vuelve a iterar con el $A G$ pero esta vez sobre los porcentajes de área vidriada de cada fachada, utilizando un rango desde $10 \%$ para la fachada Sur y $20 \%$ para las fachadas Norte, Este y Oeste hasta $100 \%$ para 
10. Etapa 2. Edificio de nueva planta en el Área Metropolitana de Buenos Aires.

Sub-etapa 2.3: Optimización de la morfología

todas las orientaciones (Tabla 10.2). Se parte de las alternativas ya obtenidas en la optimización de $B_{\text {REF }}$ y se aumenta la población de 75 a 100 individuos.

\begin{tabular}{|c|c|c|c|c|c|c|c|c|c|}
\hline \multirow{3}{*}{ Alternativas } & $B_{\text {REF }}$ & $B_{\text {REF }}$ & $\mathbf{G}_{R}$ & $\mathbf{G}_{\mathrm{R} \text { ADM }}$ & $\mathrm{B}_{\mathrm{CAL}}$ & $\mathrm{BS}_{\mathrm{CAL}}$ & $\mathbf{G}_{\text {CAL }}$ & $\begin{array}{l}\mathbf{G}_{\mathrm{CAL}} \\
\mathrm{ADM}\end{array}$ & $\begin{array}{l}Q_{\text {CAL }} \\
\text { 144 }\end{array}$ \\
\hline & Wh/ & Wh/ & & & Wh/ & Wh/ & & & \\
\hline & $\begin{array}{c}\mathrm{m}^{3} . \text { dia } \\
\text { ver. }\end{array}$ & $\begin{array}{l}\mathrm{m}^{2} . \\
\text { día } \\
\text { ver. }\end{array}$ & $\mathrm{W} / \mathrm{m}^{3}$ & $\mathrm{~W} / \mathrm{m}^{3}$ & $\begin{array}{c}\mathrm{m}^{3} \text {.dia } \\
\text { inv. }\end{array}$ & $\begin{array}{c}\mathrm{m}^{2} \text { día } \\
\text { inv. }\end{array}$ & $\underset{{ }^{3} \mathrm{~K}}{\mathrm{~W} / \mathrm{m}}$ & $\underset{K}{W / m^{3}}$ & $\mathrm{~W} / \mathrm{m}$ \\
\hline 1E & 320,5 & 801,25 & 17,9 & 19,33 & 48,87 & 122,19 & 0,58 & 1,36 & $-8,64$ \\
\hline $2 E$ & 313,80 & 784,50 & 17,52 & 19,33 & 48,17 & 120,42 & 0,57 & 1,35 & $-8,46$ \\
\hline $3 E$ & 309,32 & 773,31 & 18,19 & 19,33 & 50,51 & 126,27 & 0,59 & 1,34 & -9 \\
\hline $4 E$ & 321,81 & 804,52 & 18,72 & 19,33 & 50,60 & 125,17 & 0,60 & 1,36 & $-9,12$ \\
\hline $5 \mathrm{E}$ & 321,27 & 803,17 & 17,92 & 19,33 & 48,64 & 121,61 & 0,58 & 1,36 & $-8,63$ \\
\hline $6 \mathrm{E}$ & 325,07 & 812,68 & 18,21 & 19,33 & 50,39 & 125,97 & 0,60 & 1,36 & $-8,87$ \\
\hline $7 E$ & 315,75 & 789,37 & 18,06 & 19,33 & 50,25 & 125,65 & 0,59 & 1,36 & $-8,86$ \\
\hline $8 \mathrm{E}$ & 333,38 & 833,44 & 18,50 & 19,33 & 53,20 & 132,99 & 0,62 & 1,36 & $-9,11$ \\
\hline $9 \mathrm{E}$ & 336,04 & 840,10 & 18,76 & 19,33 & 51,42 & 128,56 & 0,62 & 1,37 & $-9,09$ \\
\hline $10 \mathrm{E}$ & 322,65 & 806,63 & 18,45 & 19,33 & 51,17 & 127,92 & 0,60 & 1,36 & $-9,06$ \\
\hline 11E & 302,98 & 757,46 & 17,92 & 19,33 & 50,44 & 126,09 & 0,59 & 1,43 & $-8,91$ \\
\hline $12 E$ & 300,65 & 751,62 & 17,63 & 19,33 & 50,11 & 125,27 & 0,58 & 1,35 & $-8,77$ \\
\hline $13 E$ & 289,38 & 723,46 & 16,91 & 19,33 & 48,14 & 120,34 & 0,57 & 1,29 & $-8,33$ \\
\hline $14 E$ & 313,21 & 783,03 & 17,67 & 19,33 & 50,63 & 126,58 & 0,57 & 1,3 & $-8,69$ \\
\hline $15 E$ & 307,52 & 768,80 & 17,75 & 19,33 & 51,25 & 128,14 & 0,59 & 1,35 & $-8,67$ \\
\hline $16 E$ & 330,55 & 826,36 & 18,26 & 19,33 & 49,74 & 124,35 & 0,60 & 1,34 & $-8,79$ \\
\hline $17 E$ & 320,19 & 800,48 & 18,11 & 19,33 & 53,08 & 132,71 & 0,60 & 1,36 & $-9,07$ \\
\hline $18 \mathrm{E}$ & 312,11 & 780,27 & 18,29 & 19,33 & 53,13 & 132,82 & 0,61 & 1,35 & $-9,19$ \\
\hline
\end{tabular}

Tabla 10.1. Valores de $G_{R E F}, G_{C A L}, B_{R E F}, B_{C A L}, B S_{R E F}, B S_{C A L}$ y $Q_{H 14}$ para la optimización geométrica.

Fuente: la autora 
El uso de algoritmos genéticos aplicados al diseño bioambiental paramétrico

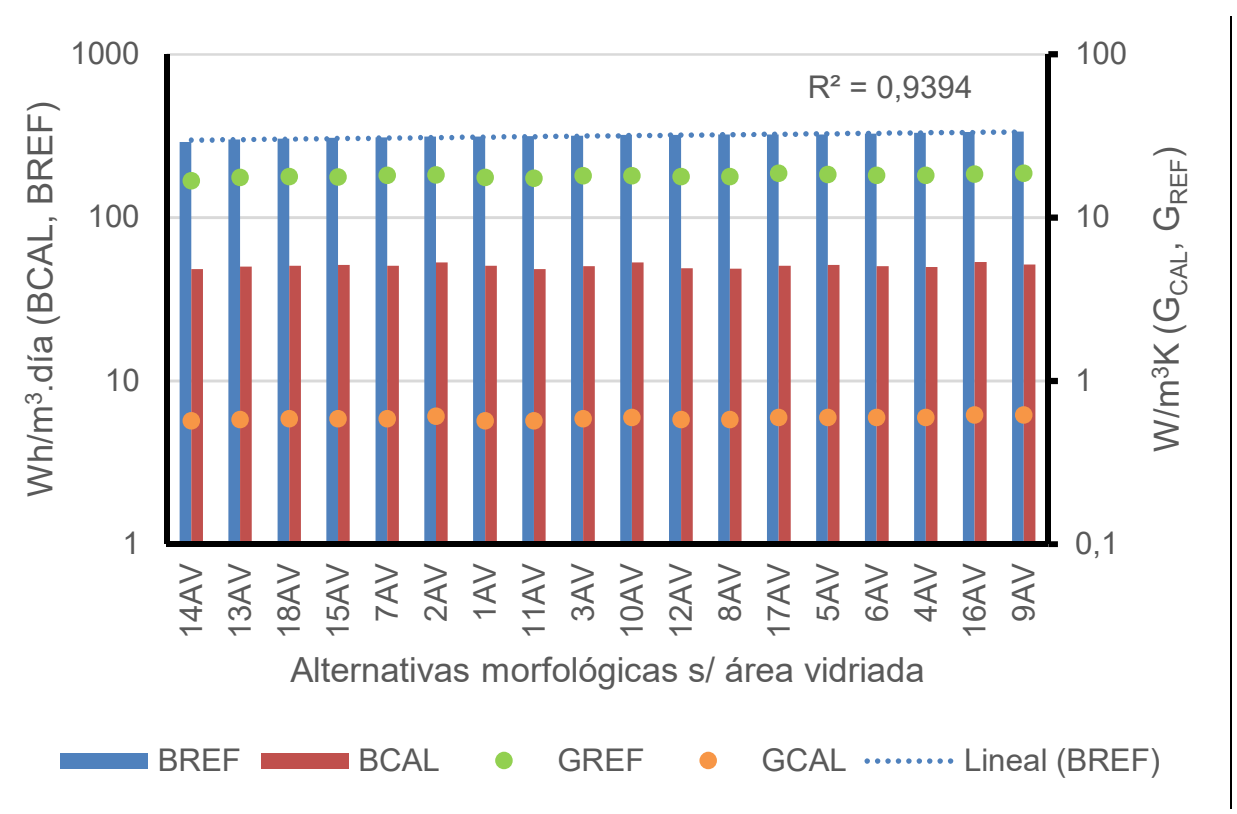

Fig. 10.4. Valores de los indicadores $B_{C A L}$ y $B_{R E F}$ y los coeficientes $G_{C A L}$ y $G_{R E F}$ para la optimización de la geometría. Fuente: la autora

\begin{tabular}{|c|c|c|c|c|c|c|c|c|c|}
\hline Alternativas & $\begin{array}{c}\mathrm{B}_{\mathrm{REF}} \\
\mathrm{Wh} / \\
\mathbf{m}^{3} . \text { dia } \\
\text { ver. }\end{array}$ & $\begin{array}{c}\text { BS }_{\text {REF }} \\
\text { Wh/ } \\
\text { m². día }^{\text {ver. }}\end{array}$ & $\mathrm{W} / \mathrm{m}^{3}$ & $\mathbf{G}_{\mathrm{R} \text { ADM }}$ & $\begin{array}{c}\mathrm{B}_{\mathrm{CAL}} \\
\mathrm{Wh} / \\
\mathrm{m}^{3} \cdot \mathrm{di} \\
\mathrm{a} \text { inv. }\end{array}$ & $\begin{array}{c}\mathrm{BS}_{\mathrm{CAL}} \\
\mathrm{Wh} / \\
\mathrm{m}^{2} \text { día } \\
\text { inv. }\end{array}$ & $\begin{array}{c}W / m^{3} \\
K\end{array}$ & $\begin{array}{c}\mathbf{G}_{\mathrm{CAL}} \\
\mathrm{ADM}\end{array}$ & $\begin{array}{c}Q_{\text {CAL }} \\
\text { h14 }\end{array}$ \\
\hline 1AV & 312,18 & 780,46 & 17,84 & 19,33 & 27,04 & 67,6 & 0,6 & 1,38 & $-10,46$ \\
\hline $2 A V$ & 310,71 & 776,78 & 17,45 & 19,33 & 58,72 & 146,81 & 0,56 & 1,47 & $-7,50$ \\
\hline 3AV & 320,27 & 800,69 & 19,16 & 19,33 & 73,54 & 183,86 & 0,64 & 1,35 & $-7,93$ \\
\hline 4AV & 354,20 & 885,49 & 17,85 & 19,33 & 4,52 & 11,31 & 0,57 & 1,38 & $-12,83$ \\
\hline $5 A V$ & 331,77 & 829,44 & 18,87 & 19,33 & 59,68 & 149,21 & 0,63 & 1,45 & $-8,49$ \\
\hline 6AV & 335,59 & 838,97 & 19,26 & 19,33 & 68,96 & 172,41 & 0,65 & 1,37 & $-8,19$ \\
\hline $7 A V$ & 309,37 & 773,44 & 17,95 & 19,33 & 26,83 & 67,06 & 0,60 & 1,38 & $-10,81$ \\
\hline 8AV & 331,15 & 827,87 & 18,12 & 19,33 & 20,61 & 51,52 & 0,62 & 1,37 & $-11,82$ \\
\hline 9AV & 426,17 & 1065,1 & 19,16 & 19,33 & 34,12 & 85,29 & 0,63 & 1,4 & $-11,80$ \\
\hline 10AV & 324,18 & 810,45 & 18,99 & 19,33 & 54,13 & 135,33 & 0,64 & 1,43 & $-9,43$ \\
\hline 11AV & 315,37 & 788,43 & 19,05 & 19,33 & 88,51 & 221,26 & 0,63 & 1,45 & $-6,70$ \\
\hline 12AV & 330,31 & 825,78 & 17,52 & 19,33 & 2,18 & 5,49 & 0,61 & 1,4 & $-13,59$ \\
\hline 13AV & 279,03 & 697,57 & 17,34 & 19,33 & 0,06 & 0,14 & 0,59 & 1,39 & $-12,50$ \\
\hline 14AV & 266,66 & 666,65 & 18,09 & 19,33 & 48,86 & 122,17 & 0,60 & 1,36 & $-8,61$ \\
\hline 15AV & 307,23 & 768,08 & 18,56 & 19,33 & 68,88 & 172,19 & 0,63 & 1,44 & $-8,05$ \\
\hline 16AV & 357,92 & 894,80 & 19,04 & 19,33 & 83,90 & 209,76 & 0,63 & 1,42 & $-6,93$ \\
\hline 17AV & 331,37 & 828,41 & 19,02 & 19,33 & 49,39 & 123,47 & 0,66 & 1,48 & $-10,34$ \\
\hline 18AV & 293,29 & 733,23 & 18,97 & 19,33 & 46,04 & 115,11 & 0,66 & 1,45 & $-10,20$ \\
\hline
\end{tabular}

Tabla 10.2. Valores de $G_{R E F}, G_{C A L}, B_{R E F}, B_{C A L}, B S_{R E F}, B S_{C A L}$ y $Q_{H 14}$ para la optimización del área vidriada. Fuente: la autora 
En esta segunda optimización, se itera sobre el índice $B_{R E F}$ que, -como se expresó en el Apartado 9.7- considera la demanda de un día típico de verano completo (24h) y no sobre $\mathrm{G}_{\mathrm{REF}}$ (hora pico solar). El umbral se fija en $300 \mathrm{~W} / \mathrm{m}^{3}$.día verano, que es aproximadamente el valor de $B_{R E F}$ de la optimización geométrica. La población se aumenta a 100 individuos, (éste es el límite que fija el algoritmo para esta rutina de cálculo), manteniendo los demás parámetros en los valores por defecto. Se corre el programa para cada una de las dieciocho alternativas obtenidas (Fig. 10.5), variando los porcentajes de área vidriada anteriormente fijos (Apartado 8.1.3). No es posible iterar la variable geométrica y el acristalamiento simultáneamente, debido a que el AG es mono-objetivo.

Índices bioclimáticos y coeficientes volumétricos s/área vidriada optimizada $B_{R E F}$ equivalente

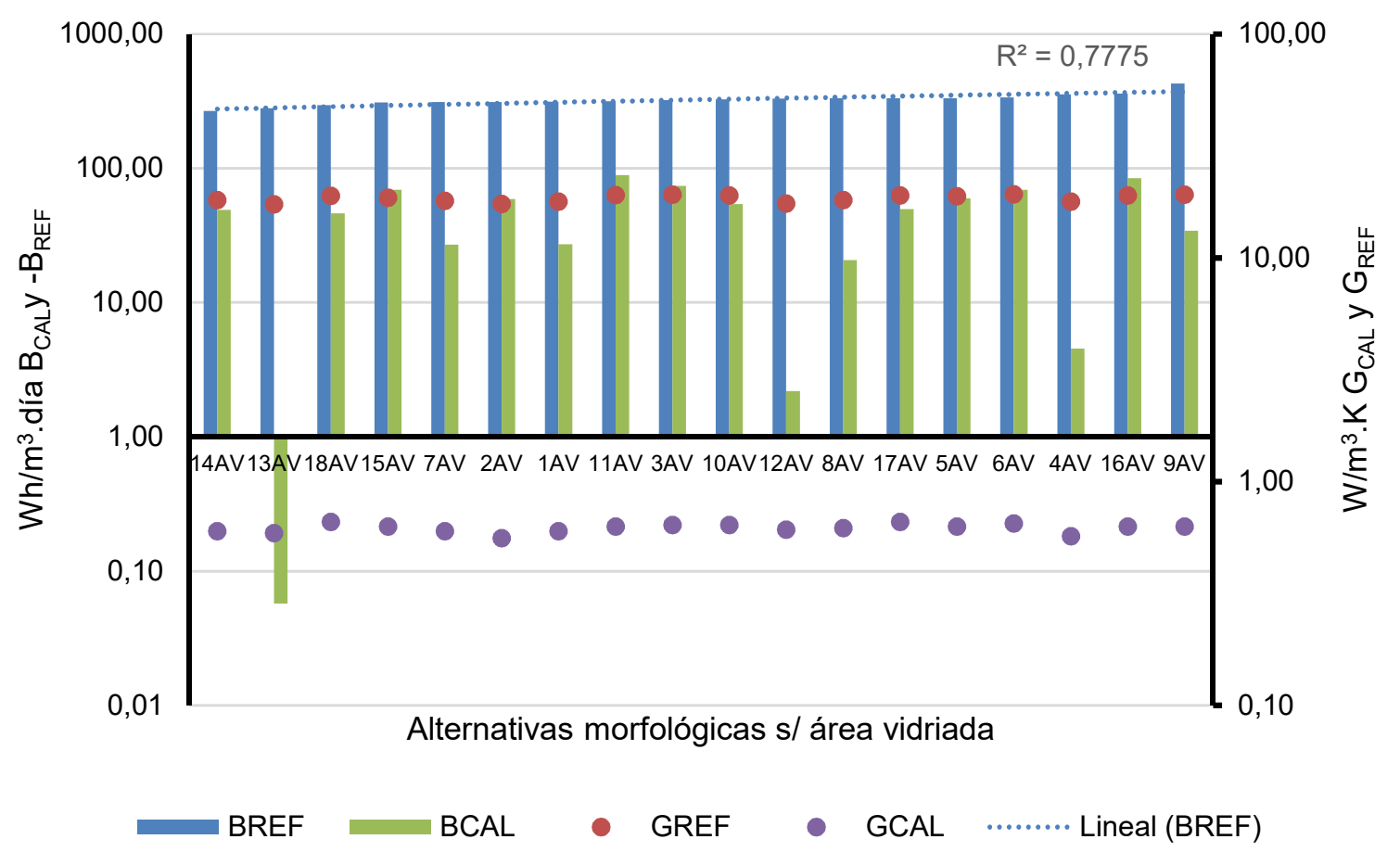

Fig. 10.5. Valores de los indicadores $B_{C A L}$ y $B_{R E F}$ y los coeficientes $G_{C A L}$ y $G_{R E F}$ para la optimización del área vidriada. Fuente: la autora

Se observa una mayor dispersión entre los valores obtenidos, ya que la optimización es alrededor de un umbral de $300 \mathrm{~W} / \mathrm{m}^{3}$. día verano, afectando el acristalamiento y no minimizando el valor del coeficiente $B_{R E F}$.

En la Tabla A2.1 del Anexo 2 se especifican las superficies de área vidriada y muro según cada orientación para las alternativas que optimizan la morfología y el aventamiento. La Tabla A2.2 del mismo anexo, relaciona los porcentajes de área vidriada según la orientación 
El uso de algoritmos genéticos aplicados al diseño bioambiental paramétrico respecto del área opaca de cada fachada, el total del área de cada fachada y el total de área vidriada de cada alternativa.

\subsection{El cálculo de la demanda de calefacción a la hora pico solar: QcaLh14}

Simultáneamente con los índices y coeficientes mencionados más arriba, el programa calcula la demanda de calefacción a la hora pico solar (Tabla 10.2).

Las ganancias solares, la ocupación y los equipos aportan calor al ambiente, el cual, sumado a la aislación térmica del edificio, puede resultar en un excedente de calor y superar la temperatura de confort, previamente fijada en $20^{\circ} \mathrm{C}$, si el edificio no cuenta con masa térmica para absorberlo. En la Fig. 10.6 se observa la comparación de la demanda de calefacción para la hora pico solar en la optimización de la morfología y del acristalamiento. Si se ordena en orden creciente la demanda QcaLh14 (Fig. 10.6), se observa que los primeros seis valores corresponden a alternativas optimizadas según el área vidriada (17\% de las 36 alternativas).

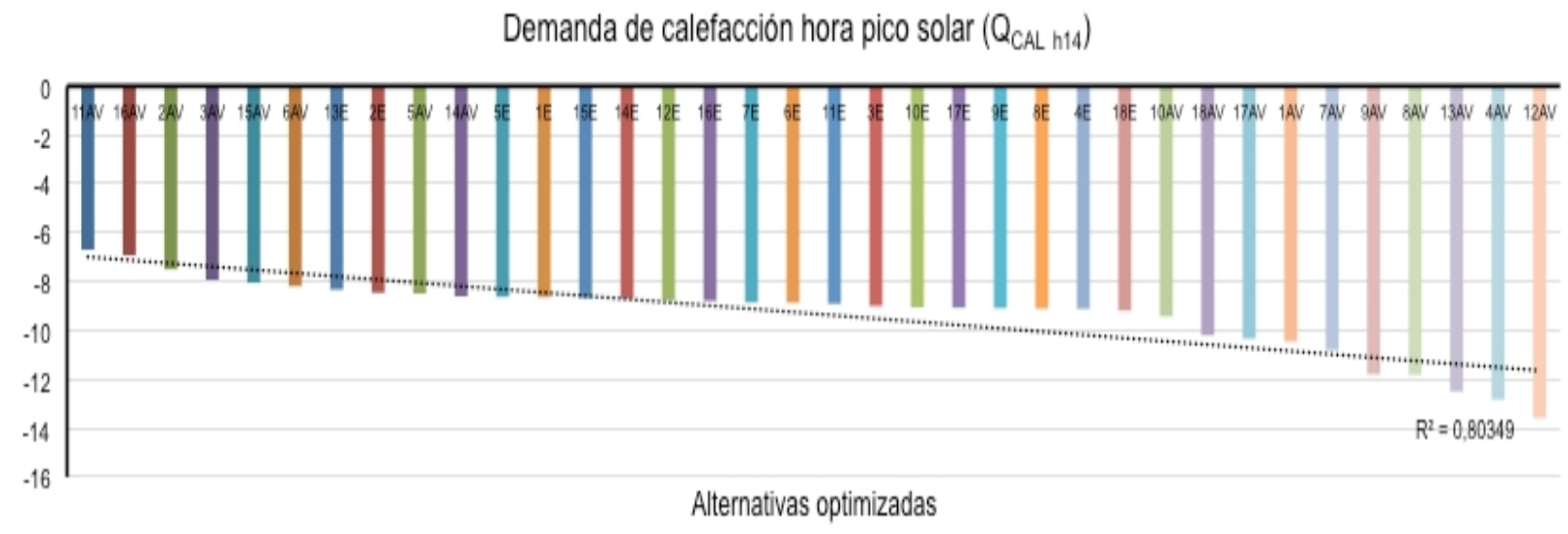

Fig. 10.6. Demanda de calefacción a la hora pico solar para las alternativas morfológicas optimizadas según geometría (E) y área vidriada (AV). Fuente: la autora

En la figura 10.7 se muestran por separado las seis alternativas con menor demanda de calefacción para la hora pico solar. 
10. Etapa 2. Edificio de nueva planta en el Área Metropolitana de Buenos Aires. Sub-etapa 2.3: Optimización de la morfología

\section{Relación entre área vidriada y demanda de calefacción en invierno hora pico solar}

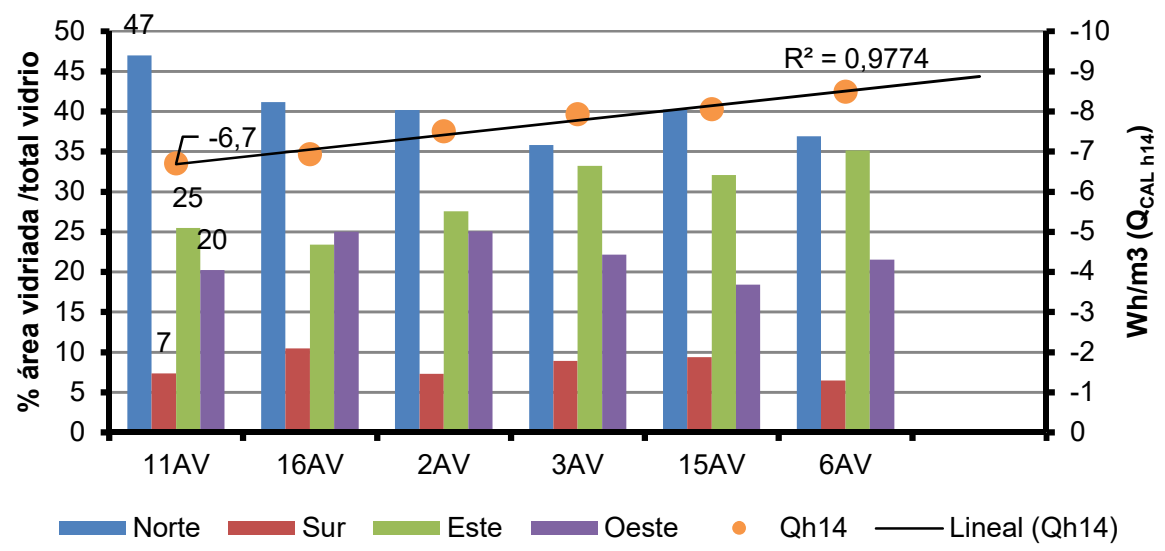

Fig. 10.7. Porcentajes de área vidriada de las alternativas con menor $Q_{n 14 .}$ Fuente: la autora

Estas alternativas presentan un área vidriada que va desde $37 \%$ hasta $47 \%$ al Norte, $6 \%$ al $10 \%$ al Sur, de $23 \%$ al $35 \%$ al Este, y de $18 \%$ al $25 \%$ al Oeste. En la figura de referencia (Fig. 10.7) se indican los porcentajes de área vidriada: $47 \%$ al Norte, $7 \%$ al Sur, $25 \%$ al Este y $20 \%$ al Oeste para la alternativa de menor demanda de calefacción (11AV).

Cuando se relacionan los porcentajes de área vidriada por orientación respecto del total del área vidriada del edificio, se observa una fuerte relación inversa entre el porcentaje de área vidriada de la fachada Norte y la demanda para la hora pico solar (Fig. 10.8). Esto nos indica que sería conveniente acumular las ganancias solares de las ventanas mediante masa térmica y liberar dicha energía al ambiente durante la noche.

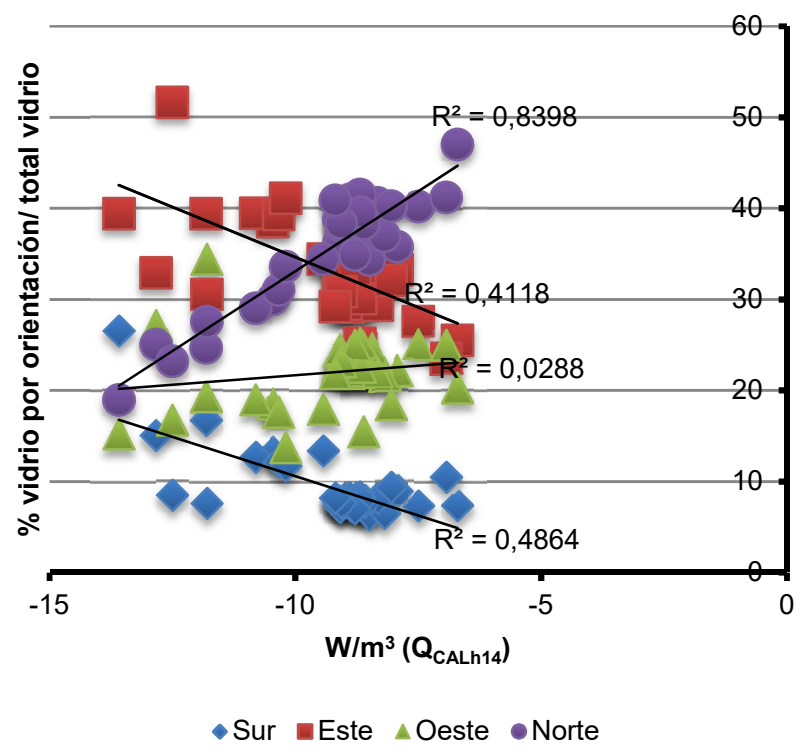

Fig. 10.8. Relación entre el área vidriada por orientación y la demanda de calefacción a la hora pico solar (Qcaln14). Fuente: la autora 
10.5. Relación entre el índice bioclimático de refrigeración $B_{R E F}$ y la demanda de calefacción a la hora pico solar: QcaLh14

Cuando se relaciona la demanda de calefacción $\left(Q_{\mathrm{CALh14}}\right)$ con el índice bioclimático $B_{\mathrm{REF}}$, se obtienen los valores de la Fig. 10.9. Se puede observar una tendencia inversamente

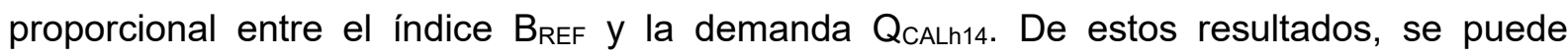
deducir que las mejores alternativas serían las 13E, 12E y 11E sino se tiene previsto colocar protección solar en las ventanas de las fachadas Norte que contrarresten las ganancias solares en verano. $\mathrm{Si}$, en cambio, se tiene previsto colocar protección solar (parasoles, cortinas exteriores), las alternativas que ofrecen menor $B_{R E F}$ son la $13 \mathrm{AV}, 12 \mathrm{AV}$, y $4 \mathrm{AV}$. $\mathrm{A}$ partir de estos resultados, se relacionan las seis mejores alternativas en cuanto al índice $B_{R E F}$, que se muestran en la Fig. 10.10, en orden creciente. El gráfico muestra que existe una relación directa entre el aumento del $B_{R E F}$ y el aumento de área vidriada al Norte, siendo menor en cuanto al área vidriada al Oeste. Para la orientación Este y Sur, el aumento del área vidriada es inversamente proporcional al aumento del $B_{R E F}$.

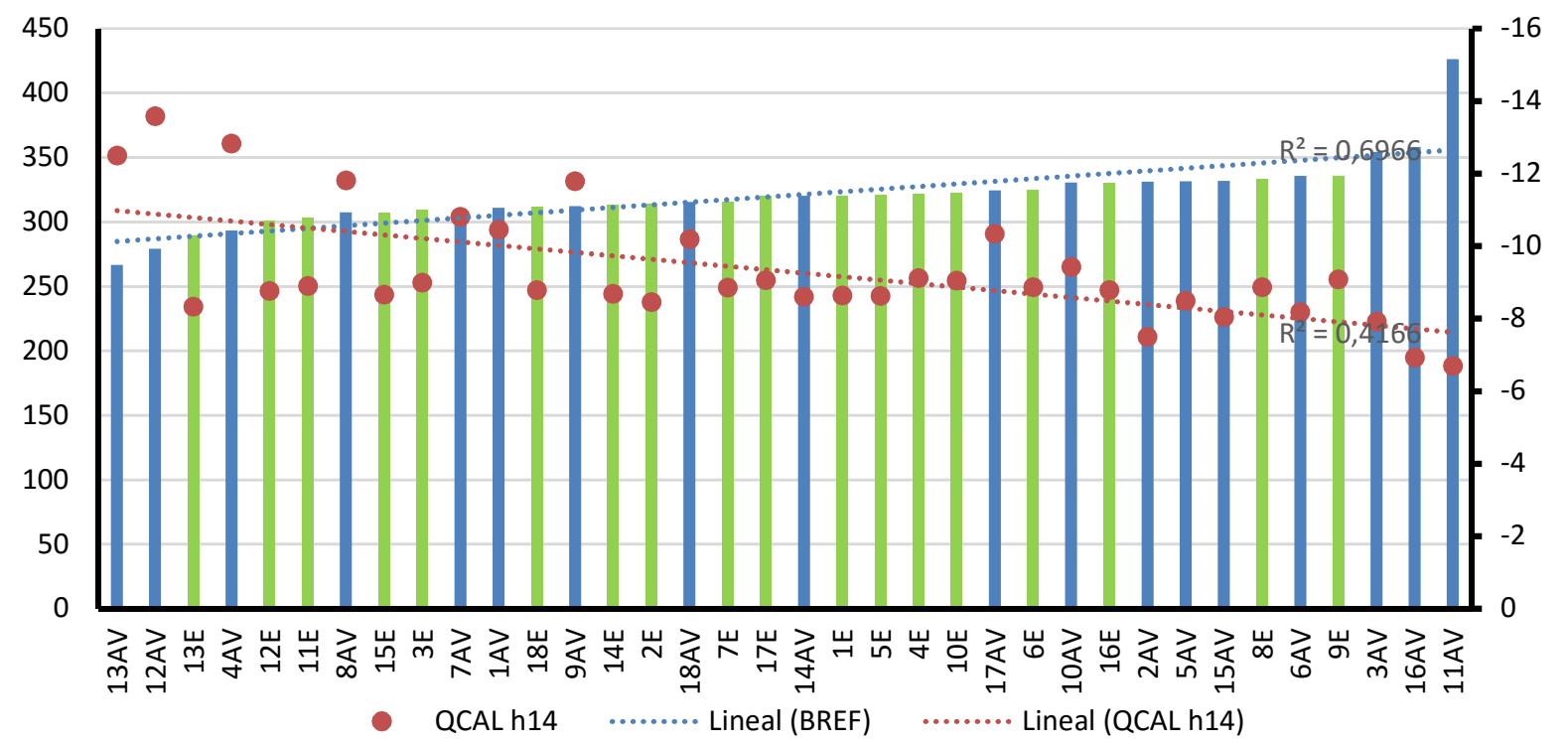

Fig. 10.9. Relación entre $B_{R E F}$ y $Q_{\text {CALh14. Fuente: la autora }}$ 
10. Etapa 2. Edificio de nueva planta en el Área Metropolitana de Buenos Aires. Sub-etapa 2.3: Optimización de la morfología

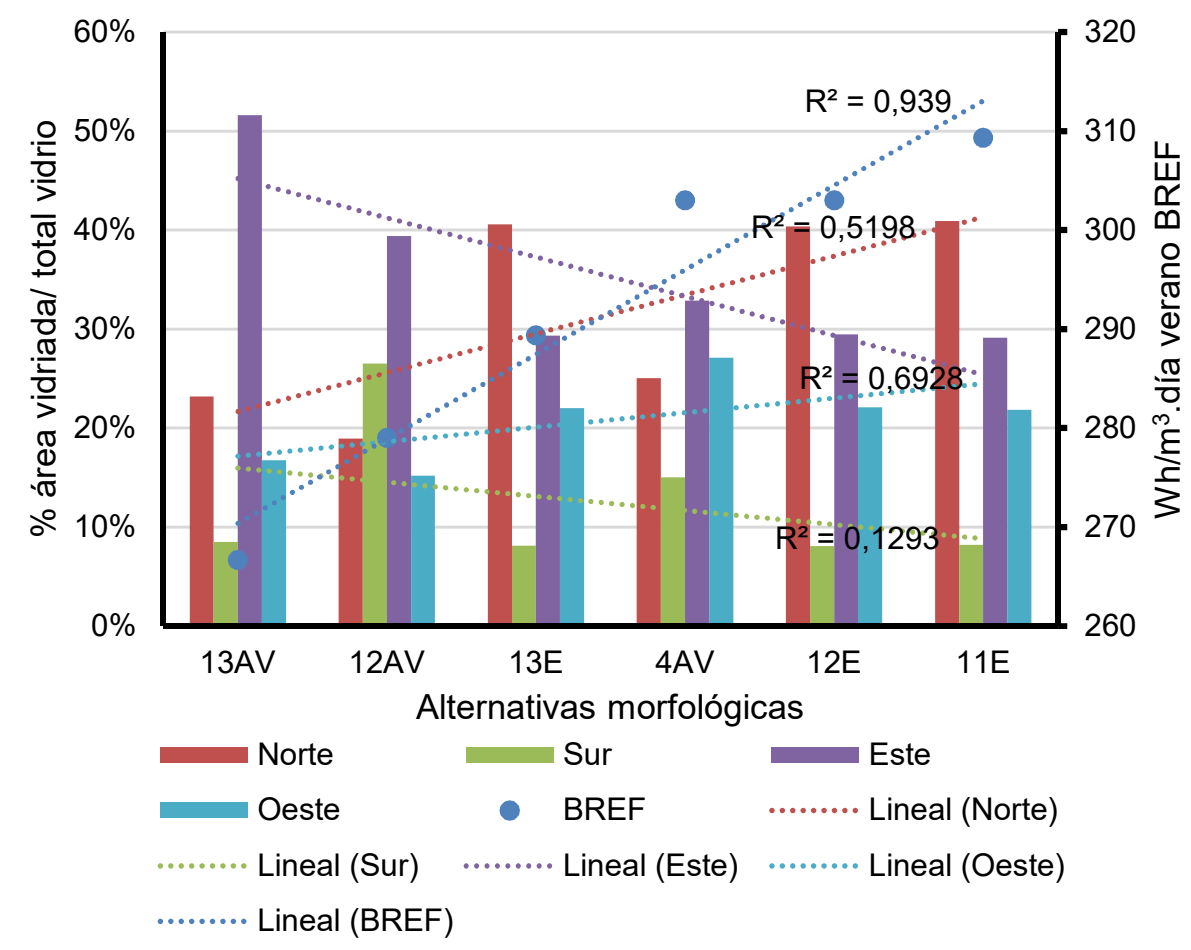

Fig. 10.10. Relación entre $B_{R E F}$ creciente y el área vidriada por orientación. Fuente: la autora

\subsection{Validación de los resultados}

Para la validación de los resultados del modelo, se decidió ejecutar una simulación en Energy Plus mediante el plug-in DIVA (ver apartado 2.5) de un sector del edificio correspondiente a la alternativa morfológica 1 , en sus dos variantes de optimización: envolvente (1E) y área vidriada (1AV). Se eligió el tercer nivel, donde se intersectan los tres volúmenes que constituyen el edificio, porque ofrece máxima superficie por planta y posee piso y techo adiabáticos.

La zonificación de la planta se muestra en la Fig. 10.11 Para la simulación, se dividió la planta en cinco zonas: Norte, Sur, Este, Oeste e interna. Los resultados completos de la simulación por zona se encuentran en la Tabla A 2.3 del Anexo 2. En la Fig. 10.12 se muestran la pantalla de DIVA con los resultados para una zona.

Los porcentajes de área vidriada se modificaron entre una y otra optimización. El área vidriada pasó de $50 \%$ a $39 \%$ de la fachada Norte, de $10 \%$ a $17 \%$ de la fachada Sur, de $40 \%$ a $52 \%$ de la fachada Este y de $30 \%$ a $25 \%$ de la fachada Oeste (Tabla 10. 3 ).

\begin{tabular}{r|cccccc} 
ALTERNATIVA & \multicolumn{3}{c}{ \% VIDRIADO/OPACO } & \multicolumn{3}{c}{ INTENSIDAD ENERGÉTICA (kWh/m2.año) } \\
& NORTE & SUR & ESTE & OESTE & CALEFACCIÓN & REFRIGERACIÓN \\
\hline 1E & 50 & 10 & 40 & 30 & 35,81 & 36,23 \\
1AV & 39 & 17 & 52 & 25 & 13,37 & 36,23 \\
Tabla 10.3: Alternativa 1E y su optimización del área vidirada 1AV. Fuente: la autora
\end{tabular}



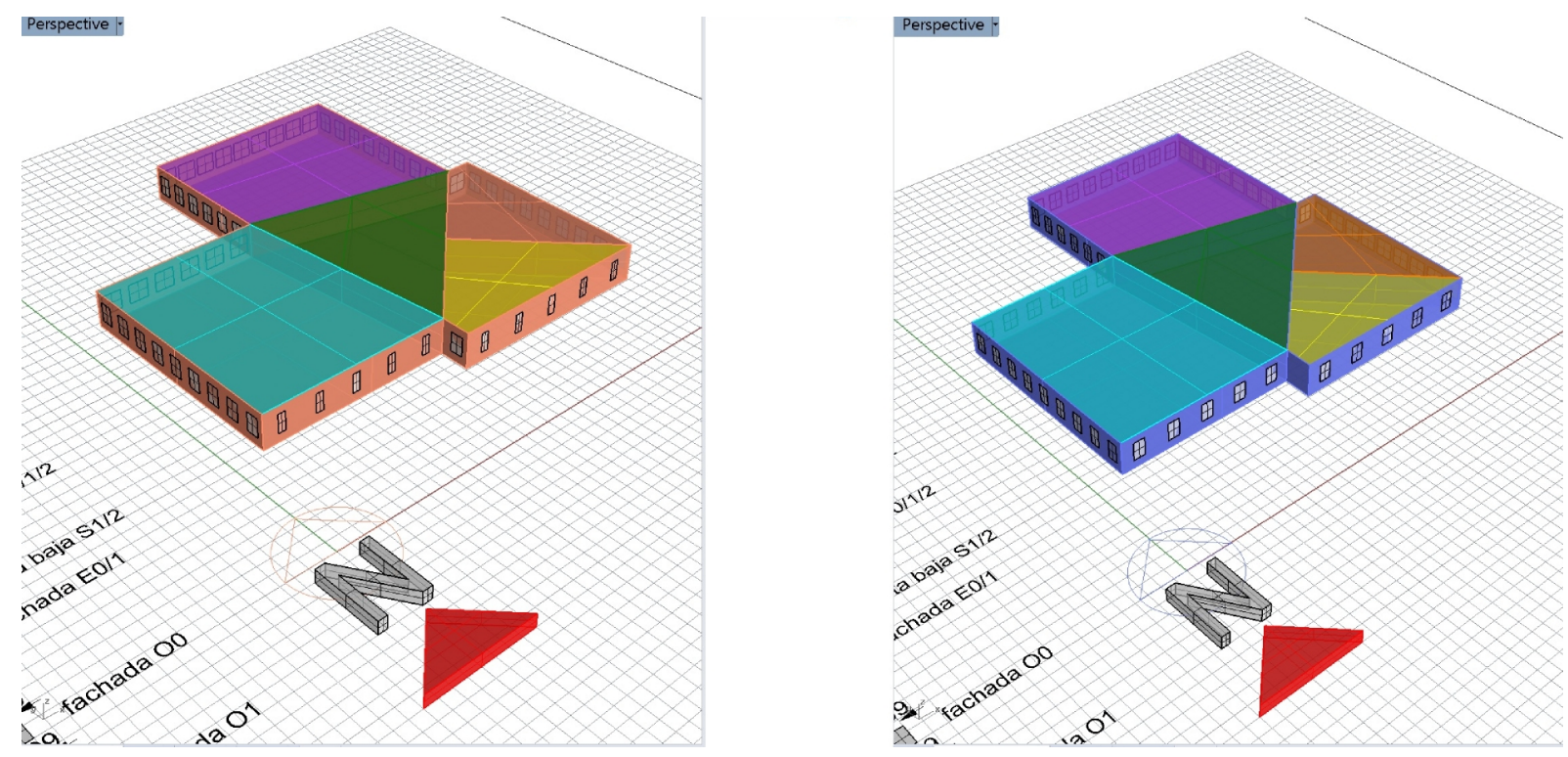

Fig. 10.11. Alternativa morfológica 1 con optimización de la geometría $1 E$ (izquierda)y del área vidriada 1AV (derecha). Fuente: la autora

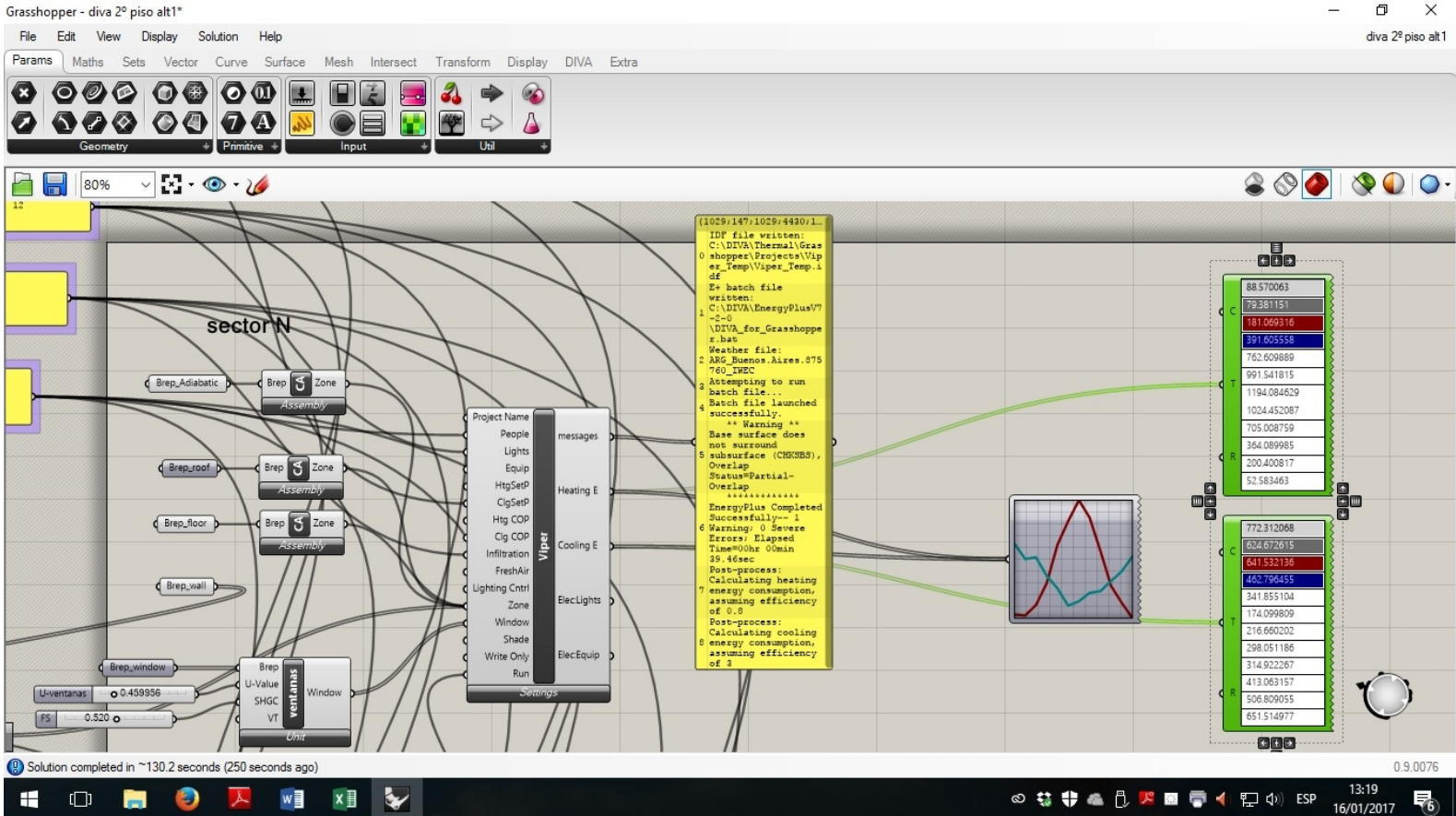

Fig. 10.12. Resultados de los consumos energéticos s/Energy+ para la zona $N$ de la alternativa $1 E$ (vidriado fijo) en DIVA. Fuente: la autora

En la Fig. 10.13, se observa una disminución del consumo de refrigeración y un aumento del consumo para calefacción, para la optimización del área vidriada (1AV). Aun así, el total de energía anual consumida por unidad de superficie disminuye un 3,63\% para la opción $1 \mathrm{AV}$. Al iterar sobre el $B_{R E F}$, el $A G$ busca iterar sobre el área vidriada sin incrementar o disminuir la demanda de energía en refrigeración, no pretende la minimización de $\mathrm{B}_{\mathrm{CAL}}$. 
10. Etapa 2. Edificio de nueva planta en el Área Metropolitana de Buenos Aires. Sub-etapa 2.3: Optimización de la morfología

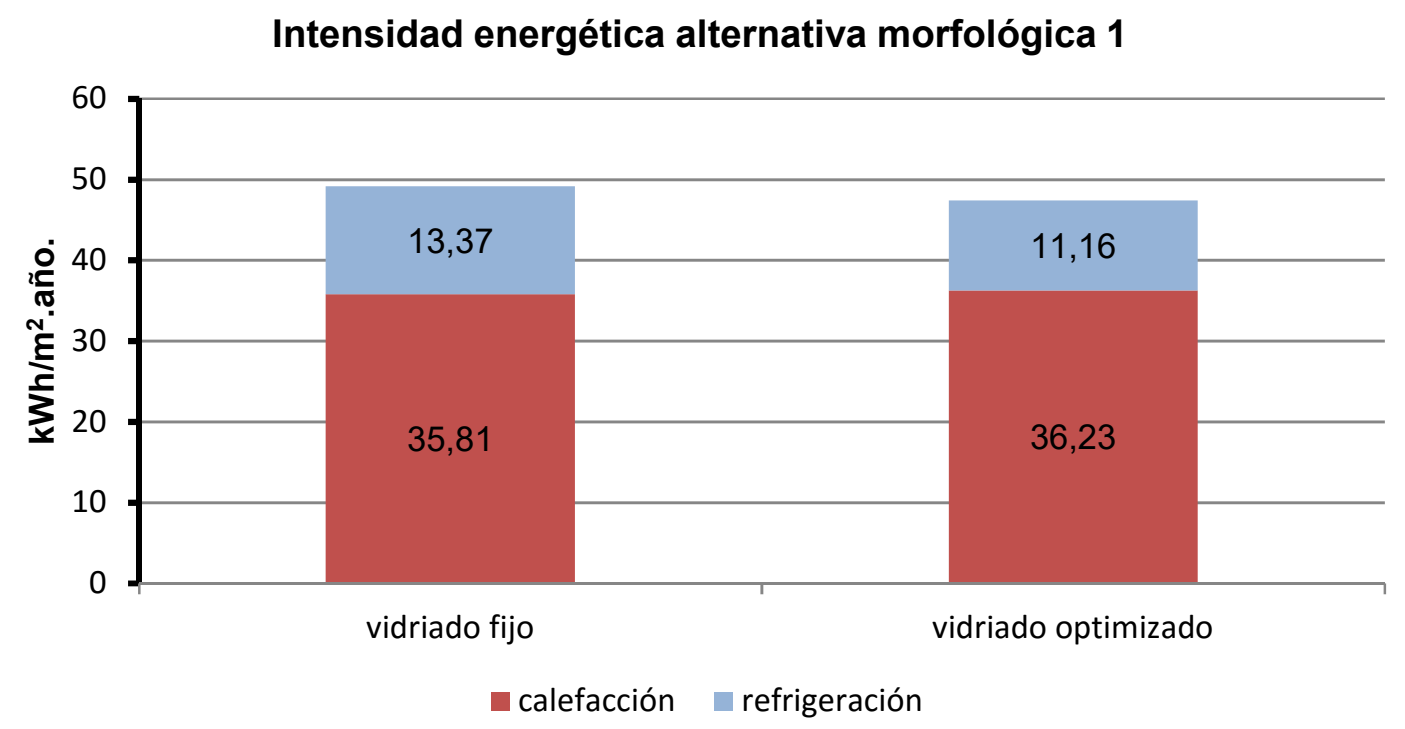

Fig. 10.13. Intensidad energética de las optimizaciones de la alternativa morfológica 1: 1E y 1AV.

Fuente: la autora

Las demandas mensuales están graficadas en la Fig. 10.14. Se puede observar que son casi coincidentes para ambas alternativas, lo cual demuestra la relación entre los índices bioclimáticos usados para la optimización y el consumo calculado con EnergyPlus.

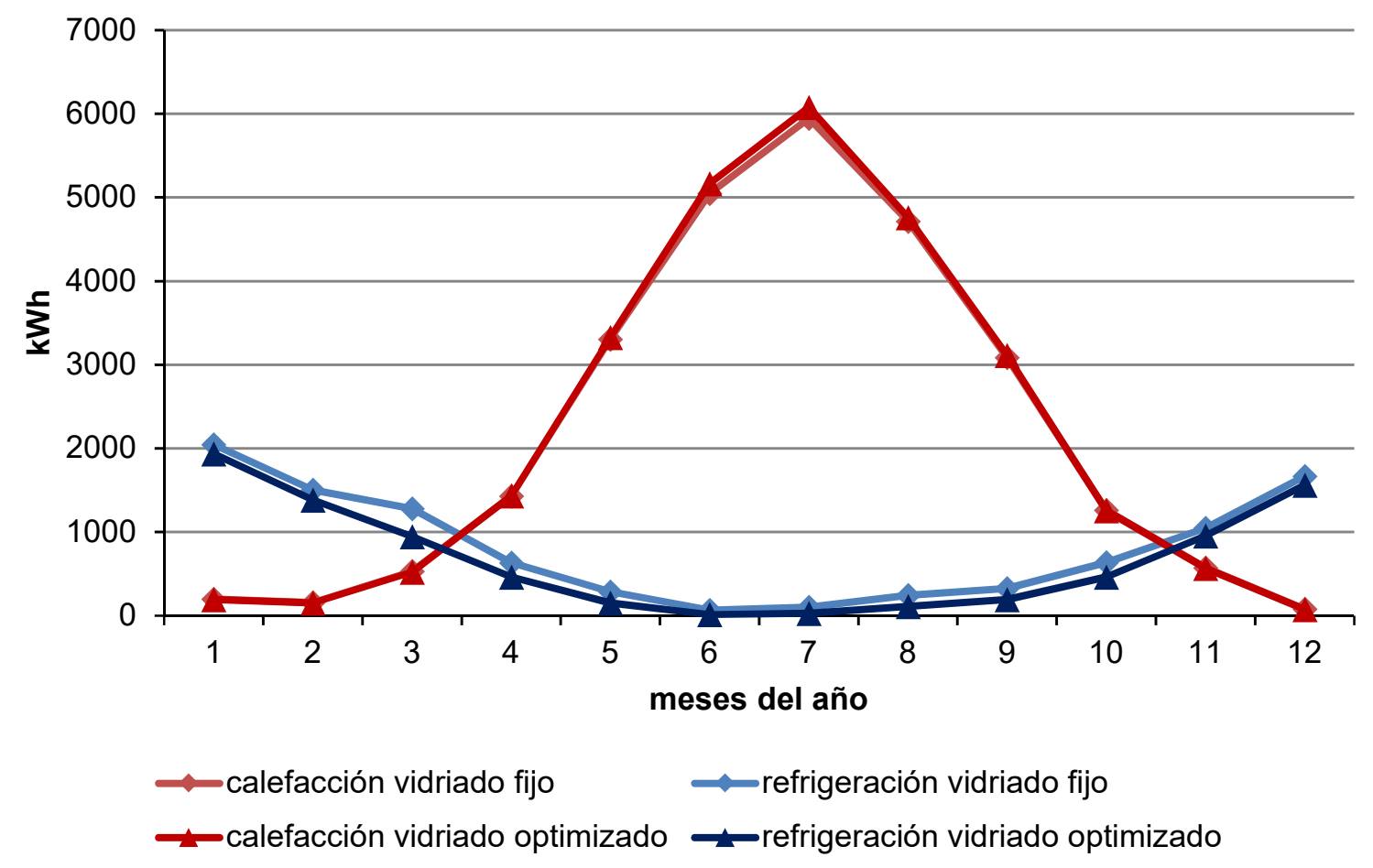

Fig. 10.14. Consumo mensual de calefacción y refrigeración para ambas alternativas optimizadas $1 E$ (vidriado fijo) y $1 \mathrm{AV}$ (vidriado optimizado) s/EnergyPlus. Fuente: la autora 


\subsection{Conclusiones}

La innovación de la aplicación de este proceso de optimización es que, independientemente de la demanda energética exacta, provee al diseñador con alternativas energo-equivalentes pero con imágenes del edificio estéticamente diferentes. Esto amplía la selección entre una u otra morfología, según criterios formales y no solamente en función de la eficiencia energética. Como se dijo anteriormente, la iteración del AG, en dos instancias, permite el mejoramiento de la geometría en primer lugar y el área vidriada, en segundo lugar.

Según el objetivo que se pretenda, el análisis pormenorizado de las cargas térmicas permite conocer el comportamiento del edificio en la condición de verano y de invierno, pudiendo así disminuir la demanda de calefacción, acumular el excedente de calor en invierno y/o minimizar la demanda de refrigeración. 
11. Etapa 3

Rehabilitación energética: viviendas en Sevilla 
El uso de algoritmos genéticos aplicados al diseño bioambiental paramétrico 


\subsection{El modelo de diseño paramétrico bioambiental aplicado a un caso de rehabilitación energética: su adaptación metodológica.}

El modelo está originalmente dirigido a edificios de nueva planta en las etapas iniciales de diseño (Camporeale, P. \& Czajkowski, J., 2016) y se adapta a casos de rehabilitación, donde la exploración se limita a los componentes de la envolvente: aislación térmica y reposición de carpinterías. Esta herramienta optimiza aspectos del diseño los coeficientes de transmitancia térmica de la envolvente y la relación vidriado-opaco para reducir la demanda energética, desde una perspectiva bioclimática y de factibilidad financiera. Se integra el diseño paramétrico con Rhino-GH-Galápagos, agregando una optimización multiobjetivo. (MOMO), en un flujo de trabajo integrado, apropiado para resolver objetivos competitivos entre sí (Calcerano \& Martinelli, 2016). El modelo minimiza la demanda de calefacción y refrigeración para mejorar el desempeño energético y maximiza el valor actualizado neto (VAN). El esquema muestra el flujo de trabajo dividido en diferentes etapas como se muestra en la Fig. 11.1 Los datos de entrada comprenden la forma y materialidad del edificio, la ocupación, el clima, el lugar, la normativa local vigente y cualquier otro parámetro aplicable. Esta información se ingresa manualmente en el entorno 3D Rhinoceros y se parametriza en Grasshopper. En este caso, por tratarse de una rehabilitación de un edificio existente, la morfología no varía de acuerdo a la retroalimentación del $A G$ en un proceso iterativo, sino que se ingresa tal cual está el edificio. Luego, se calculan los índices bioclimáticos $\mathrm{B}_{\mathrm{CAL}}$ and $\mathrm{B}_{\mathrm{REF}}$. Galápagos minimiza la primera función objetivo cuyo valor de

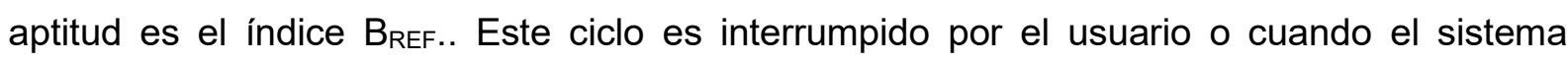
alcanza su límite fijado de acuerdo a un criterio. Luego, el usuario habilita a DIVA mediante un conmutador verdadero-falso, a conectarse con EnergyPlus. Con el dato de la demanda energética mediante la simulación, el modelo calcula la intensidad energética de uso (IEU), el ahorro en gasto anual de energía eléctrica y los gastos de la rehabilitación de la envolvente de un conjunto de opciones seleccionadas.

Los costos de rehabilitación y el ahorro son exportados a Microsoft Excel ${ }^{\mathrm{TM}}$ para calcular el Valor Actualizado Neto (VAN) y evaluar el rendimiento financiero de dichas opciones. Un frente de Pareto maximiza las opciones con VAN positivo y selecciona las mejores (Karmellos, Kiprakis, \& Mavrotas, 2015).

El objetivo de incluir el Valor Actualizado Neto como indicador de la factibilidad financiera es para evaluar las soluciones morfológicas potenciales considerando costos estimados de construcción y futuras ganancias. El VAN relaciona los costos de construcción, los de operación y los ingresos futuros para un determinado período de tiempo. Los costos de construcción se calculan a partir de la geometría edilicia, obteniendo las cantidades de cada 
material y su respectivo precio unitario provisto por el usuario o precios por defecto. Los costos de operación no incluyen la performance del equipamiento porque la intención es evaluar sólo la demanda de calefacción y refrigeración y la inversión necesaria para ello.

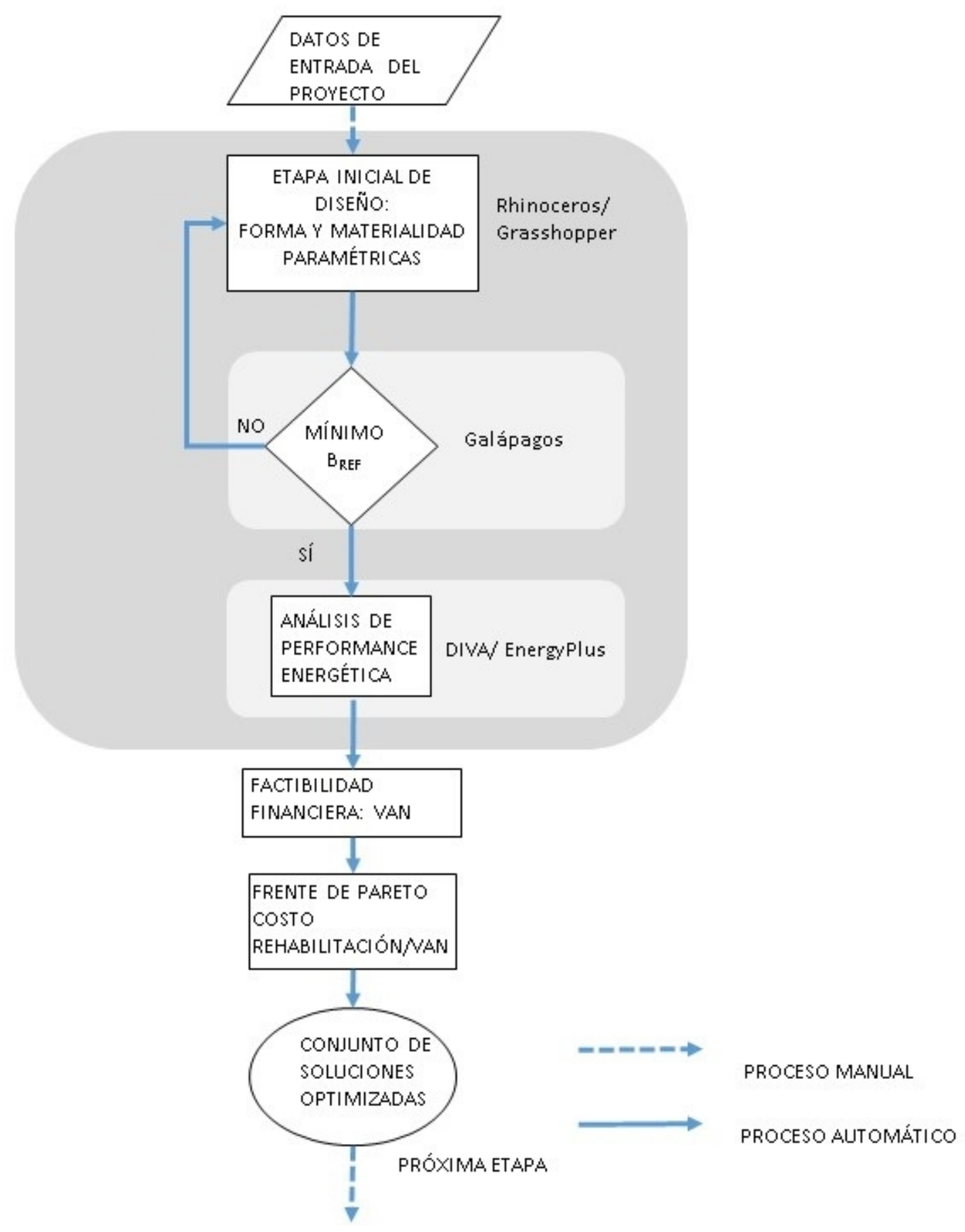

Fig. 11.1: Diagrama mostrando los pasos de la metodología

Al considerar la factibilidad financiera, se espera que las medidas de eficiencia energética sean efectivas y realizables. Por lo tanto, optimizamos a continuación el grupo seleccionado mediante un frente de Pareto (Wang, Zhao, Wu, \& Wu, 2017). EI VAN requiere el plazo de 
financiación, la tasa anual de interés, los costos de operación y la ganancia (Eq.5). En el caso de edificios sostenibles, los ahorros en gastos de energía son parte de la ganancia.

$$
V \quad=\left(\sum_{t=1}^{T} \frac{C_{t}}{(1+r)^{t}}-C_{0}\right)
$$

VAN $=$ valor neto anual

$\mathrm{T}=$ período de repago

$\mathrm{R}=$ tasa anual de interés

$\mathrm{C}_{0}=$ costo inicial de la construcción

$\mathrm{C}_{\mathrm{t}}=$ costo de operación

Debe hacerse notar que el VAN variará dependiendo de los datos de entrada, según las condiciones locales de cada mercado.

\subsection{Descripción del caso de estudio}

Las viviendas RENFE se ubican en un predio situado en la zona norte de la ciudad de Sevilla, junto al límite del trazado histórico, en terrenos aluvionales de uso originalmente agrícola. Con el desvío del cauce del río Guadalquivir y la consolidación del suelo para la construcción del ferrocarril, estos terrenos se transformaron en urbanos (Ferreira, A., 2015) (Fig. 11.2).

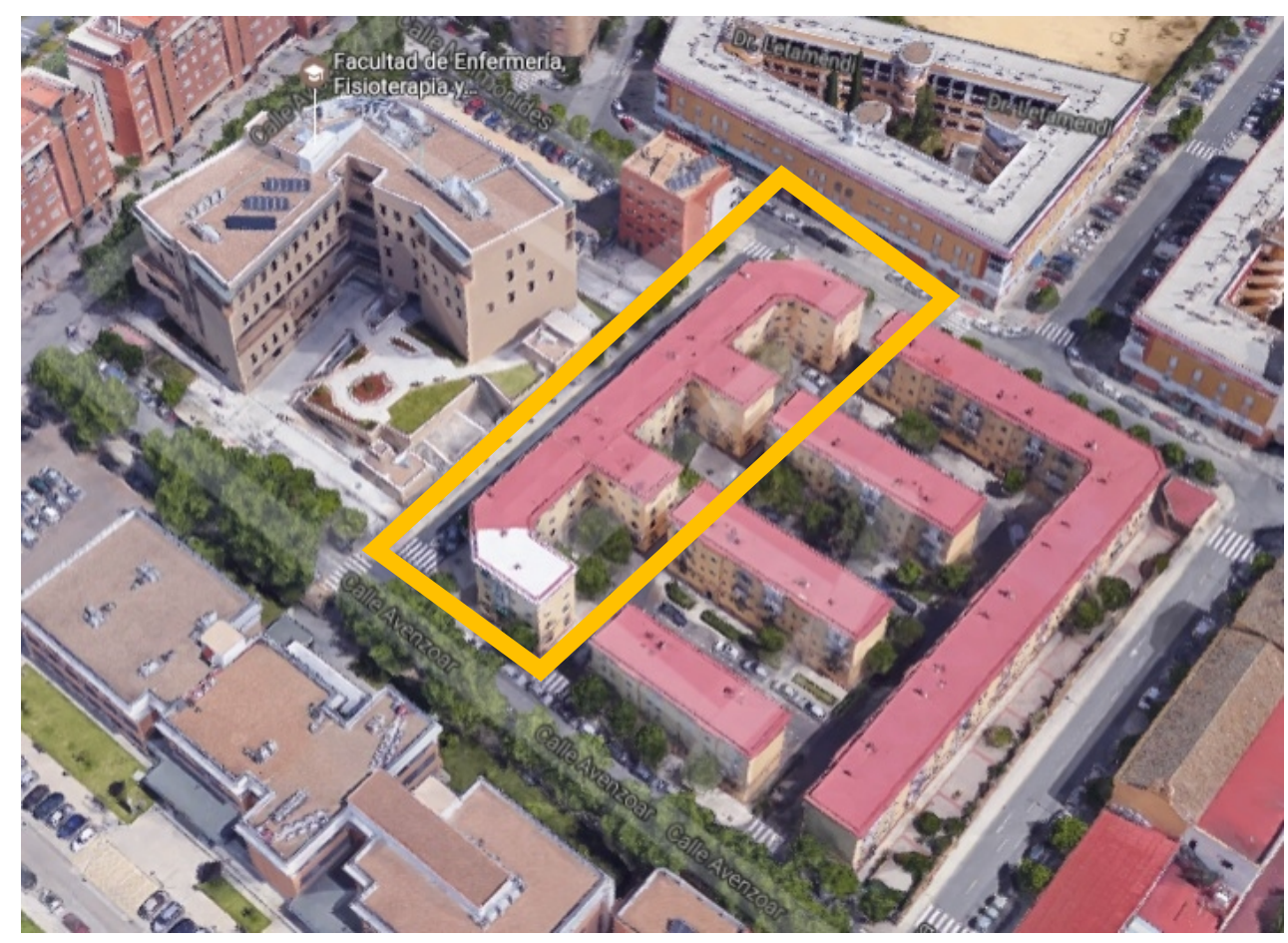


Fig. 11.2. Vista aérea del conjunto de viviendas RENFE (el rectángulo amarillo señala el bloque rehabilitado). Fuente: modificado de Google Maps por la autora

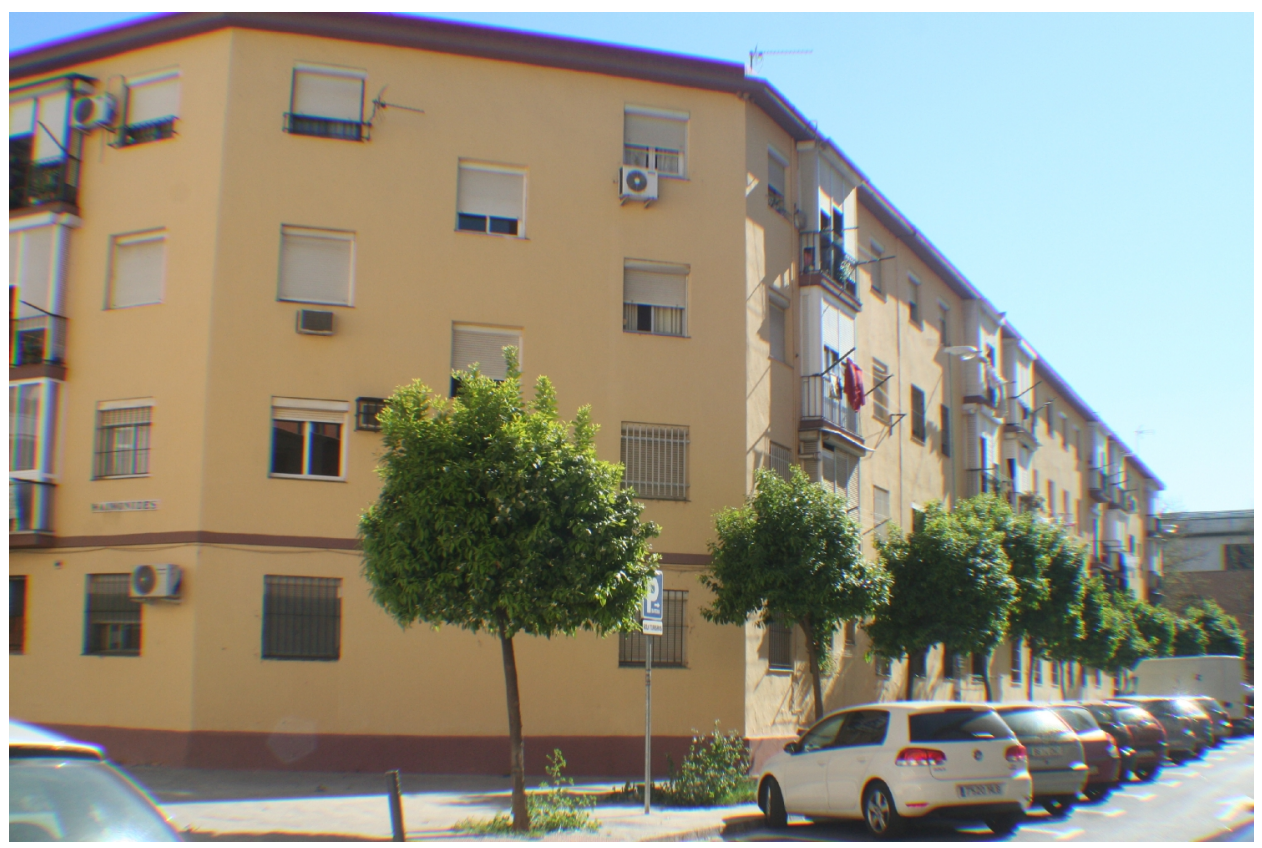

Fig. 11.3 Esquina $N$ del edificio RENFE

Las viviendas para el personal del ferrocarril (RENFE) se construyeron en la década del '50. Constituyen un conjunto de 4 edificios. Al iniciarse los trabajos para la construcción de la Facultad de Ciencias de la Salud de la Universidad de Sevilla en un área lindera, se removió una pantalla de hormigón que oficiaba de contención del terreno y el bloque de viviendas, contiguo a esta área, sufrió el desplazamiento de su base de sustentación, ocasionándole grietas y fisuras en muros y cubierta. Fue necesaria la evacuación de los ocupantes de las cuarenta viviendas (Ferreira, A., 2015).

Se decidió la recuperación de las mismas en el término de un año, para lo cual, se realizaron obras de recalce de los cimientos mediante micropilotaje. Los muros agrietados fueron reparados con ladrillo de características similares al original. Las aberturas dañadas fueron reemplazadas por otras de similares características. La cubierta fisurada, fue reparada devolviéndole su integridad junto con una nueva aislación hidrófuga (Ferreira, A., 2015).

Como el CTE (Ministerio de Fomento, 2016) obliga a adecuar a los edificios existentes a los estándares de la Directiva 2010/31 modificada, cuando la rehabilitación implica un área mayor al $25 \%$ del edificio, este edificio debería haber sido rehabilitado a la eficiencia energética. Sin embargo, la compañía aseguradora no cumplió con las regulaciones 
vigentes y solamente aceptó pagar una rehabilitación que devolviera al edificio su estado anterior.

En nuestro estudio de caso, suponemos una hipotética rehabilitación que evalúe diferentes tipos de envolvente, considerando la demanda energética y el costo inicial de las obras, utilizando un MOMO adaptado a un caso de rehabilitación. De haberse dispuesto de los medios económicos de una rehabilitación energética del edificio para su adecuación a la legislación vigente, se deberían haber incrementado notablemente los niveles de aislación térmica en muros, carpinterías y cubiertas.

\subsubsection{Clima}

La ciudad de Sevilla posee un clima templado con temperaturas medias de $11,8^{\circ} \mathrm{C}$ en invierno y $27^{\circ} \mathrm{C}$ en verano. Las precipitaciones predominan en noviembre $(91 \mathrm{~mm})$ y diciembre $(99 \mathrm{~mm})$ con un total anual de $539 \mathrm{~mm}$, una humedad relativa media anual de $59 \%$ y 129 días despejados al año (Agencia Estatal de Meteorología, s. f.) (Tabla 11.1)

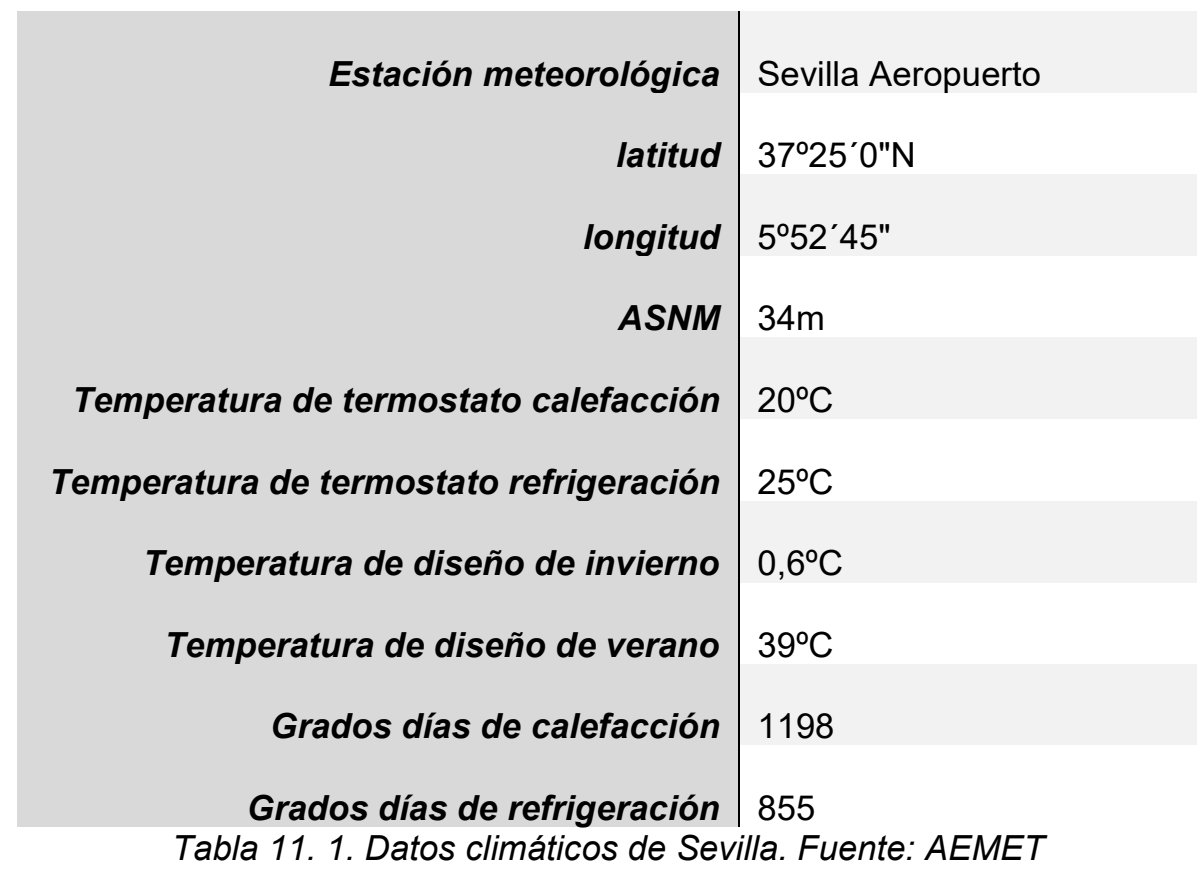

En las figs. 11.4 y 5 , se observan las distribuciones normales de las temperaturas máximas y mínimas de enero, en la ciudad de Sevilla para el período 2006/2016. 


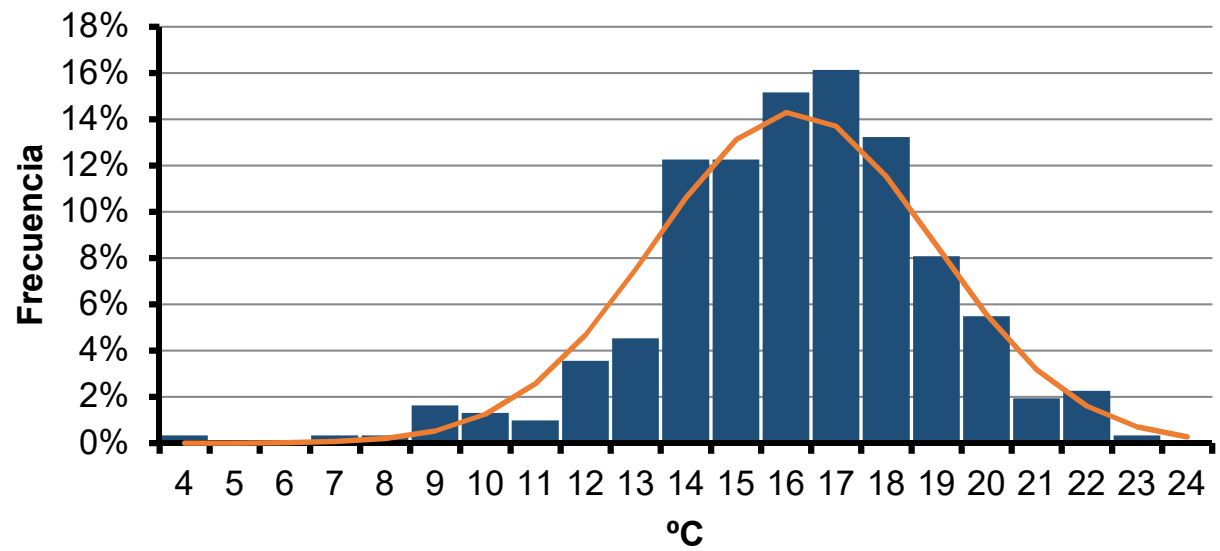

temp. máx.enero 2007 al 2016 normal

Fig. 11.4. Temperaturas máximas enero 2007/2016. Fuente: la autora

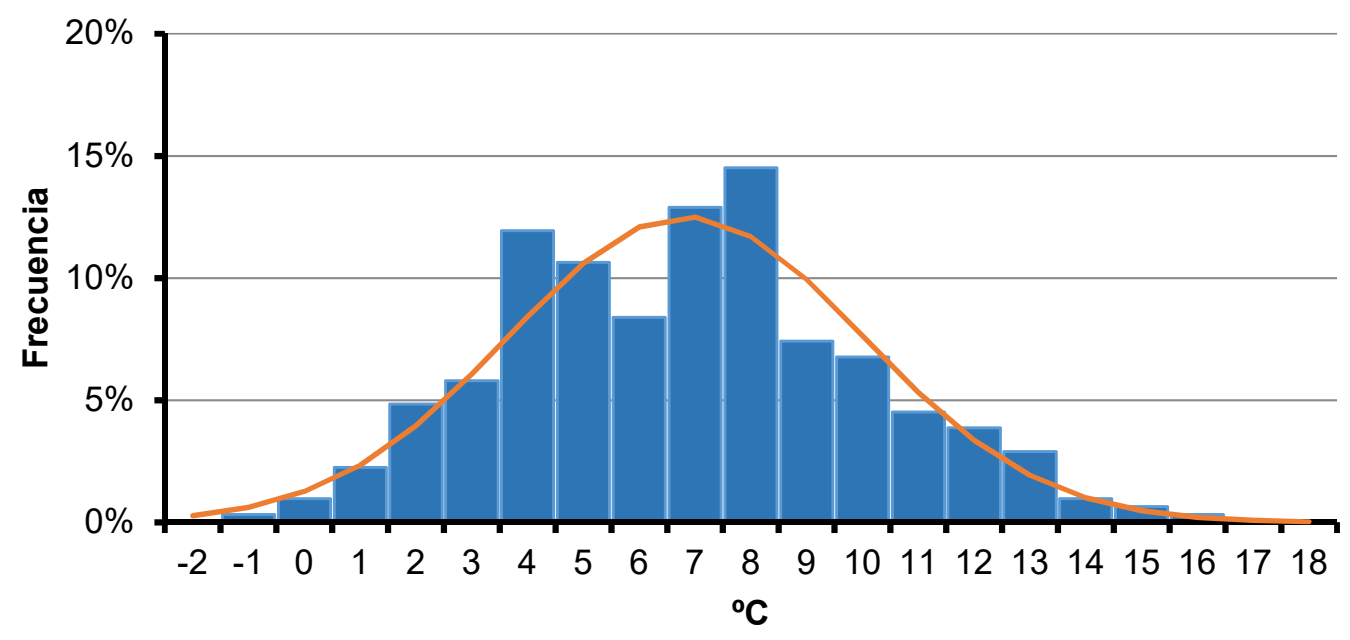

temp. mín. enero 2007 al 2016 normal

Fig. 11.5. Temperaturas mínimas enero 2007/2016. Fuente: la autora

Asimismo, en las figs. 11.6 y 7 , se observan las mismas distribuciones para el mes de julio del mismo período (Weather Underground, s. f.) ${ }^{1}$. Para el mes de enero (invierno), las máximas más frecuentes rondan los $17^{\circ} \mathrm{C}$ y las mínimas, los $8^{\circ} \mathrm{C}$. Para el mes de julio (verano), las máximas más frecuentes rondan los $38^{\circ} \mathrm{C}$ y las mínimas, los $20^{\circ} \mathrm{C}$.

1 Datos climáticos obtenidos de Weather Underground. Consultado el 10/1/17 en: https://www.wunderground.com 
11. Etapa 3. Rehabilitación energética: viviendas en Sevilla.

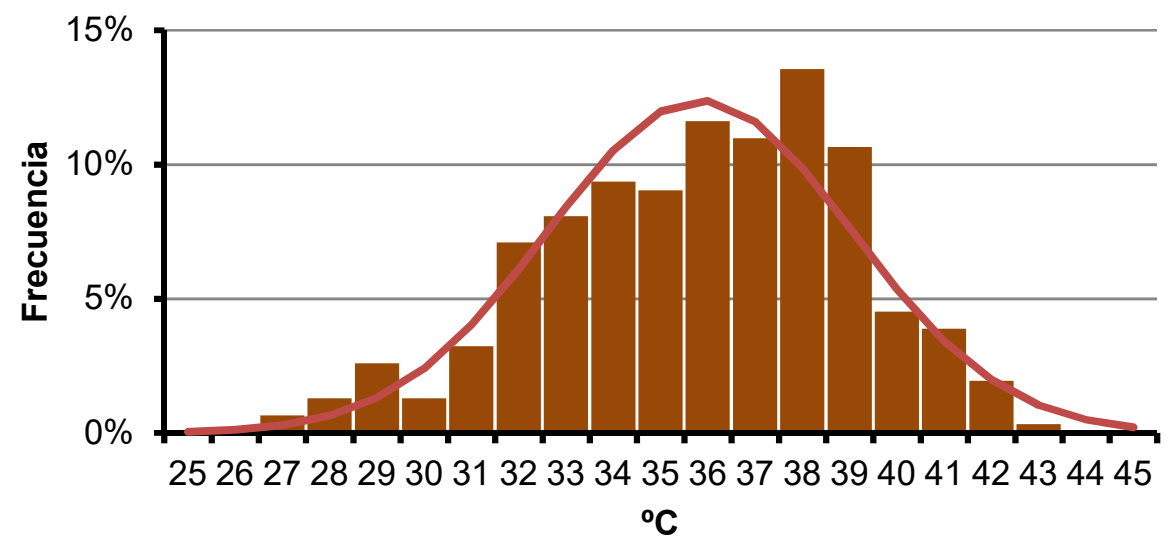

temperaturas máx. julio 2007/16 normal

Fig. 11.6. Temperaturas máximas julio 2006/17

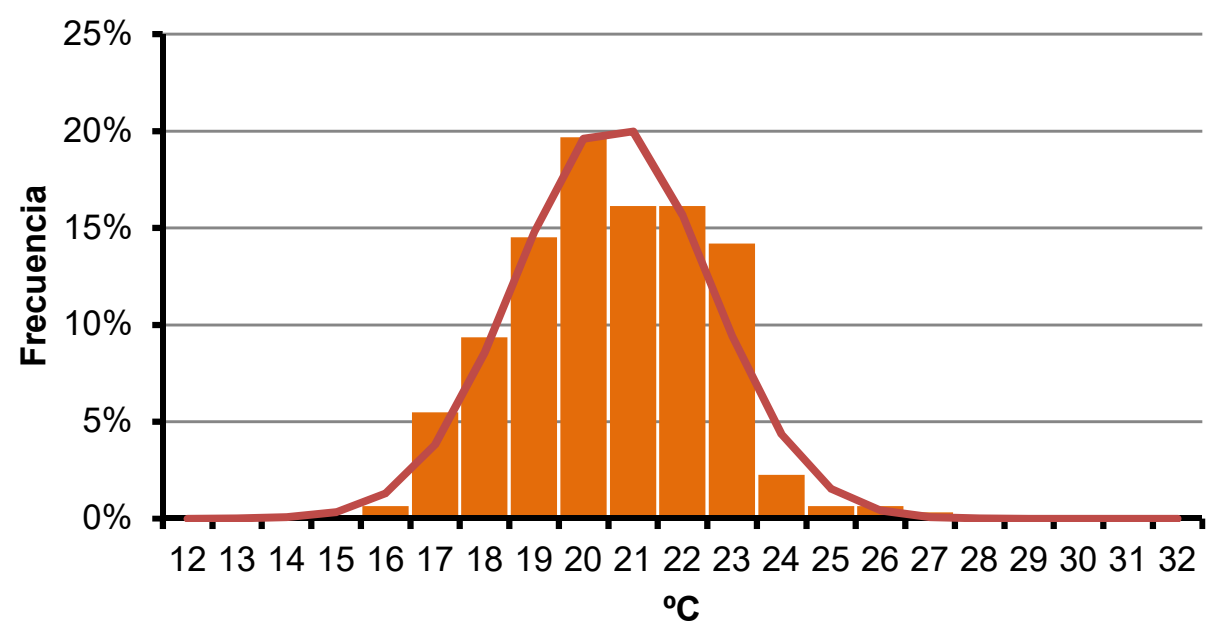

temperaturas mín. julio 2006/16 normal

Fig. 11.7. Temperaturas mínimas julio 2006/17. Fuente: reeleborado de AEMET

Las temperaturas horarias calculadas para Sevilla se indican en la Fig. 11.8 con las temperaturas máximas y mínimas medias. 


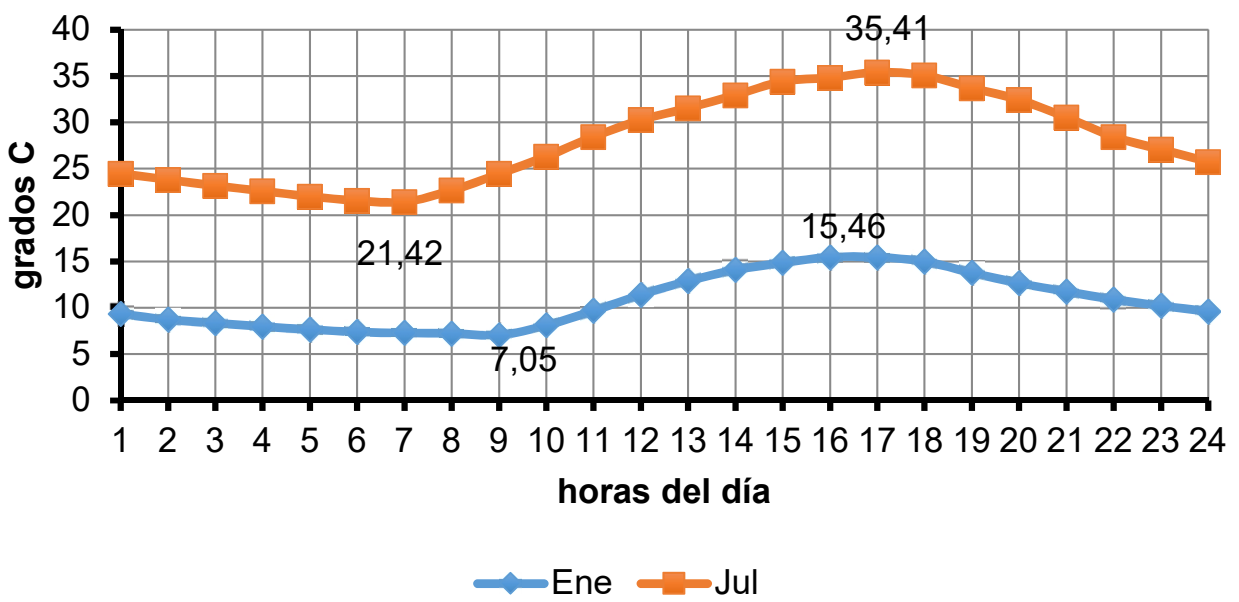

Fig. 11.8. Temperaturas horarias indicando máxima y mínima medias. Fuente: reelaborado de AEMET

Los datos de radiación solar para la ciudad de Sevilla se obtuvieron de la estación solarimétrica Lebrija 2, situada en la localidad de Cuervo de Sevilla (Agencia Andaluza de Energía, s. f.) . La radiación solar, discriminada por orientaciones, se muestra en las figs. 11.9 y 10 para los meses de enero y julio. Se observan las orientaciones con mayor captación S, SE y SO para invierno y Este y Oeste para el verano.

En el Anexo 3 se amplían los datos climáticos correspondientes a Sevilla. Las tablas ofrecen las características del clima (Tabla A3.1), la radiación solar media horaria para enero (invierno) (Tabla A3.2) y julio (Tabla A3.3), las temperaturas horarias para enero (Tabla A3.4) y julio (Tabla A3.5), las temperaturas sol-aire de los muros para cada orientación $\mathrm{N}, \mathrm{S}$, E, O, NE, No, SE, SO y las cubiertas para enero (Tablas A3.6 a 14) y para julio (A3.15 a 23).

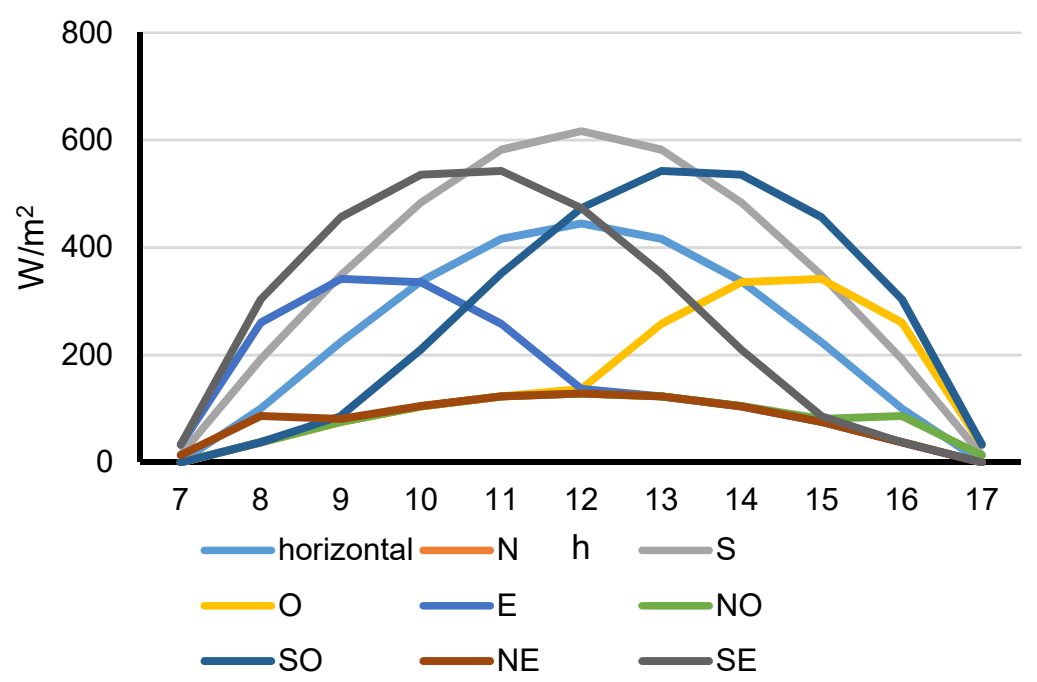

Fig. 11.9. Radiación solar para el mes de enero (invierno). Fuente: reelaborado de $A A E$ 


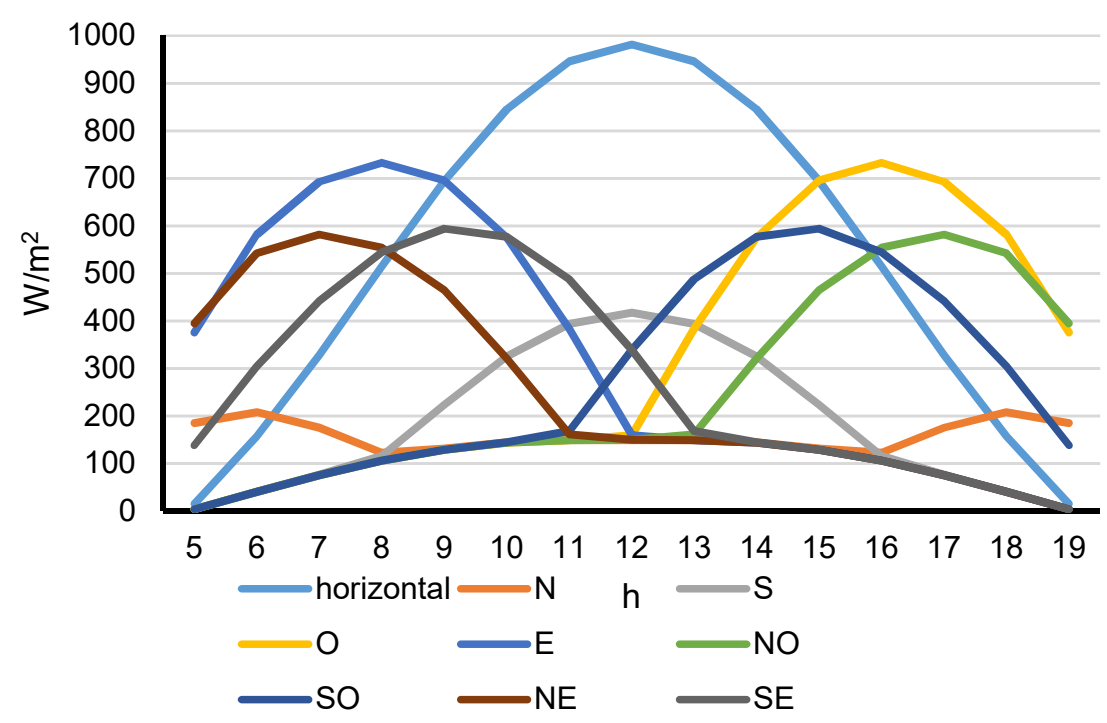

Fig. 11.10. Radiación solar para el mes de julio (verano). Fuente: reelaborado de $A A E$

\subsubsection{El edificio}

El caso de estudio es un bloque de vivienda de protección oficial situado en Sevilla y construído en los '50 para los empleados de la compañía estatal de ferrocarriles RENFE. Consta de 40 apartamentos distribuídos en cuatro plantas que totalizan $3500 \mathrm{~m}^{2}$. El Sistema constructivo es el tradicional de Andalucía (Mercader Moyano, M., 2010). Los muros portantes son de fábrica de ladrillo basto con revoque cementicio en ambas caras y sin aislación térmica adicional. Los forjados intermedios y la cubierta están constituídos de vigas de hormigón armado de baja resistencia y ladrillos cerámicos. La cubierta es plana y no transitable; posee una capa de carbonilla que provee la pendiente para el escurrimiento pluvial y está terminada con baldosas cerámicas. Los marcos de las carpinterías son de madera y vidrio simple con cortina de enrollar y la relación vidriado/opaco es de 19,8\% (Ferreira, A., 2015).

Este edificio colapsó parcialmente en 2010, cuando comenzaron las obras de excavación para la construcción de la facultad de Fisioterapia y enfermería en un predio frente a nuestro edificio. Dichas excavaciones rompieron una pantalla de concreto que oficiaba de sostén del suelo y los cimientos del edificio cedieron, también debido a la baja resistencia del mismo por su origen aluvial. Como consecuencia, aparecieron muchas grietas y fisuras en muros, pisos y cubierta y los habitantes debieron ser evacuados y reubicados hasta que se reconstruyera la obra.

Como el CTE (Ministerio de Fomento, 2016) obliga a adecuar a los edificios existentes a los estándares de la Directiva 2010/31 modificada, cuando la rehabilitación implica un área mayor al $25 \%$ del edificio, éste debería haber sido rehabilitado a la eficiencia energética. Sin 
embargo, la compañía aseguradora no cumplió con las regulaciones vigentes y solamente aceptó pagar una rehabilitación que devolviera al edificio su estado anterior. En nuestro estudio de caso, suponemos una hipotética rehabilitación que evalúe diferentes tipos de envolvente, considerando la demanda energética y el costo inicial de las obras, utilizando un modelo de optimización multi-objetivo, adaptado a un caso de rehabilitación.

El modelo bioambiental paramétrico se aplicó a este caso de viviendas sociales, a los efectos de obtener alternativas de rehabilitación energética, que hubieran adecuado el edificio a las exigencias de ahorro energético requeridas por el CTE-DB-HE1. Se consideró la información de la propuesta de rehabilitación realizada por María Desirée Alba en su estudio de la barriada RENFE (Alba, M., 2016). En dicho estudio, se propone una hipotética rehabilitación energética, consistente en la incorporación de aislación térmica en muros y cubierta y recambio de las carpinterías existentes. Los costos de los materiales a renovar se extrajeron de la Base de Costes de la Construcción de la Junta de Andalucía, que son los utilizados por dicha administración, desde hace veinticinco años, para la ejecución de sus proyectos (Barón, J. et al, 2016).

Los parámetros fijos del edificio son la forma y la envolvente actual, la relación vidriado/opaco, los valores mínimos exigibles de transmitancia térmica de la envolvente, la tasa mínima horaria de renovación de aire, el horario de ocupación, la intensidad de la iluminación artificial, y las temperaturas de termostato de calefacción y refrigeración (Ministerio de Fomento, 2015). Adoptamos los datos provistos por Alba (Alba, M., 2016) para calcular los valores de transmitancia térmica de la envolvente para adecuarlos a los exigidos por el CTE para Sevilla, que se encuentra en la zona climática B4 (Tabla 11.1) (Ministerio de Fomento, 2017).

\begin{tabular}{|c|c|c|c|c|}
\hline \multirow[b]{2}{*}{ ESTADO } & \multicolumn{3}{|c|}{$K$} & \multirow{2}{*}{$\begin{array}{c}\text { TASA DE } \\
\text { INFILTRACIÓN } \\
1 / h\end{array}$} \\
\hline & $\begin{array}{c}\text { fachadas } \\
W / m^{2} K\end{array}$ & $\begin{array}{c}\text { cubierta } \\
W / m^{2} K\end{array}$ & $\begin{array}{c}\text { ventanas } \\
W / m^{2} K\end{array}$ & \\
\hline ACTUAL & 2.12 & 1.11 & 5.7 & 2.0 \\
\hline CTE MIN.B4 & 1 & 0.65 & 4.2 & 0.8 \\
\hline
\end{tabular}

Tabla 11.1: Mínimos valores de transmitancia térmica y tasa de infiltración. Fuente: reelaborado de Alba (op.cit.)

El presupuesto previsto para la rehabilitación energética del modelo de referencia adoptado (Alba, M., 2016) se detalla en la Tabla 11.2. 


\begin{tabular}{r|lll} 
& costo rehabilitación & \% presupuesto & Observaciones \\
\hline & energética & total & \\
\hline carpinterías & 187247,5 & & \\
muros & 276222,4 & $18,90 \%$ & Al lacado RPT vidrio 4+6+4 lowE \\
cubiertas & 87610,06 & $12,81 \%$ & $8 \mathrm{~cm}$ EPS \\
total & 551079,96 & $6 \%$ & $8 \mathrm{~cm}$ EPS \\
\hline
\end{tabular}

Tabla 11.2. Costo de la rehabilitación energética propuesta. Fuente: reelaborado de Alba, (op.cit.)

Uno de los parámetros que alimentan el AG es el espesor del aislamiento térmico de fachadas y cubierta. Para ello, consideramos un rango de $0.1 \mathrm{~cm}$ a $34 \mathrm{~cm}$ para la cubierta y a $8 \mathrm{~cm}$ para las fachadas (Tabla 11.3). Los otros parámetros condicionantes son la transmitancia térmica $(\mathrm{K})$ de las ventanas y el factor solar modificado. Como el $\mathrm{K}$ es un rango continuo para ser optimizado por Galápagos, dividimos ese dato de salida entre tres valores posibles en correspondencia con los tipos de ventanas seleccionadas. Se seleccionaron 2 tipos de vidriado y dos tipos de material para los marcos para reemplazar las ventanas existentes. (Tabla 11.4) (Instituto Eduardo Torroja de Ciencias de la Construcción, CEPCO y AICIA, 2010).

\begin{tabular}{c|ccccc} 
AISLACIÓN & $\begin{array}{c}\boldsymbol{\lambda} \\
\boldsymbol{k g} / \mathrm{m}^{3}\end{array}$ & $\begin{array}{c}\boldsymbol{\lambda} \\
\mathbf{W} \mathbf{m K}\end{array}$ & $\begin{array}{c}\boldsymbol{k} \\
\boldsymbol{W} / \mathbf{m}^{2} \boldsymbol{K}\end{array}$ & $\begin{array}{c}\text { ESPESOR EPS } \\
\mathrm{cm}\end{array}$ & $\begin{array}{c}\text { Costo } \\
\boldsymbol{\epsilon} / \mathbf{c m} \cdot \mathbf{m}^{2}\end{array}$ \\
\hline CUBIERTA & 15 & 0.0375 & $0.65 / 0.16$ & $1 / 34$ & 2.60 \\
FACHADAS & 15 & 0.0375 & $1 / 0.383$ & $1 / 8$ & 2.60
\end{tabular}

Tabla 11.3: Aislamiento térmico de cubierta y fachadas, rangos de EPS. Fuente: BCCCA, Catálogo de Elementos Constructivos del CTE

\begin{tabular}{|c|c|c|c|c|c|c|c|}
\hline TIPO & $\begin{array}{l}\text { SISTEMA DE } \\
\text { APERTURA }\end{array}$ & $\begin{array}{c}K \\
W / m^{2} K\end{array}$ & $\begin{array}{c}\text { FSM } \\
\text { n/act./act. }\end{array}$ & MARCO & VIDRIO & $R P T$ & $\begin{array}{l}\text { Costo } \\
\epsilon / m 2\end{array}$ \\
\hline 0 & corrediza & 5.7 & $0.69 / 0.14$ & madera & Vidrio simple & & 163.42 \\
\hline 1 & de abrir & 4.2 & $0.62 / 0.14$ & madera & $D V H 4+6+4$ & $x$ & 148.8 \\
\hline 2 & de abrir & 3.2 & $0.62 / 0.14$ & Aluminio & $\mathrm{DVH} 4+6+4$ & $x$ & 232.9 \\
\hline 3 & de abrir & 2.3 & $0.52 / 0.14$ & Aluminio & $\begin{array}{c}\text { DVH 4+6+4 baja } \\
\text { emisividad }\end{array}$ & $x$ & 302.38 \\
\hline
\end{tabular}

Tabla 11.4: Tipos de ventanas seleccionadas, sistema de apertura, $K$, factor solar modificado, material de marcos y vidrios, ruptura de puente térmico y costos 
El tipo 0 es la ventana actual que no alcanza el mínimo exigido por el CTE (Tabla 11.1) y por ello solo se considera para el cálculo de la demanda energética de la opción denominada actual. No se consideran ventanas de PVC por ser dañino al ambiente y los ocupantes, debido a su composición química, sobre todo cloro.

\subsection{Optimización multi-objetivo}

Los valores a optimizar son la demanda de calefacción y refrigeración y la factibilidad financiera. El esquema para optimizar estos objetivos competitivos entre sí utiliza el algoritmo evolutivo de Grasshopper, Galápagos, para la demanda energética y un frente de Pareto para el aspecto financiero. Galápagos sólo optimiza la demanda de calefacción y refrigeración porque es un algoritmo mono-objetivo como han señalado Calcerano y otros (Calcerano \& Martinelli, 2016). Cuando se lo aplica a una rehabilitación, como la forma y la relación vidriado opaco no varían, los datos de la retroalimentación sólo modifican los parámetros de los componentes de la envolvente. Luego, Grasshopper se conecta con EnergyPlus mediante DIVA para calcular la demanda energética del conjunto de soluciones optimizadas. Calculamos el costo de la rehabilitación y el ahorro en gasto de energía de cada una de ellas y calculamos el VAN. Un frente de Pareto optimiza las alternativas relacionando ahorro y VAN de cada una.

\subsubsection{Proceso de optimización. Etapa 1: Performance energética}

El proceso de optimización se divide en dos etapas: la minimización de la demanda energética y la maximización del VAN. Como ambos son objetivos independientes que compiten entre sí, un algoritmo genético mono-objetivo y un frente de Pareto resuelven cada uno de ellos respectivamente. Para la demanda energética empleamos Galápagos, el algoritmo genético de Grasshopper. Galápagos corre durante 100 generaciones con un 75\% de endogamia, un $5 \%$ de conservación y una población inicial de dos individuos. Los genes que alimentan al $A G$ son los valores de transmitancia térmica de fachadas y ventanas y el factor solar modificado. En el caso de las fachadas y cubierta, sólo el espesor del aislamiento varía independiente en cada caso, mientras que los otros componentes de la envolvente no varían. El valor de ajuste es el mínimo índice $B_{R E F}$, de ahí seleccionamos las mejores 30 opciones que se muestran en la Tabla 11.5 . 


\begin{tabular}{|c|c|c|}
\hline & $\begin{array}{c}B_{C A L} \\
k W h / m^{2} \text {.day }\end{array}$ & $\begin{array}{c}B_{R E F} \\
k W h / m^{2} \text {.day }\end{array}$ \\
\hline actual & 686,79 & 1201,31 \\
\hline $\max$ & 286,62 & 705,06 \\
\hline CTE & 378,32 & 812,94 \\
\hline opc. 1 & 369,03 & 830,74 \\
\hline оpc. 2 & 369,18 & 829,25 \\
\hline opc. 3 & 373,59 & 837,35 \\
\hline opc. 4 & 373,65 & 834,10 \\
\hline оpc. 5 & 371,69 & 826,61 \\
\hline оpc. 6 & 372,02 & 834,26 \\
\hline opc. 7 & 373,90 & 840,20 \\
\hline оpc. 8 & 369,61 & 823,02 \\
\hline оpc. 9 & 376,42 & 832,91 \\
\hline opt. 10 & 395,32 & 845,11 \\
\hline opt. 11 & 300,03 & 718,39 \\
\hline opt. 12 & 431,91 & 880,58 \\
\hline opt. 13 & 417,40 & 865,30 \\
\hline opt. 14 & 428,94 & 872,15 \\
\hline opt. 1EI & 368,74 & 891,99 \\
\hline opt. 3EI & 293,52 & 778,07 \\
\hline opt. 6EI & 291,12 & 709,45 \\
\hline opt. 7EI & 294,84 & 716,67 \\
\hline opt. 8EI & 362,41 & 813,14 \\
\hline opt. 10EI & 354,83 & 805,18 \\
\hline opt. 11EI & 370,43 & 826,36 \\
\hline opt. 13EI & 295,99 & 715,70 \\
\hline opt. 14El & $286 ., 86$ & 705,64 \\
\hline opt.15El & 292,44 & 716,30 \\
\hline
\end{tabular}

Tabla 11.5: Índices $B_{C A L}$ y $B_{R E F}$ minimizados por el $A G$ 
Después de correr Galápagos, DIVA ${ }^{\mathrm{TM}}$ conecta GH a EnergyPlus para calcular la demanda anual de calefacción y refrigeración de las opciones optimizadas (Fig. 11.11). La sectorización térmica se indica en la figura 11.12 con cinco zonas por planta. Los parámetros de EnergyPlus se muestran en la Tabla 11.6.

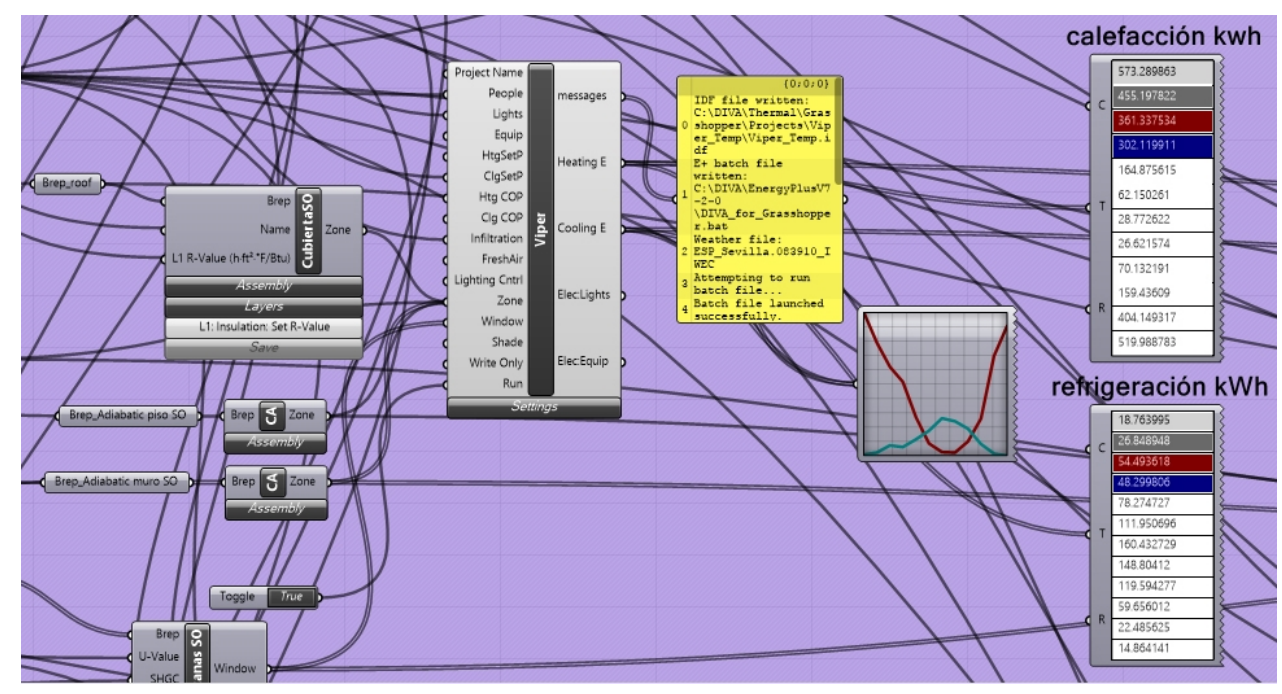

Fig. 11.11: Simulación DIVA/ Energy+ en el entorno Rhino/GH. Fuente: la autora

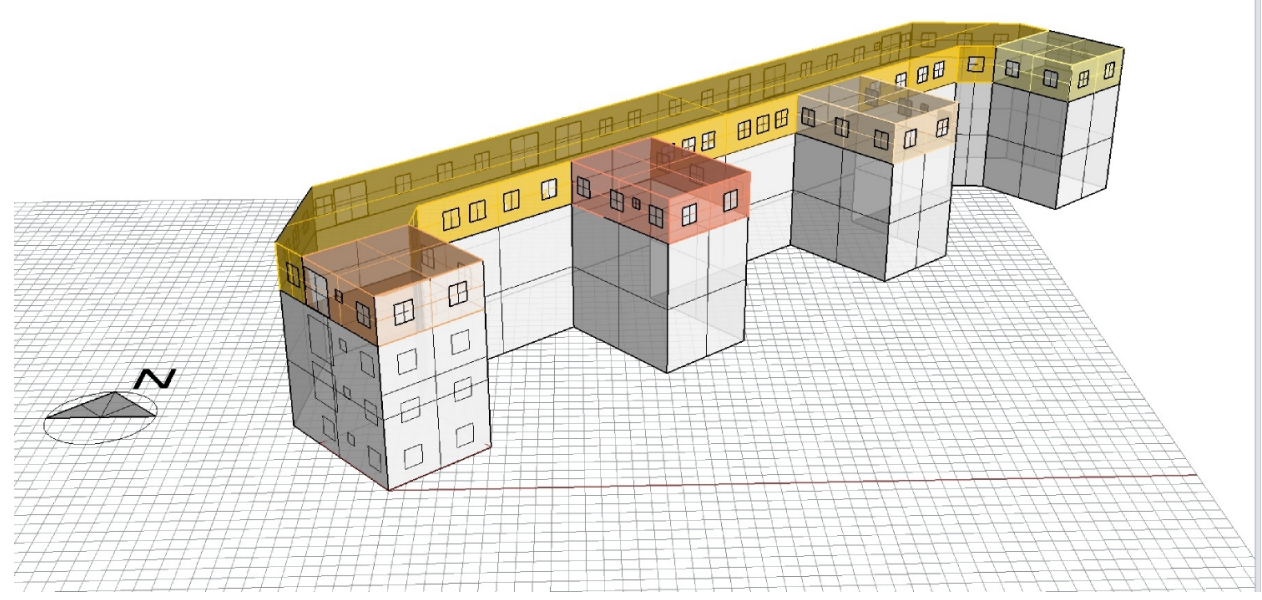

Fig. 11.12: Zonificación para DIVA/ Energy+ en el entorno Rhino/GH. Fuente: la autora

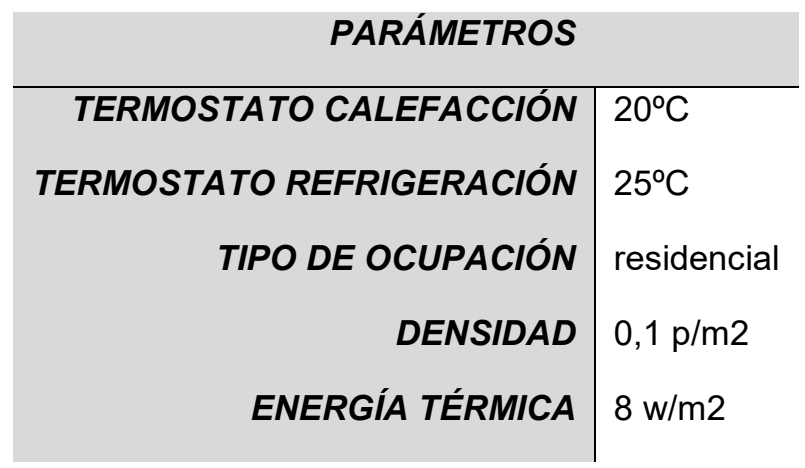


Tabla 11.6: Parámetros de EnergyPlus/DIVA. Fuente: la autora

Se simulan las 33 opciones geométricamente optimizadas y también el edificio en su estado actual sin ninguna medida de eficiencia energética (opción ACTUAL) y la llamada opción CTE que adopta los mínimos $\mathrm{K}$ recomendados por el CTE. En este caso representa $1 \mathrm{~cm}$ de EPS en fachadas y $2.4 \mathrm{~cm}$ de EPS en la cubierta, con ventanas tipo 2. La última opción no optimizada es la que considera los valores máximos de $\mathrm{K}$ con $8 \mathrm{~cm}$ de espesor de EPS en fachadas y $34 \mathrm{~cm}$, en la cubierta. La Tabla 11.7 muestra los valores $\mathrm{K}$ de la envolvente, el espesor del aislante térmico, el tipo de carpinterías, la intensidad de uso energética anual (IUE) y el ahorro monetario para las 33 opciones.

\begin{tabular}{|c|c|c|c|c|c|c|c|}
\hline opciones & $\begin{array}{l}\text { VENTANAS } \\
\qquad / m^{2} K\end{array}$ & tipo & $\begin{array}{l}\text { MUROS } \\
W / m^{2} K\end{array}$ & $\begin{array}{c}E P S w \\
c m\end{array}$ & $\begin{array}{c}\text { CUBIERTA } \\
\text { W/m }{ }^{2} K\end{array}$ & $\begin{array}{c}E P S r \\
\mathrm{~cm}\end{array}$ & $\begin{array}{c}\text { IUE } \\
k W h / m 2 . a n ̃ o\end{array}$ \\
\hline actual & 5,7 & 0 & 2.11 & 0,0 & 1,11 & 0,0 & 109,55 \\
\hline $\max$ & 2,3 & 3 & 0.38 & 8,0 & 0,10 & 34,0 & 63,55 \\
\hline$S B C$ & 4,2 & 2 & 1,00 & 2,0 & 0,65 & 2.4 & 79,48 \\
\hline opt. 1 & 3,2 & 1 & 0.43 & 7,0 & 0,36 & 7,0 & 70,27 \\
\hline opt. 2 & 3,2 & 1 & 0.44 & 6,7 & 0,33 & 8,1 & 70,01 \\
\hline opt. 3 & 3,2 & 1 & 0.46 & 6,5 & 0,41 & 5,7 & 67,08 \\
\hline opt. 4 & 3,2 & 1 & 0.47 & 6,1 & 0,35 & 7,4 & 70,80 \\
\hline opt. 5 & 3,2 & 1 & 0.49 & 5,9 & 0,24 & 12,7 & 69,52 \\
\hline opt. 6 & 3,2 & 1 & 0.45 & 6,5 & 0,38 & 6,5 & 70,85 \\
\hline opt. 7 & 3,2 & 1 & 0.46 & 6,6 & 0,44 & 4,7 & 71,85 \\
\hline opt. 8 & 3,2 & 1 & 0.48 & 6,0 & 0,20 & 15,6 & 68,92 \\
\hline opt. 9 & 3,2 & 1 & 0.52 & 5.5 & 0,27 & 10,2 & 72,20 \\
\hline opt. 10 & 3,2 & 1 & 0.70 & 3.6 & 0,19 & 16,2 & 72,09 \\
\hline opt. 11 & 2,3 & 3 & 0.49 & 6,0 & 0,13 & 25,0 & 65,74 \\
\hline opt. 12 & 2,3 & 3 & 0.98 & 2,0 & 0,26 & 11,0 & 77,20 \\
\hline opt. 13 & 2,3 & 3 & 0.87 & 2,5 & 0,21 & 14,5 & 74,64 \\
\hline opt. 14 & 2,3 & 3 & 0.99 & 22,2 & 0,15 & 2,0 & 75,10 \\
\hline opt. 1EI & 3,2 & 1 & 0,43 & 7,0 & 0,36 & 7,0 & 70,21 \\
\hline opt. 3EI & 2,3 & 3 & 0,41 & 7,3 & 0,21 & 14,8 & 65,48 \\
\hline opt. 6EI & 2,3 & 3 & 0,42 & 7.2 & 0,11 & 30,9 & 64,29 \\
\hline opt. 7EI & 2,3 & 3 & 0,43 & 7,0 & 0,19 & 16,6 & 65,51 \\
\hline opt. 8EI & 3,2 & 1 & 0,44 & 6.8 & 0,13 & 26.2 & 67,29 \\
\hline opt. 10EI & 3,2 & 1 & 0,38 & 8,0 & 0,10 & 34,0 & 65,96 \\
\hline opt. 11EI & 3,2 & 1 & 0.47 & 6.1 & 0,25 & 11,6 & 69,50 \\
\hline opt. 13EI & 2,3 & 3 & 0,45 & 6,6 & 0,15 & 21,8 & 65,33 \\
\hline opt. 14EI & 2,3 & 3 & 0,38 & 8,0 & 0,11 & 31,0 & 63,56 \\
\hline opt.15EI & 2,3 & 3 & 0,40 & 7,6 & 0.22 & 13,5 & 65,45 \\
\hline
\end{tabular}

Tabla 11.7: Valores $K$ de la envolvente, espesor del aislamiento térmico, tipo de ventanas e IUE 
El grupo de opciones optimizadas por el AG muestran una dispersión de las soluciones en dos grupos: el inferior, que tiene IUE similar al grupo superior, pero con costos iniciales más bajos (Fig. 11.13). Este podría ser un primer criterio para seleccionar las mejores opciones pero no se están considerando el ahorro en gastos de electricidad ni la factibilidad financiera.

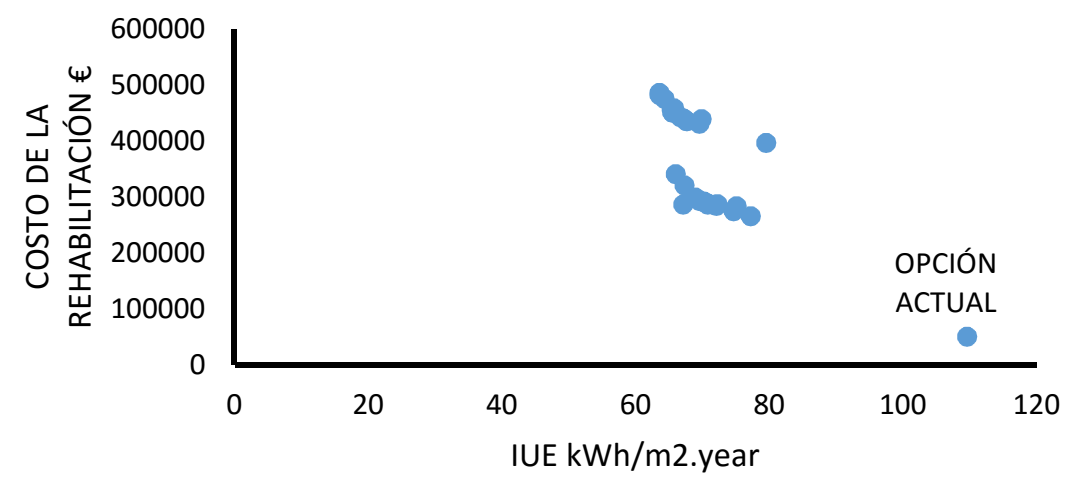

Fig. 11.13: Relación entre la IUE y el costo de la rehabilitación para todas las opciones. Fuente: la autora

Comparando la IUE y el costo inicial de la rehabilitación, obtenemos los resultados que se muestran a continuación (Fig. 11.14), donde se observa el amesetamiento de la IUE aun cuando mejoremos la eficiencia de la envolvente mediante una inversión mayor.

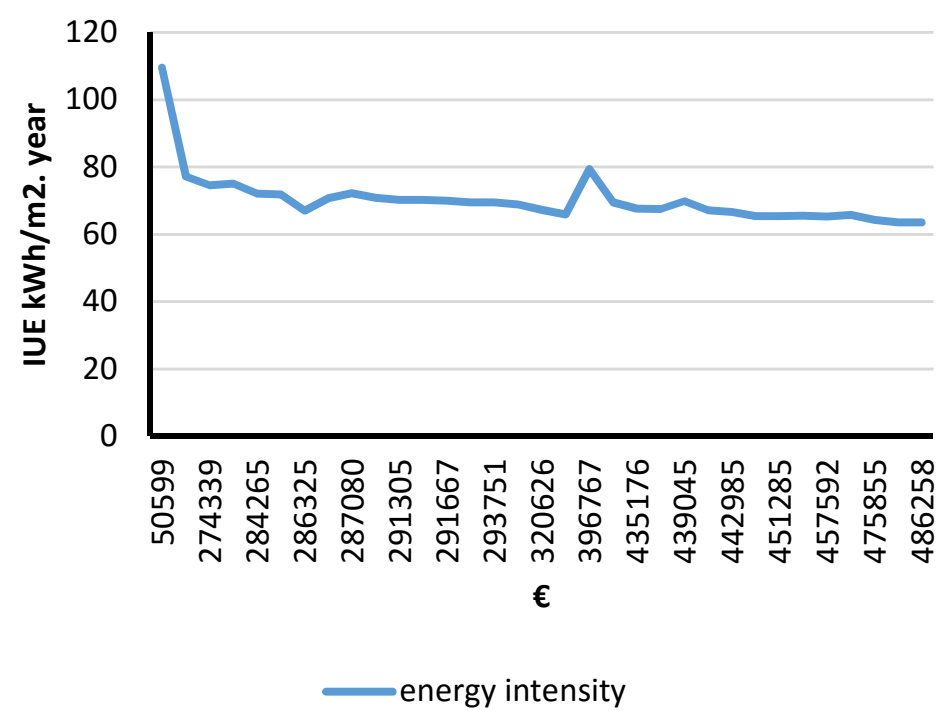

Fig.11.14: Relación entre la inversión de la rehabilitación y la IUE

Cuando analizamos el costo de rehabilitación y la intensidad de uso energético que determina un mayor o menor ahorro, vemos que el aumento de la inversión inicial no es 200 
linealmente dependiente de la IUE, o sea, de la eficiencia alcanzada. Por ello, se hace necesaria una segunda evaluación desde la factibilidad financiera (Fig. 11.15)

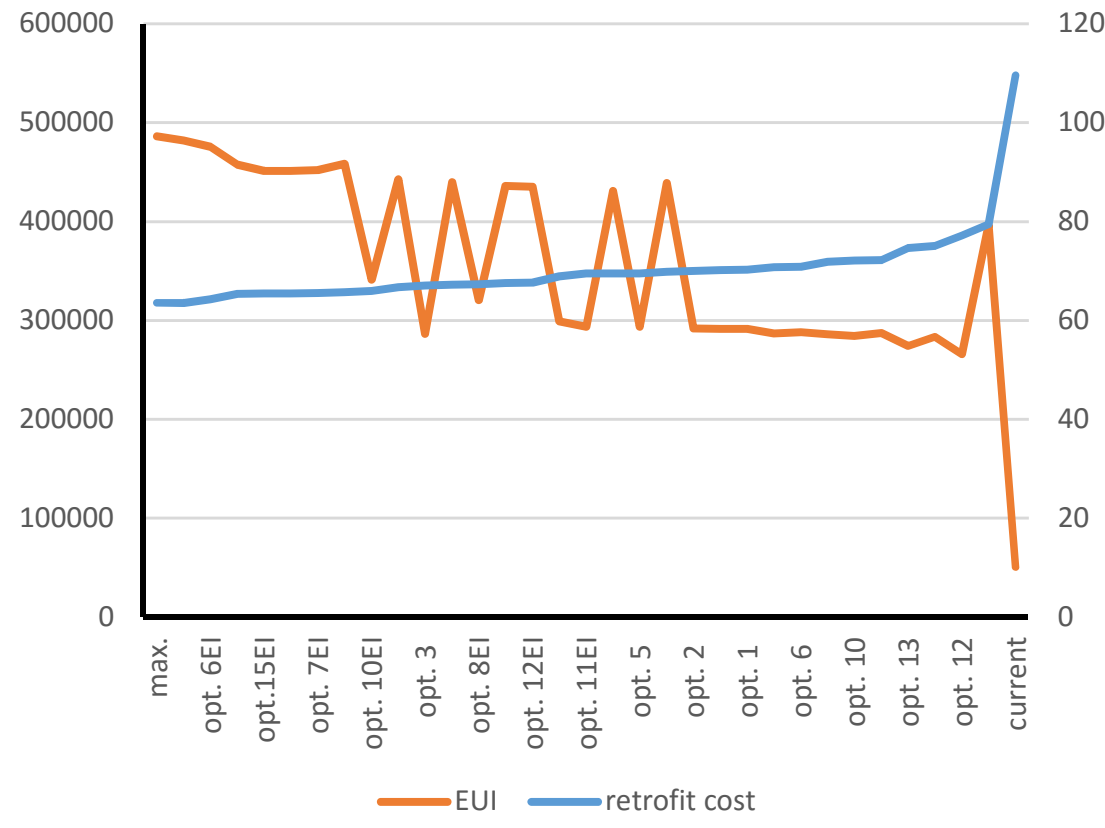

Fig. 11.15: Relación entre la IUE y la inversión inicial de la rehabilitación

\subsubsection{Validación de BCAL-B $B_{\text {REF }}$ con EnergyPlus}

Los índices $B_{C A L}$ and $B_{R E F}$ son validados con los resultados de EnergyPlus. $B_{R E F}$ tiene una alta correlación $\left(R^{2}=0.9469\right)$ con la intensidad de uso energética de EnergyPlus como se

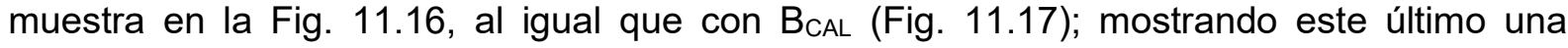
correlación más baja con la IUE de EnergyPlus $\left(R^{2}=0.8719\right)$ (Fig. 11.18).

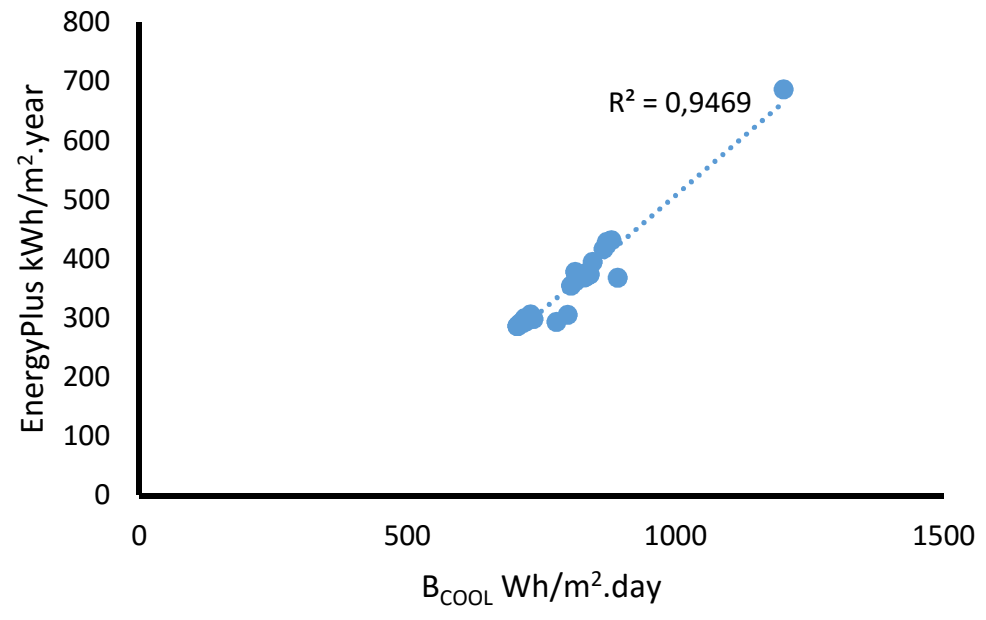

Fig. 11.16. Relación entre BREF/EnergyPlus EUI 


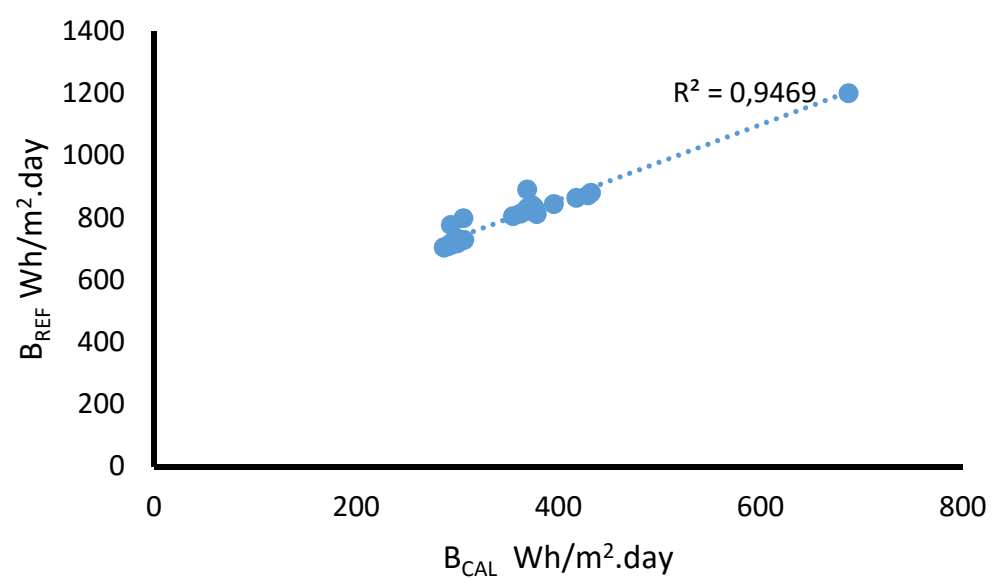

Fig. 11.17: Relación entre $B_{C A L} / B_{R E F}$

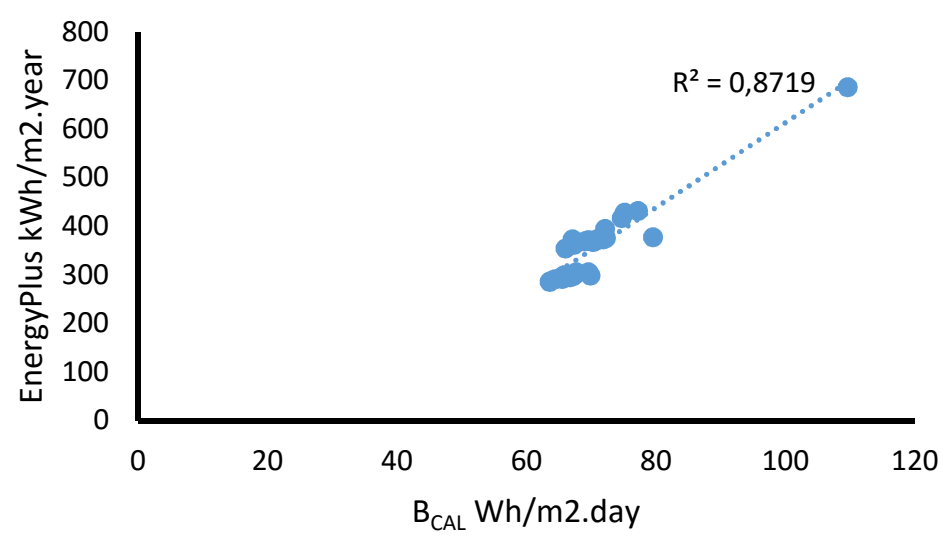

Fig. 11.18: Relación entre $B_{C A L} /$ EnergyPlus EUI

\subsubsection{Proceso de optimización. Etapa 2: Factibilidad financiera}

La factibilidad financiera determina las mejores opciones finales. Para optimizar esta función-objetivo, el VAN evalúa la factibilidad financiera de las diferentes opciones (Ec. 6], con la información exportada desde $\mathrm{GH}$ a una planilla de cálculo Microsoft Excel ${ }^{\mathrm{TM}}$. EI período de repago es de 30 años y la tasa de interés anual de 4\%, como recomiendan las guías (Official Journal of the European Union, 2012) que acompañan la Directiva 2010/31/EU. El costo de la electricidad para calcular los ahorros en energía es el promedio ponderado de los precios del mercado local español, 0.125€/kWh (Arbona, J., 2017).

$$
V=\frac{A}{(1+r)^{t}}-C \quad d \text { le } r h a \quad \text { ón } \quad \text { Eq. } 6
$$


VAN= Valor actualizado neto $(€)$

Ahorros $=$ diferencia entre los gastos actuales y los gastos en electricidad después de la rehabilitación $(€)$

$\mathrm{t}=$ período de repago (años)

$r=$ tasa de interés anual (\%)

Costo de la rehabilitación= inversión inicial $(€)$

Luego de calculado el VAN, los valores negativos son omitidos (Tabla 11.8) y un frente de Pareto optimiza las opciones con valores positivos de VAN y los ahorros correspondientes (Tabla 11.9) (Fig. 11.16). Dentro de los valores con VAN negativo quedan las opciones ACTUAL, CTE y MÁXIMA, aquéllas que no habían sido optimizadas sino que sólo reflejaban alguna condición determinada a priori.

\begin{tabular}{|c|cccc}
\hline & ELECTRICIDAD & AHORRO & COSTO INICIAL & VAN \\
\hline OPC. & $\boldsymbol{\epsilon}$ & $\boldsymbol{\epsilon}$ & $\boldsymbol{\epsilon}$ & $\boldsymbol{\epsilon}$ \\
\hline opc. 3 & 29351,62 & 18582.90 & 286325 & 35010,69 \\
\hline opc. 11EI & 30407.50 & 17527.00 & 293638 & 34852,73 \\
\hline optc 5 & 30417.50 & 17517.00 & 293751 & 12111,45 \\
opc. 2 & 30630.50 & 17304.00 & 291667 & 11103,34 \\
\hline opc. 4 & 30978.87 & 16955.60 & 286899 & 10814,00 \\
\hline opc. 8 & 30155.62 & 17778.90 & 299086 & $10578 ., 07$ \\
\hline opc. 1EI & 30721.25 & 17213.30 & 291645 & 9807,93 \\
\hline opc. 6 & 30999.50 & 16935.00 & 288003 & 9410,59 \\
opc. 1 & 30745.62 & 17188.90 & 291305 & 7916,34 \\
\hline opc. 10 & 31540.62 & 16393.90 & 284265 & 5293,11 \\
\hline opc. 7 & 31435.62 & 16498.90 & 285987 & 5095,39 \\
\hline opc. 9 & 31592.25 & 16342.30 & 287080 & 1728,67 \\
\hline Tabla 11.8: & & & & \\
\hline
\end{tabular}




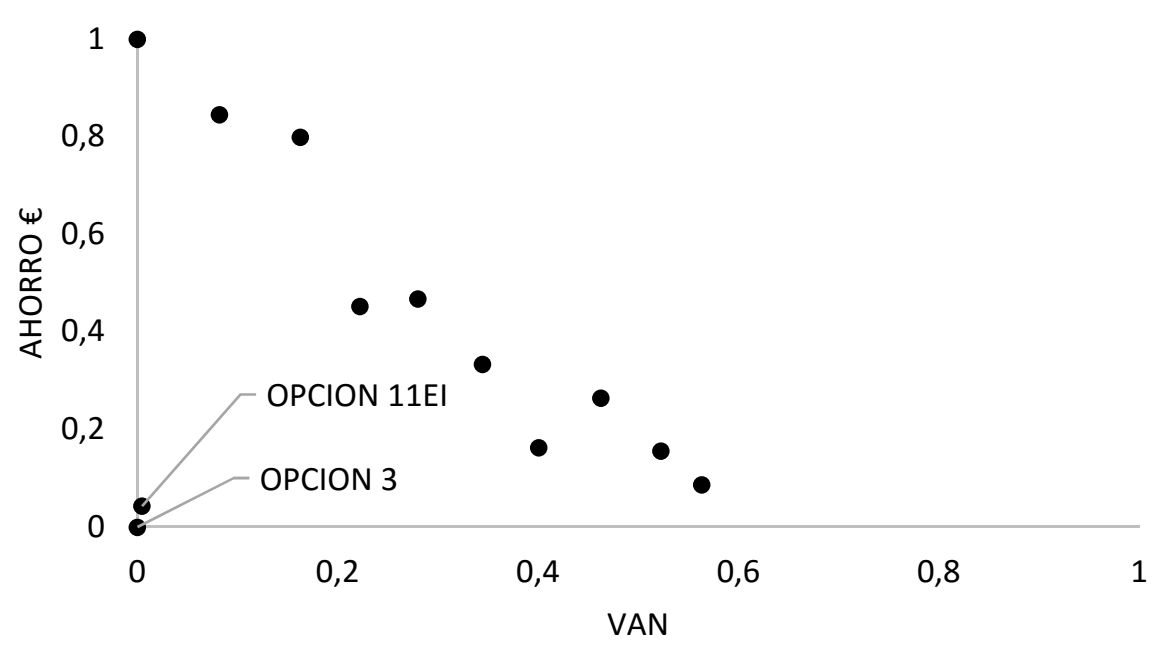

Fig. 11.19: Frente de Pareto de las opciones con VAN positivo /ahorro

\begin{tabular}{|c|c|c|c|c|c|c|c|c|}
\hline & VAN & AHORRO & & & & & & \\
\hline & $€$ & $€$ & MAX & MAX & p1 & p2 & MAX x p1 & MAX $\times$ p2 \\
\hline opc. 3 & 35010.69 & 18582.875 & 0.00 & 0.00 & 1.00 & 0.00 & 0.00 & 0.00 \\
\hline opc. 11EI & 34852.73 & 17527.00 & 0.00 & 0.47 & 0.91 & 0.09 & 0.00 & 0.04 \\
\hline opc. 5 & 12111,45 & 17517,00 & 0,69 & 0,48 & 0,82 & 0,18 & 0,56 & 0,09 \\
\hline opc. 2 & 11103,34 & 17304,00 & 0,72 & 0,57 & 0,73 & 0,27 & 0,52 & 0,16 \\
\hline opc. 4 & 10814,00 & 16955,62 & 0,73 & 0,73 & 0,64 & 0,36 & 0,46 & 0,26 \\
\hline opc. 8 & 10578,07 & 17778,87 & 0,73 & 0,36 & 0,55 & 0,45 & 0.40 & 0,16 \\
\hline opc. 1EI & 9807,93 & 17213,25 & 0,76 & 0,61 & 0,45 & 0,55 & 0,34 & 0,33 \\
\hline opc. 6 & 9410,59 & 16935,00 & 0,77 & 0,74 & 0,36 & 0,64 & 0,28 & 0,47 \\
\hline opc. 1 & 7916,34 & 17188,87 & 0,81 & 0,62 & 0,27 & 0,73 & 0,22 & 0,45 \\
\hline opc. 10 & 5293,11 & 16393,87 & 0,89 & 0,98 & 0,18 & 0,82 & 0,16 & 0,80 \\
\hline opc. 7 & 5095,39 & 16498,87 & 0,90 & 0,93 & 0,09 & 0,91 & 0,08 & 0,85 \\
\hline opc. 9 & 1728,67 & 16342,25 & 1,00 & 1,00 & 0,00 & 1,00 & 0,00 & 1,00 \\
\hline
\end{tabular}

La mejor opción es la 3, seguida de la 11El. En este caso particular, el conjunto de soluciones óptimas está integrado por estas opciones y las demás se encuentran muy lejos, pero no significa que sea un caso frecuente. Ambas soluciones poseen ventanas tipo 1. En la opción 3 la IUE es 3,48\% inferior a la opción 11EI, debido a que la aislación térmica de las 
fachadas se incrementa de 6,1 a $6,5 \mathrm{~cm}$, aun cuando en la cubierta, ésta decrece de $11.6 \mathrm{~cm}$ para la opción 11El a $6,1 \mathrm{~cm}$ para la opción 3 (Tabla 11.10).

\begin{tabular}{|c|c|c|c|c|c|}
\hline OPCIONES & $\begin{array}{c}\text { TIPO DE } \\
\text { VENTANA }\end{array}$ & $\begin{array}{l}\text { EPS FACHADAS } \\
\mathrm{cm}\end{array}$ & $\begin{array}{l}\text { EPS CUBIERTA } \\
\mathrm{cm}\end{array}$ & $\begin{array}{c}\text { IUE } \\
k W h / m^{2} \text {.year }\end{array}$ & $\begin{array}{l}\text { COSTO DE LA } \\
\text { REHABILITACIÓN } \\
€ / \mathrm{m}^{2}\end{array}$ \\
\hline 3 & 1 & 6,5 & 5,7 & 67,08 & 81,81 \\
\hline 11EI & 1 & 6,1 & 11,6 & 69,50 & 84,75 \\
\hline
\end{tabular}

Tabla 11.10: Características materiales de las opciones 3 y 11EI

La opción CTE muestra una buena performance energética $\left(79,80 \mathrm{kWh} / \mathrm{m}^{2}\right.$.a) (Tabla 9) pero con un VAN negativo ( $€-169191$ ), debido a que esta opción posee ventanas tipo 2 que tienen el mínimo K exigido pero son más caras y no tan eficientes como el tipo 1.

\subsection{Conclusiones}

Se obtuvo un conjunto de soluciones para rehabilitar la envolvente del edificio de viviendas RENFE, siguiendo el modelo bioambiental paramétrico adaptado al caso. El análisis de los resultados obtenidos demuestra que es un proceso no intuitivo, donde la mejor solución puede no ser la más cara o la más eficiente. La multiplicidad de aspectos interdependientes considerados en este caso de rehabilitación, con un número muy acotado de variables, demuestra la complejidad de los problemas que el diseñador o el tomador de decisiones deben afrontar si pretenden dar una respuesta basada en el desempeño energético de un edificio o conjunto de edificios, incluyendo su factibilidad financiera. Este tipo de problemas complejos deben instrumentarse a través de metaheurísticas que provean el conjunto de soluciones posibles cuando existen objetivos competitivos entre sí, ya que generalmente no exite una única solución.

Esta aplicación del modelo bioambiental paramétrico a un caso de rehabilitación, permite demostrar su adaptabilidad y su carácter abierto. La metodología cuasi-estacionaria empleada le ofrece a alguien sin conocimientos de programación, poder efectuar una evaluación energética y financiera, sin recurrir a una simulación energética que demanda tiempo y costos, en las primeras etapas de la resolución del problema.

Se puede afirmar que las barreras a la eficiencia sólo pueden ser traspuestas con respuestas sólidas científicamente fundamentadas, como la propuesta en este trabajo. 
El uso de algoritmos genéticos aplicados al diseño bioambiental paramétrico 
III. Conclusiones 
El uso de algoritmos genéticos aplicados al diseño bioambiental paramétrico 
Este trabajo tiene como objetivo principal el desarrollo de un modelo ambiental digital, basado en la performance energética, que optimice el prediseño de morfologías edilicias mediante algoritmos genéticos (AGs), en las fases iniciales del proyecto arquitectónico en el caso de edificios de nueva planta o en el de rehabilitación energética de edificios existentes. Para su consecución se fijaron objetivos secundarios que se enumeran a continuación:

El Objetivo 1 consiste en la creación de un modelo digital para resolver morfologías y/o envolventes sostenibles, en climas templados: Buenos Aires y Sevilla.

El Objetivo 2 propone el desarrollo de un caso de estudio, aplicando el modelo a un edificio de nueva planta en torre, situado en Buenos Aires, mediante la parametrización de las variables geométricas, materiales (composición de la envolvente), climáticas, operativas (ocupación) y normativas, que permita la optimización de la morfología edilicia.

El Objetivo 3 plantea la aplicación del modelo a un caso de rehabilitación energética de un edificio en tira: Barriada RENFE, Sevilla, optimizando no sólo el desempeño energético de la envolvente sino también su factibilidad financiera.

Se da cumplimiento a los objetivos a través del desarrollo de la metodología y se verifican las hipótesis planteadas al comienzo de la investigación. Se puede afirmar que las barreras a la eficiencia sólo pueden ser traspuestas con respuestas sólidas científicamente fundamentadas, como la propuesta en este trabajo.

\section{1. Conclusiones acerca del estado del arte}

A lo largo de la Parte I, se ha recorrido el estado del arte de las fuentes de las disciplinas que alimentan este trabajo; pudiéndose vislumbrar una urdimbre que conecta aspectos aparentemente tan disímiles como la energía, la simulación de procesos biológicos, el diseño del ambiente y el equilibrio ecológico (Herrera, R., 2013). A esa misma intensa cooperación, pero desde un punto de vista más estricitamente disciplinar, hacen referencia Lootsma (Lootsma, 1999) y (Koolhaas, 1994) cuando expresan cuál podría ser el rol del arquitecto entre todos los actores involucrados en la construcción del ambiente.

Como ya se expresó, el sector edilicio es responsable de más de un tercio del consumo de energía y de las emisiones de GEI. Mitigando el Cambio Climático, la arquitectura sostenible puede dar una respuesta a la reducción de estas emisiones y del consumo de energía mediante la eficiencia energética, las estrategias pasivas y las activas como la incorporación de las energías renovables. Por su naturaleza, esta arquitectura, se adapta al entorno físico, clima, recursos y tecnología locales, pero necesita nuevas herramientas que permitan resolver estas complejas problemáticas del producto arquitectónico. 
El uso de algoritmos genéticos aplicados al diseño bioambiental paramétrico

Ya Olgyay (Olgyay \& Olgyay, 1963) proponía un enfoque multidisciplinario de biología, arquitectura, clima y tecnología para resolver los problemas de la construcción del ambiente; luego, la teoría de sistemas, la cibernética, la teoría de la complejidad y, últimamente, la arquitectura emergente, convergen en la concepción del funcionamiento de los sistemas complejos, como el ambiente construido. El uso de los medios digitales de diseño no se limita a exploradores de forma, sino que el diseño de espacio y materialidad, junto con clima y energía puede sintetizarse en un proceso integral y no desde acciones y disciplinas separadas, para lo cual, es necesario un cambio metodológico estructural y un cuestionamiento de conceptos enraizados en la práctica arquitectónica actual. Cada sistema material necesita del desarrollo técnicas propias que correspondan a las características del mismo: no existe una solución única para todos los casos. Se trata de un cambio de actitud metodológica frente a la forma de aproximarse al diseño, permitiendo el despliegue de capacidades y cualidades espaciales inherentes a cada sistema material.

Una vez realizado un estudio pormenorizado de la normativa y legislación existentes tanto en Argentina como en España, Europa y EEUU, y evaluados críticamente los diferentes métodos para medir la demanda de calefacción y refrigeración de los edificios con sus aspectos a favor y en contra, los parámetros que se consideran para dichos cálculos y las limitaciones que condicionan cada clima de referencia, se consideran con particular interés, las recomendaciones para aquellos climas templados soleados, a los que está destinada la herramienta digital, específicamente el área metropolitana de Buenos Aires (Argentina) y la ciudad de Sevilla (España), ya que muchas de estas normativas estuvieron originalmente dirigidas a ser aplicadas en climas fríos con cielos cubiertos.

\subsection{Conclusiones acerca del modelo propuesto y sus aplicaciones}

En la parte II, hemos desarrollado una herramienta para dar respuesta al objetivo principal, mediante la instrumentación de etapas metodológicas en correspondencia a los objetivos secundarios arriba enunciados. El modelo bioambiental paramétrico desarrollado permite introducir variables geométricas, ambientales, normativas y financieras para asistir al arquitecto y/o tomador de decisiones en las etapas iniciales del proyecto en edificios de nueva planta, así como también en el caso de rehabilitaciones energéticas.

La incorporación de la computadora como partícipe imprescindible del proceso de diseño, utilizando herramientas como la recursividad, la retroalimentación y la optimización provocaron un salto cualitativo en cuanto al proceso de diseño arquitectónico, pero éstas aún se encuentran restringidas al ámbito académico y experimental. Desde siempre, se ha buscado estimular la creatividad mediante nuevas técnicas, por lo que, el modelo aquí propuesto no consume demasiado tiempo, no se necesitan grandes recursos digitales, así como tampoco, especialistas en simulación energética con el consecuente costo que eso 
implica, lo que lo transforma en una herramienta ideal para las primeras etapas del proceso de diseño arquitectónico/ urbano.

\subsubsection{Caso de estudio: edificio de nueva planta}

La innovación de la aplicación de este proceso de optimización es que, independientemente de la demanda energética exacta, provee al diseñador con alternativas energo-equivalentes estéticamente diferentes. Se puede así ampliar la selección, según criterios formales y no solamente en función de la eficiencia energética. La iteración del AG, en dos instancias, permite el mejoramiento de la geometría en primer lugar y el área vidriada, en segundo lugar. Los índices bioclimáticos elaborados para la optimización morfológica tienen en cuenta las características de los climas templados soleados, corrigiendo las deficiencias de los métodos elaborados para climas fríos de cielos cubiertos. El análisis pormenorizado de las cargas térmicas permite conocer el comportamiento del edificio en la condición de verano y de invierno, pudiendo así disminuir la demanda de calefacción, acumular el excedente de calor en invierno y/o minimizar la demanda de refrigeración.

\subsubsection{Caso de estudio: rehabilitación energética}

El conjunto de soluciones para rehabilitar la envolvente del edificio de viviendas RENFE, siguiendo el modelo bioambiental paramétrico demuestra que es un proceso no intuitivo, al verificar que la mejor solución puede no ser la más cara o la más eficiente. La complejidad de los problemas que el diseñador o el tomador de decisiones deben afrontar, si pretenden dar una respuesta basada en el desempeño energético y la factibilidad financiera de una rehabilitación de un edificio o conjunto de edificios, comprende una multiplicidad de aspectos interdependientes, aun con un número muy acotado de variables. Se comprueba como generalmente, cuando se trata de objetivos que compiten entre sí, no existe una única respuesta óptima sino un conjunto de soluciones no dominadas que satisfacen dichos requisitos.

Esta aplicación del modelo bioambiental paramétrico a un caso de rehabilitación, permite demostrar su adaptabilidad y su carácter abierto. La metodología cuasi-estacionaria empleada le ofrece a alguien sin conocimientos de programación, poder efectuar una evaluación energética y financiera, sin recurrir a una simulación energética que demanda tiempo y costos, en las primeras etapas de la resolución del problema.

\subsection{Futuras líneas de investigación}

Así como esta investigación es una continuación de líneas de investigación desarrolladas tanto en la Universidad de La Plata como en la de Sevilla, se propone proseguir el desarrollo 
de este modelo, cubriendo otros aspectos que aparecerán a medida que se aplique a mayor número de casos de estudio.

A partir de los resultados obtenidos, se sugiere la profundización de las siguientes cuestiones:

- incorporación de la influencia de la masa térmica al análisis de las cargas del edificio, que ha sido omitida adrede por tratarse de un modelo de día típico, donde ese fenómeno no interviene.

- confección de las bases de datos climáticos para otras ciudades de clima similar para agilizar la aplicación del modelo en esas áreas

- aplicación del modelo a otras tipologías además de torre y bloque

- calibración de los índices bioclimáticos con los resultados de auditorías de edificios existentes para corroborar el funcionamiento térmico de los mismos

- adaptación de los modelos térmicos diseñados para climas fríos y cielos cubiertos a climas templados y cielos claros. 
Bibliografía 
El uso de algoritmos genéticos aplicados al diseño bioambiental paramétrico 
Ábalos I., \& Herreros J. (2002). Una nueva naturalidad (7 micromanifiestos). 2G: revista internacional de arquitectura, (22), 26-33.

Acosta, W. (1936). Vivienda y clima. Buenos Aires: Nueva Visión.

Acosta, W. (1976). Vivienda y ciudad. Buenos Aires: Aresti.

AENOR. (2011). UNE-EN ISO 13790: 2011 Eficiencia energética de los edificios. Cálculo del consumo de energía para calefacción y refrigeración de espacios. (ISO 13790: 2008). Asociación Española de Normalización y Certificación.

Agencia Andaluza de Energía. (s. f.). Radiación solar. Recuperado 21 de marzo de 2017, a partir de http://www.agenciaandaluzadelaenergia.es/Radiacion/radiacion1.php

Agencia Estatal de Meteorología. (s. f.). Valores climatológicos normales: Sevilla Aeropuerto - Agencia Estatal de Meteorología - AEMET. Gobierno de España. Recuperado 21 de marzo de 2017, a partir de http://www.aemet.es/es/serviciosclimaticos/datosclimatologicos/valoresclimatologicos Alba, M. (2016). Modelo de Evaluación de la viabilidad económica y ambiental de la recuperación de edificios. Aplicación en edificios residenciales de la ciudad de Sevilla. University of Seville, Seville.

Alexander, C., Ishikawa, S. and Silverstein, M. (1977) A pattern language: towns, buildings, construction. New York: Oxford University Press.

Alexander, C. (1983) La ciudad no es un árbol. Bogotá: Escala.

Aliata, F., Liernur, F., Crispiani, A., \& Silvestri, G. (2004). Diccionario de arquitectura en la Argentina: estilos obras biografías instituciones ciudades. Clarín Arquitectura.

Álvarez Forn, R, \& Lotersztain, I. (1970). Quality Rules for Thermal Performance of Low Cost Dwellings. Building Science. IBPSA US, 613-632.

Arbona, J. (2017, marzo 21). Precio kWh electricidad [Text]. Recuperado 21 de marzo de 2017, a partir de http://comparadorluz.com/faq/precio-kwh-electricidad

Aristóteles and Sola, J. de C. (1956) Metafisica libro gamma, texto griego crítico y traducción. Barcelona: Borgiana. 
El uso de algoritmos genéticos aplicados al diseño bioambiental paramétrico

Asadi, E., da Silva, M. G., Antunes, C. H. and Dias, L. (2012) 'A multi-objective optimization model for building retrofit strategies using TRNSYS simulations, GenOpt and MATLAB', Building and Environment, 56, pp. 370-378. doi:

10.1016/j.buildenv.2012.04.005.

ASHRAE (Ed.). (2000). ANSI/ASHRAE/IESNA Standard 90.1-1999: Energy standard for building except low-rise residential buildings. Atlanta, Georgia: American Society of Heating, Refrigerating and Air-Conditioning Engineers.

ASHRAE. (2007). ASHRAE Standard 90.2-2007: Energy-Efficient design of Low-Rise Residential Buildings. American Society of Heating, Refrigerating and AirConditioning Engineers. Recuperado a partir de https://ashrae.iwrapper.com/ViewOnline/Standard_90.2-2007

ASHRAE. (2013). 2013 ASHRAE Handbook: Fundamentals. Atlanta: American Society of Heating, Refrigerating and Air-conditioning Engineers.

Attia, S., Hensen, J. L. M., Beltrán, L. and Herde, A. D. (2012) 'Selection criteria for building performance simulation tools: contrasting architects' and engineers' needs', Journal of Building Performance Simulation, 5(3), pp. 155-169. doi: 10.1080/19401493.2010.549573.

B

Banihashemi S, Golizadeh H, Reza Hosseini M and Shakouri M (2015) ‘Climatic, parametric and non-parametric analysis of energy performance of double-glazed windows in different climates', Int. J. Sustain. Environ. International Journal of Sustainable Built Environment, 4(2), pp. 307-322.

Barón, J., Conde, J., Osuna, M., Ramírez, A., \& Solís, J. (2016). Consejería de Fomento y Vivienda / Vivienda y Rehabilitación / Base de Costes de la Construcción de Andalucía (BCCA) 29 abril 2016. Banco de precios. Recuperado a partir de http://www.juntadeandalucia.es/fomentoyvivienda/portalweb/web/areas/vivienda/texto/403b7931-0d21-11e6-a18a-052bf9b4a08b 
Bassegoda Nonell, J. (1971) Gaudi ... Madrid: Publicaciones Españolas.

Beer, S. (2001) ¿Qué es cibernética? Valladolid: Universidad de Valladolid.

Benevolo, L. (1988) Historia de la arquitectura del Renacimiento: la arquitectura clásica (del siglo XV al siglo XVIII). Barcelona: Gili.

C

Caldas, L. G. y Norford, L. K. (2002) 'A design optimization tool based on a genetic algorithm', Automation in Construction, 11(2), pp. 173-184. doi: 10.1016/S09265805(00)00096-0.

Caldas, L. (2008) 'Generation of energy-efficient architecture solutions applying GENE_ARCH: An evolution-based generative design system', Advanced Engineering Informatics, 22(1), pp. 59-70. doi: 10.1016/j.aei.2007.08.012.

Calcerano, F. y Martinelli, L. (2016) 'Numerical optimisation through dynamic simulation of the position of trees around a stand-alone building to reduce cooling energy consumption', Energy and Buildings, 112, pp. 234-243. doi:

10.1016/j.enbuild.2015.12.023.

Camporeale, Patricia E. (2013a) 'Genetic algorithms applied to urban growth optimization. Solar envelope and solar fan.', in Proceedings of the 31st Education and Research in Computer Aided Architectural Design in Europe (eCAADe) Conference. 31st Education and research in Computer Aided Architectural Design in Europe (eCAADe) Conference, Delft: Faculty of Architecture, Delft University of Technology, pp. 227236. Available at: http://papers.cumincad.org/cgibin/works/Search?search=Camporeale $\& x=37 \& y=20$.

Camporeale, Patricia E. (2013b) 'Genetic algorithms applied to urban growth optimizing solar radiation', in Proceedings of the 29th Conference Passive and Low Energy Architecture. PLEA2013 - 29th Conference, Sustainable Architecture for a Renewable Future, Munich. Available at: http://pleaarch.org/ARCHIVE/2013/Conference\%20Papers/Session\%20V\%20Poster/V.2\%20R 
El uso de algoritmos genéticos aplicados al diseño bioambiental paramétrico egions, \%20Cities, \%20Neighborhoods\%20-

\%20Tools\%202/genetic_algorithms_applied_to_urban_growth_optimizing_solar_radi ation.pdf.

Camporeale, P., \& Czajkowski, J. (2016). Environmental index of energy demand in buildings. Optimization of a parametric model. International Journal of Civil and Structural Engineering, Volume 3(Issue 2), 82-87. https://doi.org/10.15224/978-163248-093-4-17

Chronis, A., Liapi, K. A. and Sibetheros, I. (2012) 'A parametric approach to the bioclimatic design of large scale projects: The case of a student housing complex', Automation in Construction. (Planning Future Cities-Selected papers from the 2010 eCAADe Conference), 22, pp. 24-35. doi: 10.1016/j.autcon.2011.09.007.

CIBSE. (2006). Degree-Days - Theory and Application - TM41: 2006. Londres: Chartered Institution of Building Services Engineers. Recuperado a partir de http://app.knovel.com/hotlink/toc/id:kpDDTATM0A/degree-days-theory

Comisión de Planeamiento y Urbanismo. Ordenanza 8757: Aspectos Higrotérmicos y Demanda Energética de las Construcciones, Reglamento de Edificación de la Ciudad de Rosario § (2011). Recuperado a partir de http://www.rosario.gov.ar/normativa/verArchivo?tipo=pdf\&id=75004

Cook, P. (2013) Rhinoceros v5.0, Level 1, Training Manual. Seattle: Robert McNeel \& Associates.

Czajkowski, J., \& Rosenfeld, E. (1992). EnergoCAD”: Sistema informatizado para el diseño bioclimático de alternativas edilicias. En Actas del Encuentro de las nuevas energías. Catamarca.

Czajkowski, Jorge D. (2009). Análisis y modelización energético-ambiental de la edilicia urbana basado en técnicas de auditoría y procedimientos estadísticos multivariados. Desarrollo de herramientas de diagnóstico y simulación (tesis doctoral). Facultad de ingeniería. Universidad Nacional de La Plata, La Plata. Recuperado a partir de http://hdl.handle.net/10915/1371 
D

Dawkins, R. (2006) The blind watchmaker. London: Penguin.

Depecker, P., Menezo, C., Virgone, J. and Lepers, S. (2001) 'Design of buildings shape and energetic consumption', Building and Environment, 36(5), pp. 627-635. doi: 10.1016/S0360-1323(00)00044-5.

De Landa, M. (2011). Philosophy and simulation: the emergence of synthetic reason. London; New York, NY: Continuum.

Dogan, T., Reinhart, C., \& Michalatos, P. (2016). Autozoner: an algorithm for automatic thermal zoning of buildings with unknown interior space definitions. Journal of Building Performance Simulation, 9(2), 176-189. https://doi.org/10.1080/19401493.2015.1006527

Dutt, G., \& Camporeale, P. ed. (2006). Manual de lluminación Eficiente (varios autores). Buenos Aires. Recuperado a partir de http://www.edutecne.utn.edu.ar/eli\%2Diluminacion/\#libro

$E$

Evans, J. M. and de Schiller, S. (1988) Diseño bioambiental y arquitectura solar. Buenos Aires: Secretaría de Extensión Universitaria, Facultad de Arquitectura y Urbanismo, Universidad de Buenos Aires.

Evans, J. M., \& Reyes, J. (1995). ISOL [DOS]. Buenos Aires: Centro de Hábitat y EnergíaFacultad de Arquitectura, diseño y Urbanismo. Universidad de Buenos Aires.

Evans, J. M. (2007) The comfort triangles: A new tool for bioclimatic design. tesis doctoral. Universidad Tecnológica de Delft. Available at: http://repository.tudelft.nl/islandora/object/uuid:5a12f90e-2e07-4ba7-b21f1da81c5c523a?collection=research (Accessed: 10 May 2017).

Ercan, B. and Elias-Ozkan, S. T. (2015) 'Performance-based parametric design explorations: A method for generating appropriate building components', Design Studies, 38, pp. 33-53. doi: 10.1016/j.destud.2015.01.001. 
Ferrara, M., Fabrizio, E., Virgone, J. and Filippi, M. (2014) 'A simulation-based optimization method for cost-optimal analysis of nearly Zero Energy Buildings', Energy and Buildings, 84, pp. 442-457. doi: 10.1016/j.enbuild.2014.08.031.

Ferreira, A. (2015). Recuperación de viviendas en condiciones de emergencia. Estudio de caso: viviendas RENFE (Sevilla). University of Seville, Seville.

Flores Larsen, S. and Lesino, G. (2001) 'Modelo térmico del programa SIMEDIF de simulación de edificios', Energías Renovables y Medio Ambiente. Editorial de la Universidad Nacional de Salta, 9, p. pág. 15 y ss.

Fonseca i Casas, P., Fonseca i Casas, A., Garrido-Soriano, N., \& Casanovas, J. (2014). Formal simulation model to optimize building sustainability. Advances in Engineering Software, 69, 62-74. https://doi.org/10.1016/j.advengsoft.2013.12.009

Frazer, J. (1995) An evolutionary architecture. London: Architectural Association.

G

Geco (2016) Food4Rhino. Available at: http://www.food4rhino.com/app/geco (Accessed: 21 March 2017).

Gerber, D. J., Pantazis, E. and Wang, A. (2017) 'A multi-agent approach for performance based architecture: Design exploring geometry, user, and environmental agencies in façades', Automation in Construction, 76, pp. 45-58. doi: 10.1016/j.autcon.2017.01.001.

Givoni, B. (1969). Man, climate, and architecture. Amsterdam: Elsevier.

Gobierno de la Ciudad Autónoma de Buenos Aires. (2013). Ley 4458 Normas de Acondicionamiento térmico en la construcción de edificios. En Boletín Oficial 4142. Buenos Alres. Recuperado a partir de http://boletinoficial.buenosaires.gob.ar/documentos/boletines/2013/04/20130430.pdf 
Gobierno de la Ciudad Autónoma de Buenos Aires. (2016, diciembre 31). Código de Planeamiento Urbano. Recuperado a partir de http://www.buenosaires.gob.ar/planeamiento/codigo-de-planeamiento-urbano Gobierno de la Provincia de Buenos Aires. Ley 13059. Condiciones de Acondicionamientos Térmico exigibles en la construcción de edificios. Decreto Reglamentario 1.030/2010 (2010). Recuperado a partir de http://www.gob.gba.gov.ar/legislacion/legislacion/101030.html

González, J. and Fiorito, F. (2015) 'Daylight Design of Office Buildings: Optimisation of External Solar Shadings by Using Combined Simulation Methods', Buildings, 5(2), pp. 560-580. doi: 10.3390/buildings5020560.

Goldberg, D. E. (2003) Genetic algorithms in search, optimization, and machine learning. Boston. Addison-Wesley.

Granadeiro, V., Pina, L., Duarte, J. P., Correia, J. R., y Leal, V. M. S. (2013). A general indirect representation for optimization of generative design systems by genetic algorithms: Application to a shape grammar-based design system. Automation in Construction, 35, 374-382. https://doi.org/10.1016/j.autcon.2013.05.012

Granadeiro, V., Correia, J. R., Leal, V. M. S., y Duarte, J. P. (2013). Envelope-related energy demand: A design indicator of energy performance for residential buildings in early design stages. Energy and Buildings, 61, 215-223. https://doi.org/10.1016/j.enbuild.2013.02.018

Grabner, T. and Frick, U. (2013) 'GECOTM: Architectural Design Through Environmental Feedback', Architectural Design, 83(2), pp. 142-143. doi: 10.1002/ad.1572.

Guinée, J. B. (ed.) (2002) Handbook on life cycle assessment: operational guide to the ISO standards. Dordrecht ; Boston: Kluwer Academic Publishers (Eco-efficiency in industry and science, v. 7).

$\mathrm{H}$ 
Harding, J. E. and Shepherd, P. (no date) 'Meta-Parametric Design', Design Studies. doi:

10.1016/j.destud.2016.09.005.

Hemberg, M., O'Reilly, U.-M., Menges, A., Jonas, K., Gonçalves, M. da C. and Fuchs, S. R. (2008) 'Genr8: Architects' Experience with an Emergent Design Tool'.

Hensel, M., Menges, A. and Weinstock, M. (2010) Emergent technologies and design. Oxon, U.K.: Routledge.

Herrera, R. (2013, diciembre 13). La urdimbre sostenible como táctica para un hacer arquitectónico: de la "arquitectura de países cálidos" hasta los nuevos escenarios y modos de vida emergentes, a través de la dimensión dialógica (tesis doctoral). Universidad de Sevilla.

Holland, J. H. (1992) Adaptation in natural and artificial systems: an introductory analysis with applications to biology, control, and artificial intelligence. Cambridge, Mass.: MIT Press.

Holland, J. (2001) Adaptation in natural and artificial systems: an introductory analysis with applications to biology, control, and artificial intelligence. Cambridge, Mass., [etc.: MIT Press.

IDAE. (2015). Consumo de Energía Final. Instituto para la Diversificación y el Ahorro de la Energía, Ministerio de Industria, Energía y Turismo. Gobierno de España. Recuperado a partir de http://sieeweb.idae.es/consumofinal/

IEA. (2013). Transition to Sustainable Buildings: Strategies and Opportunities to 2050. Paris. INDEC. (2010). Censo Nacional de Población, Hogares y Viviendas 2010. Instituto Nacional de Estadísticas y Censos. Ministerio de Economía de la Nación. Recuperado a partir de

http://www.indec.gov.ar/censos_provinciales.asp?id_tema_1=2\&id_tema_2=41\&id_te ma_3 $=135 \& p=06 \& d=998 \& t=3 \& s=0 \& c=2010$ 
Instituto Eduardo Torroja de Ciencias de la Construcción,CEPCO y AICIA. (2010). Catálogo de Elementos Constructivos del CTE. En Código Técnico Español. Madrid.

Iqbal, I. and Al-Homoud, M. S. (2007) 'Parametric analysis of alternative energy conservation measures in an office building in hot and humid climate', Building and Environment, 42(5), pp. 2166-2177. doi: 10.1016/j.buildenv.2006.04.011.

IRAM. (1996). IRAM 11605. Acondicionamiento térmico de edificios. condiciones de habitabilidad en edificios Valores máximos de trasmitancla térmica en cerramientos opacos. Buenos Aires: Instituto Argentino de Normalización y Certificación.

IRAM. (2001) IRAM 11604 Aislamiento térmico de edificios. Verificación de sus condiciones higrotérmicas. Ahorro de energía en calefacción. Coeficiente volumétrico G de pérdidas de calor. Cálculo y valores límites (2nd ed.). Buenos Aires Instituto Argentino de Normalización y Certificación.

IRAM. (2002). Norma IRAM 11549. Aislamiento térmico de edificios. Vocabulario. Buenos Aires Instituto Argentino de Normalización y Certificación.

IRAM. (2004). IRAM 11659-1 Esquema 2. Aislamiento térmico de edificios. Verificación de sus condiciones higrotérmicas. Ahorro de energía en refrigeración. Parte 1: vocabulario, definiciones, tablas y datos para determinar la carga la carga térmica de refrigeración. Buenos Aires Instituto Argentino de Normalización y Certificación.

IRAM. (2007). IRAM 11659-2. Proyecto 1 de Norma Argentina. Acondicionamiento térmico de edificio. Verificación de sus condiciones higrotérmicas. Ahorro de energía en refrigeración. Parte 2: Edificios para vivienda. Buenos Aires Instituto Argentino de Normalización y Certificación.

IRAM. (2010a). IRAM STANDARD 11507-1 Carpintería de obra. Ventanas exteriores. Requisitos básicos y clasificación. Buenos Aires: Instituto Argentino de Normalización y Certificación.

IRAM. (2010b). IRAM STANDARD 11507-4 Carpintería de obra y fachadas integrales livianas. Ventanas exteriores. Parte 4- Requisitos complementarios. Aislación térmica. Buenos Aires: Instituto Argentino de Normalización y Certificación. 
El uso de algoritmos genéticos aplicados al diseño bioambiental paramétrico

IRAM. (2010c, mayo 19). IRAM 11900 Etiqueta de eficiencia energética de calefacción para edificios. Clasificación según la transmitancia térmica de la envolvente. Instituto Argentino de Normalización y Certificación.

IRAM. (2010c, mayo 19). IRAM 11900 Etiqueta de eficiencia energética de calefacción para edificios. Clasificación según la transmitancia térmica de la envolvente. Buenos Aires Instituto Argentino de Normalización y Certificación.

IRAM. (2012). IRAM 11603. Acondicionamiento térmico de edificios. Clasificación bioambiental de la República Argentina. Buenos Aires. Instituto Argentino de Normalización y Certificación.

ISO. (2006). ISO 14040: 2006. Environmental management -- Life cycle assessment -Principles and framework.

$J$

Jakubiec, A. and Reinhardt, C. (2011) 'DIVA 2.0: Integrating daylight and thermal simulations using Rhinoceros 3D, DAYSIM and EnergyPlus', in Proceedings of the 12th Conference of International Building Performance Simulation Association. 12th Conference of International Building Performance Simulation Association, Sydney, pp. 2002-2009.

Jin, J.-T. y Jeong, J.-W. (2014) 'Optimization of a free-form building shape to minimize external thermal load using genetic algorithm', Energy and Buildings, 85, pp. 473482. doi: 10.1016/j.enbuild.2014.09.080.

Johnson, S. (2004) Emergence: the Connected Lives of Ants, Brains, Cities, and Software. New York, N.Y.: Scribner.

Jonas, K. (2011) ‘Genr8’ comunicación personal 11-8-2011.

Jones, J. C., Broadbent, G., Bonta, J. P. and Design Methods in Architecture Symposium (eds) (1969) El simposio de Portsmouth: problemas de metodología del diseño arquitectónico. Buenos Aires: Editorial Universitaria de Buenos Aires.

Jones, C. (1982) Métodos de diseño. Barcelona: Gili. 
Kanters, J. and Horvat, M. (2012) 'Solar Energy as a Design Parameter in Urban Planning', Energy Procedia. (1st International Conference on Solar Heating and Coolingfor Buildings and Industry (SHC 2012)), 30, pp. 1143-1152. doi: 10.1016/j.egypro.2012.11.127.

Karmellos, M., Kiprakis, A., \& Mavrotas, G. (2015). A multi-objective approach for optimal prioritization of energy efficiency measures in buildings: Model, software and case studies. Applied Energy, 139, 131-150.

https://doi.org/10.1016/j.apenergy.2014.11.023

Knowles, R. (2003) 'The solar envelope: its meaning for energy and buildings', Energy and Buildings. (Special issue on urban research), 35(1), pp. 15-25. doi: 10.1016/S03787788(02)00076-2.

Koolhaas, R. (1994). Delirious New York: a Retroactive Manifesto for Manhattan. Rotterdam: 010 Publishers.

Kourkoutas, V. (2007) Parametric Form Finding in Contemporary Architecture. tesis de maestría. Universidad Tecnológica de Viena. Available at: http://papers.cumincad.org/data/works/att/bsct_kourkoutas.content.03024.pdf.

$\mathrm{L}$

Lagios, K., Niemasz J and C. Reinhardt (2010) 'Animated Building Performance Simulation (ABPS). Linking Rhinoceros/Grasshopper with Radiance/DaySim', in Proceedings of the Fourth International Conference of IBPSA. 4th International Conference of IBPSA, New York.

Laureano, P. (2013). La piramide rovesciata: il modello dell'oasi per il pianeta Terra. Torino: Bollati Boringhieri.

Laurel, B. (2003). Design research: methods and perspectives. Cambridge, Mass.: MIT Press. 
El uso de algoritmos genéticos aplicados al diseño bioambiental paramétrico

Lin, E., \& Gerber, D. (2013). Designing Designing-In Performance: A case study of a net zero energy school design. En PLEA Proceedings 2013. Munich.

Lin, S.-H. E. and Gerber, D. J. (2014) ‘Designing-in performance: A framework for evolutionary energy performance feedback in early stage design', Automation in Construction, 38, pp. 59-73. doi: 10.1016/j.autcon.2013.10.007.

Lootsma, B. (1999). Reality Bytes. The meaning of research in the Second Modernity. Birkhäuser. Recuperado a partir de http://www.myilibrary.com?id=968806

López, J. (2013, mayo 26). Optimización Multi-objetivo. aplicaciones a problemas del mundo real. Facultad de Informática- Universidad Nacional de La Plata, La Plata.

Lootsma, B. (1999). Reality Bytes. The meaning of research in the Second Modernity. Birkhäuser. Recuperado a partir de http://www.myilibrary.com?id=968806

$\mathrm{M}$

Maturana, H. R., \& Varela García, F. J. (1994). De máquinas y seres vivos: autopoiesis la organización de lo vivo. Santiago de Chile: Universitaria.

Mercader Moyano, M. (2010). Cuantificación de los recursos consumidos y cuantificación de las emisiones de $\mathrm{CO} 2$ producidas en las construcciones de Andalucía y sus implicaciones en el Protocolo de Kioto. School of Architecture-University of Seville, Seville. Recuperado a partir de http://fondosdigitales.us.es/tesis/tesis/1256/cuantificacion-de-los-recursosconsumidos-y-emisiones-de-co2-producidas-en-las-construcciones-de-andalucia-ysus-implicaciones-en-el-protocolo-de-kioto/

Mazria, E. (1985). El Libro de la energía solar pasiva. Mexico D.F.: Gustavo Gili.

Mazria, E., Reynolds, J., Roaf, S., Fisk, P., University of Nevada, L. V., College of Fine Arts, Natural Energies Advanced Technologies Laboratory. (2007). The 2030 challenge environmental design in the face of climate change. Las Vegas, Nev.: UNLV School of Architecture. 
Ministerio de Economía de la República Argentina. (2014). BEN 2013 NATIONAL ENERGY BALANCE. Recuperado a partir de http://www.energia.gov.ar/contenidos/verpagina.php?idpagina=3366-

Maturana, H. R. and Varela, F. J. (1972) De máquinas y seres vivos: una teoría sobre la organización biológica. Santiago de Chile: Ed. Universitaria.

Méndez Echenagucia, T., Capozzoli, A., Cascone, Y. and Sassone, M. (2015) 'The early design stage of a building envelope: Multi-objective search through heating, cooling and lighting energy performance analysis', Applied Energy, 154, pp. 577-591. doi: 10.1016/j.apenergy.2015.04.090.

Mercader Moyano, M. (2010). Cuantificación de los recursos consumidos y cuantificación de las emisiones de $\mathrm{CO} 2$ producidas en las construcciones de Andalucía y sus implicaciones en el Protocolo de Kioto. School of Architecture-University of Seville, Seville. Recuperado a partir de http://fondosdigitales.us.es/tesis/tesis/1256/cuantificacion-de-los-recursosconsumidos-y-emisiones-de-co2-producidas-en-las-construcciones-de-andalucia-ysus-implicaciones-en-el-protocolo-de-kioto/

Mercader Moyano, M., Claro, J., \& Ramos, M. (2016). Sistemas de Certificación en Clima Templado. En Actas del I Encuentro Nacional sobre Ciudad, Arquitectura y Construcción Sustentable. La Plata: Laboratorio de Arquitectura y Hábitat Sustentable. Facultad de Arquitectura y Urbanismo. Universidad Nacional de La Plata.

Ministerio de Fomento (Ed.). (1999). Ley 38/1999 de 5 de noviembre de ordenación de la edificación: [BOE núm 266, sábado6 de noviembre de 1999]. Madrid: BOE.

Ministerio de Fomento (Ed.). (2013). Código Técnico de la Edificación (4a ed. / preparada por Departamento de Redacción Aranzadi). Cizur Menor, Navarra: Aranzadi. Ministerio de Fomento. (2016). Documento Básico HE Ahorro de energía. En Código Técnico de la Edificación. Madrid: Secretaría de Estado de Infraestructuras, Transporte y Vivienda, Dirección General de Arquitectura, Vivienda y Suelo. 
El uso de algoritmos genéticos aplicados al diseño bioambiental paramétrico

Recuperado a partir de

http://www.codigotecnico.org/images/stories/pdf/ahorroEnergia/DccHE.pdf

Ministerio de Fomento. (2017). Documento descriptivo climas de referencia. En Código

Técnico de la Edificación (Vol. Documentos de apoyo). Madrid: Secretaría de Estado

de Infraestructuras, Transporte y Vivienda. Dirección General de Arquitectura,

Vivienda y Suelo. Recuperado a partir de

https://www.codigotecnico.org/images/stories/pdf/ahorroEnergia/20170202-DOC-DB-

HE-0-Climas\%20de\%20referencia.pdf

Ministerio de Fomento. (2015). DA DB-HE / 1 Cálculo de parámetros característicos de la envolvente. Documento de Apoyo al Documento Básico DB-HE Ahorro de energía. En Código Técnico de la Edificación. Madrid: Ministerio de Fomento. Secretaría de Estado de Infraestructuras, Transporte y Vivienda. Dirección General de Arquitectura, Vivienda y Suelo. Recuperado a partir de http://www.codigotecnico.org/images/stories/pdf/ahorroEnergia/DA-DB-HE-1Calculo_de_parametros_caracteristicos.pdf

Ministerio de Fomento. (2016). Documento Básico HE Ahorro de energía. En Código Técnico de la Edificación. Madrid: Secretaría de Estado de Infraestructuras, Transporte y Vivienda, Dirección General de Arquitectura, Vivienda y Suelo. Recuperado a partir de http://www.codigotecnico.org/images/stories/pdf/ahorroEnergia/DccHE.pdf Ministerio de Fomento. (2017). Documento descriptivo climas de referencia. En Código Técnico de la Edificación (Vol. Documentos de apoyo). Madrid: Secretaría de Estado de Infraestructuras, Transporte y Vivienda. Dirección General de Arquitectura, Vivienda y Suelo. Recuperado a partir de https://www.codigotecnico.org/images/stories/pdf/ahorroEnergia/20170202-DOC-DBHE-0-Climas\%20de\%20referencia.pdf

Mitchell, M. (2006) An introduction to genetic algorithms. Cambridge, Mass.; London: MIT. Murray, S. N., Walsh, B. P., Kelliher, D. and O’Sullivan, D. T. J. (2014) ‘Multi-variable optimization of thermal energy efficiency retrofitting of buildings using static modelling 
and genetic algorithms - A case study', Building and Environment, 75, pp. 98-107. doi: 10.1016/j.buildenv.2014.01.011.

Morin, E. (2004) 'La epistemología de la complejidad', Gazeta de Antropología. Repositorio Institucional de la Universidad de Granada, (20). Available at: http://hdl.handle.net/10481/7253.

$\mathrm{N}$

Nembrini, J., Samberger, S. and Labelle, G. (2014) 'Parametric scripting for early design performance simulation', ENB Energy \& Buildings: Part C, 68, pp. 786-798.

Nguyen, A.-T., Reiter, S. and Rigo, P. (2014) 'A review on simulation-based optimization methods applied to building performance analysis', Applied Energy, 113, pp. 10431058. doi: 10.1016/j.apenergy.2013.08.061.

$\mathrm{O}$

ONU. (1987, agosto 4). Informe de la Comisón Mundial sobre el Medio Ambiente y el Desarrollo. Nuestro futuro común. Recuperado a partir de http://www.un.org/es/comun/docs/?symbol=A/42/427

Olgyay, V., \& Olgyay, A. (1963). Design with climate: bioclimatic approach to architectural regionalism. New Jersey: Princeton University Press.

O'Reilly, U., Hemberg, M. and Menges, A. (2004) 'Evolutionary computation and artificial life in architecture: Exploring the potentials of generative and genetic algorithms as operative design tools', Architectural Design, pp. 48-53.

Otto, F., Rasch, B. and Schanz, S. (2006) Freí Otto, Bodo Rasch: finding form : towards an architecture of the minimal. Fellbach: Axel Menges.

Olgyay, V. and Olgyay, A. (1963) Design with climate: bioclimatic approach to architectural regionalism. New Jersey: Princeton University Press.

Otto, F., Burkhardt, B., Pankoke, U., Helmcke, J. G., Wagner, J., Universität Stuttgart, Institut für Leichte Flächentragwerke, Technische Universität Berlin and Institut für Biologie 
El uso de algoritmos genéticos aplicados al diseño bioambiental paramétrico und Anthropologie (eds) (1971) Biologie und Bauen. Biology and building. Part 1 Teil $1=$ Teil $1=$. Stuttgart [W. Ger.]; New York, N.Y.: Institute for Lightweight Structures, University of Stuttgart ; Distributor, Wittenborn \& Co.

Official Journal of the European Union. (2012, abril 19). Guidelines accompanying Commission Delegated Regulation (EU) No 244/2012 of 16 January 2012 supplementing Directive 2010/31/EU of the European Parliament and of the Council on the energy performance of buildings by establishing a comparative methodology framework for calculating cost-optimal levels of minimum energy performance requirements for buildings and building elements.

\section{$P$}

Page, S. E., \& Miller, J. H. (2007). Complex Adaptive Systems An Introduction to Computational Models of Social Life. Princeton, N.J.: Princeton University Press.

Payne, A. and R. Issa (2009) The Grasshopper Primer. 2nd edition. USA: Lift Architects. Available at:

https://static1.squarespace.com/static/51c6f9f3e4b0e47ad1bbc71c/t/521cf940e4b021 571fc7d3a5/1377630528615/Grasshopper+Primer_Second+Edition_090323.pdf.

Parlamento Europeo. DIRECTIVA 2002/91/CE. Eficiencia energética de los edificios (2002). Recuperado a partir de http://icaen.gencat.cat/web/.content/20_Energia/25_empreses_servei_energetic/arxiu s/directiva_2002_91_ce_eficiencia_energetica_edificios.pdf

Parlamento Europeo. UNE-EN ISO 15927-6:2009. Comportamiento higrotérmico de edificios. Cálculo y presentación de datos climáticos. Parte 6: Diferencias acumuladas de temperatura (en grados por día). (ISO 15927-6:2007) (2009).

Parlamento Europeo. DIRECTIVA 2010/31/UE. Eficiencia energética en edificios (refundición) (2010). Recuperado a partir de http://eurlex.europa.eu/LexUriServ/LexUriServ.do?uri=OJ:L:2010:153:0013:0035:Es:PDF 
$\mathrm{R}$

Rosenfeld, E., Czajkowski, J., Discoli, C., \& Ferreyro, C. (1996). Reducción de la contaminación urbana por ahorro energético en el sector residencial. El caso del área metropolitana de Buenos Aires. En Actas de la 19o Reunión de Trabajo de la Asociación Argentina de Energías Renovables y Ambiente (ASADES) (p. 08.5/8). Mar del Plata.

Rahmani Asl, M., Zarrinmehr, S., Bergin, M. and Yan, W. (2015) 'BPOpt: A framework for BIM-based performance optimization', Energy and Buildings, 108, pp. 401-412. doi: 10.1016/j.enbuild.2015.09.011.

Read, H. (1968) Art now: an introduction to the theory of modern painting and sculpture. New York: Pitman.

Rodríguez, D. and Torres, J. (2003) Autopoiesis, la unidad de una diferencia: Luhmann y Maturana. Available at: http://www.scielo.br/scielo.php?script=sci_arttext\&pid=S151745222003000100005 (Accessed: 8 May 2017).

Russell, S. J. (2016) Artificial intelligence: a modern approach. Global ed. of 3rd revised ed. Edited by P. Norvig. Boston Columbus Indianapolis New York San Francisco: Pearson Education (Always learning).

Rutten, D. (2013) 'Galapagos: On the Logic and Limitations of Generic Solvers', Architectural Design, 83(2), pp. 132-135. doi: 10.1002/ad.1568.

\section{S}

Schumacher, P. (2011). The autopoiesis of architecture. Chichester: John Wiley \& Sons.

Schweers, R. (2002). Descripción en VHDL de arquitecturas para implementar el algoritmo CORDIC (tesis doctoral). Facultad de Informática- Universidad Nacional de La Plata, La Plata. Recuperado a partir de http://hdl.handle.net/10915/3835

Sacriste, E. (1968). Qué es la casa. Buenos Aires: Editorial Columba. 
El uso de algoritmos genéticos aplicados al diseño bioambiental paramétrico

Secretaría de Estado de Energía. (2016). La energía en España 2015 (10). Madrid:

Ministerio de Industria, Energía y Turismo.Secretaría General Técnica. Subdirección de desarrollo normativo, informes y publicaciones. Centro de publicaciones.

S. Bambardekar and U. Poerschke (2009) 'The architect as performer of energy simulation in the early design stage', in Proceedings of the 11th international IBPSA Conference. 11th International IBPSA Conference, Glasgow: IBPSA, pp. 1306-1313. Available at: http://www.ibpsa.org/proceedings/BS2009/BS09_1306_1313.pdf (Accessed: 21 March 2017).

Sevaldson, B. (2000) 'Dynamic Generative Diagrams', in Proceedings of the 18th Conference on Education in Computer Aided Architectural Design in Europe. Promise and reality. Education in Computer Aided Architectural Design in Europe (eCAADe), Weimar, pp. 273-276.

Schweers, R. (2002). Descripción en VHDL de arquitecturas para implementar el algoritmo CORDIC (tesis doctoral). Facultad de Informática- Universidad Nacional de La Plata, La Plata. Recuperado a partir de http://hdl.handle.net/10915/3835

Sevaldson, B. (2005). Developing digital design techniques: investigations on creative design computing. Oslo: Oslo School of Architecture and Design.

\section{$\mathrm{T}$}

Tanides, C., Nicchi, F., Lavoria, M., \& Mazzitelli, A. (2013). Calefacción en el sector residencial argentino: Primera modelización y estudio de las consecuencias de la sustitución de bombas calor en reemplazo de calefactores a gas. En Actas del Encuentro Latinoamericano de Uso Racional y Eficiente de la Energía ELUREE 2013 (Vol. 1, p. 81/90). Buenos Aires.

Taleb, H. and Musleh, M. A. (2015) 'Applying urban parametric design optimisation processes to a hot climate: Case study of the UAE', Sustainable Cities and Society, 14, pp. 236-253. doi: 10.1016/j.scs.2014.09.001. 
Terzidis, K. (2006) Algorithmic architecture. London; New York: Routledge Taylor \& Francis Group Architectural Press.

Terzidis, K. (2009) Algorithms for Visual Design Using the Processing Language. John Wiley \& Sons.

Turrin, M., von Buelow, P., Kilian, A. and Stouffs, R. (2012) ‘Performative skins for passive climatic comfort:A parametric design process', AUTCON Automation in Construction, 22, pp. 36-50.

Turrin, M., von Buelow, P. and Stouffs, R. (2011) 'Design explorations of performance driven geometry in architectural design using parametric modeling and genetic algorithms', Advanced Engineering Informatics. (Special Section: Advances and Challenges in Computing in Civil and Building Engineering), 25(4), pp. 656-675. doi: 10.1016/j.aei.2011.07.009.

U

US Department of Energy (2015) Building Technologies Office: EnergyPlus Energy Simulation Software. Available at: http://apps1.eere.energy.gov/buildings/energyplus/ (Accessed: 21 March 2017).

\section{$\mathrm{V}$}

Verso, V. R. M. L., Serra, V., Giovannini, L. and lennarella, S. (2014) 'Light versus Energy Performance of Office Rooms with Curtain Walls: A Parametric Study', Energy Procedia. (6th International Conference on Sustainability in Energy and Buildings, SEB-14), 62, pp. 462-471. doi: 10.1016/j.egypro.2014.12.408.

Vivanco, M. (2014) ‘Emergencia: Concepto y método’, Cinta de moebio, (49), pp. 31-38. Von Neumann, J. (2012) The computer \& the brain. New Haven: Yale University Press. Available at: http://public.eblib.com/choice/publicfullrecord.aspx?p=3420880 (Accessed: 8 May 2017). 
W

Weinstock, M. (2010) The architecture of emergence: the evolution of form in nature and civilisation. Chichester: John Wiley \& Sons.

Wiener, N. (1999) Cybernetics or control and communication in the animal and the machine. Cambridge, Mass: MIT Press.

Wright, J. A., Loosemore, H. A. and Farmani, R. (2002) 'Optimization of building thermal design and control by multi-criterion genetic algorithm', Energy and Buildings. (A View of Energy and Building Performance Simulation at the start of the third millennium), 34(9), pp. 959-972. doi: 10.1016/S0378-7788(02)00071-3.

Wang, N., Zhao, W., Wu, N., \& Wu, D. (2017). Multi-objective optimization: A method for selecting the optimal solution from Pareto non-inferior solutions. Expert Systems with Applications, 74, 96-104. https://doi.org/10.1016/j.eswa.2017.01.004

Weather Underground. (s. f.). Weather History for Sevilla, El Salvador. Recuperado 21 de marzo de 2017, a partir de https://www.wunderground.com/history/airport/LEZL/2016/1/1/CustomHistory.html?da yend=1\&monthend=1\&yearend=2017\&req_city=\&req_state=\&req_statename=\&reqd b.zip $=\&$ reqdb. magic $=\&$ reqdb. $w m o=\& M R=1$

$X-Y-Z$

Yañez Parareda, G. (2008). Arquitectura solar e iluminación natural conceptos, métodos y ejemplos. Madrid: Munilla-Lería 
Anexo 1: Datos climáticos Buenos Aires 
El uso de algoritmos genéticos aplicados al diseño bioambiental paramétrico 
Tabla A1-1: Temperaturas máximas y mínimas julio estación Gonnet. Fuente: relaborado de datos del LAyHS

\begin{tabular}{|c|c|c|c|c|c|c|c|c|}
\hline \multirow{2}{*}{$\begin{array}{c}\text { Temp. } \\
\text { julio }\end{array}$} & \multicolumn{2}{|c|}{2009} & \multicolumn{2}{|c|}{2010} & \multicolumn{2}{|c|}{2011} & \multicolumn{2}{|c|}{2012} \\
\hline & máx. & mín. & máx. & mín. & máx. & mín. & máx. & mín. \\
\hline 01-jul & 16,1 & 3,2 & 12,9 & 3,2 & 9,6 & 2,8 & 18,4 & 16,5 \\
\hline 02-jul & 16,1 & 2,7 & 12,5 & 2,7 & 10,2 & $-0,4$ & 10 & 10,7 \\
\hline 03-jul & 18,9 & 5,6 & 21,8 & 5,6 & 8,8 & 0,8 & 11,5 & 5,8 \\
\hline 04-jul & 18 & 8,2 & 22,7 & 8,2 & 11,9 & 0,9 & 8,7 & 5,5 \\
\hline 05-jul & 17,8 & 12,4 & 16,4 & 12,4 & 11,4 & 3,8 & 11,1 & 2,9 \\
\hline 06-jul & 14,9 & 14,8 & 13,8 & 14,8 & 11,8 & 2,3 & 11,2 & 3,1 \\
\hline 07-jul & 19,4 & 13,7 & 12 & 13,7 & 14,3 & 1,7 & 12 & 0,4 \\
\hline 08-jul & 11,2 & 3,6 & 16,2 & 3,6 & 14,6 & 3,4 & 12,5 & 8,2 \\
\hline 09-jul & 11,6 & $-0,9$ & 13,9 & $-0,9$ & 15,6 & 7,1 & 12,3 & 4,5 \\
\hline 10-jul & 12,8 & 3,6 & 14,5 & 3,6 & & 10,3 & 8,1 & 4,6 \\
\hline 11-jul & 10,4 & 1,9 & 12,9 & 1,9 & 9,4 & 10,2 & 9,5 & $-1,8$ \\
\hline 12-jul & 14,3 & 5,2 & 7,7 & 5,2 & 20,4 & 9,9 & 11,6 & 3,9 \\
\hline 13-jul & 15 & 7,6 & 9,7 & 7,6 & 16,9 & 7,1 & 15,2 & 6,6 \\
\hline 14-jul & 12,2 & 1,4 & 8,6 & 1,4 & 13,2 & 8,9 & 10,6 & 3,3 \\
\hline 15-jul & 11,6 & 4,9 & 7,7 & 4,9 & 14,7 & 14,7 & 8,4 & 1,6 \\
\hline 16-jul & 11,7 & 7,3 & 8,2 & 7,3 & 15,8 & 10,1 & 9,4 & 3,7 \\
\hline 17-jul & 15,8 & 6,8 & 8,9 & 6,8 & 14,9 & 3,8 & 12,9 & 0,3 \\
\hline 18-jul & 14,3 & 7,8 & 10,1 & 7,8 & 10,8 & 11,1 & 15,5 & 1,7 \\
\hline 19-jul & 15,8 & 12,7 & 7,4 & 12,7 & 9,5 & 9,9 & 15,2 & 5,1 \\
\hline 20-jul & 14,9 & 9,8 & 14,4 & 9,8 & 9,3 & 7,1 & 14,8 & 7 \\
\hline 21-jul & 11,3 & 11,5 & 14,7 & 11,5 & 12,4 & 7,6 & 8,7 & 7,8 \\
\hline 22-jul & 6,6 & 6,7 & 11,9 & 6,7 & 13,2 & 5,4 & 12,2 & 5,2 \\
\hline 23-jul & 6,8 & 1,4 & 12,7 & 1,4 & 14,4 & 9 & 8,9 & 5,3 \\
\hline 24-jul & 9,9 & 1,6 & 10,6 & 1,6 & 15 & 8,5 & 12,4 & 4,9 \\
\hline 25-jul & 11,3 & 3,2 & 10,8 & 3,2 & 20,8 & 14,8 & & $-0,1$ \\
\hline 26-jul & 11,1 & 2,3 & 14,6 & 2,3 & 15 & 9 & & \\
\hline 27-jul & 15,8 & 5 & 14,8 & 5 & 13,4 & 6,9 & & \\
\hline 28-jul & 11,9 & 4,1 & 15,9 & 4,1 & 15,8 & 11,6 & & \\
\hline 29-jul & 13,3 & $-1,2$ & 13 & $-1,2$ & 12,6 & 7,7 & & \\
\hline 30-jul & 10,8 & 2 & 11,6 & 2 & 8,4 & 1,1 & & \\
\hline 31-jul & 9,2 & 1 & 11,7 & 1 & 8,2 & 3,1 & & \\
\hline
\end{tabular}


Tabla A1.2: Temperaturas máximas y mínimas enero estación Gonnet. Fuente: relaborado de datos del LAyHS

\begin{tabular}{|c|c|c|c|c|c|c|c|c|}
\hline \multirow{2}{*}{$\begin{array}{l}\text { Temp. } \\
\text { enero }\end{array}$} & \multicolumn{2}{|c|}{2009} & \multicolumn{2}{|c|}{2010} & \multicolumn{2}{|c|}{2011} & \multicolumn{2}{|c|}{2012} \\
\hline & máx. & mín. & máx. & mín. & máx. & mín. & máx. & mín. \\
\hline 01-ene & 23,1 & 16,2 & 23,2 & 18,9 & 27,2 & 21,7 & 21,9 & 19,7 \\
\hline 02-ene & 23,80 & 14,2 & 29,80 & 17,7 & 28,00 & 21,5 & 20,50 & 18,3 \\
\hline 03-ene & 25,40 & 14,6 & 31,40 & 21,8 & 26,80 & 23 & 27,20 & 16,8 \\
\hline 04-ene & 30,10 & 14,8 & 26,70 & 22,7 & 26,80 & 22,2 & 25,60 & 15,5 \\
\hline 05-ene & 32,20 & 18,8 & 29,10 & 20,4 & 26,40 & 22,6 & 30,80 & 19,1 \\
\hline 06-ene & 31,60 & 19,9 & 23,50 & 19,7 & 27,20 & 17,3 & 36,80 & 20,1 \\
\hline 07-ene & 28,20 & 17,8 & 24,40 & 15,7 & 28,60 & 20,4 & 26,20 & 21 \\
\hline 08-ene & 28,80 & 19,7 & 26,60 & 18,8 & 26,00 & 20 & 28,90 & 19,6 \\
\hline 09-ene & 30,70 & 20,7 & 29,80 & 20,3 & 27,20 & 21,5 & 35,30 & 23,3 \\
\hline 10-ene & 28,90 & 21,3 & 32,50 & 22,9 & 27,10 & 18,3 & 37,40 & 27,1 \\
\hline 11-ene & 26,80 & 19,3 & 26,60 & 20,2 & 25,80 & 21,7 & 27,20 & 20,1 \\
\hline 12-ene & 26,40 & 20 & 23,90 & 19,2 & 26,80 & 20,8 & 25,40 & 17,6 \\
\hline 13-ene & 25,90 & 22,1 & 26,20 & 12,6 & 28,70 & 19,6 & 25,60 & 16,3 \\
\hline 14-ene & 27,30 & 20,8 & 28,50 & 15 & 31,40 & 21,6 & 25,60 & 16,9 \\
\hline 15-ene & 32,30 & 19,6 & 29,60 & 20,8 & 27,60 & 19,3 & 27,70 & 18,7 \\
\hline 16-ene & 32,10 & 20,2 & 22,80 & 23,8 & 33,70 & 25,7 & 32,80 & 18,8 \\
\hline 17-ene & 33,70 & 22,8 & 30,40 & 18,6 & 27,80 & 15,2 & 30,20 & 20,9 \\
\hline 18-ene & 22,50 & 15,8 & 29,90 & 23,1 & 28,60 & 16,4 & 29,90 & 21,8 \\
\hline 19-ene & 25,70 & 12,7 & 21,80 & 21,3 & 19,20 & 23,8 & 25,20 & 22,4 \\
\hline 20-ene & 30,80 & 15,8 & 27,30 & 15,9 & 26,20 & 16,4 & 34,90 & 22,7 \\
\hline 21-ene & 32,40 & 19,8 & 30,20 & 21,1 & 26,40 & 19,8 & 32,90 & 24,7 \\
\hline 22-ene & 30,90 & 22,4 & 25,40 & 19,4 & 30,60 & 20,7 & 27,30 & 22,5 \\
\hline 23-ene & 30,20 & 22,3 & 32,10 & 20,5 & 30,80 & 21,7 & 28,50 & 20,7 \\
\hline 24-ene & 31,70 & 23,6 & 30,10 & 22 & 31,80 & 22,6 & 26,70 & 19,8 \\
\hline 25-ene & 29,80 & 24,1 & 31,30 & 22 & 33,50 & 23,3 & 23,60 & 14,3 \\
\hline 26-ene & 26,80 & 17,4 & 29,80 & 22,8 & 28,20 & 22,9 & 25,00 & 17,6 \\
\hline 27-ene & 27,30 & 21,8 & 24,80 & 23,5 & 27,70 & 21,4 & 26,70 & 19,9 \\
\hline 28-ene & 25,80 & 23,1 & 30,60 & 23,9 & 32,90 & 21,6 & 28,90 & 20,8 \\
\hline 29-ene & 26,70 & 21,9 & 25,90 & 23,9 & 27,30 & 18,9 & 31,90 & 21,6 \\
\hline 30-ene & 23,10 & 20,2 & 32,60 & 21,1 & 31,70 & 21,2 & 24,30 & 24,2 \\
\hline 31-ene & 26,30 & 17,4 & 26,80 & 23,4 & 25,80 & 24,5 & 24,20 & 23,5 \\
\hline
\end{tabular}


Tabla A1.3: Radiación solar por orientación y horizontal (invierno). Fuente: la autora

\begin{tabular}{|c|c|c|c|c|c|}
\hline hora & $\begin{array}{r}N \\
W / m 2\end{array}$ & $\begin{array}{r}S \\
W / m 2\end{array}$ & $\begin{array}{r}E \\
W / m 2\end{array}$ & $\begin{array}{r}0 \\
W / m 2\end{array}$ & $\begin{array}{r}\text { cubierta } \\
\text { W/m2 }\end{array}$ \\
\hline 1 & 0 & 0 & 0 & 0 & 0 \\
\hline 2 & 0 & 0 & 0 & 0 & 0 \\
\hline 3 & 0 & 0 & 0 & 0 & 0 \\
\hline 4 & 0 & 0 & 0 & 0 & 0 \\
\hline 5 & 0 & 0 & 0 & 8 & 0 \\
\hline 6 & 0 & 0 & 0 & 67 & 0 \\
\hline 7 & 0 & 0 & 0 & 124 & 0 \\
\hline 8 & 156 & 46 & 209 & 178 & 104 \\
\hline 9 & 222 & 93 & 226 & 224 & 208 \\
\hline 10 & 274 & 129 & 223 & 260 & 288 \\
\hline 11 & 307 & 151 & 200 & 283 & 338 \\
\hline 12 & 318 & 149 & 159 & 291 & 355 \\
\hline 13 & 307 & 151 & 151 & 328 & 328 \\
\hline 14 & 274 & 129 & 129 & 347 & 288 \\
\hline 15 & 222 & 93 & 93 & 346 & 208 \\
\hline 16 & 156 & 46 & 46 & 328 & 104 \\
\hline 17 & 0 & 0 & 0 & 291 & 0 \\
\hline 18 & 0 & 0 & 0 & 240 & 0 \\
\hline 19 & 0 & 0 & 0 & 175 & 0 \\
\hline 20 & 0 & 0 & 0 & 0 & 0 \\
\hline 21 & 0 & 0 & 0 & 0 & 0 \\
\hline 22 & 0 & 0 & 0 & 0 & 0 \\
\hline 23 & 0 & 0 & 0 & 0 & 0 \\
\hline 24 & 0 & 0 & 0 & 0 & 0 \\
\hline $\begin{array}{l}\text { dotal } \\
\text { diari }\end{array}$ & 2236 & 987 & 1436 & 3490 & 2231 \\
\hline
\end{tabular}


Tabla A1.4: Radiación solar por orientación y horizontal (verano). Fuente: la autora

\begin{tabular}{|c|c|c|c|c|c|}
\hline hora & $\mathrm{N}$ & $S$ & $E$ & $\mathrm{O}$ & horizontal \\
\hline & $\mathrm{W} / \mathrm{m} 2$ & $\mathrm{~W} / \mathrm{m} 2$ & $\mathrm{~W} / \mathrm{m} 2$ & $\mathrm{~W} / \mathrm{m} 2$ & $\mathrm{~W} / \mathrm{m} 2$ \\
\hline 1 & 0 & 0 & 0 & 0 & 0 \\
\hline 2 & 0 & 0 & 0 & 0 & 0 \\
\hline 3 & 0 & 0 & 0 & 0 & 0 \\
\hline 4 & 0 & 0 & 0 & 0 & 0 \\
\hline 5 & 8 & 181 & 340 & 8 & 23 \\
\hline 6 & 65 & 188 & 409 & 65 & 172 \\
\hline 7 & 121 & 193 & 453 & 121 & 321 \\
\hline 8 & 174 & 199 & 472 & 174 & 460 \\
\hline 9 & 233 & 218 & 461 & 218 & 580 \\
\hline 10 & 299 & 253 & 425 & 253 & 672 \\
\hline 11 & 341 & 275 & 364 & 275 & 730 \\
\hline 12 & 355 & 283 & 283 & 283 & 749 \\
\hline 13 & 341 & 275 & 275 & 364 & 730 \\
\hline 14 & 299 & 253 & 253 & 425 & 672 \\
\hline 15 & 233 & 218 & 218 & 461 & 580 \\
\hline 16 & 174 & 199 & 174 & 472 & 460 \\
\hline 17 & 121 & 193 & 121 & 453 & 321 \\
\hline 18 & 65 & 188 & 65 & 409 & 172 \\
\hline 19 & 8 & 181 & 8 & 341 & 23 \\
\hline 20 & 0 & 0 & 0 & 0 & 0 \\
\hline 21 & 0 & 0 & 0 & 0 & 0 \\
\hline 22 & 0 & 0 & 0 & 0 & 0 \\
\hline 23 & 0 & 0 & 0 & 0 & 0 \\
\hline 24 & 0 & 0 & 0 & 0 & 0 \\
\hline $\begin{array}{c}\text { total } \\
\text { diario }\end{array}$ & 2837 & 3297 & 4321 & 4023 & 6665 \\
\hline
\end{tabular}


Tabla A1.5: Temperaturas horarias julio (invierno). Fuente: la autora

\begin{tabular}{r|rr} 
HORA & \multicolumn{2}{|c}{ COEFICIENTES } \\
\hline $\mathbf{1}$ & 0,46 & 7,75 \\
$\mathbf{2}$ & 0,32 & 7,11 \\
$\mathbf{3}$ & 0,19 & 6,52 \\
$\mathbf{4}$ & 0,08 & 6,02 \\
$\mathbf{5}$ & 0,02 & 5,74 \\
$\mathbf{6}$ & 0 & 5,65 \\
$\mathbf{7}$ & 0,06 & 5,92 \\
$\mathbf{8}$ & 0,15 & 6,34 \\
$\mathbf{9}$ & 0,26 & 6,84 \\
$\mathbf{1 0}$ & 0,44 & 7,93 \\
$\mathbf{1 1}$ & 0,79 & 9,26 \\
$\mathbf{1 2}$ & 0,91 & 9,81 \\
$\mathbf{1 3}$ & 0,97 & 10,08 \\
$\mathbf{1 4}$ & 1 & 10,22 \\
$\mathbf{1 5}$ & 0,98 & 10,13 \\
$\mathbf{1 6}$ & 0,94 & 9,94 \\
$\mathbf{1 7}$ & 0,91 & 9,81 \\
$\mathbf{1 8}$ & 0,87 & 9,62 \\
$\mathbf{1 9}$ & 0,83 & 9,44 \\
$\mathbf{2 0}$ & 0,8 & 9,30 \\
$\mathbf{2 1}$ & 0,75 & 9,08 \\
$\mathbf{2 2}$ & 0,7 & 8,85 \\
$\mathbf{2 3}$ & 0,64 & 8,57 \\
$\mathbf{2 4}$ & 0,57 & 8,25 \\
& & \\
\hline
\end{tabular}


Tabla A 1.6: Temperaturas horarias enero (verano). Fuente: la autora HORA COEFICIENTES

\begin{tabular}{|c|c|c|}
\hline 1 & 0,46 & 22,309 \\
\hline 2 & 0,32 & 21,675 \\
\hline 3 & 0,19 & 21,086 \\
\hline 4 & 0,08 & 20,588 \\
\hline 5 & 0,02 & 20,316 \\
\hline 6 & 0 & 20,226 \\
\hline 7 & 0,06 & 20,497 \\
\hline 8 & 0,15 & 21,177 \\
\hline 9 & 0,26 & 21,403 \\
\hline 10 & 0,44 & 22,218 \\
\hline 11 & 0,79 & 23,803 \\
\hline 12 & 0,91 & 24,346 \\
\hline 13 & 0,97 & 24,618 \\
\hline 14 & 1 & 24,753 \\
\hline 15 & 0,98 & 24,663 \\
\hline 16 & 0,94 & 24,482 \\
\hline 17 & 0,91 & 24,346 \\
\hline 18 & 0,87 & 24,165 \\
\hline 19 & 0,83 & 23,984 \\
\hline 20 & 0,8 & 23,848 \\
\hline 21 & 0,75 & 23,622 \\
\hline 22 & 0,7 & 23,395 \\
\hline 23 & 0,64 & 23,124 \\
\hline 24 & 0,57 & 22,807 \\
\hline
\end{tabular}


Tabla A1.7: Temperaturas sol-aire $14 \mathrm{~h}$ enero (verano). Fuente: la autora

\begin{tabular}{r|ccc} 
ELEMENTO & $\boldsymbol{I}$ & $\boldsymbol{\alpha}$ & $\boldsymbol{T}_{S A}$ \\
& $\boldsymbol{W} / \mathbf{m} 2$ & & ${ }^{\circ} \mathbf{C}$ \\
\hline muro N & 370 & 0,3 & 35,6 \\
muro S & 268 & 0,3 & 34,4 \\
muro E & 268 & 0,3 & 34,4 \\
muro O & 360 & 0,3 & 35,5 \\
\hline ventanas N & 370 & 0,2 & 34,2 \\
\hline ventanas S & 268 & 0,2 & 33,3 \\
\hline ventanas E & 268 & 0,2 & 33,3 \\
ventanas O & 360 & 0,2 & 34,1 \\
cubierta & 736 & 0,15 & 35,6
\end{tabular}


Tabla A1.8: Temperaturas sol-aire en muros $\mathbf{N}$ julio (invierno). Fuente: la autora

\begin{tabular}{r|rrrrr}
\multicolumn{7}{|c}{$\boldsymbol{I}$} & $\boldsymbol{\alpha}$ & & & \\
hora & Norte & muro & $\boldsymbol{T}^{\circ} \boldsymbol{C}$ & $\boldsymbol{R}_{\boldsymbol{s e}}$ & $\boldsymbol{T}_{\text {SA }}$ \\
\hline $\mathbf{1}$ & 0 & 0,3 & 10,90 & 0,04 & 10,90 \\
$\mathbf{2}$ & 0 & 0,3 & 10,02 & 0,04 & 10,02 \\
$\mathbf{3}$ & 0 & 0,3 & 9,20 & 0,04 & 9,20 \\
$\mathbf{4}$ & 0 & 0,3 & 8,50 & 0,04 & 8,50 \\
$\mathbf{5}$ & 0 & 0,3 & 8,13 & 0,04 & 8,13 \\
$\mathbf{6}$ & 0 & 0,3 & 8,00 & 0,04 & 8,00 \\
$\mathbf{7}$ & 0 & 0,3 & 8,38 & 0,04 & 8,38 \\
$\mathbf{8}$ & 156 & 0,3 & 8,95 & 0,04 & 10,82 \\
$\mathbf{9}$ & 222 & 0,3 & 9,64 & 0,04 & 12,30 \\
$\mathbf{1 0}$ & 274 & 0,3 & 10,77 & 0,04 & 14,06 \\
$\mathbf{1 1}$ & 307 & 0,3 & 12,98 & 0,04 & 16,66 \\
$\mathbf{1 2}$ & 318 & 0,3 & 13,73 & 0,04 & 17,55 \\
$\mathbf{1 3}$ & 307 & 0,3 & 14,11 & 0,04 & 17,80 \\
$\mathbf{1 4}$ & 274 & 0,3 & 14,30 & 0,04 & 17,59 \\
$\mathbf{1 5}$ & 222 & 0,3 & 14,17 & 0,04 & 16,84 \\
$\mathbf{1 6}$ & 156 & 0,3 & 13,92 & 0,04 & 15,79 \\
$\mathbf{1 7}$ & 0 & 0,3 & 13,73 & 0,04 & 13,73 \\
$\mathbf{1 8}$ & 0 & 0,3 & 13,48 & 0,04 & 13,48 \\
$\mathbf{1 9}$ & 0 & 0,3 & 13,23 & 0,04 & 13,23 \\
$\mathbf{2 0}$ & 0 & 0,3 & 13,04 & 0,04 & 13,04 \\
$\mathbf{2 1}$ & 0 & 0,3 & 12,73 & 0,04 & 12,73 \\
$\mathbf{2 2}$ & 0 & 0,3 & 12,41 & 0,04 & 12,41 \\
$\mathbf{2 3}$ & 0 & 0,3 & 12,03 & 0,04 & 12,03 \\
$\mathbf{2 4}$ & 0 & 0,3 & 11,59 & 0,04 & 11,59 \\
& & & & & \\
& & & & &
\end{tabular}


Tabla A1.9: Temperaturas sol-aire en muros $\mathbf{S}$ julio (invierno). Fuente: la autora

\begin{tabular}{|c|c|c|c|c|c|}
\hline hora & $\begin{array}{l}\text { I } \\
\text { Sur }\end{array}$ & a muro & $T^{\circ} \mathrm{C}$ & $R_{s e}$ & $T_{S A}$ \\
\hline 1 & 0 & 0,3 & 10,90 & 0,04 & 10,90 \\
\hline 2 & 0 & 0,3 & 10,02 & 0,04 & 10,02 \\
\hline 3 & 0 & 0,3 & 9,20 & 0,04 & 9,20 \\
\hline 4 & 0 & 0,3 & 8,50 & 0,04 & 8,50 \\
\hline 5 & 0 & 0,3 & 8,13 & 0,04 & 8,13 \\
\hline 6 & 0 & 0,3 & 8,00 & 0,04 & 8,00 \\
\hline 7 & 0 & 0,3 & 8,38 & 0,04 & 8,38 \\
\hline 8 & 46 &, 3 & 8,95 & 0,04 & 9,50 \\
\hline 9 & 93 & 0,3 & 9,64 & 0,04 & 10,75 \\
\hline 10 & 129 & 0,3 & 10,77 & 0,04 & 12,32 \\
\hline 11 & 151 & 0,3 & 12,98 & 0,04 & 14,79 \\
\hline 12 & 149 & 0,3 & 13,73 & 0,04 & 15,52 \\
\hline 13 & 151 & 0,3 & 14,11 & 0,04 & 15,92 \\
\hline 14 & 129 & 0,3 & 14,30 & 0,04 & 15,85 \\
\hline 15 & 93 & 0,3 & 14,17 & 0,04 & 15,29 \\
\hline 16 & 46 & 0,3 & 13,92 & 0,04 & 14,47 \\
\hline 17 & 0 & 0,3 & 13,73 & 0,04 & 13,73 \\
\hline 18 & 0 & 0,3 & 13,48 & 0,04 & 13,48 \\
\hline 19 & 0 & 0,3 & 13,23 & 0,04 & 13,23 \\
\hline 20 & 0 & 0,3 & 13,04 & 0,04 & 13,04 \\
\hline 21 & 0 & 0,3 & 12,73 & 0,04 & 12,73 \\
\hline 22 & 0 & 0,3 & 12,41 & 0,04 & 12,41 \\
\hline 23 & 0 & 0,3 & 12,03 & 0,04 & 12,03 \\
\hline 24 & 0 & 0,3 & 11,59 & 0,04 & 11,59 \\
\hline
\end{tabular}


Tabla A1.10: Temperaturas sol-aire en muros E julio (invierno). Fuente: la autora

\begin{tabular}{|c|c|c|c|c|c|}
\hline hora & $\begin{array}{r}\text { I } \\
\text { Este }\end{array}$ & $\begin{array}{r}\alpha \\
\text { muro }\end{array}$ & $T^{\circ} \mathrm{C}$ & $R_{\text {se }}$ & $T_{S A}$ \\
\hline 1 & 0 & 0,3 & 10,90 & 0,04 & 10,90 \\
\hline 2 & 0 & 0,3 & 10,02 & 0,04 & 10,02 \\
\hline 3 & 0 & 0,3 & 9,20 & 0,04 & 9,20 \\
\hline 4 & 0 & 0,3 & 8,50 & 0,04 & 8,50 \\
\hline 5 & 0 & 0,3 & 8,13 & 0,04 & 8,13 \\
\hline 6 & 0 & 0,3 & 8,00 & 0,04 & 8,00 \\
\hline 7 & 0 & 0,3 & 8,38 & 0,04 & 8,38 \\
\hline 8 & 209 & 0,3 & 8,95 & 0,04 & 11,45 \\
\hline 9 & 226 & 0,3 & 9,64 & 0,04 & 12,35 \\
\hline 10 & 223 & 0,3 & 10,77 & 0,04 & 13,45 \\
\hline 11 & 200 & 0,3 & 12,98 & 0,04 & 15,38 \\
\hline 12 & 159 & 0,3 & 13,73 & 0,04 & 15,64 \\
\hline 13 & 151 & 0,3 & 14,11 & 0,04 & 15,92 \\
\hline 14 & 129 & 0,3 & 14,30 & 0,04 & 15,85 \\
\hline 15 & 93 & 0,3 & 14,17 & 0,04 & 15,29 \\
\hline 16 & 46 & 0,3 & 13,92 & 0,04 & 14,47 \\
\hline 17 & 0 & 0,3 & 13,73 & 0,04 & 13,73 \\
\hline 18 & 0 & 0,3 & 13,48 & 0,04 & 13,48 \\
\hline 19 & 0 & 0,3 & 13,23 & 0,04 & 13,23 \\
\hline 20 & 0 & 0,3 & 13,04 & 0,04 & 13,04 \\
\hline 21 & 0 & 0,3 & 12,73 & 0,04 & 12,73 \\
\hline 22 & 0 & 0,3 & 12,41 & 0,04 & 12,41 \\
\hline 23 & 0 & 0,3 & 12,03 & 0,04 & 12,03 \\
\hline 24 & 0 & 0,3 & 11,59 & 0,04 & 11,59 \\
\hline
\end{tabular}


Tabla A1.11 Temperaturas sol-aire en muros 0 julio (invierno). Fuente: la autora

\begin{tabular}{r|rrrrr}
\multicolumn{2}{|l}{$\boldsymbol{I}$} \\
hora & Oeste & a muro & \multicolumn{1}{l}{$\boldsymbol{T}$} & $\boldsymbol{R}_{\text {se }}$ & $\boldsymbol{T}_{\boldsymbol{s A}}$ \\
\hline $\mathbf{1}$ & 0 & 0,3 & 10,90 & 0,04 & 10,90 \\
$\mathbf{2}$ & 0 & 0,3 & 10,02 & 0,04 & 10,02 \\
$\mathbf{3}$ & 0 & 0,3 & 9,20 & 0,04 & 9,20 \\
$\mathbf{4}$ & 0 & 0,3 & 8,50 & 0,04 & 8,50 \\
$\mathbf{5}$ & 8 & 0,3 & 8,13 & 0,04 & 8,22 \\
$\mathbf{6}$ & 67 & 0,3 & 8,00 & 0,04 & 8,80 \\
$\mathbf{7}$ & 124 & 0,3 & 8,38 & 0,04 & 9,87 \\
$\mathbf{8}$ & 178 & 0,3 & 8,95 & 0,04 & 11,08 \\
$\mathbf{9}$ & 224 & 0,3 & 9,64 & 0,04 & 12,33 \\
$\mathbf{1 0}$ & 260 & 0,3 & 10,77 & 0,04 & 13,89 \\
$\mathbf{1 1}$ & 283 & 0,3 & 12,98 & 0,04 & 16,37 \\
$\mathbf{1 2}$ & 291 & 0,3 & 13,73 & 0,04 & 17,23 \\
$\mathbf{1 3}$ & 328 & 0,3 & 14,11 & 0,04 & 18,05 \\
$\mathbf{1 4}$ & 347 & 0,3 & 14,30 & 0,04 & 18,46 \\
$\mathbf{1 5}$ & 346 & 0,3 & 14,17 & 0,04 & 18,33 \\
$\mathbf{1 6}$ & 328 & 0,3 & 13,92 & 0,04 & 17,86 \\
$\mathbf{1 7}$ & 291 & 0,3 & 13,73 & 0,04 & 17,23 \\
$\mathbf{1 8}$ & 240 & 0,3 & 13,48 & 0,04 & 16,36 \\
$\mathbf{1 9}$ & 175 & 0,3 & 13,23 & 0,04 & 15,33 \\
$\mathbf{2 0}$ & 0 & 0,3 & 13,04 & 0,04 & 13,04 \\
$\mathbf{2 1}$ & 0 & 0,3 & 12,73 & 0,04 & 12,73 \\
$\mathbf{2 2}$ & 0 & 0,3 & 12,41 & 0,04 & 12,41 \\
$\mathbf{2 3}$ & 0 & 0,3 & 12,03 & 0,04 & 12,03 \\
$\mathbf{2 4}$ & 0 & 0,3 & 11,59 & 0,04 & 11,59 \\
& & & & & \\
& & & & &
\end{tabular}


Tabla A1.12. Temperaturas sol-aire en cubiertas julio (invierno). Fuente: la autora

\begin{tabular}{|c|c|c|c|c|c|}
\hline & $I$ & & & & \\
\hline hora & horizontal & a cub. & $T^{\circ} \mathrm{C}$ & $R_{s e}$ & $T_{S A}$ \\
\hline 1 & 0 & 0,15 & 10,90 & 0,04 & 10,90 \\
\hline 2 & 0 & 0,15 & 10,02 & 0,04 & 10,02 \\
\hline 3 & 0 & 0,15 & 9,20 & 0,04 & 9,20 \\
\hline 4 & 0 & 0,15 & 8,50 & 0,04 & 8,50 \\
\hline 5 & 0 & 0,15 & 8,13 & 0,04 & 8,13 \\
\hline 6 & 0 & 0,15 & 8,00 & 0,04 & 8,00 \\
\hline 7 & 0 & 0,15 & 8,38 & 0,04 & 8,38 \\
\hline 8 & 104 & 0,15 & 8,95 & 0,04 & 9,57 \\
\hline 9 & 208 & 0,15 & 9,64 & 0,04 & 10,89 \\
\hline 10 & 288 & 0,15 & 10,77 & 0,04 & 12,50 \\
\hline 11 & 338 & 0,15 & 12,98 & 0,04 & 15,01 \\
\hline 12 & 355 & 0,15 & 13,73 & 0,04 & 15,86 \\
\hline 13 & 328 & 0,15 & 14,11 & 0,04 & 16,08 \\
\hline 14 & 288 & 0,15 & 14,30 & 0,04 & 16,03 \\
\hline 15 & 208 & 0,15 & 14,17 & 0,04 & 15,42 \\
\hline 16 & 104 & 0,15 & 13,92 & 0,04 & 14,55 \\
\hline 17 & 0 & 0,15 & 13,73 & 0,04 & 13,73 \\
\hline 18 & 0 & 0,15 & 13,48 & 0,04 & 13,48 \\
\hline 19 & 0 & 0,15 & 13,23 & 0,04 & 13,23 \\
\hline 20 & 0 & 0,15 & 13,04 & 0,04 & 13,04 \\
\hline 21 & 0 & 0,15 & 12,73 & 0,04 & 12,73 \\
\hline 22 & 0 & 0,15 & 12,41 & 0,04 & 12,41 \\
\hline 23 & 0 & 0,15 & 12,03 & 0,04 & 12,03 \\
\hline 24 & 0 & 0,15 & 11,59 & 0,04 & 11,59 \\
\hline
\end{tabular}


Tabla A1.13 Temperaturas sol-aire en muros Norte enero (verano). Fuente: la autora

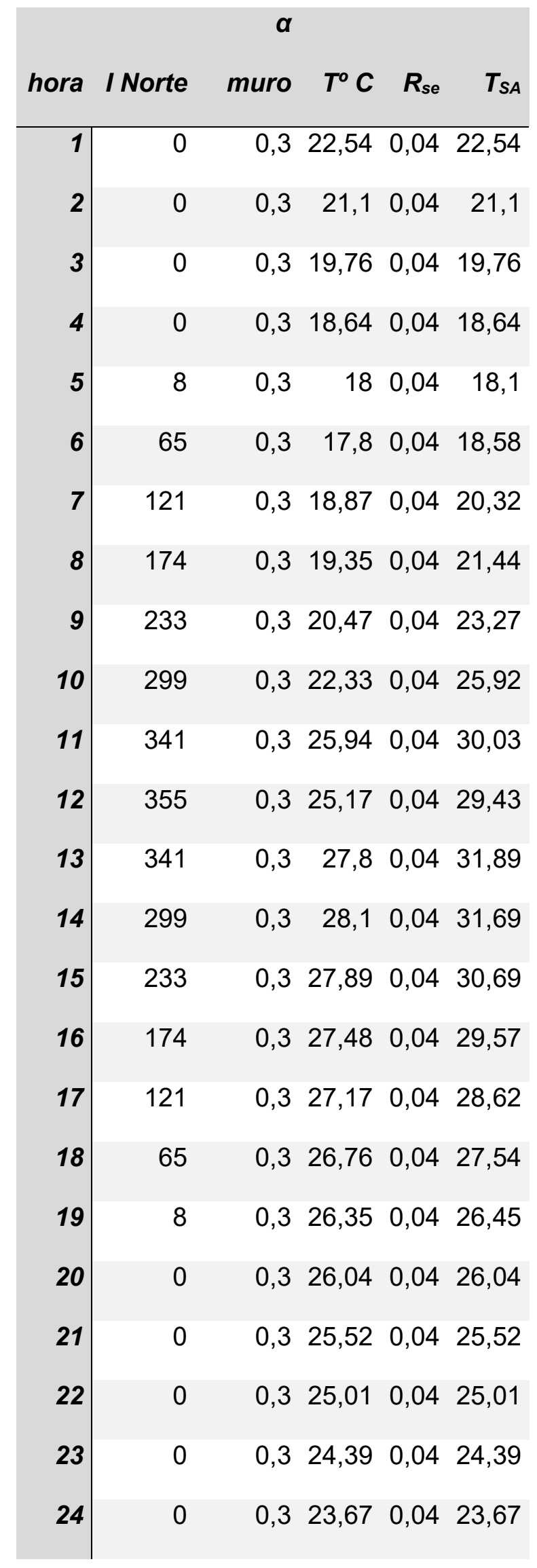


Tabla A1.14. Temperaturas sol-aire en muros Sur enero (verano). Fuente: la autora

\begin{tabular}{|c|c|c|c|c|c|}
\hline hora & I Sur & $\begin{array}{r}\alpha \\
\text { muro }\end{array}$ & $T$ & $R_{\text {se }}$ & $T_{S A}$ \\
\hline 1 & 0 & 0,3 & 22,54 & 0,04 & 22,54 \\
\hline 2 & 0 & 0,3 & 21,1 & 0,04 & 21,1 \\
\hline 3 & 0 & 0,3 & 19,76 & 0,04 & 19,76 \\
\hline 4 & 0 & 0,3 & 18,64 & 0,04 & 18,64 \\
\hline 5 & 181 & 0,3 & 18 & 0,04 & 20,17 \\
\hline 6 & 188 & 0,3 & 17,8 & 0,04 & 20,06 \\
\hline 7 & 193 & 0,3 & 18,87 & 0,04 & 21,19 \\
\hline 8 & 199 & 0,3 & 19,35 & 0,04 & 21,74 \\
\hline 9 & 218 & 0,3 & 20,47 & 0,04 & 23,09 \\
\hline 10 & 253 & 0,3 & 22,33 & 0,04 & 25,37 \\
\hline 11 & 275 & 0,3 & 25,94 & 0,04 & 29,24 \\
\hline 12 & 283 & 0,3 & 25,17 & 0,04 & 28,57 \\
\hline 13 & 275 & 0,3 & 27,8 & 0,04 & 31,1 \\
\hline 14 & 253 & 0,3 & 28,1 & 0,04 & 31,14 \\
\hline 15 & 218 & 0,3 & 27,89 & 0,04 & 30,51 \\
\hline 16 & 199 & 0,3 & 27,48 & 0,04 & 29,87 \\
\hline 17 & 193 & 0,3 & 27,17 & 0,04 & 29,49 \\
\hline 18 & 188 & 0,3 & 26,76 & 0,04 & 29,02 \\
\hline 19 & 181 & 0,3 & 26,35 & 0,04 & 28,52 \\
\hline 20 & 0 & 0,3 & 26,04 & 0,04 & 26,04 \\
\hline 21 & 0 & 0,3 & 25,52 & 0,04 & 25,52 \\
\hline 22 & 0 & 0,3 & 25,01 & 0,04 & 25,01 \\
\hline 23 & 0 & 0,3 & 24,39 & 0,04 & 24,39 \\
\hline 24 & 0 & 0,3 & 23,67 & 0,04 & 23,67 \\
\hline
\end{tabular}


Tabla A1.15. Temperaturas sol-aire en muros Este enero (verano). Fuente: la autora

\begin{tabular}{|c|c|c|c|c|c|}
\hline hora & I Este & $\begin{array}{l}\alpha \\
\text { muro }\end{array}$ & $T$ & $R_{\text {se }}$ & $T_{S A}$ \\
\hline 1 & 0 & 0,3 & 22,54 & 0,04 & 22,54 \\
\hline 2 & 0 & 0,3 & 21,1 & 0,04 & 21,1 \\
\hline 3 & 0 & 0,3 & 19,76 & 0,04 & 19,76 \\
\hline 4 & 0 & 0,3 & 18,64 & 0,04 & 18,64 \\
\hline 5 & 340 & 0,3 & 18 & 0,04 & 22,08 \\
\hline 6 & 409 & 0,3 & 17,8 & 0,04 & 22,71 \\
\hline 7 & 453 & 0,3 & 18,87 & 0,04 & 24,31 \\
\hline 8 & 472 & 0,3 & 19,35 & 0,04 & 25,01 \\
\hline 9 & 461 & 0,3 & 20,47 & 0,04 & 26 \\
\hline 10 & 425 & 0,3 & 22,33 & 0,04 & 27,43 \\
\hline 11 & 364 & 0,3 & 25,94 & 0,04 & 30,31 \\
\hline 12 & 283 & 0,3 & 25,17 & 0,04 & 28,57 \\
\hline 13 & 275 & 0,3 & 27,8 & 0,04 & 31,1 \\
\hline 14 & 253 & 0,3 & 28,1 & 0,04 & 31,14 \\
\hline 15 & 218 & 0,3 & 27,89 & 0,04 & 30,51 \\
\hline 16 & 174 & 0,3 & 27,48 & 0,04 & 29,57 \\
\hline 17 & 121 & 0,3 & 27,17 & 0,04 & 28,62 \\
\hline 18 & 65 & 0,3 & 26,76 & 0,04 & 27,54 \\
\hline 19 & 8 & 0,3 & 26,35 & 0,04 & 26,45 \\
\hline 20 & 0 & 0,3 & 26,04 & 0,04 & 26,04 \\
\hline 21 & 0 & 0,3 & 25,52 & 0,04 & 25,52 \\
\hline 22 & 0 & 0,3 & 25,01 & 0,04 & 25,01 \\
\hline 23 & 0 & 0,3 & 24,39 & 0,04 & 24,39 \\
\hline 24 & 0 & 0,3 & 23,67 & 0,04 & 23,67 \\
\hline
\end{tabular}


Tabla A1.16.Temperaturas sol-aire en muros Oeste enero (verano). Fuente: la autora

\begin{tabular}{|c|c|c|c|c|c|}
\hline hora & I Oeste & $\begin{array}{r}\alpha \\
\text { muro }\end{array}$ & $T$ & $R_{\text {se }}$ & $T_{S A}$ \\
\hline 1 & 0 & 0,3 & 22,54 & 0,04 & 22,54 \\
\hline 2 & 0 & 0,3 & 21,1 & 0,04 & 21,1 \\
\hline 3 & 0 & 0,3 & 19,76 & 0,04 & 19,76 \\
\hline 4 & 0 & 0,3 & 18,64 & 0,04 & 18,64 \\
\hline 5 & 8 & 0,3 & 18 & 0,04 & 18,1 \\
\hline 6 & 65 & 0,3 & 17,8 & 0,04 & 18,58 \\
\hline 7 & 121 & 0,3 & 18,87 & 0,04 & 20,32 \\
\hline 8 & 174 & 0,3 & 19,35 & 0,04 & 21,44 \\
\hline 9 & 218 & 0,3 & 20,47 & 0,04 & 23,09 \\
\hline 10 & 253 & 0,3 & 22,33 & 0,04 & 25,37 \\
\hline 11 & 275 & 0,3 & 25,94 & 0,04 & 29,24 \\
\hline 12 & 283 & 0,3 & 25,17 & 0,04 & 28,57 \\
\hline 13 & 364 & 0,3 & 27,8 & 0,04 & 32,17 \\
\hline 14 & 425 & 0,3 & 28,1 & 0,04 & 33,2 \\
\hline 15 & 461 & 0,3 & 27,89 & 0,04 & 33,42 \\
\hline 16 & 472 & 0,3 & 27,48 & 0,04 & 33,14 \\
\hline 17 & 154 & 0,3 & 27,17 & 0,04 & 29,02 \\
\hline 18 & 409 & 0,3 & 26,76 & 0,04 & 31,67 \\
\hline 19 & 341 & 0,3 & 26,35 & 0,04 & 30,44 \\
\hline 20 & 0 & 0,3 & 26,04 & 0,04 & 26,04 \\
\hline 21 & 0 & 0,3 & 25,52 & 0,04 & 25,52 \\
\hline 22 & 0 & 0,3 & 25,01 & 0,04 & 25,01 \\
\hline 23 & 0 & 0,3 & 24,39 & 0,04 & 24,39 \\
\hline 24 & 0 & 0,3 & 23,67 & 0,04 & 23,67 \\
\hline
\end{tabular}


Tabla A1.17. Temperaturas sol-aire en cubiertas para un día típico de verano. Fuente: la autora

\begin{tabular}{|c|c|c|c|c|c|}
\hline hora & horizontal & $\begin{array}{r}\alpha \\
\text { cubierta }\end{array}$ & $T^{\circ} \mathrm{C}$ & $R_{\text {se }}$ & $T_{S A}$ \\
\hline 1 & 0 & 0,15 & 22,54 & 0,04 & 22,54 \\
\hline 2 & 0 & 0,15 & 21,1 & 0,04 & 21,10 \\
\hline 3 & 0 & 0,15 & 19,76 & 0,04 & 19,76 \\
\hline 4 & 0 & 0,15 & 18,64 & 0,04 & 18,64 \\
\hline 5 & 23 & 0,15 & 18 & 0,04 & 18,14 \\
\hline 6 & 172 & 0,15 & 17,8 & 0,04 & 18,83 \\
\hline 7 & 321 & 0,15 & 18,87 & 0,04 & 20,80 \\
\hline 8 & 460 & 0,15 & 19,35 & 0,04 & 22,11 \\
\hline 9 & 580 & 0,15 & 20,47 & 0,04 & 23,95 \\
\hline 10 & 672 & 0,15 & 22,33 & 0,04 & 26,36 \\
\hline 11 & 730 & 0,15 & 25,94 & 0,04 & 30,32 \\
\hline 12 & 749 & 0,15 & 25,17 & 0,04 & 29,66 \\
\hline 13 & 730 & 0,15 & 27,8 & 0,04 & 32,18 \\
\hline 14 & 672 & 0,15 & 28,1 & 0,04 & 32,13 \\
\hline 15 & 580 & 0,15 & 27,89 & 0,04 & 31,37 \\
\hline 16 & 460 & 0,15 & 27,48 & 0,04 & 30,24 \\
\hline 17 & 321 & 0,15 & 27,17 & 0,04 & 29,10 \\
\hline 18 & 172 & 0,15 & 26,76 & 0,04 & 27,79 \\
\hline 19 & 23 & 0,15 & 26,35 & 0,04 & 26,49 \\
\hline 20 & 0 & 0,15 & 26,04 & 0,04 & 26,04 \\
\hline 21 & 0 & 0,15 & 25,52 & 0,04 & 25,52 \\
\hline 22 & 0 & 0,15 & 25,01 & 0,04 & 25,01 \\
\hline 23 & 0 & 0,15 & 24,39 & 0,04 & 24,39 \\
\hline 24 & 0 & 0,15 & 23,67 & 0,04 & 23,67 \\
\hline
\end{tabular}


Tabla 2.3.2. 1:

Tabla A1.18. Variación de la velocidad del viento y del largo de junta de carpintería con la altura. Fuente: la autora

\begin{tabular}{|c|c|c|c|}
\hline $\begin{array}{l}\mathbf{h} \\
\mathbf{m}\end{array}$ & $\begin{array}{c}\text { velocidad } \\
\text { del viento } \\
\mathrm{m} / \mathrm{s}\end{array}$ & $\begin{array}{l}\text { coeficiente } \\
\text { corrección }\end{array}$ & $\begin{array}{l}\text { junta } \\
\mathrm{m} / \mathrm{m} 2\end{array}$ \\
\hline 150 & 7,18 & 1,84 & 0,64 \\
\hline 140 & 7,1 & 1,82 & 0,72 \\
\hline 130 & 7,01 & 1,80 & 0,81 \\
\hline 120 & 6,91 & 1,77 & 0,91 \\
\hline 110 & 6,81 & 1,75 & 1,02 \\
\hline 100 & 6,69 & 1,72 & 1,14 \\
\hline 90 & 6,56 & 1,68 & 1,27 \\
\hline 80 & 6,42 & 1,65 & 1,42 \\
\hline 70 & 6,26 & 1,61 & 1,58 \\
\hline 60 & 6,07 & 1,56 & 1,77 \\
\hline 50 & 5,85 & 1,50 & 2,00 \\
\hline 40 & 5,58 & 1,43 & 2,28 \\
\hline 30 & 5,23 & 1,34 & 2,64 \\
\hline 20 & 4,74 & 1,22 & 3,14 \\
\hline 10 & 3,9 & 1 & 4 \\
\hline
\end{tabular}


Anexo 2

Resultados de la optimización del modelo 
El uso de algoritmos genéticos aplicados al diseño bioambiental paramétrico 
Tabla A2.1: Resultados de la optimización geométrica y del área vidriada del edificio en torre

\begin{tabular}{|c|c|c|c|c|c|c|c|c|c|c|c|c|c|c|c|c|}
\hline \multirow{3}{*}{ Alt. } & \multicolumn{11}{|c|}{ superficies muros y vidrio por orientacion $\mathrm{m}^{2}$} & \multirow[b]{3}{*}{ total } & \multirow{3}{*}{$\begin{array}{c}0 \\
\text { vidrio }\end{array}$} & \multirow[b]{3}{*}{$\%$} & \multirow[b]{3}{*}{ muro } & \multirow[b]{3}{*}{ total } \\
\hline & \multicolumn{2}{|l|}{$\mathrm{N}$} & \multirow[b]{2}{*}{ muro } & \multirow[b]{2}{*}{ total } & \multirow{2}{*}{$\begin{array}{c}\text { S } \\
\text { vidrio }\end{array}$} & \multirow[b]{2}{*}{$\%$} & \multirow[b]{2}{*}{ muro } & \multicolumn{3}{|c|}{$\mathrm{E}$} & \multirow[b]{2}{*}{ muro } & & & & & \\
\hline & vidrio & $\%$ & & & & & & total & vidrio & $\%$ & & & & & & \\
\hline $1 \mathrm{E}$ & 651 & 50 & 651 & 1303 & 130 & 10 & 1173 & 1303 & 595 & 40 & 893 & 1488 & 447 & 30 & 1042 & 1488 \\
\hline $1 \mathrm{AV}$ & 532 & 39 & 832 & 1365 & 232 & 17 & 1133 & 1365 & 685 & 52 & 632 & 1317 & 329 & 25 & 987 & 1317 \\
\hline $2 \mathrm{E}$ & 651 & 50 & 651 & 1303 & 130 & 10 & 1173 & 1303 & 595 & 40 & 893 & 1488 & 447 & 30 & 1042 & 1488 \\
\hline $2 \mathrm{AV}$ & 717 & 55 & 586 & 1303 & 130 & 10 & 1042 & 1173 & 491 & 33 & 997 & 1488 & 447 & 30 & 1042 & 1488 \\
\hline $3 \mathrm{E}$ & 734 & 50 & 734 & 1468 & 147 & 10 & 1321 & 1468 & 538 & 40 & 806 & 1344 & 403 & 30 & 941 & 1344 \\
\hline 3AV & 651 & 58 & 617 & 1268 & 161 & 11 & 1306 & 1468 & 605 & 45 & 739 & 1344 & 403 & 30 & 941 & 1344 \\
\hline $4 \mathrm{E}$ & 693 & 50 & 693 & 1385 & 139 & 10 & 1247 & 1385 & 546 & 40 & 819 & 1365 & 409 & 30 & 955 & 1365 \\
\hline 4AV & 416 & 30 & 970 & 1385 & 249 & 18 & 1136 & 1385 & 546 & 40 & 819 & 1365 & 450 & 33 & 914 & 1365 \\
\hline $5 \mathrm{E}$ & 645 & 50 & 645 & 1289 & 129 & 10 & 1160 & 1289 & 595 & 40 & 893 & 1488 & 447 & 30 & 1042 & 1488 \\
\hline $5 \mathrm{AV}$ & 696 & 54 & 593 & 1289 & 129 & 10 & 1160 & 1289 & 759 & 51 & 729 & 1488 & 447 & 30 & 1042 & 1488 \\
\hline $6 \mathrm{E}$ & 672 & 50 & 672 & 1344 & 134 & 10 & 1210 & 1344 & 595 & 40 & 893 & 1488 & 447 & 30 & 1042 & 1488 \\
\hline $6 \mathrm{AV}$ & 766 & 57 & 578 & 1344 & 134 & 10 & 1210 & 1344 & 729 & 49 & 759 & 1488 & 447 & 30 & 1042 & 1488 \\
\hline 7E & 700 & 50 & 700 & 1399 & 140 & 10 & 1259 & 1399 & 571 & 40 & 856 & 1427 & 428 & 30 & 999 & 1427 \\
\hline $7 \mathrm{AV}$ & 546 & 39 & 853 & 1399 & 238 & 17 & 1161 & 1399 & 742 & 52 & 685 & 1427 & 357 & 25 & 1070 & 1427 \\
\hline $8 \mathrm{E}$ & 693 & 50 & 693 & 1385 & 139 & 10 & 1247 & 1385 & 615 & 40 & 922 & 1537 & 461 & 30 & 1076 & 1537 \\
\hline $8 \mathrm{AV}$ & 471 & 34 & 914 & 1385 & 319 & 23 & 1067 & 1385 & 753 & 49 & 1168 & 1921 & 369 & 24 & 1168 & 1537 \\
\hline $9 \mathrm{E}$ & 658 & 50 & 658 & 1317 & 132 & 10 & 1185 & 1317 & 598 & 40 & 897 & 1495 & 449 & 30 & 1047 & 1495 \\
\hline 9AV & 527 & 40 & 790 & 1317 & 145 & 11 & 1172 & 1317 & 583 & 39 & 912 & 1495 & 658 & 44 & 837 & 1495 \\
\hline $10 \mathrm{E}$ & 700 & 50 & 700 & 1399 & 140 & 10 & 1259 & 1399 & 571 & 40 & 856 & 1427 & 428 & 30 & 999 & 1427 \\
\hline $10 \mathrm{AV}$ & 686 & 49 & 714 & 1399 & 266 & 19 & 1133 & 1399 & 685 & 48 & 742 & 1427 & 357 & 25 & 1070 & 1427 \\
\hline $11 \mathrm{E}$ & 748 & 50 & 748 & 1495 & 150 & 10 & 1346 & 1495 & 532 & 40 & 798 & 1330 & 399 & 30 & 931 & 1330 \\
\hline $11 \mathrm{AV}$ & 957 & 64 & 538 & 1495 & 150 & 10 & 1346 & 1495 & 519 & 39 & 812 & 1330 & 412 & 31 & 918 & 1330 \\
\hline $12 \mathrm{E}$ & 744 & 50 & 744 & 1488 & 149 & 10 & 1340 & 1488 & 543 & 40 & 815 & 1358 & 407 & 30 & 951 & 1358 \\
\hline $12 \mathrm{AV}$ & 372 & 25 & 1116 & 1488 & 521 & 35 & 967 & 1488 & 774 & 57 & 584 & 1358 & 299 & 22 & 1059 & 1358 \\
\hline $13 \mathrm{E}$ & 744 & 50 & 744 & 1488 & 149 & 10 & 1340 & 1488 & 538 & 40 & 806 & 1344 & 403 & 30 & 941 & 1344 \\
\hline $13 \mathrm{AV}$ & 447 & 30 & 1042 & 1488 & 164 & 11 & 1325 & 1488 & 995 & 74 & 349 & 1344 & 323 & 24 & 1022 & 1344 \\
\hline $14 \mathrm{E}$ & 720 & 50 & 720 & 1440 & 144 & 10 & 1296 & 1440 & 436 & 30 & 1018 & 1454 & 436 & 30 & 1018 & 1454 \\
\hline $14 \mathrm{AV}$ & 720 & 50 & 720 & 1440 & 144 & 10 & 1296 & 1440 & 727 & 50 & 727 & 1454 & 291 & 20 & 1163 & 1454 \\
\hline $15 \mathrm{E}$ & 744 & 50 & 744 & 1488 & 149 & 10 & 1340 & 1488 & 565 & 40 & 848 & 1413 & 424 & 30 & 989 & 1413 \\
\hline $15 \mathrm{AV}$ & 833 & 56 & 655 & 1488 & 193 & 13 & 1295 & 1488 & 664 & 47 & 749 & 1413 & 381 & 27 & 1031 & 1413 \\
\hline $16 \mathrm{E}$ & 638 & 50 & 638 & 1275 & 128 & 10 & 1148 & 1275 & 609 & 40 & 914 & 1523 & 457 & 30 & 1066 & 1523 \\
\hline $16 \mathrm{AV}$ & 803 & 63 & 472 & 1275 & 204 & 16 & 1071 & 1275 & 457 & 30 & 1066 & 1523 & 487 & 32 & 1036 & 1523 \\
\hline 17E & 741 & 50 & 741 & 1482 & 148 & 10 & 1333 & 1482 & 595 & 40 & 893 & 1488 & 447 & 30 & 1042 & 1488 \\
\hline $17 \mathrm{AV}$ & 682 & 46 & 800 & 1482 & 267 & 18 & 1215 & 1482 & 863 & 58 & 625 & 1488 & 387 & 26 & 1101 & 1488 \\
\hline $18 \mathrm{E}$ & 768 & 50 & 768 & 1537 & 154 & 10 & 1383 & 1537 & 549 & 40 & 823 & 1372 & 411 & 30 & 960 & 1372 \\
\hline $18 \mathrm{AV}$ & 707 & 46 & 830 & 1537 & 246 & 16 & 1291 & 1537 & 864 & 63 & 508 & 1372 & 288 & 21 & 1084 & 1372 \\
\hline
\end{tabular}


Tabla A 2.2.: Porcentajes de muro y área vidriada según cada orientación

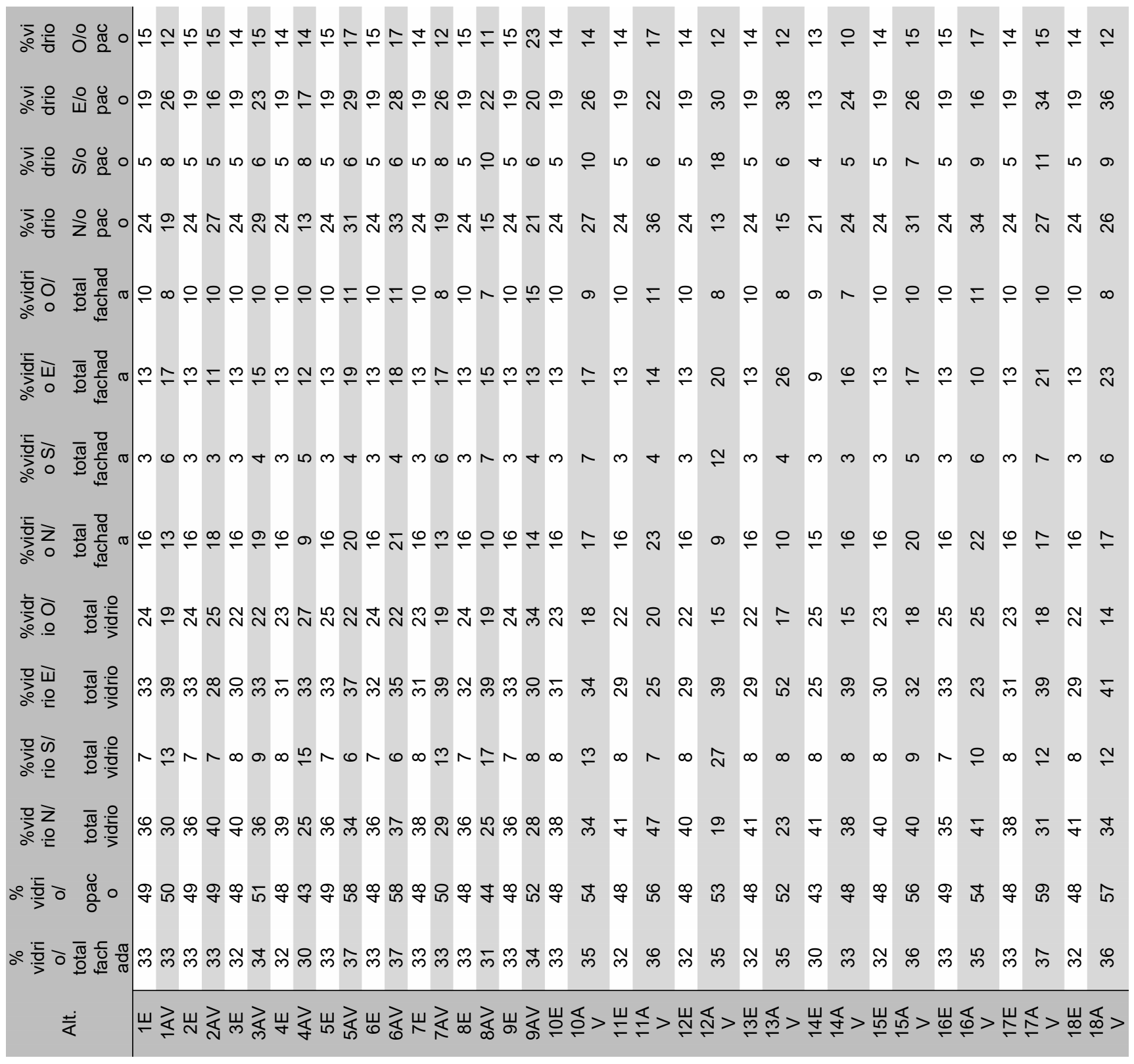


Anexo 3: Datos climáticos Sevilla 
El uso de algoritmos genéticos aplicados al diseño bioambiental paramétrico 
Tabla A3-1: Datos estación meteorológica Sevilla Aeropuerto. Latitud: $37^{\circ}{ }^{2} 5^{\prime}$ 0" N- longitud: $5^{\circ} 52$ ' 45" O- altitud (m):34'. Fuente: la autora

\begin{tabular}{|c|c|c|c|c|c|c|c|c|c|c|c|c|}
\hline Mes & $\begin{array}{c}T . \\
\text { med. } \\
{ }^{\circ} \mathrm{C}\end{array}$ & $\begin{array}{c}T . \\
\text { med. } \\
\text { máx. } \\
{ }^{\circ} \mathrm{C}\end{array}$ & $\begin{array}{c}T \\
\text { med } \\
\text { mín. } \\
{ }^{\circ} \mathrm{C}\end{array}$ & $\begin{array}{l}\text { Precip. } \\
\text { mm }\end{array}$ & $H R$ & $\begin{array}{l}n^{\circ} \text { días } \\
\text { precip. } \\
\geq 1 \mathrm{~mm}\end{array}$ & $\begin{array}{c}n^{\circ} \\
\text { días } \\
\text { nieve }\end{array}$ & $\begin{array}{c}n^{\circ} \\
\text { días } \\
\text { torm. }\end{array}$ & $\begin{array}{c}n^{\circ} \\
\text { días } \\
\text { nieb. }\end{array}$ & $\begin{array}{c}n^{\circ} \\
\text { días } \\
\text { helad. }\end{array}$ & $\begin{array}{c}n^{\circ} \\
\text { días } \\
\text { claros }\end{array}$ & $\begin{array}{c}h \\
\text { de } \\
\text { sol }\end{array}$ \\
\hline enero & 10,9 & 16 & 5,7 & 66 & 71 & 6,1 & 0 & 0 & 2,7 & 1,8 & 11,2 & 183 \\
\hline febr. & 12,5 & 18,1 & 7 & 50 & 67 & 5,8 & 0 & 1 & 3 & 0,7 & 7,9 & 189 \\
\hline marzo & 15,6 & 21,9 & 9,2 & 36 & 59 & 4,3 & 0 & 1 & 2,3 & 0 & 8,6 & 220 \\
\hline abril & 17,3 & 23,4 & 11,1 & 54 & 57 & 6,1 & 0 & 1 & 1,4 & 0 & 6 & 238 \\
\hline mayo & 20,7 & 27,2 & 14,2 & 30 & 53 & 3,7 & 0 & 1 & 0,7 & 0 & 6,9 & 293 \\
\hline junio & 25,1 & 32,2 & 18 & 10 & 48 & 1,3 & 0 & 1 & 0,2 & 0 & 12,9 & 317 \\
\hline julio & 28,2 & 36 & 20,3 & 2 & 44 & 0,2 & 0 & 0 & 0,2 & 0 & 21,1 & 354 \\
\hline agost. & 27,9 & 35,5 & 20,4 & 5 & 48 & 0,5 & 0 & 0 & 0,2 & 0 & 18,7 & 328 \\
\hline sept. & 25 & 31,7 & 18,2 & 27 & 54 & 2,4 & 0 & 1 & 0,5 & 0 & 10,3 & 244 \\
\hline oct. & 20,2 & 26 & 14,4 & 68 & 62 & 6,1 & 0 & 1 & 2,4 & 0 & 7,8 & 216 \\
\hline nov. & 15,1 & 20,2 & 10 & 91 & 70 & 6,4 & 0 & 1 & 2,1 & 0 & 8 & 181 \\
\hline dic. & 11,9 & 16,6 & 7,3 & 99 & 74 & 7,5 & 0 & 1 & 3 & 0,5 & 8,4 & 154 \\
\hline anual & 19,2 & 25,4 & 13 & 539 & 59 & 50,5 & 0 & 9 & 18,7 & 3,2 & 129 & - \\
\hline
\end{tabular}

Tabla A3-2: Radiación solar media horaria enero (invierno). Estación Lebrija 2.

\section{Cuervo de Sevilla². Fuente: la autora}

\begin{tabular}{r|ccccccccc}
\multicolumn{1}{r|}{ hora } & horizontal & $\boldsymbol{N}$ & $\mathbf{S}$ & $\mathbf{O}$ & $\boldsymbol{E}$ & $\mathbf{N O}$ & $\mathbf{S O}$ & $\mathbf{N E}$ & $\mathbf{S E}$ \\
\hline $\mathbf{7}$ & 1,10 & 0,44 & 14,54 & 0,44 & 33,03 & 0,44 & 0,44 & 13,52 & 33,45 \\
$\mathbf{8}$ & 100,42 & 37,89 & 191,96 & 37,89 & 260,35 & 37,89 & 38,17 & 86,50 & 304,14 \\
$\mathbf{9}$ & 223,94 & 75,86 & 348,61 & 75,86 & 341,80 & 75,86 & 86,43 & 81,62 & 456,78 \\
$\mathbf{1 0}$ & 337,17 & 104,78 & 483,99 & 104,78 & 335,88 & 104,78 & 209,74 & 105,04 & 536,34 \\
$\mathbf{1 1}$ & 416,54 & 122,87 & 582,21 & 122,89 & 257,87 & 122,87 & 352,20 & 122,87 & 543,13 \\
$\mathbf{1 2}$ & 445,06 & 128,80 & 616,87 & 137,41 & 137,41 & 128,80 & 473,92 & 128,80 & 473,92 \\
$\mathbf{1 3}$ & 416,54 & 122,87 & 582,21 & 257,87 & 122,89 & 122,87 & 543,13 & 122,87 & 352,20 \\
$\mathbf{1 4}$ & 337,17 & 104,78 & 483,99 & 335,88 & 104,78 & 105,04 & 536,34 & 104,78 & 209,74 \\
$\mathbf{1 5}$ & 223,94 & 75,86 & 348,61 & 341,80 & 75,86 & 81,62 & 456,78 & 75,86 & 86,43 \\
$\mathbf{1 6}$ & 100,42 & 37,89 & 191,96 & 260,35 & 37,89 & 86,50 & 304,14 & 37,89 & 38,17 \\
$\mathbf{1 7}$ & 1,10 & 0,44 & 14,54 & 33,03 & 0,44 & 13,52 & 33,45 & 0,44 & 0,44
\end{tabular}

\footnotetext{
1 Obtenido a partir de datos de la Agencia Estatal de Meteorología. Ministerio de Agricultura y Pesca, Alimentación y Medio Ambiente. Gobierno de España. Consultado el 1/2/17:

http://www.aemet.es/es/serviciosclimaticos/datosclimatologicos/valoresclimatologicos

${ }^{2}$ Obtenido a partir de datos de la Agencia Andaluza de la Energía. Conserjería de Innovación, Ciencia y Empresa. Junta de Andalucía. Consultado el 1/2/17:

http://www.agenciaandaluzadelaenergia.es/Radiacion/radiacion1.php
} 
Tabla A3.3: Radiación solar media horaria julio (verano). Estación Lebrija 2. Cuervo de Sevilla ${ }^{3}$. Fuente: la autora

\begin{tabular}{|c|c|c|c|c|c|c|c|c|c|}
\hline hora & horizontal & $\mathbf{N}$ & $S$ & 0 & $E$ & NO & so & NE & SE \\
\hline 5 & 15,58 & 185,33 & 4,44 & 4,44 & 375,34 & 4,44 & 4,44 & 394,61 & 138,80 \\
\hline 6 & 157,17 & 208,29 & 40,40 & 40,40 & 581,35 & 40,40 & 40,40 & 541,63 & 304,19 \\
\hline 7 & 328,50 & 175,51 & 76,88 & 75,83 & 692,47 & 75,83 & 75,83 & 581,63 & 442,09 \\
\hline 8 & 514,56 & 123,03 & 116,02 & 106,21 & 732,96 & 106,21 & 106,21 & 554,36 & 544,44 \\
\hline 9 & 694,66 & 132,21 & 223,87 & 129,54 & 695,03 & 129,54 & 129,54 & 464,56 & 594,27 \\
\hline 10 & 845,62 & 144,71 & 325,71 & 144,10 & 575,04 & 144,10 & 144,78 & 321,38 & 576,85 \\
\hline 11 & 946,16 & 149,68 & 394,04 & 149,65 & 383,83 & 149,61 & 168,80 & 161,60 & 488,02 \\
\hline 12 & 981,46 & 149,81 & 417,53 & 160,33 & 160,33 & 150,57 & 339,80 & 150,57 & 339,80 \\
\hline 13 & 946,16 & 149,68 & 394,04 & 383,83 & 149,65 & 161,60 & 488,02 & 149,61 & 168,80 \\
\hline 14 & 845,62 & 144,71 & 325,71 & 575,04 & 144,10 & 321,38 & 576,85 & 144,10 & 144,78 \\
\hline 15 & 694,66 & 132,21 & 223,87 & 695,03 & 129,54 & 464,56 & 594,27 & 129,54 & 129,54 \\
\hline 16 & 514,56 & 123,03 & 116,02 & 732,96 & 106,21 & 554,36 & 544,44 & 106,21 & 106,21 \\
\hline 17 & 328,50 & 175,51 & 76,88 & 692,47 & 75,83 & 581,63 & 442,09 & 75,83 & 75,83 \\
\hline 18 & 157,17 & 208,29 & 40,40 & 581,35 & 40,40 & 541,63 & 304,19 & 40,40 & 40,40 \\
\hline 19 & 15,58 & 185,33 & 4,44 & 375,34 & 4,44 & 394,61 & 138,80 & 4,44 & 4,44 \\
\hline
\end{tabular}

\footnotetext{
${ }^{3}$ Obtenido a partir de datos de la Agencia Andaluza de la Energía. Conserjería de Innovación, Ciencia y Empresa. Junta de Andalucía. Consultado el 1/2/17:

http://www.agenciaandaluzadelaenergia.es/Radiacion/radiacion1.php
} 
Tabla A3.4: Temperaturas horarias julio (verano). Fuente: la autora

\begin{tabular}{|c|c|c|}
\hline HORA & \multicolumn{2}{|c|}{ COEFICIENTES } \\
\hline 1 & 0,57 & 29,27 \\
\hline 2 & 0,46 & 27,59 \\
\hline 3 & 0,32 & 25,45 \\
\hline 4 & 0,19 & 23,47 \\
\hline 5 & 0,08 & 21,79 \\
\hline 6 & 0,02 & 20,88 \\
\hline 7 & 0 & 20,57 \\
\hline 8 & 0,06 & 21,49 \\
\hline 9 & 0,15 & 22,86 \\
\hline 10 & 0,26 & 24,54 \\
\hline 11 & 0,44 & 27,28 \\
\hline 12 & 0,79 & 32,62 \\
\hline 13 & 0,91 & 34,46 \\
\hline 14 & 0,97 & 35,37 \\
\hline 15 & 1 & 35,83 \\
\hline 16 & 0,98 & 35,83 \\
\hline 17 & 0,94 & 34,91 \\
\hline 18 & 0,91 & 34,46 \\
\hline 19 & 0,87 & 33,85 \\
\hline 20 & 0,83 & 33,24 \\
\hline 21 & 0,8 & 32,78 \\
\hline 22 & 0,75 & 32,01 \\
\hline 23 & 0,7 & 31,25 \\
\hline 24 & 0,64 & 30,34 \\
\hline
\end{tabular}


Tabla A3.5: Temperaturas horarias enero (invierno). Fuente: la autora

\begin{tabular}{|c|c|c|}
\hline HORA & COEFI & ENTES \\
\hline 1 & 0,7 & 9,32 \\
\hline 2 & 0,64 & 8,72 \\
\hline 3 & 0,57 & 8,35 \\
\hline 4 & 0,46 & 7,98 \\
\hline 5 & 0,32 & 7,65 \\
\hline 6 & 0,19 & 7,38 \\
\hline 7 & 0,08 & 7,28 \\
\hline 8 & 0,02 & 7,23 \\
\hline 9 & 0 & 7,05 \\
\hline 10 & 0,06 & 8,11 \\
\hline 11 & 0,15 & 9,67 \\
\hline 12 & 0,26 & 11,41 \\
\hline 13 & 0,44 & 12,90 \\
\hline 14 & 0,79 & 14,09 \\
\hline 15 & 0,91 & 14,85 \\
\hline 16 & 0,97 & 15,46 \\
\hline 17 & 1 & 15,45 \\
\hline 18 & 0,98 & 14,98 \\
\hline 19 & 0,94 & 13,77 \\
\hline 20 & 0,91 & 12,66 \\
\hline 21 & 0,87 & 11,75 \\
\hline 22 & 0,83 & 10,90 \\
\hline 23 & 0,8 & 10,21 \\
\hline 24 & 0,75 & 9,61 \\
\hline
\end{tabular}


Tabla A3.6: Temperaturas sol-aire en muros $\mathbf{N}$ enero (invierno). Fuente: la autora

\begin{tabular}{|c|c|c|c|c|c|}
\hline hora & $\begin{array}{r}\text { I } \\
\text { Norte }\end{array}$ & $\begin{array}{r}\alpha \\
\text { muro }\end{array}$ & $T^{\circ} \mathrm{C}$ & $R_{s e}$ & $T_{S A}$ \\
\hline 1 & 0 & 0,3 & 9,32 & 0,04 & 9,32 \\
\hline 2 & 0 & 0,3 & 8,72 & 0,04 & 8,72 \\
\hline 3 & 0 & 0,3 & 8,35 & 0,04 & 8,35 \\
\hline 4 & 0 & 0,3 & 7,98 & 0,04 & 7,98 \\
\hline 5 & 0 & 0,3 & 7,65 & 0,04 & 7,65 \\
\hline 6 & 0 & 0,3 & 7,38 & 0,04 & 7,38 \\
\hline 7 & 0,44 & 0,3 & 7,28 & 0,04 & 7,29 \\
\hline 8 & 37,89 & 0,3 & 7,23 & 0,04 & 7,68 \\
\hline 9 & 75,86 & 0,3 & 7,05 & 0,04 & 7,96 \\
\hline 10 & 104,78 & 0,3 & 8,11 & 0,04 & 9,37 \\
\hline 11 & 122,87 & 0,3 & 9,67 & 0,04 & 11,14 \\
\hline 12 & 128,80 & 0,3 & 11,41 & 0,04 & 12,96 \\
\hline 13 & 122,87 & 0,3 & 12,9 & 0,04 & 14,37 \\
\hline 14 & 104,78 & 0,3 & 14,09 & 0,04 & 15,35 \\
\hline 15 & 75,86 & 0,3 & 14,85 & 0,04 & 15,76 \\
\hline 16 & 37,89 & 0,3 & 15,46 & 0,04 & 15,91 \\
\hline 17 & 0,44 & 0,3 & 15,45 & 0,04 & 15,46 \\
\hline 18 & 0 & 0,3 & 14,98 & 0,04 & 14,98 \\
\hline 19 & 0 & 0,3 & 13,77 & 0,04 & 13,77 \\
\hline 20 & 0 & 0,3 & 12,66 & 0,04 & 12,66 \\
\hline 21 & 0 & 0,3 & 11,75 & 0,04 & 11,75 \\
\hline 22 & 0 & 0,3 & 10,9 & 0,04 & 10,90 \\
\hline 23 & 0 & 0,3 & 10,21 & 0,04 & 10,21 \\
\hline 24 & 0 & 0,3 & 9,61 & 0,04 & 9,61 \\
\hline
\end{tabular}


Tabla A3.7: Temperaturas sol-aire en muros $\mathbf{S}$ enero (invierno). Fuente: la autora

\begin{tabular}{|c|c|c|c|c|c|}
\hline hora & I Sur & a muro & $T^{\circ} \mathrm{C}$ & $\boldsymbol{R}_{\mathrm{se}}$ & $T_{S A}$ \\
\hline 1 & 0 & 0,3 & 9,32 & 0,04 & 9,32 \\
\hline 2 & 0 & 0,3 & 8,72 & 0,04 & 8,72 \\
\hline 3 & 0 & 0,3 & 8,35 & 0,04 & 8,35 \\
\hline 4 & 0 & 0,3 & 7,98 & 0,04 & 7,98 \\
\hline 5 & 0 & 0,3 & 7,65 & 0,04 & 7,65 \\
\hline 6 & 0 & 0,3 & 7,38 & 0,04 & 7,38 \\
\hline 7 & 14,54 & 0,3 & 7,28 & 0,04 & 7,45 \\
\hline 8 & 191,96 & 0,3 & 7,23 & 0,04 & 9,53 \\
\hline 9 & 348,61 & 0,3 & 7,05 & 0,04 & 11,23 \\
\hline 10 & 483,99 & 0,3 & 8,11 & 0,04 & 13,92 \\
\hline 11 & 582,21 & 0,3 & 9,67 & 0,04 & 16,66 \\
\hline 12 & 616,87 & 0,3 & 11,41 & 0,04 & 18,81 \\
\hline 13 & 582,21 & 0,3 & 12,9 & 0,04 & 19,89 \\
\hline 14 & 483,99 & 0,3 & 14,09 & 0,04 & 19,90 \\
\hline 15 & 348,61 & 0,3 & 14,85 & 0,04 & 19,03 \\
\hline 16 & 191,96 & 0,3 & 15,46 & 0,04 & 17,76 \\
\hline 17 & 14,54 & 0,3 & 15,45 & 0,04 & 15,62 \\
\hline 18 & 0 & 0,3 & 14,98 & 0,04 & 14,98 \\
\hline 19 & 0 & 0,3 & 13,77 & 0,04 & 13,77 \\
\hline 20 & 0 & 0,3 & 12,66 & 0,04 & 12,66 \\
\hline 21 & 0 & 0,3 & 11,75 & 0,04 & 11,75 \\
\hline 22 & 0 & 0,3 & 10,9 & 0,04 & 10,90 \\
\hline 23 & 0 & 0,3 & 10,21 & 0,04 & 10,21 \\
\hline 24 & 0 & 0,3 & 9,61 & 0,04 & 9,61 \\
\hline
\end{tabular}


Tabla A3.8: Temperaturas sol-aire en muros $E$ enero (invierno). Fuente: la autora

\begin{tabular}{|c|c|c|c|c|c|}
\hline \multirow[b]{2}{*}{ hora } & \multicolumn{3}{|c|}{$\alpha$} & \multirow[b]{2}{*}{$\boldsymbol{R}_{\mathrm{se}}$} & \multirow[b]{2}{*}{$T_{S A}$} \\
\hline & I Este & muro & $T^{\circ} \mathrm{C}$ & & \\
\hline 1 & 0 & 0,3 & 9,32 & 0,04 & 9,32 \\
\hline 2 & 0 & 0,3 & 8,72 & 0,04 & 8,72 \\
\hline 3 & 0 & 0,3 & 8,35 & 0,04 & 8,35 \\
\hline 4 & 0 & 0,3 & 7,98 & 0,04 & 7,98 \\
\hline 5 & 0 & 0,3 & 7,65 & 0,04 & 7,65 \\
\hline 6 & 0 & 0,3 & 7,38 & 0,04 & 7,38 \\
\hline 7 & 33,03 & 0,3 & 7,28 & 0,04 & 7,68 \\
\hline 8 & 260,35 & 0,3 & 7,23 & 0,04 & 10,35 \\
\hline 9 & 341,80 & 0,3 & 7,05 & 0,04 & 11,15 \\
\hline 10 & 335,88 & 0,3 & 8,11 & 0,04 & 12,14 \\
\hline 11 & 257,87 & 0,3 & 9,67 & 0,04 & 12,76 \\
\hline 12 & 137,41 & 0,3 & 11,41 & 0,04 & 13,06 \\
\hline 13 & 122,89 & 0,3 & 12,9 & 0,04 & 14,37 \\
\hline 14 & 104,78 & 0,3 & 14,09 & 0,04 & 15,35 \\
\hline 15 & 75,86 & 0,3 & 14,85 & 0,04 & 15,76 \\
\hline 16 & 37,89 & 0,3 & 15,46 & 0,04 & 15,91 \\
\hline 17 & 0,44 & 0,3 & 15,45 & 0,04 & 15,46 \\
\hline 18 & 0 & 0,3 & 14,98 & 0,04 & 14,98 \\
\hline 19 & 0 & 0,3 & 13,77 & 0,04 & 13,77 \\
\hline 20 & 0 & 0,3 & 12,66 & 0,04 & 12,66 \\
\hline 21 & 0 & 0,3 & 11,75 & 0,04 & 11,75 \\
\hline 22 & 0 & 0,3 & 10,9 & 0,04 & 10,9 \\
\hline 23 & 0 & 0,3 & 10,21 & 0,04 & 10,21 \\
\hline 24 & 0 & 0,3 & 9,61 & 0,04 & 9,61 \\
\hline
\end{tabular}


Tabla A3.9 Temperaturas sol-aire en muros 0 enero (invierno). Fuente: la autora

\begin{tabular}{|c|c|c|c|c|c|}
\hline hora & $\begin{array}{l}\text { I } \\
\text { Oeste }\end{array}$ & a muro & $T$ & $R_{\text {se }}$ & $T_{S A}$ \\
\hline 1 & 0 & 0,3 & 9,32 & 0,04 & 9,32 \\
\hline 2 & 0 & 0,3 & 8,72 & 0,04 & 8,72 \\
\hline 3 & 0 & 0,3 & 8,35 & 0,04 & 8,35 \\
\hline 4 & 0 & 0,3 & 7,98 & 0,04 & 7,98 \\
\hline 5 & 0 & 0,3 & 7,65 & 0,04 & 7,65 \\
\hline 6 & 0 & 0,3 & 7,38 & 0,04 & 7,38 \\
\hline 7 & 0,44 & 0,3 & 7,28 & 0,04 & 7,29 \\
\hline 8 & 37,89 & 0,3 & 7,23 & 0,04 & 7,68 \\
\hline 9 & 75,86 & 0,3 & 7,05 & 0,04 & 7,96 \\
\hline 10 & 104,78 & 0,3 & 8,11 & 0,04 & 9,37 \\
\hline 11 & 122,89 & 0,3 & 9,67 & 0,04 & 11,14 \\
\hline 12 & 137,41 & 0,3 & 11,41 & 0,04 & 13,06 \\
\hline 13 & 257,87 & 0,3 & 12,9 & 0,04 & 15,99 \\
\hline 14 & 335,88 & 0,3 & 14,09 & 0,04 & 18,12 \\
\hline 15 & 341,80 & 0,3 & 14,85 & 0,04 & 18,95 \\
\hline 16 & 260,35 & 0,3 & 15,46 & 0,04 & 18,58 \\
\hline 17 & 33,03 & 0,3 & 15,45 & 0,04 & 15,85 \\
\hline 18 & 0 & 0,3 & 14,98 & 0,04 & 14,98 \\
\hline 19 & 0 & 0,3 & 13,77 & 0,04 & 13,77 \\
\hline 20 & 0 & 0,3 & 12,66 & 0,04 & 12,66 \\
\hline 21 & 0 & 0,3 & 11,75 & 0,04 & 11,75 \\
\hline 22 & 0 & 0,3 & 10,9 & 0,04 & 10,9 \\
\hline 23 & 0 & 0,3 & 10,21 & 0,04 & 10,21 \\
\hline 24 & 0 & 0,3 & 9,61 & 0,04 & 9,61 \\
\hline
\end{tabular}


Tabla A3.10 Temperaturas sol-aire en muros NO enero (invierno). Fuente: la autora

\begin{tabular}{|c|c|c|c|c|c|}
\hline hora & I NO & a muro & $T$ & $R_{s e}$ & $T_{S A}$ \\
\hline 1 & 0 & 0,3 & 9,32 & 0,04 & 9,32 \\
\hline 2 & 0 & 0,3 & 8,72 & 0,04 & 8,72 \\
\hline 3 & 0 & 0,3 & 8,35 & 0,04 & 8,35 \\
\hline 4 & 0 & 0,3 & 7,98 & 0,04 & 7,98 \\
\hline 5 & 0 & 0,3 & 7,65 & 0,04 & 7,65 \\
\hline 6 & 0 & 0,3 & 7,38 & 0,04 & 7,38 \\
\hline 7 & 0,44 & 0,3 & 7,28 & 0,04 & 7,29 \\
\hline 8 & 37,89 & 0,3 & 7,23 & 0,04 & 7,68 \\
\hline 9 & 75,86 & 0,3 & 7,05 & 0,04 & 7,96 \\
\hline 10 & 104,78 & 0,3 & 8,11 & 0,04 & 9,37 \\
\hline 11 & 122,87 & 0,3 & 9,67 & 0,04 & 11,14 \\
\hline 12 & 128,80 & 0,3 & 11,41 & 0,04 & 12,96 \\
\hline 13 & 122,87 & 0,3 & 12,9 & 0,04 & 14,37 \\
\hline 14 & 105,04 & 0,3 & 14,09 & 0,04 & 15,35 \\
\hline 15 & 81,62 & 0,3 & 14,85 & 0,04 & 15,83 \\
\hline 16 & 86,50 & 0,3 & 15,46 & 0,04 & 16,50 \\
\hline 17 & 13,52 & 0,3 & 15,45 & 0,04 & 15,61 \\
\hline 18 & 0 & 0,3 & 14,98 & 0,04 & 14,98 \\
\hline 19 & 0 & 0,3 & 13,77 & 0,04 & 13,77 \\
\hline 20 & 0 & 0,3 & 12,66 & 0,04 & 12,66 \\
\hline 21 & 0 & 0,3 & 11,75 & 0,04 & 11,75 \\
\hline 22 & 0 & 0,3 & 10,9 & 0,04 & 10,9 \\
\hline 23 & 0 & 0,3 & 10,21 & 0,04 & 10,21 \\
\hline 24 & 0 & 0,3 & 9,61 & 0,04 & 9,61 \\
\hline
\end{tabular}


Tabla A3.11 Temperaturas sol-aire en muros NE enero (invierno). Fuente: la autora

\begin{tabular}{|c|c|c|c|c|c|}
\hline hora & I NEe & a muro & $T$ & $R_{\text {se }}$ & $T_{S A}$ \\
\hline 1 & 0 & 0,3 & 9,32 & 0,04 & 9,32 \\
\hline 2 & 0 & 0,3 & 8,72 & 0,04 & 8,72 \\
\hline 3 & 0 & 0,3 & 8,35 & 0,04 & 8,35 \\
\hline 4 & 0 & 0,3 & 7,98 & 0,04 & 7,98 \\
\hline 5 & 0 & 0,3 & 7,65 & 0,04 & 7,65 \\
\hline 6 & 0 & 0,3 & 7,38 & 0,04 & 7,38 \\
\hline 7 & 13,52 & 0,3 & 7,28 & 0,04 & 7,44 \\
\hline 8 & 86,50 & 0,3 & 7,23 & 0,04 & 8,27 \\
\hline 9 & 81,62 & 0,3 & 7,05 & 0,04 & 8,03 \\
\hline 10 & 105,04 & 0,3 & 8,11 & 0,04 & 9,37 \\
\hline 11 & 122,87 & 0,3 & 9,67 & 0,04 & 11,14 \\
\hline 12 & 128,80 & 0,3 & 11,41 & 0,04 & 12,96 \\
\hline 13 & 122,87 & 0,3 & 12,9 & 0,04 & 14,37 \\
\hline 14 & 104,78 & 0,3 & 14,09 & 0,04 & 15,35 \\
\hline 15 & 75,86 & 0,3 & 14,85 & 0,04 & 15,76 \\
\hline 16 & 37,89 & 0,3 & 15,46 & 0,04 & 15,91 \\
\hline 17 & 0,44 & 0,3 & 15,45 & 0,04 & 15,46 \\
\hline 18 & 0 & 0,3 & 14,98 & 0,04 & 14,98 \\
\hline 19 & 0 & 0,3 & 13,77 & 0,04 & 13,77 \\
\hline 20 & 0 & 0,3 & 12,66 & 0,04 & 12,66 \\
\hline 21 & 0 & 0,3 & 11,75 & 0,04 & 11,75 \\
\hline 22 & 0 & 0,3 & 10,9 & 0,04 & 10,9 \\
\hline 23 & 0 & 0,3 & 10,21 & 0,04 & 10,21 \\
\hline 24 & 0 & 0,3 & 9,61 & 0,04 & 9,61 \\
\hline
\end{tabular}


Tabla A3.12 Temperaturas sol-aire en muros SE enero (invierno). Fuente: la autora

\begin{tabular}{|c|c|c|c|c|c|}
\hline hora & I SE & a muro & $T$ & $R_{s e}$ & $T_{S A}$ \\
\hline 1 & 0 & 0,3 & 9,32 & 0,04 & 9,32 \\
\hline 2 & 0 & 0,3 & 8,72 & 0,04 & 8,72 \\
\hline 3 & 0 & 0,3 & 8,35 & 0,04 & 8,35 \\
\hline 4 & 0 & 0,3 & 7,98 & 0,04 & 7,98 \\
\hline 5 & 0 & 0,3 & 7,65 & 0,04 & 7,65 \\
\hline 6 & 0 & 0,3 & 7,38 & 0,04 & 7,38 \\
\hline 7 & 33,45 & 0,3 & 7,28 & 0,04 & 7,68 \\
\hline 8 & 304,14 & 0,3 & 7,23 & 0,04 & 10,88 \\
\hline 9 & 456,78 & 0,3 & 7,05 & 0,04 & 12,53 \\
\hline 10 & 536,34 & 0,3 & 8,11 & 0,04 & 14,55 \\
\hline 11 & 543,13 & 0,3 & 9,67 & 0,04 & 16,19 \\
\hline 12 & 473,92 & 0,3 & 11,41 & 0,04 & 17,10 \\
\hline 13 & 352,20 & 0,3 & 12,9 & 0,04 & 17,13 \\
\hline 14 & 209,74 & 0,3 & 14,09 & 0,04 & 16,61 \\
\hline 15 & 86,43 & 0,3 & 14,85 & 0,04 & 15,89 \\
\hline 16 & 38,17 & 0,3 & 15,46 & 0,04 & 15,92 \\
\hline 17 & 0,44 & 0,3 & 15,45 & 0,04 & 15,46 \\
\hline 18 & 0 & 0,3 & 14,98 & 0,04 & 14,98 \\
\hline 19 & 0 & 0,3 & 13,77 & 0,04 & 13,77 \\
\hline 20 & 0 & 0,3 & 12,66 & 0,04 & 12,66 \\
\hline 21 & 0 & 0,3 & 11,75 & 0,04 & 11,75 \\
\hline 22 & 0 & 0,3 & 10,9 & 0,04 & 10,9 \\
\hline 23 & 0 & 0,3 & 10,21 & 0,04 & 10,21 \\
\hline 24 & 0 & 0,3 & 9,61 & 0,04 & 9,61 \\
\hline
\end{tabular}


Tabla A3.13 Temperaturas sol-aire en muros So enero (invierno). Fuente: la autora

\begin{tabular}{|c|c|c|c|c|c|}
\hline hora & I SO & a muro & $T$ & $R_{s e}$ & $T_{S A}$ \\
\hline 1 & 0 & 0,3 & 9,32 & 0,04 & 9,32 \\
\hline 2 & 0 & 0,3 & 8,72 & 0,04 & 8,72 \\
\hline 3 & 0 & 0,3 & 8,35 & 0,04 & 8,35 \\
\hline 4 & 0 & 0,3 & 7,98 & 0,04 & 7,98 \\
\hline 5 & 0 & 0,3 & 7,65 & 0,04 & 7,65 \\
\hline 6 & 0 & 0,3 & 7,38 & 0,04 & 7,38 \\
\hline 7 & 0,44 & 0,3 & 7,28 & 0,04 & 7,29 \\
\hline 8 & 38,17 & 0,3 & 7,23 & 0,04 & 7,69 \\
\hline 9 & 86,43 & 0,3 & 7,05 & 0,04 & 8,09 \\
\hline 10 & 209,74 & 0,3 & 8,11 & 0,04 & 10,63 \\
\hline 11 & 352,20 & 0,3 & 9,67 & 0,04 & 13,90 \\
\hline 12 & 473,92 & 0,3 & 11,41 & 0,04 & 17,10 \\
\hline 13 & 543,13 & 0,3 & 12,9 & 0,04 & 19,42 \\
\hline 14 & 536,34 & 0,3 & 14,09 & 0,04 & 20,53 \\
\hline 15 & 456,78 & 0,3 & 14,85 & 0,04 & 20,33 \\
\hline 16 & 304,14 & 0,3 & 15,46 & 0,04 & 19,11 \\
\hline 17 & 33,45 & 0,3 & 15,45 & 0,04 & 15,85 \\
\hline 18 & 0 & 0,3 & 14,98 & 0,04 & 14,98 \\
\hline 19 & 0 & 0,3 & 13,77 & 0,04 & 13,77 \\
\hline 20 & 0 & 0,3 & 12,66 & 0,04 & 12,66 \\
\hline 21 & 0 & 0,3 & 11,75 & 0,04 & 11,75 \\
\hline 22 & 0 & 0,3 & 10,9 & 0,04 & 10,9 \\
\hline 23 & 0 & 0,3 & 10,21 & 0,04 & 10,21 \\
\hline 24 & 0 & 0,3 & 9,61 & 0,04 & 9,61 \\
\hline
\end{tabular}


Tabla A3.14. Temperaturas sol-aire en cubiertas enero (invierno). Fuente: la autora

\begin{tabular}{r|ccccc}
\multicolumn{2}{|l}{$\boldsymbol{I}$} \\
hora & horizontal & $\boldsymbol{\alpha}$ cub. & $\boldsymbol{T}^{\circ} \mathbf{C}$ & $\boldsymbol{R}_{\text {se }}$ & $\boldsymbol{T}_{\text {sA }}$ \\
\hline $\mathbf{1}$ & 0 & 0,15 & 9,32 & 0,04 & 9,32 \\
$\mathbf{2}$ & 0 & 0,15 & 8,72 & 0,04 & 8,72 \\
$\mathbf{3}$ & 0 & 0,15 & 8,35 & 0,04 & 8,35 \\
$\mathbf{4}$ & 0 & 0,15 & 7,98 & 0,04 & 7,98 \\
$\mathbf{5}$ & 0 & 0,15 & 7,65 & 0,04 & 7,65 \\
$\mathbf{6}$ & 0 & 0,15 & 7,38 & 0,04 & 7,38 \\
$\mathbf{7}$ & 1,10 & 0,15 & 7,28 & 0,04 & 7,29 \\
$\mathbf{8}$ & 100,42 & 0,15 & 7,23 & 0,04 & 7,83 \\
$\mathbf{9}$ & 223,94 & 0,15 & 7,05 & 0,04 & 8,39 \\
$\mathbf{1 0}$ & 337,17 & 0,15 & 8,11 & 0,04 & 10,13 \\
$\mathbf{1 1}$ & 416,54 & 0,15 & 9,67 & 0,04 & 12,17 \\
$\mathbf{1 2}$ & 445,06 & 0,15 & 11,41 & 0,04 & 14,08 \\
$\mathbf{1 3}$ & 416,54 & 0,15 & 12,9 & 0,04 & 15,40 \\
$\mathbf{1 4}$ & 337,17 & 0,15 & 14,09 & 0,04 & 16,11 \\
$\mathbf{1 5}$ & 223,94 & 0,15 & 14,85 & 0,04 & 16,19 \\
$\mathbf{1 6}$ & 100,42 & 0,15 & 15,46 & 0,04 & 16,06 \\
$\mathbf{1 7}$ & 1,10 & 0,15 & 15,45 & 0,04 & 15,46 \\
$\mathbf{1 8}$ & 0 & 0,15 & 14,98 & 0,04 & 14,98 \\
$\mathbf{1 9}$ & 0 & 0,15 & 13,77 & 0,04 & 13,77 \\
$\mathbf{2 0}$ & 0 & 0,15 & 12,66 & 0,04 & 12,66 \\
$\mathbf{2 1}$ & 0 & 0,15 & 11,75 & 0,04 & 11,75 \\
$\mathbf{2 2}$ & 0 & 0,15 & 10,9 & 0,04 & 10,90 \\
$\mathbf{2 3}$ & 0 & 0,15 & 10,21 & 0,04 & 10,21 \\
$\mathbf{2 4}$ & 0 & 0,15 & 9,61 & 0,04 & 9,61 \\
& & & & & \\
& & 0 & & &
\end{tabular}


Tabla A3.15 Temperaturas sol-aire en muros Norte julio (verano). Fuente: la autora

\begin{tabular}{|c|c|c|c|c|c|}
\hline hora & I Norte & $\begin{array}{c}\alpha \\
\text { muro }\end{array}$ & $T^{\circ} \mathrm{C}$ & $R_{s e}$ & $T_{S A}$ \\
\hline 1 & 0 & 0,3 & 9,32 & 0,04 & 9,32 \\
\hline 2 & 0 & 0,3 & 8,72 & 0,04 & 8,72 \\
\hline 3 & 0 & 0,3 & 8,35 & 0,04 & 8,35 \\
\hline 4 & 0 & 0,3 & 7,98 & 0,04 & 7,98 \\
\hline 5 & 185,33 & 0,3 & 7,65 & 0,04 & 9,87 \\
\hline 6 & 208,29 & 0,3 & 7,38 & 0,04 & 9,88 \\
\hline 7 & 175,51 & 0,3 & 7,28 & 0,04 & 9,39 \\
\hline 8 & 123,03 & 0,3 & 7,23 & 0,04 & 8,71 \\
\hline 9 & 132,21 & 0,3 & 7,05 & 0,04 & 8,64 \\
\hline 10 & 144,71 & 0,3 & 8,11 & 0,04 & 9,85 \\
\hline 11 & 149,68 & 0,3 & 9,67 & 0,04 & 11,47 \\
\hline 12 & 149,81 & 0,3 & 11,41 & 0,04 & 13,21 \\
\hline 13 & 149,68 & 0,3 & 12,9 & 0,04 & 14,7 \\
\hline 14 & 144,71 & 0,3 & 14,09 & 0,04 & 15,83 \\
\hline 15 & 132,21 & 0,3 & 14,85 & 0,04 & 16,44 \\
\hline 16 & 123,03 & 0,3 & 15,46 & 0,04 & 16,94 \\
\hline 17 & 175,51 & 0,3 & 15,45 & 0,04 & 17,56 \\
\hline 18 & 208,29 & 0,3 & 14,98 & 0,04 & 17,48 \\
\hline 19 & 185,33 & 0,3 & 13,77 & 0,04 & 15,99 \\
\hline 20 & 0 & 0,3 & 12,66 & 0,04 & 12,66 \\
\hline 21 & 0 & 0,3 & 11,75 & 0,04 & 11,75 \\
\hline 22 & 0 & 0,3 & 10,9 & 0,04 & 10,9 \\
\hline 23 & 0 & 0,3 & 10,21 & 0,04 & 10,21 \\
\hline 24 & 0 & 0,3 & 9,61 & 0,04 & 9,61 \\
\hline
\end{tabular}


Tabla A3.16. Temperaturas sol-aire en muros Sur julio (verano). Fuente: la autora

\begin{tabular}{|c|c|c|c|c|c|}
\hline hora & I Sur & $\begin{array}{r}\alpha \\
\text { muro }\end{array}$ & $T$ & $R_{\text {se }}$ & $T_{S A}$ \\
\hline 1 & 0 & 0,3 & 9,32 & 0,04 & 9,32 \\
\hline 2 & 0 & 0,3 & 8,72 & 0,04 & 8,72 \\
\hline 3 & 0 & 0,3 & 8,35 & 0,04 & 8,35 \\
\hline 4 & 0 & 0,3 & 7,98 & 0,04 & 7,98 \\
\hline 5 & 4,44 & 0,3 & 7,65 & 0,04 & 7,70 \\
\hline 6 & 40,40 & 0,3 & 7,38 & 0,04 & 7,86 \\
\hline 7 & 76,88 & 0,3 & 7,28 & 0,04 & 8,20 \\
\hline 8 & 116,02 & 0,3 & 7,23 & 0,04 & 8,62 \\
\hline 9 & 223,87 & 0,3 & 7,05 & 0,04 & 9,74 \\
\hline 10 & 325,71 & 0,3 & 8,11 & 0,04 & 12,02 \\
\hline 11 & 394,04 & 0,3 & 9,67 & 0,04 & 14,40 \\
\hline 12 & 417,53 & 0,3 & 11,41 & 0,04 & 16,42 \\
\hline 13 & 394,04 & 0,3 & 12,9 & 0,04 & 17,63 \\
\hline 14 & 325,71 & 0,3 & 14,09 & 0,04 & 18,00 \\
\hline 15 & 223,87 & 0,3 & 14,85 & 0,04 & 17,54 \\
\hline 16 & 116,02 & 0,3 & 15,46 & 0,04 & 16,85 \\
\hline 17 & 76,88 & 0,3 & 15,45 & 0,04 & 16,37 \\
\hline 18 & 40,40 & 0,3 & 14,98 & 0,04 & 15,46 \\
\hline 19 & 4,44 & 0,3 & 13,77 & 0,04 & 13,82 \\
\hline 20 & 0 & 0,3 & 12,66 & 0,04 & 12,66 \\
\hline 21 & 0 & 0,3 & 11,75 & 0,04 & 11,75 \\
\hline 22 & 0 & 0,3 & 10,9 & 0,04 & 10,90 \\
\hline 23 & 0 & 0,3 & 10,21 & 0,04 & 10,21 \\
\hline 24 & 0 & 0,3 & 9,61 & 0,04 & 9,61 \\
\hline
\end{tabular}


Tabla A3.17. Temperaturas sol-aire en muros Este julio (verano). Fuente: la autora

\begin{tabular}{|c|c|c|c|c|c|}
\hline \multirow[b]{2}{*}{ hora } & \multirow[b]{2}{*}{ I Este } & \multicolumn{3}{|l|}{$\alpha$} & \multirow[b]{2}{*}{$T_{S A}$} \\
\hline & & muro & $T$ & $R_{\text {se }}$ & \\
\hline 1 & 0 & 0,3 & 9,32 & 0,04 & 9,32 \\
\hline 2 & 0 & 0,3 & 8,72 & 0,04 & 8,72 \\
\hline 3 & 0 & 0,3 & 8,35 & 0,04 & 8,35 \\
\hline 4 & 0 & 0,3 & 7,98 & 0,04 & 7,98 \\
\hline 5 & 375,34 & 0,3 & 7,65 & 0,04 & 12,15 \\
\hline 6 & 581,35 & 0,3 & 7,38 & 0,04 & 14,36 \\
\hline 7 & 692,47 & 0,3 & 7,28 & 0,04 & 15,59 \\
\hline 8 & 732,96 & 0,3 & 7,23 & 0,04 & 16,03 \\
\hline 9 & 695,03 & 0,3 & 7,05 & 0,04 & 15,39 \\
\hline 10 & 575,04 & 0,3 & 8,11 & 0,04 & 15,01 \\
\hline 11 & 383,83 & 0,3 & 9,67 & 0,04 & 14,28 \\
\hline 12 & 160,33 & 0,3 & 11,41 & 0,04 & 13,33 \\
\hline 13 & 149,65 & 0,3 & 12,9 & 0,04 & 14,7 \\
\hline 14 & 144,10 & 0,3 & 14,09 & 0,04 & 15,82 \\
\hline 15 & 129,54 & 0,3 & 14,85 & 0,04 & 16,40 \\
\hline 16 & 106,21 & 0,3 & 15,46 & 0,04 & 16,73 \\
\hline 17 & 75,83 & 0,3 & 15,45 & 0,04 & 16,36 \\
\hline 18 & 40,40 & 0,3 & 14,98 & 0,04 & 15,461 \\
\hline 19 & 4,44 & 0,3 & 13,77 & 0,04 & 13,82 \\
\hline 20 & 0 & 0,3 & 12,66 & 0,04 & 12,66 \\
\hline 21 & 0 & 0,3 & 11,75 & 0,04 & 11,75 \\
\hline 22 & 0 & 0,3 & 10,9 & 0,04 & 10,9 \\
\hline 23 & 0 & 0,3 & 10,21 & 0,04 & 10,21 \\
\hline 24 & 0 & 0,3 & 9,61 & 0,04 & 9,61 \\
\hline
\end{tabular}


Tabla A3.18.Temperaturas sol-aire en muros Oeste julio (verano). Fuente: la autora

\begin{tabular}{|c|c|c|c|c|c|}
\hline hora & I Oeste & $\begin{array}{r}\alpha \\
\text { muro }\end{array}$ & $T$ & $R_{\text {se }}$ & $T_{S A}$ \\
\hline 1 & 0 & 0,3 & 9,32 & 0,04 & 9,32 \\
\hline 2 & 0 & 0,3 & 8,72 & 0,04 & 8,72 \\
\hline 3 & 0 & 0,3 & 8,35 & 0,04 & 8,35 \\
\hline 4 & 0 & 0,3 & 7,98 & 0,04 & 7,98 \\
\hline 5 & 4,44 & 0,3 & 7,65 & 0,04 & 7,70 \\
\hline 6 & 40,40 & 0,3 & 7,38 & 0,04 & 7,86 \\
\hline 7 & 75,83 & 0,3 & 7,28 & 0,04 & 8,19 \\
\hline 8 & 106,21 & 0,3 & 7,23 & 0,04 & 8,50 \\
\hline 9 & 129,54 & 0,3 & 7,05 & 0,04 & 8,60 \\
\hline 10 & 144,10 & 0,3 & 8,11 & 0,04 & 9,84 \\
\hline 11 & 149,65 & 0,3 & 9,67 & 0,04 & 11,47 \\
\hline 12 & 160,33 & 0,3 & 11,41 & 0,04 & 13,33 \\
\hline 13 & 383,83 & 0,3 & 12,9 & 0,04 & 17,51 \\
\hline 14 & 575,04 & 0,3 & 14,09 & 0,04 & 20,99 \\
\hline 15 & 695,03 & 0,3 & 14,85 & 0,04 & 23,19 \\
\hline 16 & 732,96 & 0,3 & 15,46 & 0,04 & 24,26 \\
\hline 17 & 692,47 & 0,3 & 15,45 & 0,04 & 23,76 \\
\hline 18 & 581,35 & 0,3 & 14,98 & 0,04 & 21,96 \\
\hline 19 & 375,34 & 0,3 & 13,77 & 0,04 & 18,27 \\
\hline 20 & 0 & 0,3 & 12,66 & 0,04 & 12,66 \\
\hline 21 & 0 & 0,3 & 11,75 & 0,04 & 11,75 \\
\hline 22 & 0 & 0,3 & 10,9 & 0,04 & 10,9 \\
\hline 23 & 0 & 0,3 & 10,21 & 0,04 & 10,21 \\
\hline 24 & 0 & 0,3 & 9,61 & 0,04 & 9,61 \\
\hline
\end{tabular}


Tabla A3.19.Temperaturas sol-aire en muros NO julio (verano). Fuente: la autora

\begin{tabular}{|c|c|c|c|c|c|}
\hline hora & I NOe & $\begin{array}{r}\alpha \\
\text { muro }\end{array}$ & $T$ & $R_{\text {se }}$ & $T_{S A}$ \\
\hline 1 & 0 & 0,3 & 9,32 & 0,04 & 9,32 \\
\hline 2 & 0 & 0,3 & 8,72 & 0,04 & 8,72 \\
\hline 3 & 0 & 0,3 & 8,35 & 0,04 & 8,35 \\
\hline 4 & 0 & 0,3 & 7,98 & 0,04 & 7,98 \\
\hline 5 & 4,44 & 0,3 & 7,65 & 0,04 & 7,70 \\
\hline 6 & 40,40 & 0,3 & 7,38 & 0,04 & 7,86 \\
\hline 7 & 75,83 & 0,3 & 7,28 & 0,04 & 8,19 \\
\hline 8 & 106,21 & 0,3 & 7,23 & 0,04 & 8,50 \\
\hline 9 & 129,54 & 0,3 & 7,05 & 0,04 & 8,60 \\
\hline 10 & 144,10 & 0,3 & 8,11 & 0,04 & 9,84 \\
\hline 11 & 149,61 & 0,3 & 9,67 & 0,04 & 11,47 \\
\hline 12 & 150,57 & 0,3 & 11,41 & 0,04 & 13,22 \\
\hline 13 & 161,60 & 0,3 & 12,9 & 0,04 & 14,84 \\
\hline 14 & 321,38 & 0,3 & 14,09 & 0,04 & 17,95 \\
\hline 15 & 464,56 & 0,3 & 14,85 & 0,04 & 20,42 \\
\hline 16 & 554,36 & 0,3 & 15,46 & 0,04 & 22,11 \\
\hline 17 & 581,63 & 0,3 & 15,45 & 0,04 & 22,43 \\
\hline 18 & 541,63 & 0,3 & 14,98 & 0,04 & 21,48 \\
\hline 19 & 394,61 & 0,3 & 13,77 & 0,04 & 18,51 \\
\hline 20 & 0 & 0,3 & 12,66 & 0,04 & 12,66 \\
\hline 21 & 0 & 0,3 & 11,75 & 0,04 & 11,75 \\
\hline 22 & 0 & 0,3 & 10,9 & 0,04 & 10,9 \\
\hline 23 & 0 & 0,3 & 10,21 & 0,04 & 10,21 \\
\hline 24 & 0 & 0,3 & 9,61 & 0,04 & 9,61 \\
\hline
\end{tabular}


Tabla A3.20.Temperaturas sol-aire en muros NE julio (verano). Fuente: la autora

\begin{tabular}{|c|c|c|c|c|c|}
\hline hora & I NEe & $\begin{array}{r}\alpha \\
\text { muro }\end{array}$ & $T$ & $R_{\text {se }}$ & $T_{S A}$ \\
\hline 1 & 0 & 0,3 & 9,32 & 0,04 & 9,32 \\
\hline 2 & 0 & 0,3 & 8,72 & 0,04 & 8,72 \\
\hline 3 & 0 & 0,3 & 8,35 & 0,04 & 8,35 \\
\hline 4 & 0 & 0,3 & 7,98 & 0,04 & 7,98 \\
\hline 5 & 394,61 & 0,3 & 7,65 & 0,04 & 12,39 \\
\hline 6 & 541,63 & 0,3 & 7,38 & 0,04 & 13,88 \\
\hline 7 & 581,63 & 0,3 & 7,28 & 0,04 & 14,26 \\
\hline 8 & 554,36 & 0,3 & 7,23 & 0,04 & 13,88 \\
\hline 9 & 464,56 & 0,3 & 7,05 & 0,04 & 12,62 \\
\hline 10 & 321,38 & 0,3 & 8,11 & 0,04 & 11,97 \\
\hline 11 & 161,60 & 0,3 & 9,67 & 0,04 & 11,61 \\
\hline 12 & 150,57 & 0,3 & 11,41 & 0,04 & 13,22 \\
\hline 13 & 149,61 & 0,3 & 12,9 & 0,04 & 14,70 \\
\hline 14 & 144,10 & 0,3 & 14,09 & 0,04 & 15,82 \\
\hline 15 & 129,54 & 0,3 & 14,85 & 0,04 & 16,40 \\
\hline 16 & 106,21 & 0,3 & 15,46 & 0,04 & 16,73 \\
\hline 17 & 75,83 & 0,3 & 15,45 & 0,04 & 16,36 \\
\hline 18 & 40,40 & 0,3 & 14,98 & 0,04 & 15,46 \\
\hline 19 & 4,44 & 0,3 & 13,77 & 0,04 & 13,82 \\
\hline 20 & 0 & 0,3 & 12,66 & 0,04 & 12,66 \\
\hline 21 & 0 & 0,3 & 11,75 & 0,04 & 11,75 \\
\hline 22 & 0 & 0,3 & 10,9 & 0,04 & 10,9 \\
\hline 23 & 0 & 0,3 & 10,21 & 0,04 & 10,21 \\
\hline 24 & 0 & 0,3 & 9,61 & 0,04 & 9,61 \\
\hline
\end{tabular}


Tabla A3.21.Temperaturas sol-aire en muros SE julio (verano). Fuente: la autora

\begin{tabular}{|c|c|c|c|c|c|}
\hline hora & I SEe & $\begin{array}{r}\alpha \\
\text { muro }\end{array}$ & $T$ & $R_{\text {se }}$ & $T_{S A}$ \\
\hline 1 & 0 & 0,3 & 9,32 & 0,04 & 9,32 \\
\hline 2 & 0 & 0,3 & 8,72 & 0,04 & 8,72 \\
\hline 3 & 0 & 0,3 & 8,35 & 0,04 & 8,35 \\
\hline 4 & 0 & 0,3 & 7,98 & 0,04 & 7,98 \\
\hline 5 & 138,80 & 0,3 & 7,65 & 0,04 & 9,32 \\
\hline 6 & 304,19 & 0,3 & 7,38 & 0,04 & 11,03 \\
\hline 7 & 442,09 & 0,3 & 7,28 & 0,04 & 12,59 \\
\hline 8 & 544,44 & 0,3 & 7,23 & 0,04 & 13,76 \\
\hline 9 & 594,27 & 0,3 & 7,05 & 0,04 & 14,18 \\
\hline 10 & 576,85 & 0,3 & 8,11 & 0,04 & 15,03 \\
\hline 11 & 488,02 & 0,3 & 9,67 & 0,04 & 15,53 \\
\hline 12 & 339,80 & 0,3 & 11,41 & 0,04 & 15,49 \\
\hline 13 & 168,80 & 0,3 & 12,9 & 0,04 & 14,93 \\
\hline 14 & 144,78 & 0,3 & 14,09 & 0,04 & 15,83 \\
\hline 15 & 129,54 & 0,3 & 14,85 & 0,04 & 16,40 \\
\hline 16 & 106,21 & 0,3 & 15,46 & 0,04 & 16,73 \\
\hline 17 & 75,83 & 0,3 & 15,45 & 0,04 & 16,36 \\
\hline 18 & 40,40 & 0,3 & 14,98 & 0,04 & 15,46 \\
\hline 19 & 4,44 & 0,3 & 13,77 & 0,04 & 13,82 \\
\hline 20 & 0 & 0,3 & 12,66 & 0,04 & 12,66 \\
\hline 21 & 0 & 0,3 & 11,75 & 0,04 & 11,75 \\
\hline 22 & 0 & 0,3 & 10,9 & 0,04 & 10,90 \\
\hline 23 & 0 & 0,3 & 10,21 & 0,04 & 10,21 \\
\hline 24 & 0 & 0,3 & 9,61 & 0,04 & 9,61 \\
\hline
\end{tabular}


Tabla A3.22.Temperaturas sol-aire en muros So julio (verano). Fuente: la autora

\begin{tabular}{|c|c|c|c|c|c|}
\hline & & $a$ & & & \\
\hline hora & I SOe & muro & $T$ & $R_{s e}$ & $T_{S A}$ \\
\hline 1 & 0 & 0,3 & 9,32 & 0,04 & 9,32 \\
\hline 2 & 0 & 0,3 & 8,72 & 0,04 & 8,72 \\
\hline 3 & 0 & 0,3 & 8,35 & 0,04 & 8,35 \\
\hline 4 & 0 & 0,3 & 7,98 & 0,04 & 7,98 \\
\hline 5 & 4,44 & 0,3 & 7,65 & 0,04 & 7,70 \\
\hline 6 & 40,40 & 0,3 & 7,38 & 0,04 & 7,86 \\
\hline 7 & 75,83 & 0,3 & 7,28 & 0,04 & 8,19 \\
\hline 8 & 106,21 & 0,3 & 7,23 & 0,04 & 8,50 \\
\hline 9 & 129,54 & 0,3 & 7,05 & 0,04 & 8,60 \\
\hline 10 & 144,78 & 0,3 & 8,11 & 0,04 & 9,85 \\
\hline 11 & 168,80 & 0,3 & 9,67 & 0,04 & 11,70 \\
\hline 12 & 339,80 & 0,3 & 11,41 & 0,04 & 15,49 \\
\hline 13 & 488,02 & 0,3 & 12,9 & 0,04 & 18,76 \\
\hline 14 & 576,85 & 0,3 & 14,09 & 0,04 & 21,01 \\
\hline 15 & 594,27 & 0,3 & 14,85 & 0,04 & 21,98 \\
\hline 16 & 544,44 & 0,3 & 15,46 & 0,04 & 21,99 \\
\hline 17 & 442,09 & 0,3 & 15,45 & 0,04 & 20,76 \\
\hline 18 & 304,19 & 0,3 & 14,98 & 0,04 & 18,63 \\
\hline 19 & 138,80 & 0,3 & 13,77 & 0,04 & 15,44 \\
\hline 20 & 0 & 0,3 & 12,66 & 0,04 & 12,66 \\
\hline 21 & 0 & 0,3 & 11,75 & 0,04 & 11,75 \\
\hline 22 & 0 & 0,3 & 10,9 & 0,04 & 10,9 \\
\hline 23 & 0 & 0,3 & 10,21 & 0,04 & 10,21 \\
\hline 24 & 0 & 0,3 & 9,61 & 0,04 & 9,61 \\
\hline
\end{tabular}


Tabla A3.23. Temperaturas sol-aire en cubiertas para un día típico de verano. (julio). Fuente: la autora

\begin{tabular}{|c|c|c|c|c|c|}
\hline & I & $\alpha$ & & & \\
\hline hora & horizontal & cubierta & $T^{\circ} \mathrm{C}$ & $R_{\text {se }}$ & $T_{S A}$ \\
\hline 1 & 0 & 0,15 & 9,32 & 0,04 & 9,32 \\
\hline 2 & 0 & 0,15 & 8,72 & 0,04 & 8,72 \\
\hline 3 & 0 & 0,15 & 8,35 & 0,04 & 8,35 \\
\hline 4 & 0 & 0,15 & 7,98 & 0,04 & 7,98 \\
\hline 5 & 15,58 & 0,15 & 7,65 & 0,04 & 7,74 \\
\hline 6 & 157,17 & 0,15 & 7,38 & 0,04 & 8,32 \\
\hline 7 & 328,50 & 0,15 & 7,28 & 0,04 & 9,25 \\
\hline 8 & 514,56 & 0,15 & 7,23 & 0,04 & 10,32 \\
\hline 9 & 694,66 & 0,15 & 7,05 & 0,04 & 11,22 \\
\hline 10 & 845,62 & 0,15 & 8,11 & 0,04 & 13,18 \\
\hline 11 & 946,16 & 0,15 & 9,67 & 0,04 & 15,35 \\
\hline 12 & 981,46 & 0,15 & 11,41 & 0,04 & 17,30 \\
\hline 13 & 946,16 & 0,15 & 12,9 & 0,04 & 18,58 \\
\hline 14 & 845,62 & 0,15 & 14,09 & 0,04 & 19,16 \\
\hline 15 & 694,66 & 0,15 & 14,85 & 0,04 & 19,02 \\
\hline 16 & 514,56 & 0,15 & 15,46 & 0,04 & 18,55 \\
\hline 17 & 328,50 & 0,15 & 15,45 & 0,04 & 17,42 \\
\hline 18 & 157,17 & 0,15 & 14,98 & 0,04 & 15,92 \\
\hline 19 & 15,58 & 0,15 & 13,77 & 0,04 & 13,86 \\
\hline 20 & 0 & 0,15 & 12,66 & 0,04 & 12,66 \\
\hline 21 & 0 & 0,15 & 11,75 & 0,04 & 11,75 \\
\hline 22 & 0 & 0,15 & 10,9 & 0,04 & 10,90 \\
\hline 23 & 0 & 0,15 & 10,21 & 0,04 & 10,21 \\
\hline 24 & 0 & 0,15 & 9,61 & 0,04 & 9,61 \\
\hline
\end{tabular}


Anexo 3: Datos climáticos Sevilla 